$\ln \frac{-10}{10}$

12.

sin $1-2$,

(Ni)

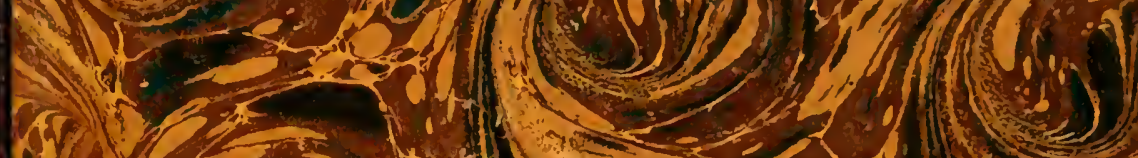

(5i) $2+1 \leq-2$.

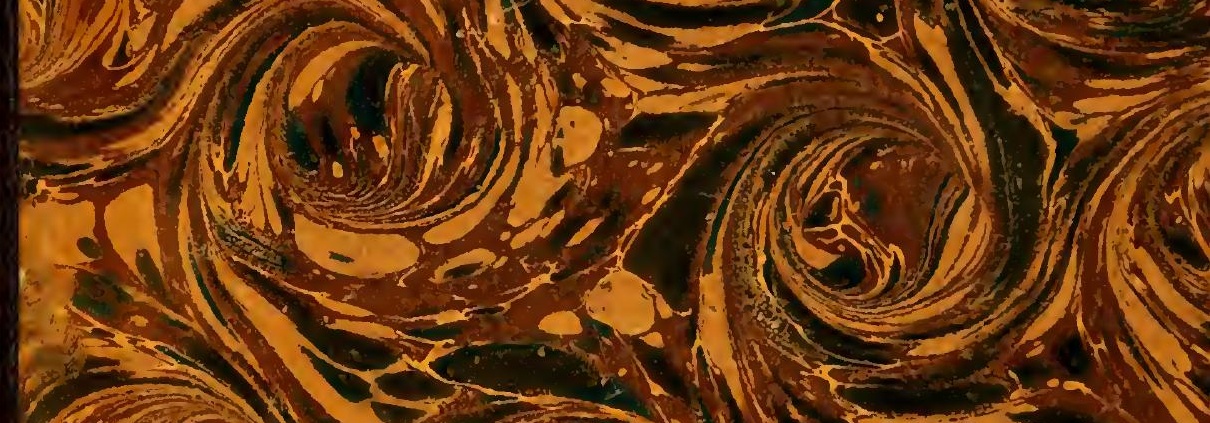
(6)

12) $(\sqrt{(-1)}$ $\left.2\left(\frac{3}{2}\right) \cdot(4)\right)^{2}(6)$

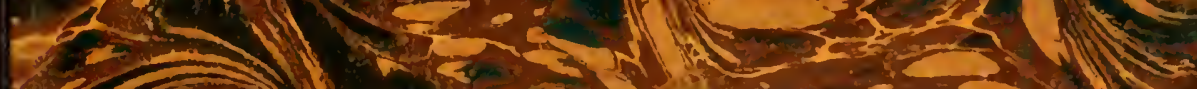

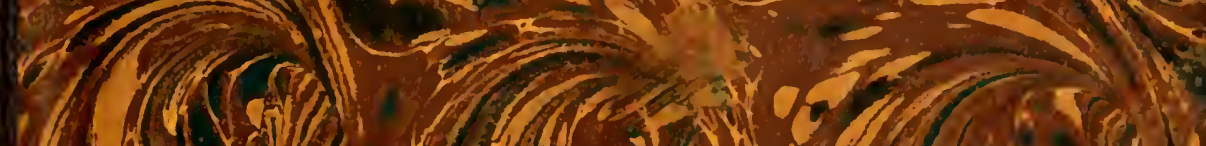




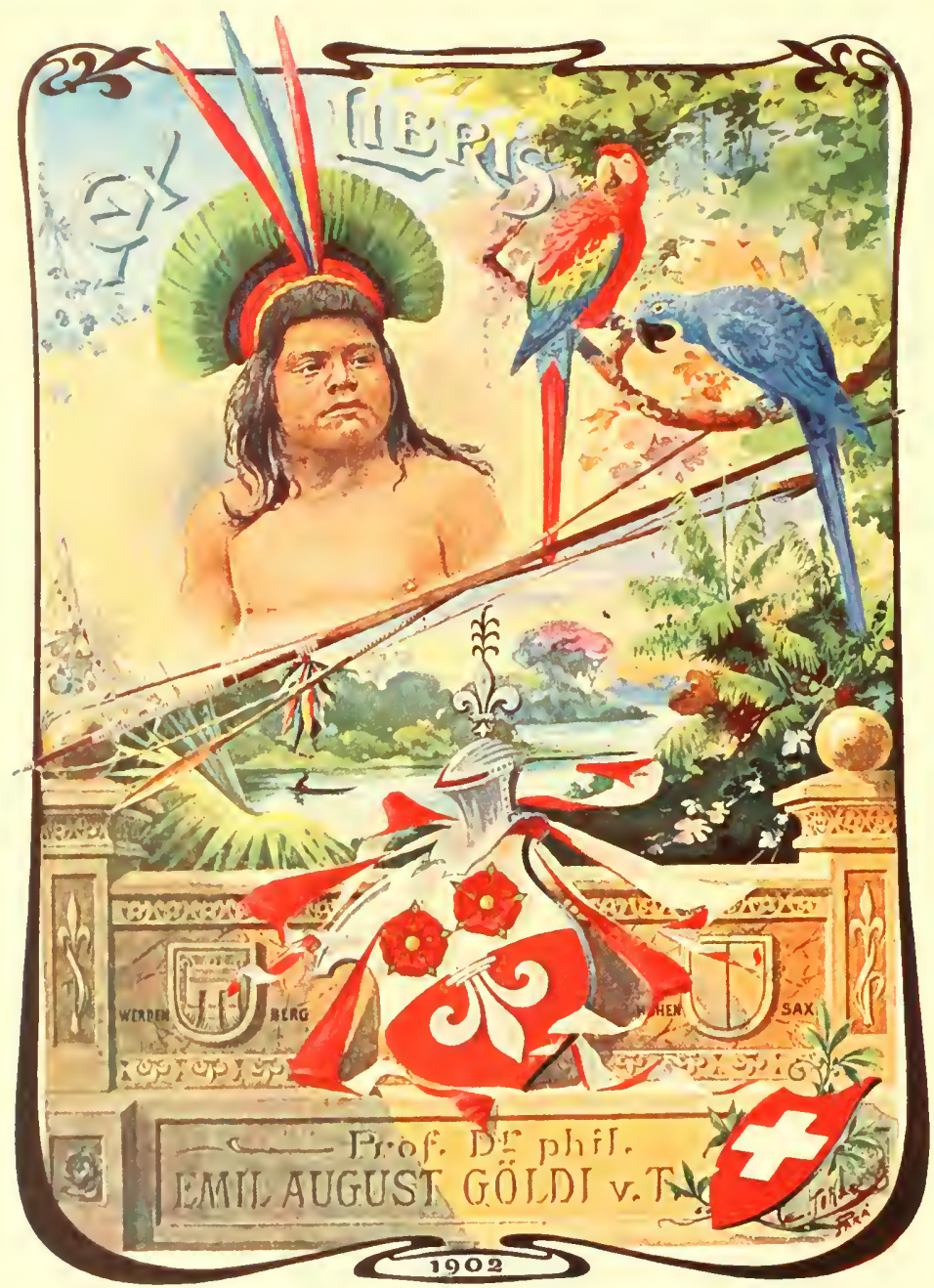


SMTHSUNIAN LIBRARY

CT of L. L. Buchum

1951 



\title{
APINTES ENTOMOLÓJICOS
}

I'OK

\author{
P. GERMAIN
}

(PUBlicado EN Los "ANALes de. LA UNIVERSIDAD", DF AliRil)
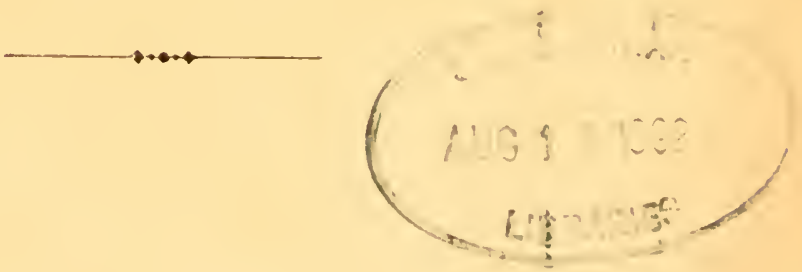

SANTIAGO DE CHILE

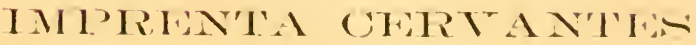

BANIIKA, 73

1897 
18,870.-Imp. Cervantes, Bandera, 73. 


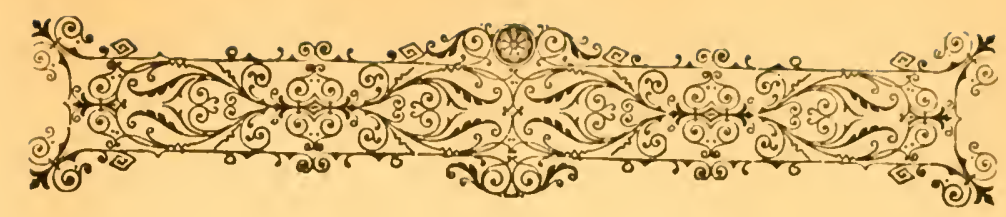

\section{APUNTES ENTOMOLÓJICOS}

一个:-

\section{LOS LONJICORNIOS CHILENOS}

Al entomólogo que no se haya dado aun cucnta cabal de las dificultades insuperables que presenta el arreglo metódico de los insectos de ciertas familias, le bastará recorrer los tomos VIII i IX del Genera, de Lacordaire: quedará ilustrado.

En ellos sc trata de los Lonjicornios, i se espone el estado en que se encontraba el estudio de csta familia un cuarto de siglo atras. Pero, desgraciadamentc, cuando este sabio entomólogo legó por fin a esta parte de su prodijiosa obra, fué solo despues de dieziocho años cle una labor inccsante; como si la familia, cuyo estudio, por scr mas dificultrso, requesia fuerzas mas jóvenes i ccrebro mas descansado, hubiese esperado, para presentarse a él, justamente el momento en que habia de sentir ya su vista debilitarse, $i$ tal ve\% apagarse tambien el ardiente entusiasmo de los prineres dias.

Sin embargo, si este gran jenio, que será la gloria de la cntomolojía contemporánca, acometió sicmpre con valor los problemas mas arduos de esta ciencia, no fué muchas veces sin poder ocultar la desesperacion que le causaba su impotencia para resolverlos. En varias partes, hai mas gue esto aun; espe. cialmente en la nota 2 de la pájina 402 de aquel tomo VIII: 
".... Dam, aucune famille de Colenptires on ne voit les formes les plus disparates juxtaposies comme elles le sont dans celle-ci, quoi qu' on fasse..... Il y a lì un problìne que d'autres résoudront peut-itre, muis qui, en ce qui me' conctrme, est an.dessus de mes forces."

Al leer estas líneas el corazon se entristece; pucs se parecen al grito de dolor del héroe exhausto i vencido que confiesa su derrota.

¡Pobre luchador, que todos los entomólogos del orbe ayudaban con la comunicacion de sus insectos! Asimismo como Moises murió sin pisar la tierra de promision, él se despidió de todos ellos sin alcanzar la conclusion de su obra.

Pero, si es evidente quc tantas especies que afluian en sus manos habian de facilitar la buena cjecucion de su tarea, es tambien manifiesto que eso no era para abreviarla. Pues, el exámen que podia hacer por sí mismo de los caractéres de todàs, le demostraba a cada momento, tanto las insuficiencias como las inexactitudes de los escritos de muchos autores.

Para él, la consecuencia lójica de esto, fué, sin duda, la disminucion diaria de su confianza en todos en jeneral; pues, por mas que $n$ lo diga, se comprende que, siempre que le fué posible, no dejó de comprobar la exactitud de sus dichos.

Es admirable, en verdad, que su cerebro haya podido resistir a la tension impuesta por un trabajo tan complicado $\mathrm{i}$ de tanta duracion; por eso los errores, en los cuales ha fatalmente caido, deben considerarse como su consecuencia inevitable.

La cantidad de Lonjicornios propios de Chile es pequeñisima en comparacion de la del mundo entero; i los datos siguientes pondrán en eviclencia esta escasez relativa.

Segun el catálogo de los Coleópteros chilenos publicado por el profesor F. Philippi, las especies de esta familia halladas en Chile hasta I 897 aicanzan solamente a 154 , i varias de ellas son dudosas; miéntras que Mr. R. Oberthür, a quien mandé las que recoji durante una esploracion de solo nueve meses en la provincia brasilera de Matto-Grosso, confiesa (An. Soc. Ent. Fr. 1887, p. CLXXXIII) que alcanzaron a 454.

Ademas, en la parte del catálogo de Gemminger i Harold, 
que corresponde a esta familia i lleva la fecha de 1872 , vemos figurar 7,568 especies; i, por otro lado, la coleccion de Thomson contenia unas 11,000 en 1888. En csta cantidad, numerosas variedades figuraban, sin duda, cono especies; sin embargo, si se considera (juc, todavía en esta época, habia en las colecciones muchas especics que no eran descritas, $i$ que, desde entónces, los naturalistas han traicio i traen diariamente otras muchas de todos los puntos de la tierra, no será exajerado dar quince mil como la cantidad probable de especies de Lonjicornios esparcidos en el orbe.

Pero, a pesar de su pequeño número, el principal interes que presenta el estudio de las especies chilenas de esta familia, proviene de que, como en otros muchos ramos del reino animal $i$ aun del vejetal, cllas forman agrupaciones que son propias de esta rejion tan estrecha, o presentan un parentesco cvidente con algunas de Australia.

Al ocuparme de ellas, trataré, cuanto pueda, rectificar los errores u omisiones en que hayan caido los autores de las descripciones de las especies ya conocidas; i, en cuanto a las nuevas, me empeñaré en describirlas con toda claridad i exactitud.

Pero, como no es posible estudiar los Lonjicornios chilenos sin consultar la obra de Gay, el Genera de Lacordaire, i "la Révision des coleoptères du Chili", que, de 1858 a 1863, escribí en colaboracion cón L. Fairmaire, indicaré especialmente las inexactitudes $\mathrm{i}$ omisiones que presentaren esos trabajos.

Es preciso, ademas, tener presente, que, con escepcion de los lóbulos maxilares, los pelos, con frecuencia sumamente abundantes en ciertos órganos de estos inscetos, no han sido indicados en las figuras, para no perjudicar a su claridad; i tambien que por "anchura basilar de los elitros" entiendo la que se toma al nivel del ápice clel escudo.

\section{1. ${ }^{\text {S SUBFA MILIA }}$}

\section{Prionidos}

Acalodegma (Thoms.) Serillei (131. in Gay)

Esta especie encabeza la lista de los Lonjicornios chilenos, $i$, bajo varios puntos de vista, merece fijar la atencion. 
Ella fué descubierta por $\mathrm{Cl}$. Gay en las cordilleras de Santa Rosa de Los Andes; pero este viajcro halló, entre unas piedras amontonadas, solamente un ejemplar muerto i cn mui mal estado de conservacion.

Este individuo único llegó a manos de E. Blanchard, quien lo colocó en el jénero Ancistrotus (Serv.), i lo hizo figurar en la obra de Gay (Zool. V, p. 452) bajo el nombre de A. Serrillei. Pero, si la descripcion quedó muda respecto al sexo de este único ejemplar, no deja de hablar del color de las antenas"antenas de un rojo parduzco; antennis fusco-rufis"-por mas que la figura dada de él (Zool., lám. 27) indique claramente su ausencia, $i$, por consiguiente, la imposibilidad en que este sabio entomólogo estuvo de verlas: lo que sigue demostrando cuál es la dósis de veracidad que caracteriza esta triste obra.

En I864 remití a mi distinguido amigo L. Fairmaire un pequeño Prionido, que recoji entre Uspallata i Villavicencio, es decir, en la parte oriental de las cordilleras inmediatas a Mendoza, en medio de un camino donde lo acababa de pisar una mula. Le faltaba la cabeza; sin embargo, L. Fairmaire creyó ver en él una segunda especie (A. marginipennis; An. Soc. Ent. Fr., I S64, p. 270) del jénero Apterocaulus, que acababa de crear para un Prionido subterráneo de las pampas vecinas; pero, para el cual ya, tres años ántes, Burmeister habia establecido el jénero Micropsalis.

Despues, en I 869 vino Lacordaire, diciendo que los pocos individuos conocidos del Ancistrotus Servillei (BI.) eran todos hembras, i habian sido hallados, todos, muertos i mas o ménos incompletos; pero que esta especie no pertenecia al jénero Ancistrotus (Serv.), sino al jénero Micropsalis (Burm.); i que el Apterocaulus marginipennis (Fairm.) era idéntico con el Ancistrotus Seritllei (Bl.)

En fin, poco tiempo despues (1872), apareció la parte del catálogo de Gemminger i Harold que trata de él: parte en la cual estos entomólogos, manteniéndose prudentemente en el papel que corresponde a los autores de catálogos, es decir, rejistrando los trabajos de los descriptores sin trastornarlos, comentarlos o modificarlos a su manera, dieron meramente una 
copia de lo que Lacordaire habia dicho en su Genera sobre este insecto.

Como se ve, el embrollo que resultaba de las bases defectuosas, sobre las cuales descansaba torlo lo que habia sido escrito hasta la fecha, respecto a eite último, no era pequeño; i duró hasta que un intclijente colector aleman-Ferderion Leyboldconsiguiese por fin hallar en laч partes bajas de la cordillera de Santiago varios ejemplares vivos de este insecto.

Resultó entónces, del estudio de esta especie, gue no tenia ninguna relacion, no solamentc con él J. Micropsalis, sino aun con la agrupacion a la cual él pertenece; pero que, al contrario, se accrcaba mucho al J. Ancistrotus, i, sobretodo, al J. Acanthinodera, que es propio de Chile.

A consecuencia de esto, sin duda, Thomson creó para él, en I 877 , el J. Acalodegma; cuyos caractéres fucron publicados en la "Rev. i Mag. Zool.p. 261. ."

He sacado este último dato del catálogo de los coleópteros chilenos del profesor F. Philippi; sin que me haya sido posible tencr a mi alcance los caractéres que Thomson da a este jénero, ni lo que dice de la especie. Pero puedo suplir ventajosamente a estas faltas; pues el cstudio minucioso que acabo de hacer de ella sobre varios ejemplares en buen estado, me permite indicar, no solamente los caractéres probables sobre los cuales tanto el jénero como la especie han sido establecidos; sino aun de todos los cuales se podia echar mano para hacerlo.

Sin embargo, lo primero que haré notar es que si todos los ejemplares que vió Lacordaire fueron hembras, segun él pretende, todos los que he visto fueron, al contrario, machos. No conozco a aquélla; i necesariamente esta falta, que tal vez no ha sufrido Thomson, va a dejar alguna duda sobre el lugar definitivo que, en mi opinion, corresponde a este jénero (I).

La forma de este insecto es ancha, corta i deprimida; su color es un castaño uniforme, con la cabeza, el protórax, el escudo i los tres segmentos esternales cubiertos de una pubescencia lanuda rubia, larga i abundante.

(1) Véase ADDEnda. p. 481 


\section{CABEZA}

Barba trasversal, encojida hácia adelante, con su borde anterior escotado para abrazar a una parte membranosa que sirve de apoyo a la lengiieta.

Anchura de la base de esta última igual a la tcrcera parte de la de aquélla; i, a la totalidad en su parte anterior, la cual está dividida en dos largos lóbulos, que estan dirijidos oblicuamente hácia afuera i pasan levemente el medio del primer artículo de sus palpos.

Estos son largos, con sus artículos obcónicos i casi de igual lonjitud; el último es levemente truncado en su ápice.

Quijadas notablemente pequeñas, con sus 2 lóbulos totalmen. te membranosos, ámbos largamente peludos en su ápice: el interno a modo de un corto diente triangular; el esterno en forma de ancho lóbulo con los costados subparalelos i el ápice redondo. Este no alcanza a la mitad del 5 art. de los palpos.

Estos son casi cinco veces mas largos que las quijadas i sobrepasan levemente la estremidad de las mandíbulas; la pieza basilar es grande i apartada del cuerpo de la quijada. El artículo I es el mas corto; el 2 es el mas largo; todos son obcónicos; el último termina como en los palpos labiales.

Todas las piezas de la boca llevan pelos lanudos largos i mui finos.

Mandíbulas horizontales, paralelas i bruscamente arqueadas en su ápice, formando así un conjunto cuadrado, cuya anchura iguala la distancia que, en la frente, separa las cavidades cotiloideas de las antenas, disposicion que las asemeja a las del J. Acanthinodera. Ademas, son mui rugosas i su borde interno lleva un grueso diente; el cual está situado un poco mas adelante en la mandíbula izquierda que en la derecha.

El labro es mui corto $i$ apénas visible, con la forma exacta de su borde anterior ocultada por una pubescencia larga i mui apretada.

Epistomio escotado adclante. El hace parte de una concavidad anterior de la frente, sin que su línea sutural con esta última esté manificsta. 
Ojos fuertemente granulados, separados igualmente encima i debajo de la cabeza: esto, casi tanto como los tubérculos ante. narios entre sí. El lóbulo inferior alcanza, adclante, solo a la mitad de la base de las antenas.

Estas últimas son filiformes i pasan un poco la estremidadde los elitros. Son de once artículos todos perfectannente glabros, con escepcion de un mechon de 10 a 12 cerditas tiesas i puntiayudas que terminan el 11. " H primero es subcilindrico, apénas ensanchado adelante $i$, mas o ménos, tres veces tan largo como ancho; cl segundo es nodiforme, como es costumbre; ámbos son brillantes i llevan ına grnesa puntuacion irregular i poco apretada; 3-10 son cilíndricos con su ápice truncado; este truncamiento puede ser levemente oblicuo, perosu borde forma un ángulo romo sin presentar nunca diente ni espina. El tercero e.s de $30 \%$ mas largo que los siguientes que son casi iguales hasta el 1 1.", que es arqueado, un poco deprimido i el mas lar. go de todos; 3 - I I son opacos por estar cubiertos de una infinidad de poros mui pequeños $\mathrm{i}$ mui apretados, con unos que otros puntitos mui ralos.

\section{PROTÓRAA, ESCUDO I ELITKOS}

Protórax con la anchura de su base doble de la lonjitud. El borde lateral lleva de cada lado dos fuertes espinas arqueadas deprimidas, cortantes i agudas, la una en el ángulo apical; la otra, mayor, poco despulues del medio; desde esta última hasta la base, una costilla angosta separa al dorso del epipleuro. El ángulo basilar, que a veces es recto, otras es saliente $\mathrm{i}$ denti. forme, o aun toma la figura de una pequeña espina.

Escudo grande, levemente trasversal $\mathrm{i}$ anchamente arqueado en su ápice.

Los elitros ticnen su mayor anchura en el $40^{\circ}$ basilar; ella representa los $2 / 3$ de la lonjitud, i pasa del 39 al $55 \%$ la del ápice, i del 75 al $78 \%$ la de la base del protórax. Los costados, casi rectos, son apénas converjentes hácia la base, $\mathrm{i}$ un poco mas hácia atras. Los ángulos humcrales son rectos, pero mui redondeados. El ápice es truncado, con el ángulo esterno del truncamiento anchamente redondeado, $\mathrm{i}$ el interno armado de una 
espina. El pliegue cpipleural es completo, pero está bruscamente dilatado i cóncavo frente al callo humcral; su borde superior es adelgazado i levantado, i envuelve a este último. El dorso no presenta puntuacion; pero si, leves rugosidades mas gruesas en la base i sembradas de tuberculillos poco apretados i bicn visibles; ademas lleva de cada lado cuatro costas lonjitudinales mui poco notables, sobre todo las dos laterales, i borradas en ámbas estremidades. La sutura está finamente ribeteada.

\section{CUERPO}

La salida prosternal tiene poca anchura, es paralela i ribeteada entre las ancas, levemente arqueada despues de ellas, $\mathrm{i}$ redondeada en su ápice.

El mesosternon, entre las ancas, es mas ancho i termina por una escotadura angular.

El episternon metatorácico es ancho, oblongo, apénas atenuado hácia el ápice, el cual es casi redondeado.

Las ancas posteriores estan separadas por una salida intercoxal del abdómen arqueada cn su estremidad.

Los segmentos abdominales son brillantes, i llevan una puntuacion i una pubescencia finas i escasas. Van acortándose levemente del $1 .^{\circ}$ al $4 .^{\circ}$; el $5 .^{\circ}$ es un poco mayor, i termina con una ancha escotadura casi semicircular.

El pyoidium está anchamente bisinuado, con el lóbulo intermediario triangular $\mathrm{i}$ saliente.

\section{PATAS}

Las patas anteriores son las mas cortas, las posteriores las mas largas. Todas estan cubiertas de una pubescencia rubia, älgo corta, oblícua i medianamente abundante.

Los muslos son delgados, casi paralclos i comprimidos. Su cara inferior está acanalada en toda su lonjitud, como si fuese destinada a alojar a las tibias.

Estas son lisas, levemente arqueadas cerca de su base, comprimidas i un poco cusanchadas en su ápice; el ángulo interno lleva dos púas afiladas, el externo un diente triangular. 
Los tarsos son alargados $i$ delgados, con sus tres primeros artículos casi de igual ancluura. El 1.0 es mas o ménrs tan largo como 2 i 3 juntos. El $3 .^{\circ}$ tienc sus lóbulos cortos i triangulares, con el externo algo mas prolongado, quedando dudoso, si se ha de considerar como brevemente bilobulato, o como profundamente escotado. El nudo basilar del 4.", mui notable, alcanza a la estremidad de dichos lóbulos, es triangrular i aislado, i toma a veces un desarrollo que podria hacer considerar al tarso como realmente pentáuncro. La pubescencia apretada i cortada a modo de cepillo, que los insectos de está familia llevan casi sicmpre en la parte inferior de los tres primeros artículos tarsales; parece haber desaparecido por completr) de las patas posteriores; pero los tres primcios artículos de todos los tarsos llevan en su parte inferior un profunclo surco lonjitudinal, $\mathrm{i}$ otro mas ancho, pero ménos notable, en la parte basilar de su cara superior.

Lam. I; Fig. I.a:barba, lengieta i palpo labial.-Aum. rojdiám. -Fig. I': quijada i palpo maxilar.-Aum. IO/diám.-Fig. I: tarso intermediario isquerilo.-Aum. 5 diám. - Figr. $1^{\text {d}}$ : antena de J.-Aum. 2.5 diám.

\section{ACANTHINODERA (Hope) Cummingrii (Hope)}

La $q$ es el primer sexo que fué conocido, segun parece. Pucs, en 1833. Hope crea para ella el jénero Acanthinoderus, i la describe bajo el nombre de A. Cummmgi (Trans. Zool. Soc. I. p. 106).

En I833, tambien, pero algunos meses mas tarde, Lequien establece, para la + ignalmente, el J. Amallopodes; i la describe bajo el nombre de 4 . Sabrosus (Mag. de Zool. de Guérin. Men.)

Por fin, en 1834 , Erichson \& Burm. la describen aun bajo el nombre de Prionus Mercurius.

En cuanto al fo, es solamente en 1835 que Dupont crea para él su J. Malloderes; i lo describc bajo el nombre de $M$. micro. cephalus (Magas. de Zool. de Guérin. Men.) 
Este insecto es, sin disputa, de todos los Coleópteros de Chile el que mas llama la atencion, tanto por su tamaño, como por las diferencias estraordinarias que presentan los sexos.

Relativamente a cstas últimas, me parece conveniente reproducir aquí unas pocas lineas sueltas que publiqué en los A NALES DE La Universidad DE Chile del año 1894. El lugar de hoi, por scr el que mas les corresponde, es adonde será mas natural venir a buscarlas, $i$, por consiguiente, donde prestarán mas utilidad.

Hablando del Amallopodes Scabrosus (Ley.) i del Malloderes microcephalus (Dup.), digo que, amnque ámbos sean Lonjicornios de la sub-familia de los Prionidos, vivan en los mismos lugares, i aparezcan en el mismo momento, sus figuras respectivas no pueden presentar contrastes mayores. Pues, miéntras que aquél, un jigante, es negro, completamente glabro, i hace aun escepcion al carácter constante de la familia, que consiste en llevar pelos esponjosos por debajo de los tres primeros artículos de los tarsos; éste, mucho menor, es ájil, de formas casi elegantes, de color castaño claro, i vestido de pelos rubios largos i tupidos, sobre todo en el protórax: el único punto de semejanza que cxiste entre ellos consisticndo en el gancho fuerte, arqueado $\mathrm{i}$ agudo que arma los ángulos anteriores del protórax I agrego lo siguiente:

"En I 854, habiendo pasado el mes de Noviembre en los alrededores del Tomé, encontré por primera vez a csos insectos con bastante frecuencia para poder estudiar su modo de vivir. Entónces noté que el primero era diurno; pero que, provisto de alas membranosas inadecuadas para el vuelo, debia contentarse con pasearse pesadamente por el suelo de las selvas; miéntras que el segundo, de costumbres nocturnas, como lo indicaban sus ojos mui desarrollados, pasaba el dia escondido en los copos de hojas mas tupidos, i que, tomando su vuelo al anochecer, venia a menudo a dar locamente contra los vidrios de mi linterna o en el fuego de mi vivac.

"Yo habia recojido quince o veinte ejemplares de cada uno de esos insectos, cuando noté con admiracion que todos los Amallopodes eran o i que todos los Malloderes eran $\jmath$. De allí hasta creer que estos insectos, tan distintos en apariencia, eran 
Ins dos sexos de una misma especic, no habia mas que un pasn: yo lo di. Entónces, aunque yo no hubiese visto la cópula, ella quedó para mi tan fucra de duda que escribí a varios amigos mi opinion a este reipectn (I).

"A fines del año $1 \$ 63$, encontrándome en Paris, tuve el honor de conversar con Lacordaire durante una sesion de la Sociedad Entomolójica de Francia, i, trayendo la discusion sobre este asunto, le dije lo yue yo pensaba, avisándole gue lá cúpula no habia sido constatada aum, i que no era cosa fácil hacerlo, por ser, de los dos sexos, el uno diurno i el otro nocturno. Pucs no fué poco mi asombro cuando, en el tomo del Genera de este sabio entomólogso, tratando de los Lonjicornios i publicado en 1969, leí que la tal cópula habia sidn constatada. ¿loor quićn? En esta época los entomólogos chilenos no existian, i los estranjeros, todos mui conocidos, no recorrian la zona habitada por estos insectos. Quedo convencidn, pues, de que Lacordaire ha asegurado el hecho fundándose únicamente sobre mis aseveraciones; i ménos atino en adivinar a qué fuente fidedigna mi cx-colaborador ha pedido los datos que, a este respecto, dió I Thomson (Arch. cnt. I. p. 38) (2).

"Ilasta mi vuelta a Chile, hace cuatro años (I S90), yo no habia tenido lugar de ocuparme del hecho de que se trata para

(1) Esta comunicacion fué hecha primerimente a L. Fairmaire, por ser él mi colaborador en la «Revision de los Coleópteros de Chile», i apareció en $\operatorname{los} \alpha \operatorname{Inn}$. Soc. Ent. de Fr. 1859, p. $484 . \%$

(2) Lo que dice Thomson es In siguiente: "Je tiens de M. Faimaire le fait suivant: Un des correspondants de cet entomologiste qui hahite le Chili, lui a ecrit aroir trouré dernièrement accouplés les Malloderes micrecphalus et les Amallopodes surrusus, qui des lors semblent ne faire qu' une seule et mème espèce. Comme on n'arait jamais reçu que séparément des ô du premier et des $q$ du second, ce fair n'a rien qui doire surprendre.n

En un pais tan reducido como Chile, idonde hai tan pocos entomólogos, los que hai se conocen todos entre si lori dia: i cuanto mas hace treinta años, en que habia ménos aun que hoi. Por mi cuenta, utuca he sabido que otro que mi amigo Fernanio Paulsen esturiese en relacion con L. Farmaire, i el tampoco no ha conocido mas que yo. Pues ninguno de los dos ha escrito a Fairmaire la noticia que el reproduce. Por lo demats, anzour trouz's acciupless estos insectos, parece dificil, si se tiene presente que la copulacion ha de hacerse de nocle i durar poco. 
constatarlo, ni tampoco habia oido decir que álguien lo hubiese hecho, o hubiese tratado de saber cuándo i cómo tenia lugar esta union. Por esto me empeñé en hacerlo; pero no accté nunca, hasta el año pasado ( 1893 ), durante mi esploracion de la hacienda de l'emchue, en que, ayudado por varias observaciones, llegué a comprender las costumbres de estos insectos.

"Para hacer el esperimento es preciso tomar una f, que no solamente tenga todavía sus huevos, sino una quc, nacida en el dia mismo, llegue vírjen a la hora en que los $\hat{e}$ se ponen en movimiento.

"Varias f, amarralas con la esperanza de que atracrian algun § lo fueron sin resultado, por no estar en la condicion que indico. Hasta que un dia, a las tres de la tarde, habiendo hallado una que salia de tierra, llena de huevos i todavía amarillenta i blanda por ser recien trasformada, yo la amarré a un palo i esperé la noche. A las ocho llegué con un farol, i tuve la satisfaccion de ver, a cinco o seis centímetros detras de ella, dos machos, quc, agarrados como dos toros, luchaban ciegamente para conquistarla.

"Desgraciadamente esta luz repentina puso un brusco término al duclo; pucs cáda uno huyó en sentido contrario i luego hechó a volar con suma precipitacion.

"Ahora que sé cómo el esperimento se ha cic hacer, lo repetiré, hasta prescnciar la cópula; pero quedo convencido de que ésta ha de tener mui poca duracion, i tambien de que ningun $\delta$ se acerca a una $q$ ya fecundada.

Como era natural, este hermoso coleóptero habia de provocar el lápiz de los dibujantes; i, efectivamentc, Lacordaire ( $G e^{-}$ nera T. VIII, P. $S_{4}$ n. (!) ) nos dicc que Hope i Erichson lo figuraron en su obra; pero agrega: "pour de belles figures des deux sexes, woyez aussi Blanchard (in Gay, Hist. de Chile; zool. $V$ col, pl. 27 fig. I, 2) 1. Es de suponer que Lacordaire ni siquiera miró a la figura $I$, ántes de reclamar para ella la admiracion del público; sin eso habria visto que estc Lonjicornio está representado escandalosamcnte pentámero. En cuanto a Blanchard, quien fué el pintor de dicha figura, no ha visto nada. Yo hubiera preferido una figura ménos bonita, pero mas exacta.

La inexactitud de las figuras de los órganos bucales, tanto 
del macho como de la hembra, publicadas en la obra de Gay (Laim. 27, fig. 1, 2) poulri apreciarse, comparándolas con las que doi aqui, las cuales hin sido ejecutadas con el mas cicrupulosin cuidado.

I De un leonado uniforme; con la cabc\%a, el protórax, cl cscudo, los esternones, i aun el abdómen i la base de los muslos cubicrtos de una pubescencia lanucla de un lconado claro i sumamente espesa; la cual se hace corta, echada i escasa sobre los elitros i las patas. I ás antcuas son completanente glabras.

Las alas son propias al vuclo.

Un ejemplar ordinario presenta lina lonjitud de fi,oo, por u1ua anchura de I6,00; aquélla tomada de la base de las manclibulas al ápice de los clitros.

Barba trapeziforme i levemente trasversal. I engiieta fuerteinente encojida en su base; su parte anterior es larganente pelucla i dividida en dos lóbulos angestos i divaricados. Los artículos 2,3 de sus palpos son de igital lnnjitud; el último, cuya anchura da los 0,35 de su lonjitud es regularmente oblongo $i$ levemente truncado en su ápice; pero su forma, tanto aquí como en los maxilares no puede esplicar estas palabras de Lacordaire: "en triangle allongé".

Lóbulos de las quijaclas mui pequeños, cóneos $\mathrm{i}$ largamente peludos; el esteruo es algro mas anģosto i alargado que el inter110; pero pasa apénas el apoyo de Ins palpos. Este último es notablemente abultado. I a lonjitud de los palpos es normal, i no admite de ninguna mancra la palabra "estremadamenten (in Gay); ol artículo 3 es mayor que 1 , i menor que 2.4, que son iguales; este último, cuya anchura da los 0,30 de su lonjitud, es ménos regularmente oblonģo i con cl ápice mas ancho que cu el de Iros labiales.

l.as mandibulas son delgadas i deprimidas, con un diente en su borde intcrno; son bruscamente arqueadas en el ápice; esta parte es lisa, la otra es rugosa, i tan larga como el espacio comprendido entre el labro i el borde posterior de los ojos.

Frente cóncava. Épistomio escotado. Labro pequeño, de forma dudosa, por ser ocultado bajo una abundante pubescencia sin conbargo se alcanza a ver que es mui corto $i$ trasversal. 
Ojos grandes. La distancia que los separa es de I, IO encima i de 0,80 abajo; pero aquí nunca estan "contigus" (Lacord). El lóbulo inferior queda atras del borde anterior de la base de la antena.

Éstas alcanzan al $1 / 3$ apical de los elitros. Los artículos I, 2, i 3 en su mitad basilar son brillantes i marcados de gruesos puntos; la mitad apical de este último i los demas estan cubiertos de surcos poríferos irregulares; el 3 es de $1 / 9$ mas corto que I, $\mathrm{i}$ de $1 / 8$ mas largo que 4. 3-Iollevan adelante un truncamiento oblicuo, cuyo ángulo esterno es levemente agudo i salicnte, perc) en ninguna manera "subépineux" (Lacord); el I I es de 3/10 inas largo que ro, ievemente arqueado i comprimido, pero tambien no es "lamelliforme" (Lacord).

Protórax con la anchura basilar doble de la lonjitud; dorso cubierto de una puntuacion fina i apretada mezclada con algunas rugosidades. Su borde apical i el basilar son ribeteados. Los ángulos anteriores estan armados de un grande gancho arqueádo dirijido lateralmente, rugoso i deprimido en su base, mui afilado en su estremidad; el borde anterior de este gancho pasa un poco el del protórax i lleva unos dientecitos agudos; el posterior parece nacer en los $2 / 3$ anteriores de la lonjitud; $i$, posteriormente a este punto, el dorso no está separado de los epipleuros por ninguna quilla.

El escudo, cuya anchura da los 0,23 de la de la base de los elitros, es casi semicircular i mui densa i finamente rugoso.

Los elitros ticnen su lonjitud doble de la mayor anchura, la cual está en el medio; la de la base da los $7 / 4$ de la del protórax; sus costados son casi paralelos, pero un poco encojidos debajo de los callos humerales; éstos son jibosos i dominan al pliegue epipleural, que está bruscamente dilatado en este punto i vi. sible casi hasta su estremidad; ápice con el ángulo sutural recto i armado de una pequeña espinilla, el marjinal está arqueado en forma de cuarto de círculo. El dorso está cubierto de finas rugosidades mucho mas gruesas cerca de la base; pero no lleva nunca asperewas, lo que hace inexacto decir que son lijosas (in Gay); lleva, sí, unas tres costillitas lonjitudinales poco visibles, $i$ borradas atras $i$ adelante. 
Salida prosternal mediana, deprimida, levemente arqueada atras de las ancas i redondeada en su ápice.

Salida mesosternal terminada por un truncamiento algo ahorquillado.

Segmentos abdominalcs fina i densamente punteados; se ven brillantes a pesar de la capa de pubescencia que los cubre, i que es miéntras mas espesa que es mas basilar. La salida intercoxal es triangular. Los segmentos $\mathrm{I} \cdot 4$ van disminuyendo levemente de lonjitud; el 5 es un poco mas largo, con cl borde apical truncado i una escotadura larga pero poco profunda en medio del truncamiento. Presentan de cada lado una ancha costa, que nace en el ángulo inferior i se clirije oblicuamente sobre la base sin alcanzarla.

El pijidio está enteramente ncultado por los clitros i termina en tres lóbulos redondeados: el del medio saliente, los laterales oblicuos.

Muslos delgados, comprimidos, disminuyendo de la base al ápice; su cara inferior está ahuecada soíamente cerca de las tibias.

Éstas son comprimiclas, i se cnsanchan gradualmente hácia cl ápice, sobre todo las posteriores; las anteriores $i$ las intermediarias son casi de igual lonjitud, i representan los $2 / 3$ de aquéllas; las intermediarias i las posteriores llevan en su filo interno unas asperezas mui agudas a modo de dientes de sierra. El ángulo interno del ápice o talon lleva en todas dos espinas finas $i$ alargadas que nacen en el mismo truncamiento apical i detras de la insercion del tarso. El ángulo esterno está prolongado en un diente espiniforme, notable sobre todo cn las anteriores.

Tarsos deprimidos; art. 1 apénas tan largo como 2.3 juntos; éstos iguales entre sí, i juntos apénas tan largos como 4; 3 profundamente bilobulado i poco mas ancho que 2 ; nudo basilar del 4 mui pequeño i enterrado entre los lóbulos del 3 . Por debajo, los tres primeros tienen un surco Innjitudinal cn cl medio, i llevan abundantes pelos esponjosos en cepillos; con escepcion del art. I de los intermediarios, donde se ven solo $\mathrm{cn}$ el ápice, i del inismo de los posteriores de donde han desaparecido por completo. Los art. 1, 2 presentan por cncima una leve depresion lonjitudinal, $\mathrm{i}$ sus ángulos apicales cstan armados de un 
diente agudo i divaricado. La lonjitud, del tarso posterior hace los 0,7 I de la de su tibia.

9-Difiere por ser negra, glabra brillante i de un tamaño mayor, pero mucho mas variable que en el otro sexo; pues el mas pequeño ejemplar que tengo a la vista presenta una lonjitud de 37,00 por una anchura de 17,00; miéntras que, en el mayor, aquélla es de 64,00 i ésta de 28,00 . La barba es mas trasversal, la lengiieta mas ancha, los palpos labiales i maxilares mas robustos, con cl último artículo mas hinchado; pues su anchura da la mitad de su lonjitud.

Los ojos están separados encima por 2,00; i debajo por 2,60: quedando pues exajerado lo que dice Lacordaire "yeux fortement sèparés en dessous, beaucoup moins en dessus."

Las antenas, levemente deprimidas hácia la estremidad, alcanzan a lo mas al 1/4 de los elitros, i a veces solo al $1 / 7$. El art. 4 da los 0,78 de 3 , i éste los 0,64 de $1 ; 1,2$ en su totalidad, i los cuatro o cinco siguientes en su cara interna, son lisos i con algunos gruesos puntos irregulares. 3, 60 7, en su cara esterna i gradualmente, así como los siguientes en su totalidad, llevan unos surcos lonjitudinales poríferos; pero " 3 -6 ayant en dessous une grande fossette porifére" (Lacoril.) es el resultado de una ilusion de óptica inesplicablc. 4-10 disminuyen levemente de lonjitud, su ápice presenta un truncamiento gradualmente mas oblicuo, i su cara esterna es levemente aquillada. II es brevemente oblongo i levemente arqueado, deprimido i mas largo que 10.

Pero es verdaderamente de notar que, entre los caractéres indicados en la obra de Gay para el jénero Amallopodes, establecido, como se sabe, para la $q$ de esta especie, se le haya ocurrido a su autor decir que las antenas alcanzan al $1 / 3$ de los elitros... ien los machos!

Cabeza mas abultada, con su parte superior marcada de un surco angosto en medio de una depresion lonjitudinal.

Protórax con una lonjitud que da los $2 / 3$ de la anchura basilar. Gancho del ángulo anterior mas ancho i mas corto. Mitad posterior sin ninguna separacion entre el dorso i los epipleuros. Aquél, casi liso en el medio, lleva de cada lado un ancho alvéolo, 
redondo, mas profundo en la parte esterna. El borde basilar i el apical estan ribeteados i llevan una franja de cortos pelos rubios.

Los elitros son mas ensanchados en su mitad posterior; el pliegue epipleural no presenta una brusca dilatacion debajo del callo humeral; en su ápicc estan redondeados separadamente, con el ángulo apical inerme; cubren alas membranosas cortas e inadecuadas para volar; su superficie lleva rugosidades confluyentes mucho mas gruesas que en el macho.

El abdómen es fino i poco densamente puntuado, con la estremidad del $5 .^{\circ}$ segmento semicircular.

El pijidio tiene la misma forma, está descubierto, ribeteado i lleva una puntuacion algo apretada i mui irregular.

Las tibias están dilatadas mas bruscamente en su ápice, con su filo interno aplanado. En las posteriores i las intermediarias, llevan de cada lado de esta parte aplanada una hilera de dientes espiniformes dirijidos hácia el ápice; i unas pocas, solo de un lado, en las tibias anteriores.

Los tarsos son cortos, pues los posteriores hacen solamente los 0,53 de sus tibias; son completamente glabros, i los tres primeros artículos son de igual anchura con una escotadura apical, mas profunda en el $2 .^{\circ}$, i sobretodo en el $3 .^{\circ}$, que en el $1 .{ }^{\circ}$, i cuyos lóbulos terminan por un diente agudo. El artículo I. ${ }^{\circ}$ es mas largo que 2,3 juntos; éste es mucho menor que aquél; $4 .^{\circ}$ es tan largo como los tres primeros juntos, i su nudo basilar cs mui visible, e iguala casi los dientes laterales del $3 .^{\circ}$

Lám. I, fig. $2^{\mathrm{a}}$ : barba. lengiueta i palpo labial de $\hat{3}$-Aum. Io diám.

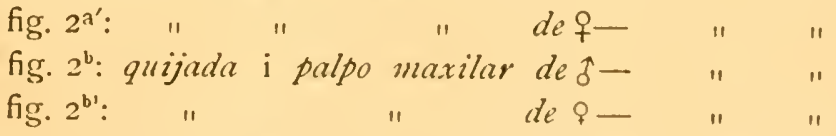

fig. $2^{\circ}$ : tarso intermediario izquierdo de un of de fo,oo de lonj.-Aum. 5 diám.

fig. $2^{c^{\prime}}$ : tarso intermediario derecho de una $q$ de 55,00 de lonj.-Aum. 5 diám. 


\section{CHIASMUS-(Thoms.) Limœ (Guérin).}

Este inseeto fué descrito por primera vez en i 830, bajo el nombre de Prionus Limae, por Guérin (Voy. de la Coq.p. 128). Poco despues Blanchard lo describió de nuevo (voy. d'Orb. Ent. p. 206); pero bajo el nombre de Macrotoma melitce-ceques.

Posteriormente Buquet lo describe aun (Guer. Menev.), i lo llama Mallodon gracilicornis.

Mas tarde, en 1847 , Erichson lo describe tambien i le da el nombre de Mallodon bajulus.

L. Fairmaire \& P. Germain (An. Soc. Ent. Fr., 1859, p. 485) le restituyen el nombre de Lima, bajo el cual apareció por primera vez en el mundo cntomolójico.

En i 860 aparece Thomson, que lo saca de los tres jéneros en los cuales se habia paseado hasta la fecha, i crea para él un jénero Chiasmus.

Pero viene Pascoe, el cual declara que este nombre de Chiasmus no sirve, por haber sido empleado ya por Mulsant para unos Hemipteros, i le sostituye el de Chiasmetes.

En I 869, Lacordaire da el poderoso apoyo de su aprobacion a esta medida, i parece que el insecto en cuestion va definitivamente a llamarse Chiasmetes Limce.

Cuando, el mismo año, Bates, que parecia haber hecho su especialidad de los insectos de las rejiones del Amazonas, donde pasó largos años, se interesa de repente en la Fauna coleopterolójica chilena con motivo de los numerosos elementos que le manda un compatriota suyo; i, tomando cartas en el asunto, restablece el nombre de brjulus que le habia dado Erichson en i 847.

Sin embargo, en I 872 , Gemminger i Harold derriban todos estos nombres, i restablecen para este insecto el de Chiasmus Lima en el cual lo dejaré descansar.

Lo que precede puede dar una idea aproximativa de las investigaciones, a las cuales ticne que entregarse el que quicra absolutamente hallar el padrino lejítimo de un insecto; para poder poner al pié del alfiler que lo tiene clavado el nombre que debe llevar en virtud de un derecho de prioridad que cada uno reclama ántes que todo. Tambien permite ver que, siel pro- 
pio de la Entomolojia ha de scr el estudio de los insectos, el de muchos Entomóloges parece ser describirlos bien o mal i sobre todo darles nombres; i que éstos son, sin disputa, la plaga de aquella.

Desde luego, se ve que varios de los caractéres indicados en Gay como distintivos del jénero Mallodon no convienen a la especie (melite-eques) descrita a continuacion, i que no pueden tomarse en consideracion; pero ninguna contradiccion o inexactitud ha de estrañar cuando se trata de esta obra.

En cuanto a la diagnósis que Lacordaire da del jénero Chiasmetes, ella encierra muchas inexactitudes; i, ademas, tenge que repetir aqui, que un defecto de este autor es cargar las cliagnósis de sus jéneros con tantos caractéres que no pueden convenir a muchas especies: lo que hace necesaria la creacion de una cantidad exajerada de jéneros.

Los sexos presentan diferencias, pero son pocas; por eso las indicaré al hablar de la hembra.

El tamaño ordinario de los machos de este insecto, es 33,00 de lonjitud por I 3,00 de anchura; sin embargo, poseemos uno que presenta solo 19,00 de lonjitud por 8,00 de anchura, pero es un enano. Es de un castaño pardo uniforme, i nunca "noir sur la tête et le prothorax (Lacord.).".

Es paralclo, levemente convexo; i desde la base del protórax su parte anterior se inclina mas $i$ mas hasta poner la cabeza perpendicular con los elitros.

El cuerpo es glabro, con cscepcion de un escaso vello leonado que cubre el mesosternon i el metasternon.

La cabeza es grandc; pues su anchura da los 0,64 de la del protórax; lleva arrugas mui gruesas en la parte superior i mui finas en la inferior.

La barba es triangular, pero mui trasversal. La parte de la lenguicta anterior a los palpos tiene la forma de un triángulo equilateral cuyo ápice, mui levemente sinuado, está adelante.

Las quijadas carecen por completo del lóbulo interno, cuyo lugar está indicado solamente por un pequeño mechon de pubescencia. En cuanto al esterno es córneo, recto, levemente dilatado hácia el ápice, que es redondeado i alcanza a lo ménos 
a la parte anterior del primer artículo de los palpos. Todos éstos son levemente alargados; sus artículos no presentan entre sí diferencias anormales en el tamaño, i el último es oblongo i mas o ménos truncado en su ápice; pero no dan de ninguna manera lugar a decir de ellos que son "très courts, rubustes, inegaux et à dernier article à peine triangulaire (Lacord.)".

Las mandíbulas son mui cortas, gruesas, arqueadas, rugosas i bifidas, con el diente de encima el mas corto i el mas pequeño; son "verticales (Lacord.)" únicamente porque siguen la direccion de la cabeza que lo es tambien.

El labro es pequeño, trasversal, convexo, i su borde anterior se oculta bajo una espesa franja de pelos rubios; pero no consigo ver en él un labro "vertical, concave, tronqué (Lacord.)".

El epistomio está en forma de un corto triángulo, cuya base es saliente, levemente arqueada, i se estiende entre las partes anteriores de los tubérculos antenales; su ápice lleva una pequeña quilla que se pierde en un surco lonjitudinal ancho i profundo que parte toda la cabeza por encima; sus líneas suturales con la frente estan perdidas en una confusion de gruesas arrugas, que cubren a aquélla hasta el vértice.

Los ojos presentan, frente al punto de insercion de las antenas, una escotadura apénas apreciable; son mui trasversales, $\mathrm{i}$ sus estremidades son algo angulosas. La distancia que los separa, tanto encima como abajo, queda siempre igual $\mathrm{i}$ es en jeneral de 3,00: no son, por consiguiente, "fortement séparés en dessus (Lacord.)".

Las antenas pasan apénas el primer quinto de los elitros; son mui delgados i filiformes. El artículo I es mui poco mas largo que los demas, pero es deprimido i dilatado hácia afuera; es decir que tiene la figura de un paralelógramo injertado con el tubérculo antenario $\mathrm{i}$ el artículo 2 por el ángulo interno de sus estremidades. Los artículos 3-I I son cilíndricos i de igual lonjitud; son lisos con unos gruesos puntos apartados que creo poriferos; los cuales, desde el 3 , se juntan mas i mas en la parte apical inferior, de modo a formar surcos lonjitudinales que aumentan gradualmente hasta llegar a cubrir enteramente los tres o cuatro últimos. Pero, en mi concepto, "la fossette porifère du 
3 article convertic en sillon porifire sur $f^{-S}$ (Lacord)." es el resultado de una ilusion de óptica.

El protórax es mui trasversal, pues su lonjitud da los 0,54 de su anchura; sus ángulos anteriores son poco salientes i redondeados; los posteriores llevan un diente cnderezado, a menudo acompañado de otro mas pequeño mui aproximado $\mathrm{i}$ situado en la parte basilar. Los costados son paralelos adelante del ángulo posterior, $i$ levemente converjentes en su $1 / 3$ o su $1 / 4$ anterior. El dorso está separado de los epipleuros por una quilla finamente almenada; su superficie está cubierta con una puntuacion rugosa mui fina i mui apretada, sembrada de tuberculillos lisos, i, ademas, está adornada con placas lisas marcadas de gruesos puntos i dispuestas como sigue: una línea lonjitudinal central, mui angosta en su mitad anterior, i surcada en toda la posterior; se ensancha bruscamente desde el medio, i va dilatándose hasta juntarse con una faja basilar del mismo ancho que el pedúnculo mesotorácico; de cada lado, pero mas aproximado al borde lateral que al centro, hai otra placa lonjitudinal i mediana, la cual, adelante, pasa levemente la mitad del protórax, i atras se junta con la estremidad de la placa basilar o se borra ántes de alcanzarla. Ademas, en el medio, se ven dos placas mayores i con forma de triángulo equilateral, dispuestas de tal manera que los ápices se juntan con la línea central en el punto en que ésta se ensancha i que las bases quedan paralelas con los costados; esta disposicion da a estas placas la figura de una cruz de Malta perfectamente dibujada. El borde anterior i el posterior llevan una franja de mui cortos pelos rubios.

El escudo está acorazonado, con la superficie cubierta de finas asperezas, $i$ un surco lonjitudinal que no alcanza al ápice. Su anchura representa la $1 / 5$ parte de la base de los elitros.

Estos ticnen sus costados casi paralelos, pues su anchura basilar es solamente de los 0.12 inferior a la de la parte apical, al mismo tiempo que excede solamente de los 0,08 la de la base del protórax; en cuanto a la lonjitud es mas o ménos doble de la mayor anchura. El ángulo apical es mui reclondeado e inermc; el callo humeral es corto i poco saledizo; el borde lateral i el sutural son finamente ribeteados; cl pliegue epiplcural es 
convexo, no bruscamente dilatado en su base i acaba en frente de las ancas posteriores. El dorso está cubierto de una puntuacion mui apretada, un poco rugosa, i mezclada con algunas asperezas en su base. Cada elitro lleva cuatro costillitas lonjitudinales mui finas i poco aparentes.

La salida prosternal es ancha, plana, redondeada en su ápice, i no pasa las ancas. La del mesosternon es, como en el jénero anterior, paralela i escotada en su estremidad.

Los segmentos abdominales son de igual lonjitud; I-4 estan cubiertos en sus $2 / 3$ basilares, i 5 en su totalidad, de una puntuacion fina mui apretada i mezclada con pequeñas arrugas; el $1 / 3$ apical de aquéllos es liso i brillante; salida intercoxal en triángulo mui agudo; borde del 5 anchamente escotado, con los ángulos de la escotadura redondeados i velludos. Pijidio en forma de paralelógramo un poco mas largo que ancho, cubierto de puntos finos mui irregularmente agrupados; el borde apical es an. chamente arqueado i lleva una franja de cerditas cortas i rubias.

Las patas son fuertes i cortas, con los muslos, las tibias i los tarsos de todas notablemente iguales entre sí. Los muslos son gruesos i comprimidos, con su cara inferior ahuecada solamente cerca de la tibia. Esta es de una lonjitud igual con la del muslo, deprimida $\mathrm{i}$ ensanchada de la base al ápice, con el filo interno aplanado o aun levemente acanalado; en todas el talon lleva dos mui cortas espinillas. En las anteriores, el ángulo esterno presenta una escotadura pequeña pero profunda, en la cual puede alojarse la base del primer artículo tarsal, i cuyos ángulos son dentiformes; en las intermediarias i las posteriores, esta escotadura está reemplazada por un truncamiento, cuyo ángulo interno forma un mui pequeño diente recto, $\mathrm{i}$ el esterno un diente algo mayor i divaricado.

Los tarsos son anchos, i su lonjitud da los $5 /$; de la de las tibias. El artículo I es mas corto que 2,3 juntos; 2 es el mas corto i triangular; 3 es mui anchamente bilobulado; 4 es mas corto que I-3 juntos, con su nudo basilar mui pequeño, i como enterrado en el fondo de la escotadura del 3. Ganchos pequenoos. Pubescencia esponjosa mui abundante debajo de los tres primeros artículos de todos los tarsos; el I, solo, presenta por debajo un surco lonjitudinal. 
\$-Es mayor, i alcanza a veces hasta 40,00 de lonjitud por 16,00 de anchura.

El protórax parece ménos trasversal, aunque la proporcion entre la ionjitud i la mayor anchura sca la misma; porque los costados, ora rectos, ora levemente arqueados, son mas converjentes, i eso desde la base; resultando que la anchura anterior da solamente de los 0,70 a los 0,75 de la basilar. Ei diente del ángulo posterior es mas marcado, como, asímismo, los de la quilla latcral. En cuanto a las placas del dorso, estan mal limitadas i presentan un dibujo embrollado.

I.cs segmentos abdominales son enteramente lisos $\mathrm{i}$ brillantes, con una puntuacion mui fina i mui rala; el último está truncado en su ápice. El borde anterior del pijidio es levemente sinuoso.

Las patas son notablemente mas delgadas, con las posteriores evidentemente mas alargadas que las otras. Las tibias estan apénas dilatadas hácia el ápice, con su filo interno convexo; en su parte apical, estan revestidas de una pubescencia rubia, corta, echada i mui espesa, que imita un poco la de debajo de los tarsos.

Este insecto no es escaso en Chile, pero no parece aventurarse mucho al sur del Maule. Su larva vive con preferencia en la "Quillaja saponaria".

Lám. I, fig. $3^{3}$ : barba, lengiieta i palpo labial-Aum. IO diám.

" fig. $3^{\mathrm{b}}:$ quijada $i$ paipo maxilur "

" fig. $3^{c}$ : tarso intermediario izquierdo de 太-Aum. 5 diám.

MICROPLOPHOKUs. (Blanch.) magellanicus (Blanch.)

El jénero Microplophorus ha sido establecido por Blanchard en I85 I (in Gay, rool. T. V., p. 454) para una especie de Lonjicornio, que describe bajo el nombre de magellanicus (loc. cit.), i que está figurada, pero no descrita, en el "Voy au Pole sud; Entom.p. 260; pl. 16; fig. I, 2 f et + .." A esta especie, que pro- 
viene de Magallanes, Blanchard agrega, bajo el nombre de "castaneus", una segunda que describe sobre un ejemplar único i hembra (loc. cit. p. 457), i figura (loc. cit., lám. 27, fig. 6).

Este sabio entomólıgo previenc que esta segunda cspecie es sumamente vecina de la primera; pero asienta, sin embargo, que es fácil distinguirla por su talla mas considerable, su matiz mas cargado, los dentellones de sus antenas mas espresados i mas largos, el protórax mas rugoso, las espinas laterales mas largas, los elitros mas oscuros i ménos ligados, ctc. Lo que se saca en claro de tantos mas i menos es que cl señor Blanchard se encontraba con ganas de hacer una especie nueva; pues, como se verá inas adelante, el tamaño, el matiz jeneral, las antenas, el protórax i sus espinas, el color de los clitros i su puntuacion, ofrecen variaciones tan graduales, que éstas no pueden servir de pretesto a especies nuevas.

Este insecto, al cual dejaré el nombre de magellanicus, se halla desde Chillan hasta Magallanes. Es paralelo i levemente convexo. Los dos tamaños estremos, en los machos que tengo a la vista, son: lonjitud 26,00 i 22,00 ; i anchura: 8,00 i 7,50 . La mayor hembra que mido tiene una lonjitud de 28,00 por una anchura de 9,00.

En cuanto al matiz jeneral, él se queda entre un castaño subido i un castaño aleonado; pero llega a ser testaceo en los elitros de algunos ejemplares, sin que esta diferencia-aunque no resulte de un estado inmaduro-me parezca suficiente, por sí sola, para hacer considerar como de una especie distinta los ejemplares que la ofrecen.

El vello es fino i lanudo, poco abundante por debajo del cuerpo i casi nulo por encima.

La barba está en trapecio mui trasversal. La lengiieta es casi culadrada, con su mayor anchura en el borde anterior, que es pubescente i mui levemente sinuado.

Las quijadas tienen su lóbulo interno mui corto, levemente velludo, córneo en la parte central, pero membranoso i glabro en su borde interno. El lóbulo esterno es ancho, redondeado i levemente arqueado en su ápice, el cual alcanza mas o ménos a la base del $3 .^{\circ}$ artículo de sus palpos.

Los palpos son todos cortos i pequeños, con los artículos casi 
de igual lonjitud; el último, oblongo, es alargado i angostado levemente en su base en los labiales, mas grueso i macizo en los maxilares; pero nunca son "ciliés à lcur estremité ( Lacord)".

Mandíbulas pequeñas; la parte arqueada del ápice es corta i no pasa la anchura basilar; su borde interno es obtusamente angosto en el medio, i su estremiclad es bificla con la punta inferior mas fina i mas corta que la otra; pero no son "fortement arquées (Lacord)", ni tampoco túnicamente "agudas en su estremidad (Blanch)".

Labro pequeño, en forma de segmento de círculo trasversal, con su borde inferior ocultado debajo de una espesa franja de pelos rubios. Su línea sutural con el cpistomio es levemente arqueada, rebajada, ancha, lisa i bien visible.

La cabeza es corta; pero no es "verticale (Lacord.)", sino que sigue el leve declive del protórax hasta la base de las antenas inclusiva: lo que hai, sí, es que los tubérculos antenarios, separados solo por un angosto surco que principia entre los ojos, forman un rodete trasversal i saliente que hace parecer vertical i cóncava la parte anterior a la base de las antenas; miéntras que, en realidad, el epistcmio, que ocupa todo el espacio entre el susodicho rodete $\mathrm{i}$ el labro, es aplanado.

Ojos gruesos, normalmente escotados, i con el lóbulo inferior no sobrepasando adelante a la base de las antenas. En un fo, su distancia es de 0,50 encima $\mathrm{i}$ de 1,00 abajo; miéntras que en una + de igual tamaño, estas cantidades son: 0,80 i r,20. Su distancia del protórax es igual a la anchura de su lóbulo superior, resultando un cuello levemente cónico i finamente rugoso, cuya anchura es inferior de $20 \%$ a la de la cabeza en el punto mas saliente de los ojos.

Las antenas alcanzan a la estremidad del cuerpo en los $\hat{b}, \mathrm{i}$ solo al medio del tercer segmento abdominal en las + . Llevan doce artículos: no dejando de ser notable que los Señores Entomólogos, que se ocuparon de estus insectos desde cincuenta años, les hayan dado todos once, por no haber, sin duda, tenido la idea o el tiempo de contarlos. Por esto se puede medir el grado de atencion que, en su afan de describir mucho, nuestros mayores maestros dan a sus descripciones. Son poco robustas, con el artículo i en forma de corta maza apénas dos veces tan larga 
como ancha, i el 2 es nodiforme como es costumbre; los siguientes son levemente arqueados, pero, por lo demas, mui diferentes segun el scxo.

En los $\hat{\jmath}$, el artículo 3 es siempre de ignal lonjitud que el 4 Cierto es que, cuando se quiere apreciar esta proporcion sin medir los artículos, puede suceder que el observador sufra una ilusion de óptica: por llcvar el 2 agregado en su base, el 3 parece mas largo. La anchura de este artículo 3 representa los $0, \mathbf{I} 8$ de su lonjitud; i, por debajo, lleva una carena lonjitudinal, que es la continuacion de la que se nota en su ramal. 4-Io van acortándose gradualmente, hasta que 8 - Io presenten mas o ménos los 0,66 de 3. El I I es de un $20 \%$ mas largo que 10 ; $\mathrm{i}$ en cuanto al 12, es el mas largo de todos, pues es casi doble de 3 i casi triple de Io. Por el ángulo infero-esterno de su ápice, los articulos 3-I I, i no "3-10 (Blanch.)", echan, en direccion oblicua hácia adelante, un ramal delgado, flajeliforme i levemente flexuoso. El primer ramal es, en jeneral, mas corto que su artículo, i el segundo un poco mas largo que el suyo: desde alli hasta el II, estos ramales son un poco engrosados hácia el ápice, el cual es redoncleado, i van alargándose hasta tener mas de dos veces la lonjitud de su artículo; pero el del i I no alcanza a sobrepasar al 12. Los artículos 1,2 en totalidad i los otros en su parte superior o dorsal, son, sobre todo los primeros, glabros, brillantes i marcados de unos gruesos puntos irregulares. La cara inferior de 3-i I, así como el i 2 i los ramales en su totalidad, llevan poros mui apretados casi ocultados por una pubescencia erizada i mui igual.

Lacordaire, al hablar de los artículos de las antenas en este sexo, dice: "article I mediocrement gros et long, en cône renversé; 3 it peine plus long que f; celui-ci it 5-10 graduellement plus courts; tous munis a leur sommet interne d'un ramean long et grêle; II plus long que 10." En primer lugar, esta frase es confusa, porque no se comprende claramente á cuáles artículos se refiere la palabra "tous". Ademas, presenta numerosas omisiones e inexactitudes, que los caractéres indicados aquí ponen en evidencia. Diré tambien que no puedo, a imitacion de cste gran naturalista, considerar como "interne" la parte del ápice de los artículos donde nace el ramal. Pues se comprende de sobra que las par- 
tes de estos órganos, provistas de poros i pubescencia, han de estar siempre dirijidas de manera a recnjer las ondas sonoras y las moléculas odorantes; i que éntas les llegan de afuera, i no del cuerpo que los lleva.

En las $q$, las antenas son glabras. El articulo 3 es mas largo i mas delgado; pues su anchura representa solamente el $10 \%$ de su lonjitud, i ésta es de una tercera parte mayor que la del 4 Las Ionjitudes de 4-I I disminuyen gradualmente, llegando la de este último a representar solo la mitad de la de aquél. El 12 es mui corto, embutido en la extremidad del i i i soldado con él, pero con su línca sutural bien marcada. Como en los $\hat{\delta}, \mathrm{cl}$ ángulo ínfero-externo del ápice se prolonga oblicuamente hácia adelante, pero en formade diente triangular i agud s; el cual principia a notarse solamente en el artículo 5, illega a su mayor desarrollo en los artículos 7-9. Allí, el diente presenta una lonjitud que puede variar desde la totalidad hasta la mitad de la del artículo que lo lleva, quedando, así, inutilizado uno de los principales caractéres que Blanchard indica para reconocer su M. castaneus. Como en los \$, la totalidad de los artículos I, 2 i la parte dorsal de los siguientes es lisa, brillante i marcada de gruesos puntos apartados e irregulares, pero solo hasta el artículo 7, haciéndose densamente rugosa despues. La parte ínfe. ro-esterna, que lleva los poros, está dividida lonjitudinalmente por una fuerte quilla que se prolonga sobre el diente i forma su borde posterior.

En el protórax, una lonjitud central de 3,40 corresponde con una mayor anchura de 4,So. El inedin del borde apical i el del basilar estan con forma de un gran lóbulo corto; que tiene la anchura del cuello en el primero, i la del pedúnculo mesotorácico en el segundo: siendo, pues, impropio decir de este último que es "bisinué ( Lacord.)" Los costados estan armados de dos pequeñas espinas casi horizontales i dirijidas hácia afuera: la una, dentiforme, en el ángulo anterior; la otra, un poco mas angostat, en el medio de la lonjitud. Esta armadura no presenta diferen. cia segun los sexos, por mas que Blanchard diga lo contrario; $i$, aunque variando un poco de lo mas a lo menos, es constante. Sin embargo, tengo a la vista un ejemplar $\hat{c}$, en el cual la espina del medio ha desaparecido casi por completo; i otro del mismo 
sexo en el cual el ángulo basilar, en jeneral simplemente recto, está dilatado lateralıncnte de modo a formar un diente alargado igual a los dos anteriores. Haciendo caso omiso de estas espinas, los costados varian entre paralelos i notablemente converjentes hácia adclante. El dorso es desigual i como abollado i su superficie está cubierta de una puntuacion mediana apretada i rugosa. Fuera de las espinas que indican un poco donde está la separacion de este último con los epipleuros, no hai nada que lo haga.

El escudo es mediano, pubescente, cubierto de una puntua. cion rugosa i lonjitudinalmente cóncavo; es mas largo que ancho, con sus costados algo paralelos i el ápice anchamente redondeado. Sin embargo, en algunos raros ejemplares, se aplana $\mathrm{i}$ adquiere la forma evidente de un triángulo agudo en su ápice.

Los elitros son levemente convexos i paralelos casi hasta su estremidad; son truncados en la base, con el callo humeral grueso, redondeado $\mathrm{i}$ saliente; el ángulo apical esterno es anchamente arqueado, $\mathrm{i}$ el interno es recto $\mathrm{i}$ lleva una espinilla. E] pliegue epipleural es angosto i corto; pues, ántes de llegar a las ancas posteriores, se trasforma en un rodete que constituye el borde del elitro, pasa por su ápice, donde se engruesa, i remonta hasta el escudo haciéndose gradualmente mas delgado. El dorso lleva una puntuacion apretada, mas gruesa hácia la base, i, sobre cada elitro, cuatro costillitas lonjitudinales mas o ménos borradas en sus dos estremidades, i de las cuales la esterna desaparece a veces por completo; pero no lleva nunca asperezas por lo cual no se pucde nunca decir que es "lijado (Blanch.)" En un ejemplar, cuyo protórax mide 4, So de anchura, la de ámbos elitros; tomada frente al ápice del escudo, es de 8,20 , i corresponde con una lonjitud de 20,50 , medida de la base al ápice: la anchura del protórax representa, pues, los 0,58 de la de los elitros i ésta los 0,40 de la lonjitud. Resulta que Blanchard, al decir que los elitros son "notablemente mas anchos que el protórax", es mas exacto que Lacordaire, cuando solo las dice "un peu plus largesı.

Salida prosternal mui arqueada atras de las ancas i densamente pubescente en los $\delta$; es mas angosta que la mesosternal, la cual es lonjitudinalmente cóncava. 
Metasternon cubierto de puntitos apretado;, de cada uno de los cuales nace un pelo fiuo i alargado. En el medio lleva una profunda, pero angosta estría lonjitudinal: la cual, en los $\hat{b}$. queda ocultada por una mancha formacla de una pubescencia rubia, lanuda, tendida i mui espesa. Sus episternones son perfectamente triangulares, con sus epimeros grandes i paralelos, pero oblicuos.

Segmentos abdominales casi de igual lonjitud, brillantes i sembrados de puntitos piliferos poco apretados. El 5 es ancho i bilobulado en los $\AA$. En las $f$, se hace gradualmente mas angosto i entero, quedando su forma bastante inconstante. El pijidío es rugoso, ancho, i arqueado en su borde apical; pero es preciso cuidar de no confundirlo con la placa que cubre el pene, la cual es angesta i bilobulada.

Las ancas $p$ csteriores son contiguas. Las patas son mediocres, i se alargan mui levemente de adelante hácia atras. Los muslos son comprimidos, brillantes i con puntitos pilíferos poco apretados. Las tibias son ásperas i opacas, levemente engrosadas hácia el ápice, i con dos mui cortas espinillas en el talon. Los tarsos son tan anchos como la tibia en su ápice; sus tres primeros artículos son de igual anchura entre sí, i todos llevan por debajo pelos esponjosos en cepillo. El artículo 3 es siempre mui bilobulado; $i$ el I es mas o ménos tan largo como 2,3 juntos i como 4. El nudo basilar de este último es pequeño, pero bien visible.

Lám. I, fig. $4^{3}$ : barba, lengïeta i palpo labial. Aum. Io diám.

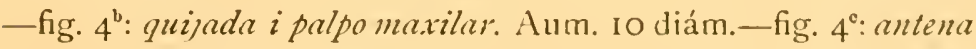

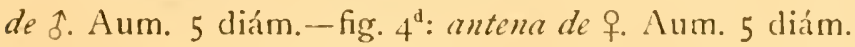

\section{Calverti (Fr. Philippi)}

Una segunda especie mui auténtica de este jénero lia sido descrita, bajo este nombre, por ini sabio amigo, el profesor don Federico Philippi; él acaba de remitirme esta descripcion para incluirla en cste trabajo. La doi a continuacion. 
"M. pubesiens, testaceus; capite, prothorace, antennis, pedibusque fus. "cis, et in utroque elytro linea media obliqua, basim et apicem haud "attingente castanea; spina antica prothoracis parra, obtusa.

"Long. $21^{\mathrm{mm}}$; lat. bas. clytr. $7^{\mathrm{mm}}$, ad apicem $61 / 2 \mathrm{~mm}$.

"Hallado al pié de la Cord. de Chillan por el señor Calvert " i cedido al Museo. II, 8I.

"El animal tiene la superficie densa i finamente puntuada, $\mathrm{i}$ "pubescente, con escepcion de los elitros; es de color testáceo "pálido, ménos la cabeza, protórax, patas i antenas que son "fuscas. El diente anterior de los lados del protórax, es mui "pequeño. Los elitros son lampiños i densämente puntuados i "muestran tres líneas elevadas, que no alcanzan ni a la base " ni al ápice, i sobre la línea del medio se halla una mancha " linear oblicua cie color castaño. El tórax es por debajo mas "denso i largamente peludo que el resto del cuerpo.

"Por su menor tamaño i su coloracion notable es bien distinta".

Esta descripcion, mui exacta i completa aunque corta, deja ver que la línea oscura de los elitros es lo que no permite confundir esta especie con la anterior; pero como ha sido redactada sobre un solo ejemplar, es bueno preveer el caso de variaciones posibles; $i$, dada la frecuencia con que suceden entre nuestros Coleópteros, nada estraño fuera que, en algunos individuos, esta línea disminuyese hasta borrarse completamente, o se ensanchase hasta invadir todo el elitro. Me permitiré, pues, indicar un carácter, que, segun creo, ha de ser constante, i que, aunque leve, podria en este caso servir a reconocerla: quiero hablar de la diferencia de proporcion que presentan ámbas especies entre la anchura de la base de los elitros i su lonjitud. En el Calverti, aquélla, frente al ápice del escudo es de $7.00 \mathrm{i}$ la última de 15,50 , lo que da una proporcion de $45 \%$; miéntras que, en el magellaniuzs, hemos visto que es solamente de $40 \%$. A esto se podria agregar la pubescencia de la parte inferior del cuerpo, que el profesor F. Philippi señala con razon, i que es, sobre todo en los muslos, algo mas larga i mas abundante que en esta última especic. Pero, lo repito, se habla aquí de lo que pasa en un ejemplar único: lo cual bien podria hallarse modificado en otros. 


\section{ADDENDA}

A última hora, i demasiado tarde para que, a mi parecer, fuese conveniente colocarla mas atras, recibí de Europa la copia de todo lo que Thomson escribió sobre el Acalonegara SeríiIlei, en "la Rearue et Mag. de Zool., p. $261,1877 . "$

Es con el mayor asombro que he leido este trabajo; i es convencido de la gran utilidad que hai en hacer figurar aquif tanto su reproduccion como las críticas que provoca, que lo doi todo a continuacion.

De esta lectura se podrán sacar algunos datos para apreciar las producciones de este gran naturalista; i ver los embrollos, en los cuales la fatalidad se complace en meter, a veces, a los entomólogos.

REVUE ET MAGASIN DE ZOOLOGIE, p. $261,1877$. Groupe des ACALODEgmites. Thoms.

"Caput paroum; mandibula parve; palpi debiles, breves; of antenna " moniliformes, corpore longiores; oculi subapproximati, subtenue granu"lati, Prothorax lateribus 4-hamatus. of abdomen lireve, projectura in"tercoxalis obtuse triangularis, + latissima rotundata. Pedes mediocres, "compressi, of of femora postica corporis extremitatem haud attingentia.

"OBs. Cette formule differe de celle des Micropsalites (Lac. "gen. col. VIII. p. 42) en ce que les antennes des ô sont mo" niliformes et plus longues que le corps, les yeux assez rappro" chés, les mandibules avancées, les palpes grèles et courts et " les cuisses postérieures bien plus courtes que l'extremité du " corps dans les deux sexes. Cc groupe nous parait devoir être "placé auprès de celui des Micropsalites.

"ACALODEGMA. Thoms.

"(nov. gren.: ak $\alpha \lambda$ ss $_{\text {tranquille, } \delta \in \gamma \mu a ~ m o r s u r e .)}$

"Caput parvum; mandidula' parva, paulo porrectie; palpi deliles, "breves, maxillares labialihus longiores, haud dilatati; of antenne cor"pore longiores, $1 T$-articulate, moniliformes, scapo articulis cateris sin- 
"gulis (2. ${ }^{\circ}$ excepto) breviore, $3{ }^{\circ}$ cateris singulis longiore, 4-To grada. " tim decrescentibus, ultimo $30^{\circ}$ quasi aquale, o vix moniliformes, sub"compressa, scapo articulu $3 .^{\circ}$ vix breviore, $30^{\circ}$ cateris singulis longiore, "ceteris decrescentilus. Prothorax transversus, lateribus 4-hamatus, "hamulis iurvatis, 2 antiiis brevioribus. Scutellum semicirculare. of Ely" tra paulo elongata, \& breviora ampla, of apice bispinosa, \& inermia; "I pygidium magnum, valde conspicum, porrectum. Prosterni et me" sosterni apendices laminiformes, illo angusto, hoc lato. of abdomen "breve; of projectura intercoxalis obtuse triangularis, of latissima ro"tundata. Pedes mediocres, compressi, gradatim a anticis paulo cres"centes, \& $q$ femora postica corporis extremitatem hand attingenia; "tarsi articulo $x^{\circ}{ }^{\circ}$ duobus sequentibus fere aquale.

"Genre ambigu à raison de ce que l'espèce qui le compose " semble emprunter des caractères à plusieurs genres très dif" ferénts, par quoi nous avons dû en constituer un groupe à " part. Ainsi les Acalodegma ont pour caractère de rappeler, " par la forme des mandibules et le rapprochement des yeux, " les Poliarthron et les Polyoza, et, par l'armature du protho"rax, les Micropsalis, les Meroscelisus et les Acanthino" dera +. Les mâles se rapprochent de la forme génerale des " mâles des Meroscelisus, et, en vertu de la modalité (?) de la " livrée, des Prionus. Enfin les femelles rappellent assez bien " celles de Micropsalis.

"A. SERVILLEI (Blanch.)

In Gay. Hist. Chile, V,p. 45 2(Ancistrotus)

"Syn. marginipennis (Fairm.) Ann. Soc. Ent. de Fr., I867,p. "270. (Apterocaulus).

"Patric: Chili et Colombie.

"Long. 27-39 mill. Lat. II 1/2-14 mill.

"Brunneo-nigricans; caput prothoraxque ruyosa, apud \& solum "flavo-pilosa; elytra obsolete punctata et longitudinaliter 6-costata. "I apice spinosa, + lata ampliata, et apice rotundata; pedes brunnei.

"Obs. M. Steinheil (de Munich) a bien voulu nous envoyer " un paire $\delta \hat{q}$ de cette interessante espèce, sous le nom de: 
"Acanthinodera bihamata (Bates). Nous en possédons un "individu $\mathfrak{c}$ entièremente d'un brun testacé."

Al leer este trabajo, se nota primero la singular persistencia del autor en dar a este insecto unas antenas moniliformes.

No sé lo que Thomson entendió por esta palabra; pero, en cuanto a mí, descle sesenta años que me ocupo de cntomo!ojía, he oido decir siempre que una antena moniliforme era esta, cuyos articulos redondeados, parecian ensartados como los granos de un rosario; i todas las personas que he consultado a este respecto, aqui-el sabio naturalista doctor $R$. A. Philippi, su hijo el profesor don Federico Philippi, el distinguido lengiiista don Fernando Paulsen, etc., etc.-me han dicho to mismo.

Si la palabra "moniliforme" no tuviese en la pluma de Thomson otro sentido que el universalmente reconocido, esta antena, que cuenta solamente i I artículos; i que va desde la cabeza hasta mas allá de la estremidad del cuerpo, en un Lonjicornio de 27 a $39 \mathrm{~mm}$. de lonjitud, presentaria por cada artículo una bolita de mas que $3 \mathrm{~mm}$. de diámetro, lo que es absurdo.

Es de notar tambien el modo estraño del autor para espresar la cantidad de los accidentes o adornos de los órganos.

Así, cuando dice: "Prothorax lateribus f-hamatus", no entiende decir que son cuatro ganchos por cada lado, sino dos: dos en un lado i dos en el otro hacen cuatro. Los adornos son siempre simétricos, i por eso siempre se habla de los de un lado. En apoyo de lo que digo, vemos que Bates, que él, habla como todo el mundo, llama "Acanthinodera bihamata" el insecto que Thomson dice "f-hamatus."

El mismo error se presenta cuando el autor dice, en la diagnósis del jénero, "elytra apice bispinosa". Todo el mundo entiende que aquí cada elitro tiene dos espinas, miéntras que no tiene mas que una; pero, para Thomson, como son dos elitros, son dos espinas. Este modo de espresarse es sumamente incorrecto: se ha de decir "elytra unispinosa"; porque es bicn evidente que eso indica una espina para cada elitro, i no para los dos. Pues con aquella manera seria correcto decir: "tarsi postici 
8-articulati". Lo mismo que cuando se dice: "elytra 6-costata", es porque hai dos elitros, i que cada uno lleva tres costillas; pero nadie lo comprencle así.

Si este sabio entomólogo ha presentado esta innovacion, como una mejora destinada a dar mas claridad a sus descripciones, me parece que se ha equivocado.

En las observaciones que siguen a la diagnósis del jénero, cuando, al hablar de la armadura del protórax de los Acalodegma, se indica su semejanza con lo que se ve en los Micropsalis, los Meroscelisus, i los Acanthinodera + ¿por qué eliminar el Acanthinodera $\hat{\jmath}$ ya que la tal armadura es idéntica en ámbos sexos?

Es tambien de notar que el autor parece haber tenido poca disposicion en desarticular las piezas de la boca, para conocer sus formas; porque habla solamente de lo que se ve de afuera i guarda, para todo lo interior, el mismo silencio que para ciertos caractéres mui importantes de los tarsos.

Pero dejaremos a un lado esas incorrecciones, inexactitudes i omisiones, que no pueden, sin duda, probar otra cosa, sino que este trabajo ha sido hecho con precipitacion $i$ despues de un estudio demasiado superficial, i nos fijaremos en dos puntos importantes que su lectura pone en vista.

I. El Acalodegma Servillei (Thoms.) habitaria, segun el autor, Colombia i Chile.

$2 .^{\circ}$ Los caractéres que le da no se aplican al Ancistrotus Servillei (Blanch.)

El cuadro siguiente pondrá en evidencia estas diferencias.

Acalodegma Servillei (Th.) Ancistrotus Servillei (Bl.)

\section{MANDÍBULAS}

Mandibules avancées. Mandibula paulo porrecte. 
PALPOS

Palpi breves.-Palpes courts. Unos palpos no pueden llamarse "cortos", cuando los labiales son $21 / 2$ veces tan largos como la lengiieta; i cuando los maxilares, cerca de 5 veces tan largos como las quijadas, sobrepasan a las mandíbulas.

\section{ANTENAS}

Antennce moniliformes. Articulis 4-Io gradatin descrescentibus;ultimo 3 quasi aquale.

Antenas filiformes.

Artículos 4-Io casi iguales; el último el mas largo de todos.

\section{oJOS}

Oculi subapproximati.

Subtenue granulati.

Tan distantes encima como debajo; i esta distancia es grande, pues iguala a la de las cavidades cotiloídeas de las antenas entre sí.

Fuertemente granulados.

\section{PROTÓRAX}

Prothorax lateribus f-hamatus; | Protórax con dos ganchos hamulis 2 anticis brevioribus. $\quad \begin{gathered}\text { espiniformes de cada lado. } \\ \text { El anterior es el mas corto. }\end{gathered}$

\section{ELITROS}

I elytra apice bispinosa;

obsolcte punctata:

longitudinaliter 6-costata.
Con una sola espina en su ápice, situada en el ángulo sutural.

Sin puntuacion ninguna; pero sí con rugosidades sembradas de pequeños tuberculillos, que las hacen ásperas.

Cada una lleva cuatro costillitas lonjitudinales poco manifiestas. 


\section{ABDÓMEN} o abdomen projectura interco-
xalis triangularis.

Salida intercoxal no triangular, sino en forma de un ló. bulo corto i redondeado.

\section{PATAS}

I. f femora postica corporis extremitatem haud attingentia. f: los muslos posteriores alcanzan a la estremidad del ab. dómen i aun la sobrepasan.

De lo cual concluyo:

I. Que estas dos especies son distintas.

2. Que es la de Colombia que Thomson ha tenido en manos para su descripcion.

3. Que es a ella sola que pertenece el nombre de Acalodegma servillei ( $T h)$.

$44^{\circ}$ Que para la nuestra que no es ni un Acalodegma ni un Ancistrotus, se habrá de crear un jénero nuevo, tan luego como se tengan los elementos necesarios para hacerlo de un modo conveniente: jénero, que tendrá probablemente su colocacion en el grupo de los Acantinoderitos.

Agregaré que sospecho mucho que, desde Blanchard hasta Lacordaire, los entomólogos se hayan equivocado respecto al sexo de los ejemplares que tenian en mano; i que Thomson haya, tal vez, mirado dos especies diferentes como los dos sexos de una misma.

No hai dudã que estamos aquí con el resultado de una confusion; la cual puede mui bien haber ocurrido en las cajas mismas de Thomson.

Ciertos datos que he podido conseguir lo indican claramente. Hélos aquí:

1. El naturalista Federico Leybold mandó, de I 862 a I 864 , a un señor Steinheil, óptico en Munich, unos veinticinco ejemplares del Ancistrotus chileno; i esto, segun supe, en pago de unos anteojos.

2. Mas tarde, otro señor Steinheil, de Munich—tal vez el hijo 
del anterior-naturalista i entomólogo, recorrió Colombia, Nuc va Granada i el Ecuador.

Lo primero que seria preciso saber es cuál de los dos Steinheil mancló el par de Ancistrotus a Thomson. Pcro, por poco que el segundo haya heredadodel primero, los de Chile i los ha ya reunido en su coleccion con los de Colombia, nunca se podrá saber exactamente cuál es la patria del par remitido a Thomson. 

L. IIIII I

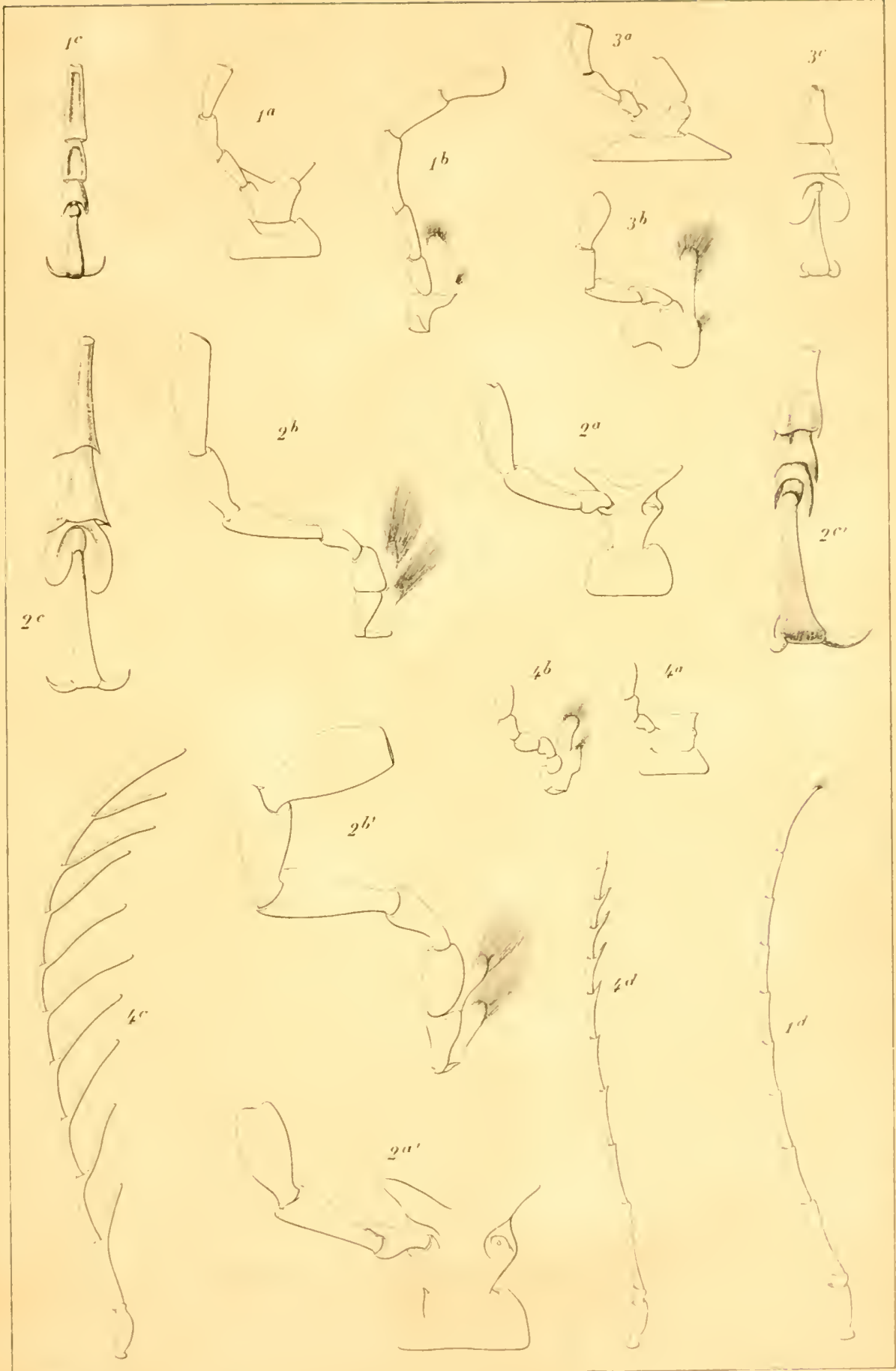

P'Grmaun del 



\section{APUNTES ENTOMOLOUJCOS}

POR

P. GERMAIN

SANTIAGO DE CHILE

IMPREINTA CERVANTES

BANDERA, NÚM. 46 
19,889.-Imp. Cervantes, Bandera 46 


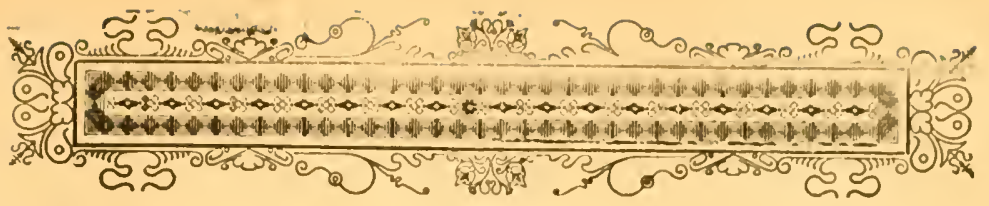

\section{APUNTES ENTOMOLÓJICOS}

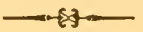

\section{Los Lonjleornios chilonos}

2. ${ }^{3}$ Sub-familia: Los Cerambicidos

ADVERTENCIAS:

I. ${ }^{8}$ Relativamente al trabajo que lleva por título: Révision des coléopteres du Chili, par L. Fairmaire et P. Germain, i cuya mayor parte fué publicada en los Annales de la Société Entomologique de France, en los años 1858-1863; debo declarar que, fuera de Familias o Iéneros que indicaré a su tiempo en mis "Apuntes entomolójicos", la parte que he tomado en esta obra ha consistido en mandar sus elementos a mi distinguido colaborador, acompañándolos de algunos datos biolójicos e indicacion de caractéres.

Declaro, pues, no haber participado a lo que este sabio entomólogo ha publicado, en cuanto a las descripciones $i$ al arreglo sistemático de los Insectos chilenos de la familia de los Lonjicornios.

$2{ }^{n} \mathrm{La}$ inexactitud, que, respecto a la procedencia de los ejemplares, reina en las colecciones europeas, es cosa demasiado conocida; para que estrañe mucho el verme considerar solamente como insectos chilenos las especies que han sido halladas por mí o por Entomólugos 
sérics del pais. En este trabajo no hablaré, por consiguiente, de las que son indicadas como tales en las obras estranjeras; pues, con frecuencia, se ha visto liegar a Europa insectos procedentes de la Arjentina, de Iolivia, del Perú, etc, pero que pasaban por chilenos por resultar de compras o de obsequios que habian tenido lugar en Valparaiso.

Ejemplos al apoyo no faltarian, si quisiera citar algunos; pero me contentaré con recordar que la Paromia dorcoides (W'estze) pasó largo tiempo, en Europa, por ser orijinaria de Columbia: lo que no es exacto; i que Lacordaire rectificó este dato erróneo, declarando bajo la autoridad de Reiche, que provenia de Australia (Jenera T. II, páj. 329): lo que no es cierto tampoco; hasta que, en 1854 , habiendo mandado este insecto a Paris, dí así a conocer que su patria verdadera es Chile.

Tan luego como se da principio al estudio de esta segunda sub-familia, las dificultades que provocaron el grito de desaliento que Lacordaire no pudo reprimir i del cual hablé en la primera pájina de este trabajo, aparecen a cada paso mas numerosas e insuperables. Pero digámoslo luego: si el arreglo sistemático de estos insectos forma un laberinto al parecer sin salida, se debe, no solamente a la cantidad de sus especies i a la estrema variabilidad de sus caractéres, sino tambien a los estudios incompletos de que fueron a menudo objeto.

Es verdaderamente deplorable que tantos sabios, persuadidos de que el rápido despacho de una obra es provechoso para su renombre, persigan su conclusion sin querer gastar la pacicncia $\mathrm{i}$ el ticmpo necesarios, para hacer las observaciones que deben servirle de base. Por esto, cuando, en busca de analojías, veré que solamente puedo valerme de estudios de esta clase, no edificaré sobre tales cimientos, sino despues de haber hecho a sus autores responsables del resultado. En el trabajo presente me esforzaré, como siempre, en descubrir i denunciar las inexactitudes $\mathrm{i}$ omisiones en las cuales habrán incurrido: $\mathrm{i}$, en cuanto a mis descripciones, por haber tenido en mis manos los insectos que las motivaron $\mathrm{i}$ visto lo que digo de ellos, esperoque, no presentarán las mismas irregularidades.

Las divisiones establecidas para agrupar las especies, siendo obra del cerebro humano i no de la Naturaleza, son siempre ar- 
tificiales i arbitrarias; $i$ adema 4 , su valor depende del cstudio mas o ménos completo que se ha hecho de los caractéres que se les ha dado por linderos. Por otra parte, éstos, pudiendo sacarse de cualquier lugar del cuerpo del insecto, i la eleccion que se hace de cllos variando segun el jénio científico de cada sabio, resulta que los arreglos sistemáticos, por mo obedecer a ninguna regla absoluta, puerlen ser cl preludio de la mayor confusion. P'cro, peor es aun el desórden que resulta, cuando se introduce en una agrupacion tipos que carecen de los caractéres indicados en la diagnósi.s. Se ve, pues, cuan necesario es señalar estos errorcs, para evitar el caos al cual conducen.

La subfamilia de los Cerambicidos puede caracterizarse así:

r." Lengiieta en jeneral membranosa, pero algunas veces córnea.

2. Quijadas casi siempre con dos lóbulos.

3. Ultimo artículo de los palpos nunca alesnado.

$4{ }^{\circ}$ Labro casi nunca perpendicular al epistomio, "ni soldado con él.

5. Pronoto pocas veces provisto de quillas laterales que lo separen de sus epipleuros.

6.0 Tibias anteriores sin surco oblícuo interno.

$7 .^{\circ}$ Ancas anteriores raras veces mui trasversales.

De lo cual resulta que, por no presentar nunca los caractéres indicados en los números 3 i 6 , que son propios de la 3 . $^{\text {a sub- }}$ familia, la 2. ${ }^{\text {a }}$ se halla nctamente separada de ella

Pero, para establecer los puntos que la separan cle la I. ${ }^{a}$, es mucho mas difícil; pues, es preciso consultar la presencia mas o ménos frecuentc de los demas caracteres. Así, se ve quc, miéntras unas quijadas con un solo lóbulo, un labro perpendicular al epistomio i soldado con él, una lengiicta córnea, un pronoto separado de sus epipleuros por una quilla lateral, i unas ancas anteriorcs trasversales son caractéres casi siempre de regla en los Prionidos, ellos constituyen, al contrario, escepciones aisladas en los Cerambicidos, es decir, que no se encuentran nunca juntos, sobre todo los ziltimos. (Lacord. T. VII, p.ij. 17). 
Al hablar de los Cerambicidos, este sabio dice ( $T$. VIII, p. 192) que, ya en 1869 , las colecciones no contenian ménos de 4500 especies de estos insectos; i, lamentando la cantidad exajerada de jéneros que sc han creado con ellas, agrega: "Quant anx genres dans lesquels on les a réparties (las especies) leur nombre est inmense et menace de s' accroître indéfniment." I, ya anteriormente (p. 5.n. $(I)$, levantaba la voz para quejarse de que, con la totalidad de la familia, se hubiera establecido mas de I,200 jéneros de los cuales la tercera parte, a lo ménos, comprendian solamente una o dos especies"cada uno; i agrega estas palabras desconsoladoras: "Il n'y aurait rien d'éxagéré a dire que le caractère le plus essentiel des Longicornes est que, ni leur ensemble ni leurs groupes secondaires, ne peuvent être caractérisés."

No hai duda que, si no el estudio, a lo ménos el arreglo sistemático de la familia ofrece dificultades escepcionales; pero, lo que creo tambien, es que, con motivo del tamaño, de la elegancia, i de los lindos colores de estos insectos, los coleccionistas han soltado demasiado la rienda a su conocido deseo de ilustrarse con la creacion de jéneros nuevos. Pues, los caractéres para distinguir las especies no faltan, en jeneral; i si éstas hubieran sido distribuidas meramente en categorias, secciones, o subjéneros, en lugar de servir a crear una infinidad de jéneros, se habria evitado cl enredo de analojias, que ha traido la confusion en medio de estos últimos, en lugar de facilitar su arreglo

Lacordaire reparte esta segunda subfamilia entre dos Lejiones.

Una que está caracterizada por unas tibias comprimidas i dentelladas hácia afuera, o la cabeza cubierta por el protórax $\mathrm{i}$ apénas visible de arriba.

Por no figurar ninguna especie chilena en esta Lejion, pasaremos lucgo a la segunda, que se encuentra, al contrario, caracterizada por unas tibias inermes; unos tarsos mas o ménos esponjosos por debajo; i una cabeza descubierta i enteramente visible de arriba.

A su turno, esta segunda Lejion se reparte entre dos Cohortes: 
La una, que no tiene tampocu representantes en Chile, está caracterizada por tener la salida intercoxal del abdómen mui ancha en las $q$, i por ser de costumbres hipójcas.

La otra es de vida libre i silvícola, con aquella salida intercoxal en triángulo alargado i mas o ménos puntiagudo.

Esta última Cohorte comprende insectos que forman un todo compacto que se deja mui difícilmente subdividir; i es, sobretodo a él que Lacordaire se refiere, cuando habla de las dificultades insuperables que presenta el arreglo sistemático de los Lonjicornios. El confiesa haber apurado todos los recursos de su esperiencia en busca de un carácter firme i lójico, que le permitiese seccionar a esta cohortc en otras dos agrupaciones; sin hallar otra cosa que la granulacion de los ojos, que es gruesa en unas cspecies i fina ell otras; resolviéndose, por fin, a establecer una Seccion A para los primeros, i una Seccion B para los segundos.

Pero este tan distinguido entomólogo, despues de disculparse humildemente por no haber sabido encontrar cosa mejor, trata luego de disminuir la imperfeccion del carácter del cual tuvo que valerse, haciendo notar ( $T$. VIII, p. 20I, n. (2) que es casi únicamente, entre las especies con ojos finamente granulados, que se encuentran las que presentan: unas quijadas con el lóbulo esterno mui delgado; una cabeza angostada atras i prolongada en rostro adclante; unas antenas cuya base está envuelta por los ojos; unos elitros en parte atrofiados; poros odoríferos; etc., concluyendo de esto, que la coexistencia de esos caractéres con una fina granulacion de los ojos, indicaria que esta última constituye un carácter de valor considerable.

¡Ya lo creo! I, si algo ha de asombrar es que un hombre como Lacordaire, haya estado un solo rato sin ver la importancia de la granulacion de los njos para un arreglo lójico de las especies, i la causa de esta importancia.

Una granulacion fina de los ojos es propia de las especies con costumbres diurnas, es decir que viven de dia, a todo sol; que se recojen cuando éste se acerca al horizonte, i duermen durante la nochc.

Una granulacion gruesa se encuentra cn las especies que, 
durmiendo durante el dia, lo pasan escondidas i quictas en los follajes u otros abrigos; que se ponen en movimiento a la hora en la cual aquellos se recojen, i estan en toda la actividad de la vida al crespúculo $i$ aun en la noche.

De todas las observaciones que he hecho a este respecto en los Lonjicornios de estas dos secciones, ninguna ha venido hasta ahora a contradecir lo que acabo de asentar.

Es evidente que, por ser indicativa de diferente modo de vivir, la diferencia que se nota en la granulacion de los ojos, ha de venir acompañada de los caractéres que resultan de la modificacion de los órganos a consecuencia de esto.

La Seccion A, caracterizada sobretodo por unos ojos fuertemente granulosos, lo cual, así que lo acabo de decir, indica sus costumbres crepusculares o nocturnas, presenta tambien, para distinguirla de la Seccion $B$, las particularidades siguientes segun Lacordaire ( $T$. VIII, p. 202):

I. ${ }^{\circ}$ Lengiieta membranosa, pero a veces córnea.

2. Lóbulo esterno de las quijadas nunca delgado, prolongado afuera de la boca i visible de arriba.

3. Cabeza mui raras veces contraida detras de los ojos.

4. ${ }^{\circ}$ Antenas sicmpre insertas sobre la frente.

5. Elitros nunca acortados, o reducidos a una tira angosta.

Ademas, este sabio entomólogo se vale, para el arreglo metódico de las veinte i cinco agrupaciones entre las cuales reparte esta primera seccion, de la forma de las ancas anteriores, $i$ de la de las cavidades cotiloídeas de éstas i de las ancas intermediarias; de la salida prosternal i de la mesosternal; de la lonjitud de las antenas, i, sobretodo, de la de sus artículos 3, 4, 5; de la dilatacion apical de los fémures o de su adelgazamiento basilar; de la forma del protórax; etc.

Pero lo que asombra, es ver cl uso arbitrario que este sabio naturalista hace de muchos de estos caractéres, i el papel inconstante al cual los condena.

Así, despues de dar algun carácter como distintivo de una agrupacion, sale luego con que tal o cual especie, que lo presen- 
ta, no ha de soncterse a la lei que acaba de dictar; porque su facies la acerca a especies de otra agrupacion que, clla, no lo presenta ¡qué confusion!

¿Qué impera en entomolojía: es un carácter de indicacion clara i de constatacion fícil; o un facies que ninguna perifrasis puede pintar exactamente?

Hemos dicho ya, que la Naturale\%a hace solamente las especies, i que, por esto, todo arreglo formado para agruparlas será forzosamente artificial. Ellas, en cualquier momento dado, provienen de tipos anteriores de los cuales han irradiado, modificándose gradualmente a razon de las influencias del medio, i de los cruzamientos sobrevenidos durante su viaje en medio de los siglos. De esto resulta, pues, para cada una, numcrosos parentescos: los cuales cstán indicados por cierta scmejanza entre los órganos de unas i de otras i constituyen sus analojías.

Pero, la forma lineal siendo la única en que nos sea posible presentar el arreglo sistemático de las especies, es cvidente que, para cada una, dos analojías solamente seran respetadas; la que la une con la especie precedente, i la que la une con la especie siguiente.

Todas las otras seran pues sacrificadas; aunque, entre ellas, hayan varias con derechos iguales a los de las favorecidas.

Ahora, a la imposibilidad manifiesta en que está un entomólogo de contentar todas las analojías de las especies, cuando, para facilitar su estudio, quicre repatirlas en varias agrupaciones, viene agregarse otra causa importante de instab!lidad i de confusion. P'ues, los caractéres, que indican las anolojías de un insecto, pudiendo, lo hemos dicho ya, sacarse de cualquicra de sus órganos, i su elcccion resultando del jénio científico de cada entomólogo, sucederá que éste, para quien una lengiieta membranosa o córnea tiene mas valor que una cavidad cotiloidea cerrada o abierta, establecerá sus agrupaciones sobre bases distintas, que el entonmólogo que verá las cosas al reves, o que el que se dejare dominar por las espinas del protórax o la forma de los fémures.

Esto dicho, i siendo evidente que ninguna agrupacion, pequeña o grande, puede dar satisfaccion a todas las analojías de las especics que comprende; estimo que se han de aplicar de 
una manera inexorable las fórmulas sobre las cuales se establecen; i que una fisonomia o un facies, rebeldes siempre a toda descripcion, no deben nunca terciar en la cuestion.

Tomar una determinacion contraria seria hacer depender la entomolojía de colecciones, mui valiosas sin duda, pero siempre perecedoras, i que, por estar entre las manos de los coleccionistas, son con frecuencia de un acceso mui difícil; miéntras que esta ciencia ha de tener por cimientos los libros, a los cuales se han para siempre confiado los estudios de los grandes maestros. Un entomólogo ha de poder determinar un insecto por la descripcion que figura en estos últimos; i no por su comparacion con un tipo, muchas veces dudoso, que se conserva en una coleccion cuyo paradero se ignora casi siempre, o está a menudo fucra de su alcance.

Vamos a estudiar las diversas modificaciones que presentan los órganos de los Lonjicornios de esta Seccion, i notar los de que podemos valernos, si no para el arreglo sistemático de sus especies, a lo ménos para su descripcion exacta i completa.

La barba (mentum) es siempre trasversal, con sus costados arqueados mas o ménos oblícuamente; i con una gran escotadura en medio del borde anterior, en la cual se inserta la base de la lenguieta (labium) i quedan pegados sus ligamentos.

Esta última tiene la parte anterior al punto de insercion de los palpos divididas en dos lóbulos mas o ménos diverjentes: esto, o por un seno anguloso o por una escotadura semicircular. Es a veces enteramente córnea, pero nunca completamente membranosa: quedando inexacto lo que Lacordaire da a comprender respecto a esto, a lo ménos en lo qne toca a los Lonjicornios chilenos de esta seccion. Los lóbulos, solos son membranosos en parte o en la totalidad; i aun, en este último caso, una nervadura los recorre lonjitudinalmente como para darles una firmeza que les faltaria sin esto.

En cuanto a las paraglosas, que Schiödte notó en estos insectos, no es sorprendente que nadie haya hablado de ellas ántes, i que aun hayan sido negadas por L. Fairmaire; pues las líneas córneas, salientes i velludas, en las cuales Lacordaire 
( T. VIII, p. 7, nota 2) ha creido verlas, i que son las nervaduras de que acabo de hablar, me parccen, tanto por su forma como por el sitio que ocupan, no poder considerarse como los rudimentos mui evidentes de estos órganos.

Respecto a la naturaleza del tejido de la lengiieta, son tantas las contradicciones en que Lacordairc se vió arrastrar, que este carácter pierde a menudo gran parte de su valor; sobre todo cuando se llega a las especies, que hacen el pasaje de las agrupaciones en las cuales la lenguieta es córnea, a las en que es membranosa.

Así, despues de haber dicho que la agrupacion de los Achrysonidos está caracterizada por una lengiueta córnea o a veces, en parte coriácea, modifican estas palabras, esplicando que es enteramente córnea en el jénero Nortia; córnea con un angosto ribcte membranoso en los jéneros Allogaster e Icosium; córnea en sus bordes i subcoriácea en su centro en el jénero Eurimerus; en fin, córnea con la estremidad de los lóbulos gradual. mente coriáceos o membranosos en el jéncro Achryson.

La naturaleza de la lenguieta, segun es córnea, coriácea o membranosa, es una cosa que es bastante difícil apreciar; pues es evidente que un estado dc madurez mas o ménos perfecto ha de hacer variar mucho el aspecto de este órgano; i, ademas, he notado que la naturaleza de su tejido no es igual, sino que piezas mas o ménos córneas, metidas en medio de partes mas o ménos coriáceas o membranosas, hacen el oficio de un armazon destinado a sostener las partes sin firmeza. Se habria, pues, de suprimir las palabras subcórneas, subcoriáceas, submembranosas; i aun la palabra coriacea; ya que ésta sirve únicamente para indicar el estado intermediario de las partes que pasan de lo córneo a lo membranoso; i como este cambio se hace a veces mui gradualmente, se necesitaria un calificativo para cada grado.

La insercion de sus palpos tiene lugar siempre en la orilla lateral, i a la altura del fondo de la escotadura del medio, con escepcion de unas pocas especies en las cuales alcanza a la mitad de los lóbulos. Los sostenes son bien visibles, pero están soldados con el cuerpo de la lengüeta. Con una o dos escepciones, tambien, en las cuales el artículo I es mas largo que el 2 , 
aquel es siempre el mas pequeño. El 3 es el mayor $\mathrm{i}$ mas o ménos securiforme, o, mui raras veces, subparalelo i anchamente truncado en su ápice.

Las mandibulas son cortas i enteras; pero el borde interno lleva casi siempre en su mitad basilar una franja de cortos pelillos; i despues, del medio, un pequeño tubérculo redondeado, o, ántes del medio, un dientecito producido por una escotadura de la parte basilar. Pero estos accidentes son, en jeneral, tan inconstantes en las mandíbulas, que no me parecen tener un valor característico.

Igual cosa diré del labro, que es siempre trasversal i pubescente en su borde anterior.

Los ojos son uno de los órganos que suministran mas caractéres importantes. Siempre gruesos i salientes, son desde profundamente escotados hasta solamente reniformes. El lóbulo anterior es siempre el mayor, $\mathrm{i}$ a veces tan abultado que invade completamente los carrillos, es decir, el espacio comprendido lateralmente entre el ojo i la base de las mandibulas; i que, aun alcanza a la frente, pasando por delante de los tubérculos anteniferos.

He dicho ya que la granulacion de los ojos, segun es gruesa o fina, presenta un carácter de primer órden; porque, siendo la cansa, o mas bien el resultado, de diferentes condiciones de vida, ha de ir acompañada de la modificacion de los demas órganos que resulta de estas. Pero vemos luego, por el uso que Lacordaire hace de éste tan precioso carácter, que los resultados no corresponden a las esperanzas que habian dado.

Pues, en la Scccion A establecida sobre la fuerte granulacion de los ojos, figuran como escepciones: los jen. Asemum i Notorhina de la ar. de los Asemidos; el jen. Opsimus de la ag. de los Safanidos; los jen. Metopocœlns i Uracus de la ag. de los Metopocelidos; el jen. Lachnopterus i algunas especies del jen. Cerambyx de la ag. de los Cerambicidos verdaderos; el jen. Adrium de la ag. de los Calidiopsidos; i cl jen. Agapanthida de la ag de los Flictenodidos. Cicrto es que, en la mayor parte, los ojos son mas bien-segun dice-subfinamente que finamente granulados.

Despues, en la seccion $\mathrm{B}$, establecida sobre la fina granula- 
cian de los ojos, vemos figurar como escepciones: el jen. Syllitus de la ag. de los Pterostenidos; los jen. Centrodera, Xylosteus. Capnolymma i Artelida de la ag. de los Lepturiclos; i el jen. Elaphopsis de la ag. de los Ropaloforidos, I vemos tambien que varias especies de los jen. Stenigra i Trachelia de la ag. de los Celartridos tienen los ojos solamente subfuer. temente granulados.

Allí principia la confusion, sicndo evidente lo indeciso que un entomólogo ha de quedar, cuando se ve en la ignorancia, tanto de los motivos de estas escepciones, como de las leyes que se han de consultar para aumentarlas o disminuirlas; i, tambien cuando se encuentra con palabras tan vagas como: subfinamente o subfuertemente; las cuales indican sin duda los pasos que cada clase de granulacion dá hácia la otra, pero no dicen su importancia ni el modo de medirlos.

La cavidad cotiloídea que recibe el cóndilo antenario ocupa la cima de una elevacion con forma de ancho tubérculo, llamado tubérculo antenífero. Situados en la frente i entre los ojos, son raras veces nulos, pero en jeneral mas o ménos salientes i separados por un angosto surco lonjitudinal. En cuanto a la cavidad cotiloídea, está truncada oblícuamente hácia afuera, o mas o ménos escotada trasversalmente; entónces su borde interno está a veces engrosado a modo de rodete, o saliente a modo de tubérculo mas o métıs dentiforme: quedando así el cóndilo a la vista.

El aspecto de la cabeza se debe principalmente a la forma $\mathrm{i}$ a la dimension de los ojos i de los tubérculos anteníferos; pues para que puedan apreciarse claramente, cuidaré dar para cada especie las distancias entre los bordes internos de las cavidades cotiloídeas, $i$ cntre los njos: en el vertex, en la frente i en la garganta; notando desde luego la semejanza que hai en jeneral entre las dos primeras i entre las dos segundas.

Las cavidades cotiloídcas antenarias acompañan casi siempre a la escotadura de los ojos, pern se conducen de diversas maneras. Creo que éstas no han sido scñaladas; pero, como con estos insectos ningun carácter es de despreciar, voi a hacerlo, $\mathrm{i}$ presentaré un modo mui sencillo para apreciarlas claramente. 
Cuando se tira una línca imajinaria tanjente a los dos lóbulos del ojo, se ve que la cavidad cotiloídea afecta con ella tres posiciones principales: o queda adentro, o está atravesada, o queda afuera.

En el primer caso, csta línea imajinaria, que llamaremos línea ocular, puede ser tanjente o no al borde interno de la cavidad cotiloídea; i no faltan especies en las cuales esta última llena tan completamente la escotadura del ojo, que está contigua con él.

En el segundo caso, es decir, cuando la línea ocular atraviesa la cavidad cotilofdea, no es difícil indicar la importancia de la parte de esta última que queda adentro o afuera.

En el tercer caso, por fin, si sucede que la tal línea sea a veces tanjente al borde esterno de la cavidad, sucede, en otras, que esté distante; i esta distancia puede espresarse. Ademas la cavidad puede estar mas cerca de un lóbulo que del otro, i aun hai el caso de que, huyendo de la escotadura ocular, venga a colocarse en la frente al lado interno del lóbulo anterior i a distancia de él.

Las antenas tienen casi siempre once artículos; $\mathrm{i}$ la lonjitud proporcional de $3 \cdot 5$, que son mui variables, da unos buenos caractéres. Su lonjitud es mayor o menor que la del cuerpo; pero siempre son mas cortas en las hembras que en los machos. El último artículo tiene unas proporciones constantes que bastan para reconocer a los sexos: pues, miéntras es filiforme arqueado i de 10 a 15 veces tan largo como ancho en estos últimos; es oblongo, deprimido i solamente de 4 a 5 veces tan largo como ancho en aquéllas. En jeneral, la mitad basilar, mas o ménos, es áspera, brillante, con unos pelillos medio erizados de una lonjitud algo mayor que la anchura del artículo i disminuyendo gradualmente en cantidad; $i$, a veces, el ángulo apical interno de los 3-5 o 6 lleva un diente o una espina-entiendo por ángulo interno, el que lleva esta posicion cuando la antena está estendida de adelante hácia atras-miéntras que, en la mitad apical, los artículos se cubren gradualmente de finísimos poros, o arruguitas trasversales, ocultos debajo de una capa espesa de pubescencia mui corta, mui fina i mui tendida. 
El protórax presenta una lonjitud que, en jeneral, es a lo mas igual a la mayor anchura. Esta se encuentra siempre mas o ménos cu el incdio, pero es a veces mui poco superior a la de la base o del ápice. Los costados son tan luego múticos como provistos de un callo, o de un tubérculo, o aun de una fuerte espina encorvada hácia atras. El disco es tambien o inerme, o provisto de tubérculos o callos; pero lo que se asoma casi siempre, i parece como la marca distintiva de un ramal de esta seccion, es una línea lonjitudinal lisa, o con forma ora de quilla, ora de surco, que no alcanza nunca hasta la base, pero se adelgaza mucho adelante i llega, aun, hasta el borde apical. A veces esta línea está bien marcada, $\mathrm{i}$ otras, se deja apénas percibir, sobre todo en las hembras.

El escudo lleva jeneralmente la forma de un triángulo curvilíneo, i está siempre cubierto de una pubescencia pálida, espesa i tendida.

Los elitros tienen su base recta, con los callos humerales salientes, i, con pocas escepciones, los costados son paralelos. En cuanto al ápice, está en jeneral ribeteado por un angosto cordoncillo, i tan luego regnlarmente redondeado, como anguloso en la sutura, o terminado por una o dos espinas. En especies de distintos jéneros aparecen con mucha frecuencia, sobre cada elitro, dos finas líneas lonjitudinales salientes, que no alcanzan ni a la base ni al ápice, i que a veces son mui poco marcadas.

Las ancas anteriores $\mathrm{i}$ las intermediarias son globulosas o angulosas, i sus cavidades están cerradas o abiertas hácia afuera; pero estas formas son de una apreciacion a veces difícil i que deja en la duda.

La salida mesosternal está siempre aplanada, truncada o escotada en su ápice i mas ancha que la salida prosternal.

El episternon metatorácico es casi siempre angosto, i atenuado gradualmente de la base al ápice.

El abdómen tiene los segmentos casi iguales, o gradualmente mas cortos; con el 5 truncado i mas corto que el $4 \mathrm{en}$ los $\hat{\delta}, 0$ casi igual con él $\mathrm{i}$ arqueado en las $q$. 
Las patas son muchas veces mas gruesas en los $\hat{\jmath}$ que en las $q$. Su lonjitud es variable segun las especies; pero, como disminuye con bastante regularidad de las anteriores a las posteriores, para poder apreciarla en cada especie, presento la proporcion de la lonjitud del fémur intermediario con la del cuerpo.

Los fémures son deprimidos igualmente por ámbos lados, con escepcion de los intermediarios, que tienen jeneralmente la cara estcrna mui visiblemente mas aplanada que la interna. Son mas o ménos delgados i arqueados en su base, i mas o ménos dilatados en su $\frac{1}{2} \circ \frac{2}{3}$ apicales; ademas, esta dilatacion se produce, o gradualmente desde la misma base, o mas o ménos brúscamente.

El trocanter está siempre en el eje del fémur, i presenta la forma de un triángulo rectángulo, cuya base está articulada con las ancas, miéntras que la hipotenusa lo está con el fémur. La estremidad de este último termina en punta aguda i alcanza, o no, a la arıca; en este último caso, el fémur se dice pedunculado; pero la distancia que lo separa de la anca i que depende del desarrollo lonjitudinal del trocanter, es tan vaga i de una apreciacion tan difícil, que este carácter no me parece tener la importancia que le da Lacordaire.

En las patas posteriores, el fémur alcanza siempre mas cerca del ápice del abdómen en los ô que en las ơ; i el artículo I de los tarsos es siempre, a lo ménos tan largo como 2,3 juntos.

He tenido ya ocasion de señalar la cantidad excesiva de caractéres que Lacordaire indica para los jéneros. En lugar de caracterizarlos con las modificaciones de unos pocos órganos, de modo que puedan abrazar todas las especies que proceden de un tronco comun, este sabio naturalista escoje entre éstas un tipo, i da sus caractéres específicos al jénero en el cual lo coloca. Resulta que, los caractéres de la especie pasando a ser los del jénero, muchas otras sin embargo mui hamojéneas quedan afuera; i que, a la necesidad de crear entónces para ellas otros jéneros, se debe en parte la cantidad exajerada de los que presenta la familia, i la confusion inestricable que es su consecuencia. 
No hai que negar, por cierto, la parte que esta última debe tambicn, tanto al enredo de parentescos que presenta esta fa. milia, como al hecho fatal que, los mas de los caractéres siendo proporcionados por los puntos estremos de una forma, no se sabe qué determinacion tomar respecto a las especies que ofrecen los intermediarios. Pero estas dificultades escepcionales imponen, justamente al entomólogo la obligacion de ser claro, exacto i completo.

\section{G. Marileus, milii.}

Mentum trapesiforme. Labium corneum, antice late enarginatum, lolulis extus apice membranaceis. Palpi articulo ultimo elongato, fere cylindrico, apice arcuatim truncato; maxillares fere duplo longiores. Ocula parvi fere transtersi. Antenme filiformes, in utroque sexu elytris breviores, mutice, articulo 5 longiore. Caput magnum, exsertum, vertice fronteque subcontexis. Prothorax cylindricus, extus utrinque tuberculo conico magno armatus, et supra transverse bicallosus. Elytra subconvexa ad apicem vix attenuata, angulo suturali recto. Corfus modice elongatum, pube lanosa supra vestitum, infra fere glabrum, nitidum. Coxae antica extus angulatce. Episterna metathoracica gradatim attenuata, apice subacuta. Abdomen segmentis tribus primis aequalibus, $4^{\circ}$ breitiore. Pedes breves, robusti; femor ibus compressis, gradatim dilatatis; tibiis ad apicem latioribus; tursis latis.

Por mas que me pese, me veo con la obligacion de seguir el movimiento iniciado por nuestros predecesores relativamente a la multiplicidad de los jéneros, i de crear uno nuevo para una especie de la cual veo tres ejemplares: un macho que pertenece a la coleccion del Musco Nacional i proviene de Chiloé, i otro macho con su hembra que pertenceen a la coleccion Delfin i provienen de Puerto Montt.

Es mui difícil elejir la agrupacion en la cual conviene mejor colocar a este jéncro; pues se nota en él una reunion de caractéres tal, que unas agrupaciones lo llaman en virtud de algunos mui notables, al mismo tiempo que lo rechazan a causa de otros de igual valor. Sin embargo, creo que los mas importantes de éstos lo colocan ccrca del j. Criocephalus ( Muls.), a pesar de un protórax con callos i tubérculos. 
La forma de la barba, que es en trapecio trasucrsal, es decir, con el ángulo basilar remiclu al íngulo de la escotadura anterior por una linea casi recti, lo dlstingue de todas las otras especies chilenas de esta seccion.

En cuanto a la lengiela es levemente córnea con una gran escotadura semicircular en su borde anterior: forma que se encucntra tambien en el Acleyson Philippii, la Ancylodonla basalis, el Grammicosum favo-fasciatum i el Semuns regalis descritos mas lćjos. Los dos lóbulos que resultan son cortos, i submembranosos en la parte esterna de su ápice.

Los lóbulos de las quijadas son cortos, sobre todo el interno, que lleva un mechon de pubescencia solamente en ${ }_{2}^{\prime \prime}$ su estremidad; el estermo es redondo i tambien brevemente pubescente.

Los palpos maxilares tienen cerca de dos veces la lonjitud de los labiales. En ámbos, el último arlículo es casi cilíndrico, tres veces tan largo como ancho, i su estremidad presenta un truncamicnto arqueado, que es oblícuo en la parte interna i perpendicular al eje en la esterna.

Las mandbulas presentan, en el medio de suborde interno, un diente anguloso, pero no saliente; pues proviene de una escotadura de la parte posterior.

Los ojos son notibles por su pequeñez, i están sobre todo acortados por delante, de tal manera que llegan solamente cnfrente del borde anterior de la cavidad cotiloidea antenaria; $\mathrm{i}$ que su anchura, allí, iguala la lonjitud de los carrillos. El lóbulo posterior es levemente dilatado en su ápice.

La cabeza es gruesa i salicnte. La frente sigue al vertex sin interupcion; i, por estar los tubérculos mui deprimidos, o casi nulos, aquella es subconvexa entre las cavidades cotiloideas; las cuales son levemente escotadas.

Las anlenas son filiformes, incrmes; $\mathrm{i}$, en ámbos sexos, mas cortas que los elitros; el artículo 5 es el mas largo.

El prothorax: seria cilíndrico, a no ser un grueso tubérculo cónico, que lleva en el incdio de cada costado. Ademas, un poco despues de la mitad, presenta en el disco dos gruesos callos lisos dispuestos trasversalmente.

lil escudo es semicircular.

Los elitros son levemente convexos i apénas atenuados há- 
cia el ápice; este es mútico, pero el ángulo sutural es recto i bicn visible.

El cmerpo es medianamente alargado i cubierto por encima, i sobre todo en los clitros, de una pubescencia lanuda apretada, pero caediza. I'or debajo es brillante i lleva solamente unos puntitos piliferos mui ralos.

las ancas anteriores e internediarias son globulosas; las cavidarles cotiloideas de aquellas son mui angulosas lateralınente; i las de éstas son abiertas. con la parte del metastemon, que va al encucntro del episternon inesotorácico, terminadia en ángulo mui agudo.

El episternon metatorácico disminuye gradualmente de anchura de la base al ápice, de modo a formar un largo triángulo terminado en ángulo agudo.

Salida prosternal angosta, arqueada despues de las ancas. La salida mesostemal es dos veces tan ancha, con su estrcmidad redonda $\mathrm{i}$ arqueada.

Abdómen con los segmentos $\mathrm{I}-3$ de igual lonjitud, el 4 es mas corto: $i$, en los f. el 5 es inas corto aun i truncado en su ápice.

Las paties son cortais i robustas, sobre tudo cul les machos.?

Los fémures son comprimidos; i, lesde su base se ensanchan gradualmente hasta 'ccrea dei ápice, pero mas en los machos que cn las hembras; los 4 postcriores estáll arqueados hácia adentro en su base.

Las tibias cstán dilatadas hácia el ápice, con las púas mui pequeñas.

Los tarsos son algo cortrs, anchos i deprimidos.

\section{CHILOENSIS mili}

Nigro fumosus. Capite dense puntulatu, in medio Inngitrorsu'n tenuiter sulato. Prothorace temuiter grumulato. Eilytris letiler inactunlithus. granulis depressis mimutissimis, saepe ombilicatis densissime tectis. Aludomine nitidiusculo, temiter punculato.

d: Long. 14.5; lat. 3.7-9: long. 19.5; lat. 4,9.

Este insecto presenta un matiz uniforme negro ahumado.

La calleza es enteramente cubierta de una puntuacion mediana, [ere mui tupida; i lleva un suron lonjitudinal en tu da :u ei- 
tension. En el macho, su anchura es de 3,2 en los ojos, i de 2,6 en el pescue\%o.

Distancia entre los bordes internos de las cavidades cotiloídeas antenarias.......................... 2,0

" " los ojos en el vertex........................ I,4

" $"$ " en la frente....................... 2,8

" " " en la garganta....................... 2,6

La línea ocular es tanjente al borde esterno de la cavidad cotiló́dea, i esta última está un poco mas aproximada al lóbulo anterior que al posterior.

Las antenas tienen sus cuatro i cinco primeros artículos algo brillantes, por llevar solamente unos puntos piliferos medianamente apretados; miéntras que los otros son opacos, por estar cubiertrs de finísimos poros (?) mui tupidos, i por llevar una pubescencia cenicienta mui densa, mui corta i mui tendida.

\begin{tabular}{|c|c|c|c|}
\hline & & $\hat{\delta}$ & $q$ \\
\hline Lonjitud de los artículos de la antena: & I & $\mathrm{I}, 4$ & 1,5 \\
\hline & 2 & 0,3 & 0,3 \\
\hline & 3 & $\mathrm{I}, \mathrm{I}$ & $\mathrm{I}, 4$ \\
\hline & 4 & 1,2 & $\mathrm{I}, 5$ \\
\hline & 5 & $\mathrm{I}, 5$ & $\mathrm{I}, \mathrm{S}$ \\
\hline & 6 & $\mathrm{I}, 3$ & 1,5 \\
\hline & 7 & $\mathrm{I}, 3$ & $\mathrm{I}, \mathrm{C}$ \\
\hline & 8 & $\mathrm{I}, \mathrm{I}$ & I I \\
\hline & 9 & $\mathrm{I}, \mathrm{I}$ & I I \\
\hline & IO & $\mathrm{I}, \mathrm{O}$ & 10 \\
\hline & I I & I 3 & IO \\
\hline & & - & - \\
\hline njitud total de la antena: & & I 2.6 & 3.6 \\
\hline del cuerpo: & & 14.5 & 9.5 \\
\hline
\end{tabular}

El protórax, con escepcion de los tubérculos i de los callos, está cubierto de pequeñas granulosidades salientes i brillantes; i presenta las medidas siguientes en un macho:

Lonjitud.......................................... 2.3

Anchura apical.................................... 2.7

" entre los ápices de los tubérculos laterales....... 3.5

" basilar....................................... 2.3 
I a anchura basilar de los elitros hatee mas o ménos la tercera parte de su lonjitud. Su superficie está cubierta de granulitos deprimidos, casi sicmpre ombilicarlos i sumamente apretados, del centro de los cuales parecen salir los pelos leonados lanosos que forman su vestidura. Ademas llevan unas cerditas mas largas, mui finas, casi erizadas i mui poco abundantes.

Lonjitud del cuerpo:

\begin{tabular}{cc}
\multirow{1}{1}{} & + \\
14,50 & 19,50 \\
3,40 & 4,30 \\
$23 \%$ & $22 \%$ \\
0,40 & 0,50 \\
1,16 & 0,96 \\
$34 \%$ & $52 \%$ \\
$34 \%$ & $22 \%$
\end{tabular}

En el f̂, el fémur posterior llega a la $3^{a}$ sutura abdominal; cn la + , pasa apenas la $2 a^{2}$. En ámb ss sexos, el tarso posterior da apénas los $2 / 3$ de su tibia; i el artículo I de este último iguala apénas 2 i 3 juntos.

Lám. II, fig. Ia: Barba, lengiiełı i palpo labial-Aum. 20 diám. fig. $1^{\text {b }}$ : Quijadas i palpo maxilar. - " "

\section{G. ACIIRYSON.-Serv.}

La especie descrita a continuacion, aunque me parezca pertenecer con evidencia a este jénero, presenta, como se podrá verlo por su descripcion, varios caractéres que no figuran en la diagnósis que Lacordaire da de él ( $T$. VIII, p. 232), i que debo suponer conforme con la que publicó su creador, A. Serville (ann. Soc. Ent. Fr, IS33, p. 572); pero no estoi en estado de juzgar si el silencio guardado sobre esos caractéres resulta de una omision, o si son propios de nuestra especie.

Ella pertenece a la seccion del j. Achryson con elitros múticos en el ápice. 


\section{A. Philippir.-mihi.}

Fulvo-testaceus, pallide pubescens. Capite dense punctato-rugoso; mandibulis intus dente rotundato ante apicem ornatis; oculis magnis, antennis elytris apud mares lonyioribus, apud feminas brevioritus; anttculo 3 omnibus longiore; articulis quinque primis nitidis, asperatis et grosse longeque pubescentibus, alteris pube brevi valde appressa dense vestitis. Prothorace leviter transzerso, antice angustiore, mutico; apud mares opaco, temissime alutaceo, sranulisque piliferis parum dense ornato; apud fo. minas dense rugoso.punctato; tergo in dimidio antico angustissime longitrorsum carinato. Elytris pallidioribus, subconvexis, ad apicem vix attenuatis; lumeris rotundatim inflatis; tergo punctis grossis, ad basim profundioribus tense impresso; utrinque carinulis tribus parum conspicuis et plus minusve oblitratis, his rel ter intermpte castaneo pictis, or. nato. Femoribus a a apicem parmm dilutatis; posticis apud mares leititer longioribus; tarsis posticis articulo $1 .{ }^{\circ}$ sequentibus duobus junctis leviler longiore.

5: Long. $18^{\prime}$ 5; lint. 4,6.-q long. 22,0 ; lat. 5,8 .

Esta especic figuraba entre los insectos traidus del desierto de Atacama p r el profesor Federico Philippi, cuando esploró esta rejion en I $\$ S_{5}$. Tengo el gusto de dedicársela; pero es de sentir que csté representada por solo dos ejemplares, felizmente 3 iq.

El color jeneral de este insccto es un leonado testaceo, algo mas oscuro sobre la cabeza i el protórax, i un poco mas claro en los elitros.

El cuerpo está cubierto de una pubesccncia pálida, algo corta i de una sola clase; en los elitros cada hebra sale de un punto, i está medianamence tendida hacia atras; la cabeza, i sobre todo el protórax, la llevan mui echada i dirijida en varios sentidos; es mui densa en el escudo; en la parte inferior es poco abundante i algo ménos tendida.

La cabeza lleva una puntuacion rugosa apretada.

Las mandibulas tiencn su parte arqueada corta i su estremiclad puntiagudia el borde interno presenta despues del medio un diente redondeado mui visible. 
La barba tiene la forma de un trapecio trasversal con losángulos basilares redondeados.

La léngïeta cs córnea, su borde antcrior es anchamente escotado; sus lóbulos son cortos, con la estremidad redondeada, pubescente i haciéndose algo membranosa. La lonjitud de sus palpos no alcanza a igualar la anchura basilar de la barba; cl artículo 2 es algo mas largo $i$ mas grucso que el 1 ; el 3 iguala en lonjitud. los dos primeros juntos, es un poco arqueado en su base i medianamente ensanchado hácia cl ápice, que es truncado); su anchura, en esta parte, da mas o ménos los $\frac{2}{5}$ de su lonjitud.

Las quijadas son cortas, i casi pasadas por cl primer artículo de sus palpos. Estos son solamente de ${ }_{5}^{1}$ mas largos que los labiales; sus tres primeros artículos son de igual lonjitud, pero los 2 i 3 son mas gruesos; $\mathrm{el} 4$ reproduce la forma i las proporciones del último de los labiales, i su lonjitud igual tambien la de los dos precedentes juntos.

Los ojos son grandes i salientes: siendo la anchura de la cabeza, en cllos, de un 20 por ciento mayor que atras. El lóbulo anterior es mıi ensanchado, i, latcralmentc, invade los carrillos hasta la base de las mandíbulas; la línea ocular atraviesa la cavidad cotiloidea, entre el medio i el borde interno.

Tistancia entre los bordes internos de las cavidades

Distancia entre los bordes internos de las cavidades cotiloídeas antenarias........................... I,O I,O

Distancia entrc los ojos en el vertex.................. $0,9 \quad 0,9$

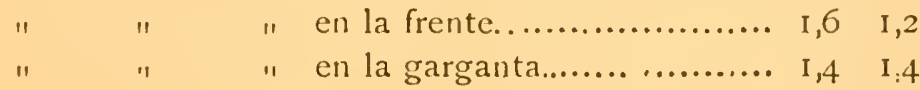

Con excepcion del artículo I, las antenas son casi de igual grosor en toda su estension; aquel es levemente atenuado i arqueado en su base, pero no deprimido, i subcilíndrico en lo demas; los 4 o 5 artículos primeros son brillantes, pero rugosos $i$ ásperos, i llevan una gruesa pubescencia medianamente apretacla, casi crizada, de una lonjitud algo mayor que la anchura de los artículos, i distribuida igualmente; clla desaparece gradual- 
mente sobre los siguientes, i está remplazada por otra mui corta, fina, tendida i apretada.

Lonitud de los articulos de latatena.to

Lonjitud de los artículos de la antena............. I I I,S I,8

\begin{tabular}{|c|c|c|c|c|c|c|}
\hline " & $"$ & " & $"$ & ……........ & 2 & 0,5 \\
\hline$"$ & $"$ & $1 "$ & $"$ & ................ & 3 & 3,6 \\
\hline " & " & " & $"$ & $\ldots \ldots \ldots$ & 4 & 2,4 \\
\hline " & " & " & " & .............. & 5 & 2,8 \\
\hline " & " & " & $"$ & ................ & 6 & 2,7 \\
\hline " & $"$ & $"$ & $"$ & 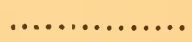 & 7 & 2,7 \\
\hline$"$ & $" 1$ & $"$ & $"$ & ................ & 8 & 2,5 \\
\hline " & $"$ & $"$ & $"$ & ............... & 9 & $2, I$ \\
\hline$"$ & $"$ & $"$ & $"$ & ................. & 10 & $\mathrm{I}, 7$ \\
\hline " & $" 1$ & $"$ & $"$ & $\ldots \ldots . . \ldots \ldots$ & I I & I,9 \\
\hline
\end{tabular}

Lonjitud total de la antena................ . $\quad 24,7 \quad 20,4$ " del cuerpo....................... I $8,5 \quad 22,0$

Los tuberculos anteniferos son salientes i profundamentc escotados, con el borde interno de esta esentadura levemente erguido; estan separados por una concavidad angulosa, en cl fondo de la cual corre un pequeño surco lonjitudinal.

El proturax presenta las medidas siguientes en el macho:

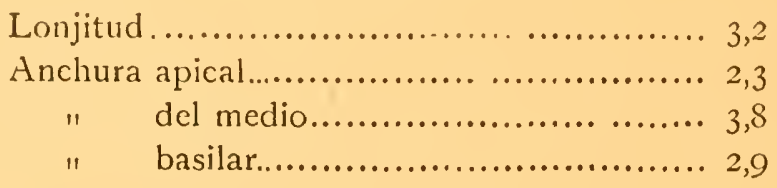

Es completamente mútico; solo se nota, en la mitad anterior una mui fina quilla lonjitudinal que no alcanza al borde apical. Su superficie varia notablemente segun el sexo: en el ó, presenta una finisima granulacion, solamente visible con el microscopio, que lo hace opaco; i lleva, ademas, unos pequeños tuberculillos pilíferos poco apretados. En la $f$, está cubierto de una puntuacion rugosa mui apretada $i$ confluente. 
Loi elitros son mui levemente atenuados hícia el ápice. Su anchura basiiar hace algo mas que la tercera parte de la lonjitud. El ángulo humeral ei jiboso, i separado de la parte esciltelar por una depresion basilar nui notable. El borde marjinal cn toda su estension, i el sutural en su mitad apical, son leve. mente ribeteado; el ángulo sutural es visible, pero mas romo en la +. La superficie está cubierta de una gruesa puntuacion apretada, i un poco mas profunda en la base; cada uno lleva tres quillas lonjitudinales mui indecisas, que son mas o ménos borradas en el ápice, sobretodo las laterales, i cstan, asi como la sutura, teñidas de castaño por espacios mui irrcgulares, cuyo número varia de dos a tres.

Prosterion con su salida mui angosta, arqueada i enterrada entre las ancas, en cuyo medio alcanza apénas.

Miesostemon lonjitudinalmente subcóncavo, tan ancho como la mitad o la tercera parte de las ancas; i gradualınente atenuado hácia su ápice, que es redondeado.

Ancas anteriores cónico-globulosas, un poco inclinadas hácia atras, i con sus cavidades cotiloídeas brevemente angulosas. Las de las ancas intermediarias son completamente abiertas.

Abdómen con lus segmentos de igual lonjitud; el $50^{\circ}$ tiene su ápice arqueado en las $\&$; miéntras que, en los $\sigma^{\circ}$, es mas corto que el $4 .^{\circ}$ i truncado.

Patas con una pubescencia casi erizada, sobre todo en las tibias. Los fémures son levemente comprimidos, con la dilatacion de su mitad apical gradual i poco importante; los posteriores alcanzan al ápice de $4 .^{\circ}$ segmento en los machos, $\mathrm{i}$ al del $3 .{ }^{\circ} \mathrm{en}$ las hembras.

子

Lonjitud del cuerpo.........................

" del fémur intemediario............

Proporcion de esta con aquella...............

Anchura de este en la base....................

Anchura de este en la parte dilatada... ........

Proporcion de aquella con esta.................

"

de csta con la lonjitud.

$\begin{array}{cc}18.50 & 22.00 \\ 5.20 & 5.80 \\ 28 \% & 25 \% \\ 0.00 & 0.54 \\ 1.06 & 0.90 \\ 57 \% & 60 \% \\ 20 \% & 16 \%\end{array}$


En los tarsos posteriores, el artículo I es proporcionalmente mas largo en el of que en la $q$; pues, pasa los dos siguientes juntus de un $25 \%$ en aquel, i solamente del $12 \%$ en la última.

Lám. II, fig. $2^{\mathrm{a}}$ : mandíbula izquierda......... aum. 20 diám. fig. $2^{\mathrm{b}}$ : quijadas i palpo maxilar...... " " " fig. $2^{\mathrm{c}}$ : barba, lengiieta i palpo labial. " "

\section{G. HESPEROPHANES (Muls.)}

Lacordaire, en su Genera (T. VIII, p. 273), parece algo perplejo relativamente a los caractéres que han de distinguir, tanto a la agrupacion de los Hesperofanidos, como al mismo j. hesperophanes. No será, pues, estraño que las tres especies cuyas descripciones siguen, presenten algunas notas discordantes. Ademas, el apuro, que parece acompañar a los entomólogos no les permite siempre ser exactos. Así, cuando Lacordaire habla $(p .27+7 n$. (2) del protórax cilíndrico i de los elitros lar. gos i deprimidos del $H$. inspergatus (Fairm \& G.), se equivoca.

Este insecto no tiene el protórax cilíndrico.

La lonjitud proporcional de los elitros no tiene nada de anor. mal, siendo, a este respecto, una de las ménos notables entre los insectos chilenos de la seccion que nos ocupa.

I, en cuanto a su depresion, ella proviene de que el ejemplar que tuvo a la vista, $\mathrm{i}$ que fué el mismo que yo habia mandado a Fairmaire, era hembra.

Es tambien por este motivo que este último da "unas antenas mui cortas" como carácter del inspergatus. El macho no está deprimido, i sus antenas no son cortas.

Pero para acabar de una vez con estas incertidumbres i vacilaciones, daré con precision los caractéres que pueden motivar dudas; de modo a que los que se empeñan tanto en hacer jéneros nuevos, puedan contentarse. 
H. INSHERGATUS (Fuirm \& G., ann. Soc. en. Fr. r859, p. 500 ).

Sulvobustus, castaneus, pube sublanosa, fulvo-testacea, breri inaliteque appressa, dense vestilus. Capile mgose punclato; fronte transierse planata, in medio longitrorsum tenuiter suliata; antennis basi incrassatis elytrorum apiem apud mares leviter superantibus, aput faminas hand attingentilus; urticulis 3-7 apice intus briviter spinulosis. Prothorace oblongo, wix transiersu, punctis mignis parum dense impresso; tergo lineis abreatiatis tribus pube concolure densius teclis longitrorsum ornato. Elytris basi rectis, prothorace latoribus; humeris callosis; dorso puncta to, punctique magnis denudatis laxe subserimis notalo, et selis acutis, whsuris, subrectis farm dense tecto: utrinque maculis duabus testaceis, untice posticeque obsure maryinatis, altera medin blique parallela, aitera apicali subouala, picto. Corpore subtus, pedibus antennarunque bisi punilis magnis denudalis laxe marulatis. Femoribus sutiompressis, apice parum inflatis. Tarsi postivis art. 1. duobus sequentilus junctis aequali.

of long. $12.5 ;$ lai. $3 \cdot 3$.
\& $1120.0 ; " 115.2$.

Esta especic, cuyos sexos presentan entre sí una tan notable diferencia de tamaño, 1 cuyos varios ej mplares, que tengo a la vista, provienen del valle de Quilluta, de los alredectores de Sintiasso, de la rejion subandina situada al sur del rio Maipú, i aun de la que está al frente de Chillan, fué descıita en IS59 por I.. Fairmaire-lo hemos dicho ya-sobre un ejemplar único i hembra, que mi amigo Fernando Paulsen habia hallado en el año anterior cerca de Santiago sobre una mata de Palqui (Cestrum Palqui), i que tuvo la jenerosidad de obsequiarme.

El inconveniente que hai en describir una especie sobre un solo individuo no está para demostrarse; pues la descripcion de una especie no habria de ser nunca la de un ejemplar aislado; sino indicar los caractéres propios a varios: esto, en prevision de las variaciones individuales, que son, a veces, mui nuncro. sas en cicrtas especies, i aun en ciertas rejiones. Sin embargn, como uno no puede hallar a voluntad una cantidad de insectos suficiente para hacer un estudio colcctivo, i que, en un trabajo como el que tengo emprendido, importa presental cuantas es- 
pecies sca posible; es preciso, a lo ménos, estudiar a fondo estos ejemplares únicos, i sobretodo dar a conocer su scxo: punto mui importante para caracterizar exactamente a las especies.

Este insecto es algo macizo i sin elegancia; i se ve por los guarismos que espresan la lonjitud i la anchura de individuos de ámbos sexos, que, a pesar de la diferencia de tainaño, la última da siempre el $26 \%$ de aquella.

Es de un aspecto sucio, i su matiz jeneral es de un castaño barroso en algunas partes, i ahumado en otras. Presenta dos clases de vestidura: I. ${ }^{\circ}$ una pubescencia lanosa, corta, apreta da i mui tendida, que varía, a veces, del leonado al testácco, i lo cubre por todas partes con escepcion de los cinco o seis últimos artículos de las antenas. $20^{\circ}$ de unas finas cerditas poco adundantes $\mathrm{i}$ medio erizadas, que son cortas $i$ oscuras en los elitros, pálidas en el abdómen i cn las patas, $\mathrm{i}$ de este mismo matiz, pero algo mas largas, en la parte inferior de los cuatro o cinco primeros articulos de las antenas.

La cabeza presenta una puntuacion rugosa i apretada, pero poco visible con motivo del vello que la cubre. Los tubérculos anteniferos son mui poco salientes, i truncados oblícuamente hácia afuera; de lo cual resulta que, cntre ellos, la frente, aunque mas alta que el vertex, es casi aplanada trasversalmente; $i$ solamente lleva en su medio el pequeño surco lonjitudinal que separa sus bases.

Distancia entre los bordes internos de las cavi-

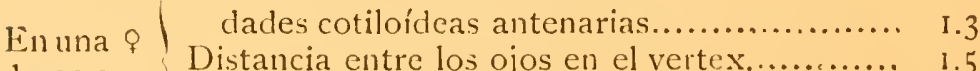
de 20.0

Distancia entre

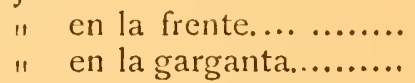

Los ojos son normalmente desarrollados: cl lóbulo posterior es corto i sin dilatacion apical; el anterior deja libre una mui corta parte de los carrillos, i se adelanta sobre la frente solo hasta llegar enfrente del borde esterno de las cavidades cotiloideas. La línea ocular es tanjente al borde esterno de eșta última.

Las antenas tienen sus artículos 3-5 O 6 levemente deprimidos: i miéntras mas anchos que son mas basilares; de tal ina- 
nera que. en un of la anchura del $1 \mathrm{I}^{\circ}$ da solamente el $50 \%$ de la del $3 .^{\circ}$; la anchura de éste da el $20 \%$ de su lonjitud. El I. ${ }^{\circ}$ es cilíndrico, pero levemente deprimido $i$ arqueado en subase. Los 3-5 o 6 llevan en el ángulo esterno de su ápice un diente agudo dirijiclo adelante i bien visible. La pubescencia de los 5 o 5 últimos artículos deja gradualmente de parecer a la de los demas del cuerpo, para hacerse mui fina i aun parecida a una pruinosidad en los dos o tres últimos.

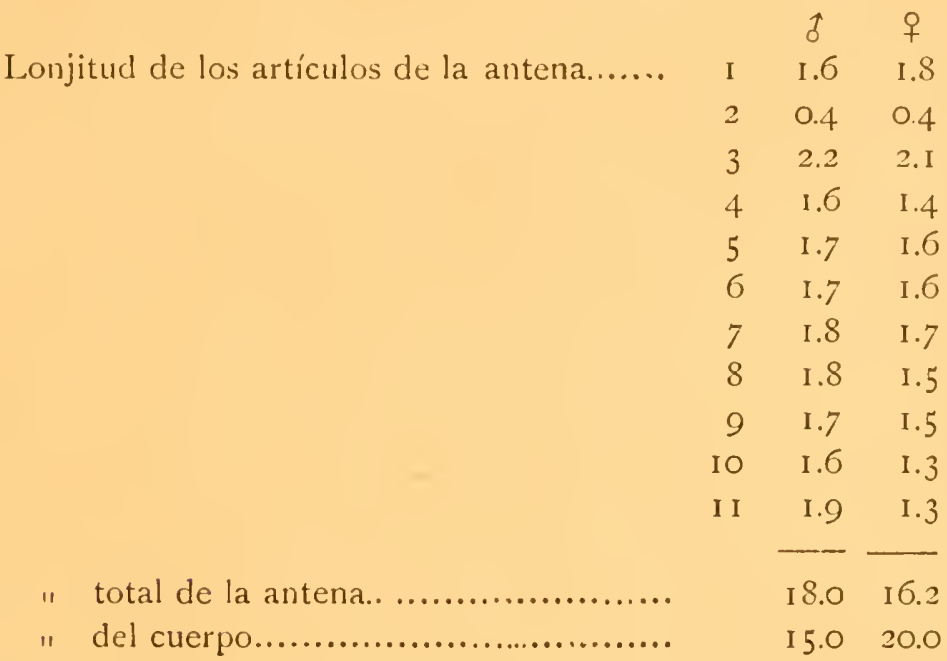

En el macho, el artículo I ${ }^{\circ}$ es filiforme, i su anchura da el $12 \%$ de su lonjitud.

En la $f$, es deprimido, ensanchado en el medio, i su anchura da el $31 \%$ de su lonjitud.

Los costados de la barba presentan cerca de su base una corta dilatacion redondeada.

La lengiieta presenta una gran escotadura en ángulo recto con el ápice puntiagudo; los lóbulos, que resultan diverjentes, son membranusos, pubescentes, redondeados en el ápice, i con el borde interno recto; el borde anterior de la parte cónnea lleva una franja de finas cerditas dirijidas hácia adclante.

El lóbulo esterno de las quijudas es corto, con la parte desnuda de su base tan ancha como larga, la estremidad de la parte sólida cscede de peco la del lóbulo interno; pero está cubier- 
ta de pelillos largos mui finos i ondeados, de los cuales varios están dilatados i como vesiculosos en su ápice; sin duda para hacer mas perfecto el scrvicio que prestan como órganos del tacto o del gusto.

Los palpos labiales i maxilares son cortos i retacos, i notablemente iguales entre si, respecto a la forma i a la lonijitud de sus artículos; pues, la de los maxilares cscede la de los labiales solamente por la de su primer artículo; la lonjitud del artículo último iguala la de los dos anteriores juntos; i la de su borde interno iguala su mayor anchura.

El protórax presenta las medidas siguientes:

$$
\text { En un ơ de } 15.0 \text { En una } q \text { de } 20.0
$$

$\begin{array}{ccc}\text { Lonjitud............. } & 2.9 & 3.5 \\ \text { Anchura apical....... } & 2.2 & 2.9 \\ \text { " mayor...... } & 3.1 & 3.8 \\ \text { " basilar...... } & 2.5 & 3.3\end{array}$

La mayor anchura está en el medio. Su superficic está cubicrta de gruesos puntos bastante apretados; i lleva cerca de la base un corto surco lonjitudinal; carece de tubérculos i callosiclades; pero la pubescencia sc aglomera en el medio de modo a formar una línea lonjitudinal central mas o ménos interrumpida, i, en cada lado, una figura algo parecida a un 6 que no alcanza ni a la base ni al borde anterior; ámbos con el ápice adelante i vuelto hácia adentro; sin embargo, la facilidad con la cual estos dibujos se borran no permite, segun creo, darles un valor característico.

Los elitros son paralelos, un poco deprimidos en las $q$, con la base recta, el ángulo humeral en forma de callo redondeado, i su ápicc redondeado separadamente. La superficie lleva una gruesa puntuacion bastante apretada $i$, ademas, unos puntos mayores, glabros, que figuran salpicaduras redondas, i están vagamente dispuestas en hilcras. Cada elitro presenta clos manchas testáccas: la una, situada en el medio, alcanza solamente a la sutura i figura una ancha faja oblícua de la base hácia cl ápice i de afuera hácia adentro; la otra es ovalada i cubre toda la estremidad; el espacio entre ellas, que cs rojizo, se 
hace negruzco al alcanzarlas; la parte basilar es de estc último matiz: la pubescencia lanosa toma mas o ménos el color de los tegumentos, i comunica a éstos adornos un aspecto nebuloso e incicrto.

La anchura de la salida prosternal es a lo ménos igual a la mitad de la de los fémures anteriores en su base; cr aplanada i sc arquea en su ápice sin esceder a las ancas. Estas son angulosas lateralmentc.

El mesosternon es subparalclo entre las ancas, con su ápicc ahorquillado para recibir una salida angulosa $d \epsilon l$ metasternon. Sus cavidades cotiloídeas están abiertas.

Los segmentos del abdómen disminuyen gradualmente de lonjitud, de tal modo que la del 4 da, mas o ménos, los $\frac{3}{5}$ de la del I, midiendo este frente a la insercion de los muslos. En los 8 , el 5 da los $2 / 3$ de la lonjitud del 4 , i es truncado on su ápice; en las $q$, cs igual con él i redondeado.

Los fémures son medianamente comprimidos i pedunculados, i algo brúscamente dilatados en el medio de su mitad apical. En el macho, el posterior llega a la estremidad del abdómen; en la hembra, llega al medio del $3 .{ }^{\circ}$ segmento.

\begin{tabular}{|c|c|c|}
\hline & हे & 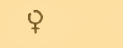 \\
\hline njiturl del cuer & I 5.0 & 20.0 \\
\hline " fémur inteme & $4 \cdot 7$ & 5.20 \\
\hline oporcion de esta con & $31 \%$ & $26 \%$ \\
\hline chura de este en la base... & 0.44 & 0.46 \\
\hline rte dilatada... & I. 10 & I.I \\
\hline $\begin{array}{c}\text { oporcion de aquella con esta............. } \\
\text { " de csta con la lonjitud........ }\end{array}$ & & 22 \\
\hline
\end{tabular}

Por las medidas aquí arriba espresadas, se ve que los cuatro fémures posteriores son proporcionalmente mas largos en el $\hat{\delta}$ que en la ?, i cual es esta proporcion.

$\mathrm{El}$ art. I de los tarsos posteriores iguala en lonjitud a 2, 3 juntos.

Lám. II, fig. $3^{\text {a: }}$ quijada i palpo maxilar..... aum. 20 diám fig. $3^{\mathrm{b}}:$ barba, lengiueta ipalpolabial " " " 


\section{H. OBSCURUS, mihi}

II. inspergato simillimus; corpore, antennis pedibusque omninó obscure castaneis et griseo-pubescentihus differt.

s. lonj. 13.0 ; lat. 3,4.

Describo esta especie como distinta de la anterior sobre un ejemplar ę $\mathrm{i}$ único, que existe en la coleccion Izquierdo; i no sé si, al hacerlo, no soi víctima de un error.

La principal diferencia, que cncuentro para justificar esta detcrmiuacion, es que este insecto es completamente de un castaño oscuro, levemente mas claro solo sobrc las antenas i los tarsos; i que la pubescencia que lo cubre es de un ceniciento uniforme; miéntras que no he cncontrado, en ningun ejemplar de la especie anterior, la menor tendencia a variar en este sentido.

Es ademas de notar, que los costados de la barba son arqueados con regularidad.

Hai otras pequenas diferencias en las proporciones de los artículos de las antcnas, en las de los fémures intermediarios i posteriores, etc.; pero son tan leves que pueden mui bien ser individuales.

Solo la vista de un mayor número de ejemplares dirá, si tenemos aquí a un $H$. inspergatus atacado de melanismo o a una especie distinta.

\section{H. SULCICORNIS mihı}

Castanens; corpore pube argenteo lanosa brevissima valdeque appressa dense vestitu. Antennis pedibusque tenuissime pubescentibus. Capite ungose punctato, in medio temuiter longitrorsum sulcato; fronte transierse subplanata. Antennis basi haud incrassatis, apud mares elytronum apicem superantilus; sed, apud fominas wix attingentibus: articulis 3.6 cylindr. cis, apice nodulosis et intus muticis; articulis 7.10 antice leviter depressis et apice exins subangulatis; articulis $7-11$ sulcis duobus latis, apud ma. res brofundioribus, longitrorsum impressis. Prothorace subcylindrico, 
longitudine latitudinem a'puante; tergo mgose punctato, in dimidio postico linea oblonga, deprissa, lavigah, basim haud allingente longitrorsum notalu. Elytris setis lrevilus suberectis tectis, laxe punctatis, et punitis ino'qualitus majoritus, demuatis, maculis rotundatis simulantibus, subseriatim ornatis; plaga postica lata communi rufo-testacea, macula apicali et utrinque macula lunata intermedia testaceis, pictis. Antennis, tibiistarsisque pryllide testaceis; antennarum articulo primo femoribusque rufo-fulitis. Abdomine maculis denudatis minutis mumerosis parum distincte oruatis.

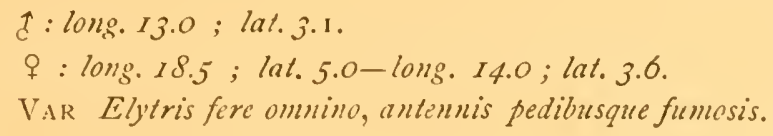

Esta especie es mui vecina de la primera; sin embargo, no puede confundirse con clla. De los seis jejemplares que tengo a la vista, dos pertenccen a la coleccion Oyarzun i provienen de Constitucion; los otros pertenecen a la colcccion Izquierdo, $\mathrm{i}$ provienen de Lautaro i Araucania; la variedad proviene de Machalí, cerca de Rancagua.

El cuerpo es tambicn de un matiz castaño; pero los muslos i el art. I de las antenas son de un leonado rojizo, miéntras que los demas artículos de estas últimas, las tibias i los tarsos son de un testáceo pálido. La pubescencia que cubre al cuerpo es, igualmente, mui tendida i espesa, sobretodo en los elitros; pero es mas corta, mas fina, $i$ lanosa con un reflejo platcado. En cuanto a la de las patas i de las antenas es toda blanquizca i suma. mentc fina i corta, pero ménos tupida en aquellas.

I a cabeza está cubierta de una puntuacion rugosa i apretada, i lleva un fino surco lonjitudial. La frente es casi aplanada, por estar los tubérculos anteníferos mui poco salientes. Ademas, éstos cstán truncados oblícuamente hácia afucra i levemente escotados, pero el borde interno de la escotadura no cstá siliente.

Los ojos son un poco mas desarrollados; su lóbulo anterior invade casi completamente a los carrillos; i, por delante, alcanza casi hasta el medio de la cavidad cotiluidea. La línea ocular atraviear esta última mui corea de su borde interno. 
algo redondeado en su estremidad. Lil artículo 2 de sus palpos es de $1 / 8$ mas largo que $1 ;$ i los dos juntos de $\frac{1}{5}$ mas largo que 3. Este tienc la forma i las proporciones del último de los palpos maxilares; i la lonjitud de los tres juntos da $170 \%$ de la de estos últimos.

El lóbulo esterno de las quijadas tiene su parte basilar i córnea dos veces tan larga como ancha; i la estremidad de su parte membranosa escede al lóbulo interno de casi toda la lonjitud de este último. Su pubescencia cs aun mas fina, maslarga $i$ mas ondeada que en la primera especic, pero 110 veo estremidades pustulosas. El último art. de sus palpos es un poco mas corto (1.O) que 2,3 juntos (I,25); el I (0.37) es profundamente sinuado en medio del lado estcrno. La anchura del 4 alcanza apénas a dar la mitad de su lonjitud esterna; cl truncamiento apical (o.6) es igual al borde interno, $i$ hace los $\frac{3}{5}$ del esterno:

El protórax presenta las medidas siguientes en una $q$ de 18.5 .

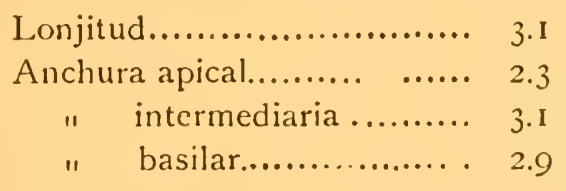

Es, pues, tan largo como ancho, i casi cilíndrico; cstí cubierto de puntos apretados i rugosos, i lleva una líne: lonjitudinal oblonga, deprimida i lisa que principia en el medio i no alcinzit a la base. Carece de callos o tubérculos mui cricientes, lo mismo que de aglomeraciones de pubescencia.

Los elitros presentan, como las especies anterirres, unas cerditas cortas i puntiagudas, pero son blanquizcas i mas tupiclas en el ápice. Llevan una puntuación poco apretada i, aclemas, estan salpicadas por otros puntos mayores i desiguales, que figuran unas manchitas redrndas, glabras $\mathrm{i}$ un poco dispucstas ell scries. Cada uno tiene cl ápice, $i$, en su medio, una maniclia redonda aislada testácca, con toda la rejion situada cntre ellas de un testácen-rojizo. Estos matices estan scparados por vetas trasversales que, sin embargo, no alcanzan a delimitarlas clarainente; i no lis puede quitar el mismo aspecto confuso, que ofrecen las manchas de lose elitrus de la pinera especi: 
El $5 .^{\circ}$ segmento abdominal del fo es red ndo en su ápice como en la $q$, pero es un poco mas corto.

\begin{tabular}{|c|c|c|}
\hline & 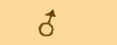 & $q$ \\
\hline Lonjitud del cuerpo...................... & 13.31 & I 8.50 \\
\hline fémur intermediario .......... & $4 \cdot 50$ & 5.40 \\
\hline Proporcion de ésta con aquélla ............ & $34 \%$ & $29 \%$ \\
\hline Anchura de éste en la base............... & 0.30 & 0.32 \\
\hline " parte dilatada...... & 0.86 & 0.90 \\
\hline $\begin{array}{c}\text { Propurcion de aquélla con ésta } . . . . . . . . . \\
" \text { ésta con la lonjitud .......... }\end{array}$ & $\begin{array}{l}35 \% \\
19 \%\end{array}$ & $\begin{array}{l}36 \% \\
17 \%\end{array}$ \\
\hline
\end{tabular}

Los fímures posteriores alcanzan a la estremidad del $5 .^{\circ} \mathrm{seg}-$ mento abdominal en los $\hat{\delta}$, i apénas a la del $4 .^{\circ}$ en las + .

Considero como una variedal del sulcicornis un ejemplar que parece atacado de melanismo; pues ha sido enteramente invadido por un matiz ahumado, que ha borrado aun los dibujos de los elitros. Podria ser que el obscurus fuese un ejemplar de ins. pergatus en un caso igual pero inas marcado.

L.ím. II. fig. $4^{a}$ : quijada i palpo maxilar ...... Aum. 20 diám. fig. $4^{\mathrm{b}}$ : barba, lengiieta ipalpolabial. " " "

\section{G. MARIPANUS (milii)}

Corpus leviter elongatum, fere depressum et vix pubescens. Labium subcorneum, angulatim emarginatum; lobulis divergentibus, intus anguste membranaceis. Palpiomnes articuloultimo securiformi; maxillares fere $1 / 3$ longiores. Ocull parum dilatati, fere tenuiter gramulati. Antennae apud mares corpore longiores; articulis 3.5 cequalibus, 4 breviore. Prothorax vix transtersus, supra callosus, lateribus inermibus. Elytra nitida, caruleo violacea et altho-plagiata, parallela, apice separatim rotundata. Coxae quatuor anticue extus angulate. Episternum metathoracicum latum, in dimidio apicali attenuatum. Femora basi angusta, in dimidio antico suhabrupte ralde dilatata. Tarsorum posticorum articulus primus duobus sequentibus junctis longior.

Cuerpo levemente alargado i deprimido, cubicrto de una pubescencia corta, rala i algo erizada. 


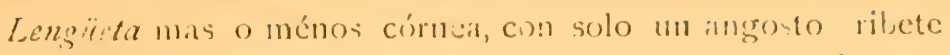
membranoin en la parte interna de los lóbulos; los cuales son diverjentes $\mathrm{i}$ scpariados por una cicotadura en ángulo levemente obtuso. 1, a lonjituil de sus palpos hace mas o ménes los $2 / 3$ de la de los maxilares; el artículo último le ímbos es mas largo que cada uno de los precedentes, trunciudo ublicumente adelante, $\mathrm{i}$ con una anchura intermediaria que dá la $1 / 2$ o los 3 de su lonjitud.

Ojos pequeños, con una gramulacion intermediaria cntre la de los Hesperophanes i la de los Chenoderus. Lil lóbulo anterior es poco dilatado, i no pasa lateralmente el borde anterior de la cavidad cotilnidea, dejando mnos carrillos cuya lonjitud (0.3) iguala la anchura del cóndilo antenal. Línca ocular tanjente al borde esterno de la cavidad cotiloídea.

Antenus mas largas que el cucrpo en los $\hat{\jmath}$; con el art. 4 mas corto que 3 i 5 , que son iguales; todos tienen su ápice perfectamente redondeado, sin rastro de espina ni diente.

Prolórax un poco mas ancho que largo, con los costados incrmes, casi paralelos, arqueados en el mismo ápice, i brúscamente contraidos mui cerca de la base, dorso con varios callos lisos.

Escudo con una pubescencia densa i tendida.

Elitros con su base truncata, I rez $2 / 3$ tan ancha como la del protórax; ángulos humerales rectos i redondeados; costados paralelos; en el ápice estan redonderdos scparadamente; disco brillante, de un azul morado, con manchas blancas no salientes. Ancas anteriores e intermediaria globulosas; aquéllas angulosas en su parte esterria, así como sus cavidades cotiloídeas; las de las últimas abiertas.

Salida prosternal mas corta que las ancas, angosta pero aplanada i no lameliforme.

Salida mesosternal aplanada, redondeada cn el ápice $\mathrm{i}$ tan ancha como la mitad de sus ancas.

Episternon metatoricico cuatro veces tan largo como ancho con sus costados paralclos en la mitad basilar i converjentes en la otra.

Abdómen con sus segmentos mas o ménos de ignal lonjitud. Patas mcdianas.

Fémures levemente peclunculados, mui angostos cu sus $\frac{2}{3}$ ba- 
silares, e hinchándose despues brúscamente i notablemente. Los posteriores alcanzan al $4 .^{\circ}$ segmentr abdominal. El art. I de sus tarsos es $\mathrm{I} 1 / 2$ ve\% tan largo como 2 i 3 juntos; i el tarso entero dá los $\frac{2}{5}$ de la tibia.

La Entomolojía chilena ofrece a menudo especies cuyas analojías quedan dudosas i oscuras, en virtud de una reunion de caractéres en pugna con todas las anotadas anteriormente, i que hacen absolutamente necesaria la creacion de jéneros nuevos. Es lo que sucede con el Lonjicornio que describo, i para el cual establezco el jénero Maripanus, en recuerdo del célcbre Cacique araucano Maripan.

Sin embargo, con esta creacion he vencidu solamente una de las dificultades; pues la otra, mucho mayor, consi-te en hallar la agrupacion de la cual mas se acerca, para precisar el punto de la escala dunde conviene culocarla. Pero me contentaré con enumerar las diversas analojías que este insecto me ha parccido presentar, sin atreverme a tomar a este respecto una determinacion definitiva, que, lo temo, no seria acertada.

Desde luego, numerosos caractéres me hicieron buscar, en las primeras agrupacione; de la Seccion $\mathrm{A}$, el puesto que convenia a este jénero: la naturaleza de su lengüeta i los ojos subfuertemente granulados ue mostraban sus analojias con los Ascmidos; la forma de sus ancas i de sus fémures me decian que tenia algunas con los Emidos, o aun con los Acrisonidos; la forma del protórax i de los elitros, i sobre todo las callosidades de aquél, indicaban que su lugar estaba entre los Esperofanidos. Pero luego sus carrillos, sus ojos subfinamente granulados, i sobre todo la forma tan típica de los cpisternones metatorácicos, me lo echaron entre estas agrupaciones anormales que Lacordaire pone al principio de la Seccion B.

Como lo tengo dicho, no he conseguido hacerme una opinion definitiva respecto a la colocacion que conviene a este insecto; sin einbargo, propongo dejarlo provisoriamente cerca del jénero Grammicosum, a pesar de su librea que, en medio de esta seccion, es de lo mas disonante. 


\section{Decoratus (mihi)}

Corpore, capite, prothorace, pedihus, antennarumque basi castanco pice is aut rufo-castaneis. Capite dense rugose-punctato, pone oculos subinflato; fronte subplanata et leviter obliqua. Antennis ad basim incrassatis, e. dense punctato-rugosis, pilisque rufescentibus subhirsutis; apicem versus gradatim testaceis, pubeque fallida lireii dense appresia tectis : art. $10^{\circ}$ brevi, obconico; $2{ }^{\circ}$ longiusculo. Prothorace rugose punctato, dorso in dimidio postico callis $;$ ornato: duobus anticis minoribus. Elytris nitidis, caruleo-violaceis, punctis minutis. setas breves, suberectas mirrasque ferentilus, parum dense impressis; utroque maculis duabus albis subquadratis: antica ante medium, postica ante apicem sitis ornato; atque in medio lineis longitudinalibus duabus abbreviatis angustissimis notato. Prosterno transverse rugato. Mesosterno dense punctato. Metasterno abdomineque nitidis et fere lavigatis.

Long. 18 " ; lat. 4.5 .

El cuerpo, la cabcza, el protórax i las patas son de un castaño oscuro, que pasa a castaño claro, i hasta a rojo, en algunos individuos, illevan una pubescencia cenicienta tendida $\mathrm{i}$ escasa.

La cabeza lleva una puntuacion rugosa i apretada. El pescue\%o es grueso; la frente, poco levantada entre las antenas, cs casi aplanada i brúscamente oblicua hácia adelante.

Distancia entre los bordes internos de las cavidades cotiloldeas................................... $\quad \mathrm{r} .3$

Distancia entre los ojos en el vertex.................. 1.3

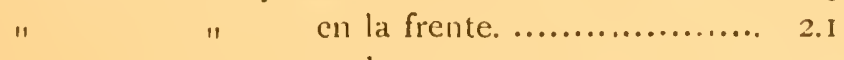

" $"$ en la garganta........... 2.2

Las antenas de los ô -único sexo que me sea conocido-ticnen las medidas siguientes:

Lonjitud de los artículos I 1.9 En su mitad basilar, mas o ménos, las antenas son os" $\quad 20.6$ curas i llevan una puntua. cion rugosa mui apretada, 
Lonjitud de los artículos $3 \quad 2.7$ grarlualunente engrosada i cubicrta de una pubescen-

11

"1

11

"

"I

11

11

,

" del cuerpo....

\section{$4 \quad 2.4$}

5

6

11 ciat rojiza espesa i casi criza(a) En la otra mitad sc vucllen testáccas, i la pubescencia se hace n: bi fua, corta i tendirla. El artículo I es corto i obcónico; i el 2

72.6 deja un poco deser nodiforme para tomar cstil tiltima 82.4 forma.

92.2 I al harler, mui trasversal, tienc sus costadosargucados Io נ.9 conregulatidad, descle el ángulo basilar lıasta elde la esI I I.S cotadura, (fur: no es saliente.

El protorax lleva las medidas siguientes:

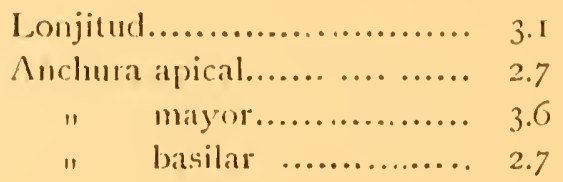

L leva ma puntuacion bastante gruesa i rpretada, i, encima, cinco callos; de los cuales los dos anteriores son pequenos, redondos i colocados trasversalnente un poeo delante del medio: los otros tres estan colocados atras i trasversalmente tambicu, pero son un poco alargados con el del medio liso i brillante.

Elitros brillantes i de 111 a\%ul morato, con puntitos poco apretates: cada uno de los cuales lleva mna cerlita negrat corta i algo parata. Cata elitro lleva dos manchas blancas casi cuat-

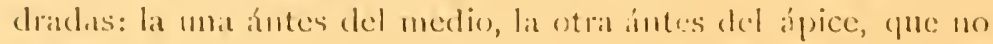
alcau\%an ni al burele lateral ni al :mlural; en el medin se ven dos funfsimas lincas lomjitmdinates mui poes salientes, i visibles 
casi ablamente en la rejion ncuphala por la manchat anterior. Lat parte apical está ribeteada por un funo rodete.

lil prosternon lleva divante las ancas muas finas atrugas trissversales.

Fil mesosternon presenta puntos gruesos i apretiulos.

El melastermon $\mathrm{i}$ el abdomen son brillantes con una puntuatcion mui funa i mui rala.

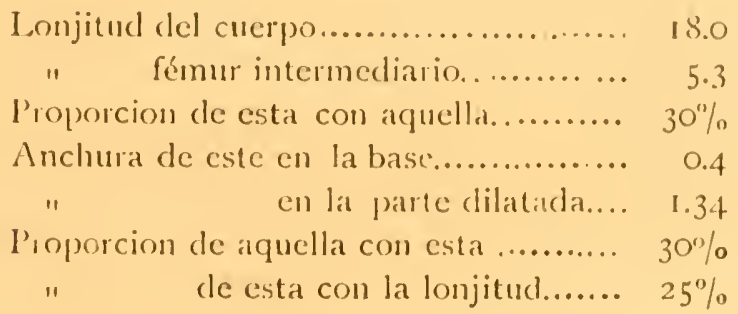

Asi como lo tengo dicho, tingo solamente a la vista machos de esta especic. l'arece cscasa, i proviene de las selvas subandinas de Chillan. Este insecto imita de $u$ modo notable al Chenoderus S-maculatus Fairm, et Germ.

Lam. Il figs. 5.a: barba, lengiieta i palpo labial. - aum 20 diám. fig. $5{ }^{\text {') }}$ palpo maxilar................ " " "

\section{G. GRAMMICOSUM ïlanch}

Cuando le tocia al j. Grammicosum ser tratado por I.acordaire (Gen \%. I'/1/,p. 2fo), fuć colocado con razun cu la agru. pacion de los lisperofánidos: i vemos que difure del j. Hesperophanes principalmente por carecer de la pubescencia apretada i lanosit, que cubre a estos tiltimos, i pus tencr un protórax pluricallosu por encima. Pero vemos tambien que, comno asimısın este sabio entomólogo no admitió en el j. Hesperophanes las especies m poen leprimidas, no atmite cu el j. Grammicosum las erpecics mo pen convexas. lil cronfusa ha-

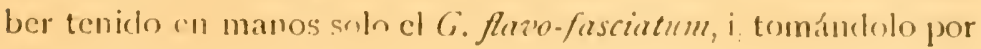


tipo del jénero, dá, como de costumbre, a este último los caractéres-no mui exactos aún-de la especie; de lo cual resulta que, por ser ésta un poco deprimida, las especies un poco convexas quedan afuera.

Es preciso absolutameute sacudir estas cadenas, o nos veremos luegron la obligacion de crear un jénero para cada espe. cie de Lonjicornio.

Dejaré en el j. Grammicosum ( $B l$.), no solamente el flarofasciatum, sino tambien el signaticolle (Bl.), el minutum (Bl.): especie escasa de la cual encontré en la coleccion Delfin dos ejemplares $q$ i el maculicorne (mihi): especie nueva de la cual encontré tres ejemplares en la coleccion Izquierdo, todos $q$ tambicn, por desgracia.

Pero daré razon a Lacordaire, rechazando los flavonitidum i semipolitum (Fairm, et G.) i el bifasciatum (Phil). El primero i el último son sinónimos i pertenecen al j. Compsa (Perty'); i, en cuanto al segundo, es una variedad albina bastante frecuente de una especie descrita mas tarde bajo el nombre de Compsa pallidicorne (F. et G., Rev. Zool. I864, 387).

En consecuencia voi a dar del j. Grammicosum una diagnósis arreglada segun las necesidades del caso, es decir, un poco ménos inhospitalaria. Para llegar a este fin, a lo dicho anteriormente agregaré lo siguiente:

Ángulos de la escotadura de la barba no salientes. Lóbulos de la lengiieta membranosos, pubescentes i diverjentes; sus palpos estan insertos ántes de llegar en frente del fondo de la escotadura. Los maxilares son a lo mas $\mathbf{I}_{\frac{2}{3}}$ veces tan largos como los labiales; el último artículo de todos es securiforme.

El surco frontal, del cual hab!a Lacordaire, no es de menta̧r: en todas las especies chilenas de esta seccion, él aparece en algunos individuos i está borrado en otros, segun la puntuacion es mas o ménos gruesa i mezclada con arrugas.

Antenas variables segun las especies, tanto respecto a su lonjitud como respecto a las proporciones de los artículos 3, 4, 5 .

En cuanto a los ojos, no se puede decir de ellos que son "largement séparés en dessus (Lacoril) "; pues, la distancia, que hai entre ellos en el vertex, es siempre igual a la que hai cntre los bordes internos de las cavidades cotiloídeas; pero hace mas o 
ménos los $2 / 3$ de la que los separa en la frente $i$ en la garganta. La linea ocular es tanjente al borde esterno de la cavidad cotiloídca, o aun lo corta levemente.

El protórax tienc una lonjitud mas o ménos igual con la anchura apical i la basilar, pero la del medio es a veces un poro mayor. El disco lleva callos; i, a veces, uno mui pequeño aparece tambien lateralmente.

Los elitros estan truncados en la base, con los ángulos humerales mas o ménos callosos. Su anchura da mas o ménos la tercera parte de su lonjitud. Su ápice termina de distintas maneras segun las especies, pero no lleva nunca espinas. El dorso es desde levemente deprimido hasta levemente convexo.

Putas mediocres. Sus muslos, algo mas gruesos en los of son dilatados hácia el ápice, o gradualmente desde la base o algo brúscamente. La lomjitud del fémur inturmediario da entre el $25 \mathrm{i}$ el 30 / 10 de la del cuerpo. El fémur posterior es $u 1 n$ poco mas cisto en las $q$. En los ơ el 5. segmento del abdómen dificre de el de las $\%$ por ser truncado i mas corto que 4 .

Primer artículo de los tarsos posteriores a lo ménos tan largo como 2 i 3 juntos.

Cavidades cotiloídeas anteriores e intermediarias abiertas hácia afuera. La salida prosternal presenta inas o ménos la mitad òe la anchura de la salida del mesosternon; ésta está aplanada, $i$ a lo inénos tan ancha como la mitad de sus ancas.

La clave analítica signiente ayudará a reconocer las cuatro especics que describo.

A.--Art. 3 de las antenas mas largo que cada uno de los dos siguientes:

a-antenas de un solo matiz.......... Flaz'ofasciatum

aa- " dos matices.................. Maculicorne

13-art. 5 de las antenas mas largo que cada uno de los dos precedentes.

b-Protórax mútico lateralmente....... signatico!le

bb- " calloso " $\quad$....... mimutum. 


\section{G. Flavofasciatum $(B /)$}

Castaneo-piceum, parce breviterque pubescens, leviter depressum. Capite dense punitato rugoso. Antennis corpore, apud mares vix longioribus, apud fieminas brevioribus. Prothorace pulie grisia, hrevissima t appressa tecto; dorso linea longitudinali levi, fostice dilatata, sed ante basin iuternpta, et in dimidio antico tuberculis duobus lavigatis, notato; lateribus, in dimidio antico leaiter convergentibus, in dimidio postico rotundatim dilatatis, et prope hasim brevissime constrictis. Apud mares, disco tenuiter ngose punctuto, in medio longitrorsum leviter excavato; lateribus in dimidio antico recte obliquis. Apud feminas, disco fortiter rugose punctato; lateribus in dimidio antico incequalibus, aut irregulariter subsimuatis. Elytris dense grosseque punctatis, longitrorsum vage bilineatis, ad apicem aliquando levter pallidiorilus; fascia media dentata maculaque apicali ovata testaceis, plus minusve linuratis, pictis; apice separatim subrotundatis. Aludomine pectoreque, apud mares subopacis, breviter denseque pubescentibus et densissime lenuiterque punctulais; apud fiminas nitidis, sat ionge laxeque pulescentibus et tenniter laxeque punctulatis.

$$
\begin{aligned}
& \text { o: long. } 25.0 \text {; lat. } 6.5 \ldots . . \text { long. } 16.0 \text {; lat. } 3.9 . \\
& \text { क: " } 25.5 ; " 6.5 \ldots . . \text { " } 14.0 ; 113.5 .
\end{aligned}
$$

Tanto en la descripcion que Blanchard da de este insecto (in Gay, Zool., T. V, p. 49o.), como en los pocos datos con que Lacordaire acompaña lo que dice del j. Grammicosum (loc. cit.), hai varias inexactitudes; pero lo que mas se hace notar son las omisiones i las insuficiencias; pues no se dice ni una palabra de las diferencias sexuales, que son tan numcrosas i tan notables.

Este insecto es de un matiz. castaño bastante variable; pues, si llega a ser oscuro en partes, en otras es notablemente alennado; i, por In que se acaba de ver, su tamaño no es ménos inconstante; ya que, tanto en el cे como en la $q$, puedc variar casi del doble. En cuanto a la depresion del cuerpo, si es bien notable en las o, es apénas visible en algunos ơ.

Cabeza glabra i cubierta de una puntuacion rugosa gruesa $\mathrm{i}$ apretada. 
Frente levemente convexa trasversalmente entre los ujos. Carrillos de una lonjitud igual a la anchura de los cóndilos antenarios. Tubérculos antenarios mui escotados.

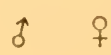

Distancia entre los borics internos de las cavidades cotiloídeas.......................... $1.5 \quad$ I.4

Distancia entre los ojoi en el vertex.......... $\quad$ I.5 $\quad$ I.4

$\begin{array}{llllll}" 1 & \text { en la frente............. } & 2.7 & 2.4 \\ 1 & \text { " } & \text { en la garganta.......... } & 2.8 & 2.5\end{array}$

Las antenas son un poco mas páliclas, sobretodo hácia tl ápice. Sus artículos 3,4 i 5 tiencn su ángulo apical interno dentiforme, i son un poco ınas gruesos en los $f$. En dos indivi. duos de ignal tainaño, la anchura del 3 en la $q(0.38)$ ha dado solarnente los $2 / 3$ de la del mismo en el ? (0.60).

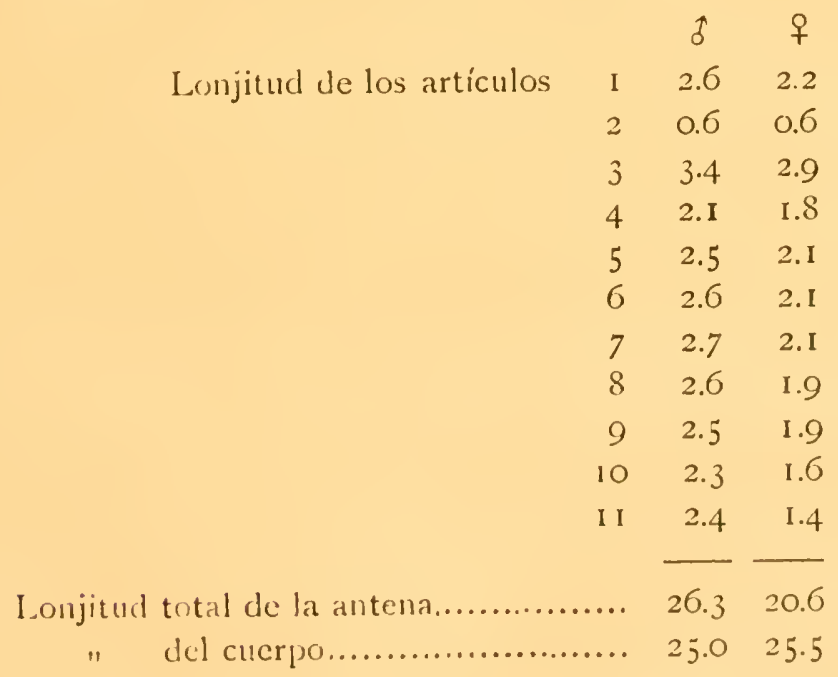

Barba un poco mas de tres veces tan ancha como larga $\left(\begin{array}{l}1 \\ 13\end{array}\right)$. con sus costados paralelos en la mitad basilar.

Lengïeti con su escotadura anchamente redondeada en cl fondo; los lóbulos sen diverjentes en ángurulo recto, relundeados en su ápice, i casi dos veces tin lirgos como anchos. El art. I 
de sus palpos alcanza mas o ménos al ápice del lóbulo, i es de igual lonjitud $i$ anchura que el 2 ; ámbos juntos son levemente mas largos que el 3; la anchura de eite último da solamente el $44 \%$ de su lonjitud; el truncamiento apical es redondeado.

La lonjitud de los palpos maxilares pasa de un $25 \%$ la de los labiales. El I es pequeño; el 3 es mas corto que el 4 , i éste es mas corto que el 2; la forma i las proporciones del 4 son iguales a las del 3 de los labiales, pero su anchura es apénas mayor que la de los dos precedentes.

En ámbos sexos el protórax ofrece las mismas proporciones, como lo demucstra el cuadro siguiente:

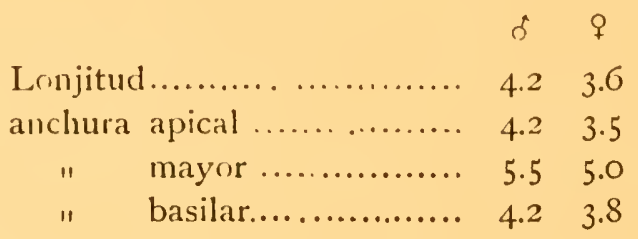

i presenta tambien los caractéres siguientes: el disco está cubierto de una pubescencia cenicienta corta, fina i tendida; lleva una quilla lonjitudinal deprimida $i$ lisa, mui fina $i$ casi borrada adelante, pero ensa:ıchada hácia atras sin alcanzar a la base; $i$, en la mitad anterior, hai dos callos lisos i deprimidos; en la mitad de adelante, los costados son converjentes hácia el ápice; $i$, ántes del inedio, son dilatados i redondeados, pero brúscamente contraidos mui cerca de la base.

Ademas presenta las diferencias sexuales siguientes:

En los ô, el disco está cubierto de una puntuacion rugosa mui fina i apretada; la quilla está colocada en un hundimiento mui notable; ademas, cn la mitad basilar, hai de cada lado dos surcos lonjitudinales angostos, vagos $i$ a veces poco visibles, de los cuales el interno alcanza casi al callo; en su mitad anterior los costados son rectos.

En las $q$, la puntracion del disco es rugosa i notablemente mayor; i, en la mitad anterior, los costados son desiguales e irregularmente sinuosos.

El escudo figura un triángulo curvilíneo, i cstá cubierto de 
una pubescencia anarillenta, lanuda, espesa i tendida; pero, on ninguno de los numerosos ejemplares que he tenido a la vista, me ha sido posible descubrir "liz linea lonjundinal alzada" de que habla Blanchard.

Loi elitros son paralelus, i, en algunos ejemplares, presentan un leve brillo; llevan una puntuacion gruesa i apretada en la parte basilar, pero algo mas fina i rugosa en la apical; estan cubirrtos de una pubescencia rubia mui corta i casi crizacla, la cual, casi nula en la basc, va haciéndose gradualınente inas larga i mas tupida en el ápice; cste, como asimismo el borde sutural i cl marjinal, estan ribeteado; por un corloncito alzado que desaparece en la mitad basilar; la estremidad varía levemente segun los individuos: en algunos cada elitro está perfectamente redondeado; en otros el ángulo anal, aunque romo, es bien visible; i por fin, en ciertos machos, se nota en medio de la parte redondeada un pequeño diente obtuso. Cada elitro lleva dos costillitas lonjitudinales algo vagas: la interna alcanza casi a la base, pero se borra en el medio; la esterna es la mas marcada i la mas larga, pero no alcanza ni a la base ni al ápicc. Llevan, ademas, una mancha ovalada apical i una faja submediana testáceas; ésta es mui variable, i hasta espuesta a desaparccer; cuando cstá lo mas desarrollada, no alcanza al borde inarjinal, pero sí al sutural, $i$ lo sigue hasta la mitad de su lonjitud, al mismo tiempo que se desprende del medio un ramal oblongo que se dirije sobre la base, pero termina mucho ántes de alcanzarla; la parte entre la faja i el ápice es a menudo de un matiz. mas claro.

El epistemon metatorácico cs convexo, con la sutura delgada i hundida, i disminuye gradualmente de anchura desde la base; la de esta última da del 20 al $250 / 0$ de la lonjitud.

En los ç, los tres segmentos pectorales i el abdómen son mas o ménos opacos, con motivo de una puntuacion mui fina i mui densa que los cubre, i llevan una pubescencia densa, corta $\mathrm{i}$ tendida.

In las 9 todas estas partes son brillantes: el prosternon lleva unas arrugas trasversales, en su parte anterior; la posterior, así como el mesosternon llevan unos gruesos puntos; miéntras que el metasternon i el abdómen presentan una puntuacion pilifera 
mui fina i mui rala, i que la pubescencia es mas larga i mas espesa, sobre todo en aquel.

Los fémures se ensanchan gradualmente desde la base, que, en jeneral, es un poco rojiza.

\begin{tabular}{|c|c|}
\hline & $\hat{\sigma}$ \\
\hline Lonjitud del cuerpo...................... & 25.0 \\
\hline fémur intermediario.......... & 6.70 \\
\hline Proporcion de esta con aquella............ & $27 \%$ \\
\hline Anchura basilar de este.................. & 0.70 \\
\hline de su parte dilatada.............. & I.86 \\
\hline Proporcion de aqualla con esta........... & $38 \%$ \\
\hline de esta con la lonjitu & $28 \%$ \\
\hline
\end{tabular}

Los posteriores alcanzan a la $4 .^{\mathrm{a}}$ sutura abdominal en los $\hat{\xi}, \mathrm{i}$ srlamente a la $3 \cdot{ }^{a}$ en las $q$.

Tarsos posteriore; con el artículo I de $\frac{1}{5}$ mas largo que 2,3 juntos.

Blanchard ha sido, sin duda, víctima de una equivocacion al dar a este insecto Coquimbo por patria; pues, es comun en la parte austral de: Chile, i creo que poco se aventura al norte del rio Maule.

Lam. II fig. $6^{\mathrm{a}}$ : barba, lengiieta $i$ palpo labial.... Aum. 20 diám. fig. $\sigma^{\mathrm{b}}:$ palpo maxilar.................. " " "

\section{G. MACULICORNE (mihi)}

9. Leviter convexum. Capite obscuro, punctato et pube grisea appressa vestilo; labio brevi, lato, obtuse angulatim emarginato, lobulis brevibus apice rotundatis. Antennis corpore vix lon,ioribus; articulis duobus pri. mis obscuris; alteris testaceis, utroque apice nigro; articulis 3.5 apice intus spinulosis; articulo 3 quinto leviter longiore. Prothorace subcylindrico, longitudine latitudinem fere aequante, dense punctato-rugoso et fube grisea appressa vestito; diso linea postica longiludinali laevigata et tuberculis minutis duobus pone medium sitis ornato. Scutello pube allida et lanosa dense tecto. Etytris nitidiusculis, testaceis; macula triangular basali, fascia dentata postica, vittaque marginali apice ablireviata obscuris, ornatis; functis grossis apice fere obiiteratis, parum dense impressis; pube albida iaxe tectis; et utringue lineis duabus angustis et vix conspi- 
cuis, longitrorsum notatis; apice leviter truncalis, angulo anali recto. Pe. dibus gracilibus obscuris, aut plus minusze rufulis; femoribus ad apicem fere gradatim dilatatis.

Long. 13.0; lat. 3.O.

Los ejemplares que veo de esta especie pertenecen a la culeccion Izquierdo, son todos hembras, i provicnen de Quillota i de los valles subandinos al sur del rio Maipú.

El cuerpo es paralelo i levemente convexo. Ia cabera i el protórax son opacos, con una puntuacion fina i rugosa, de un negro ahumado fo levemente castaño, i cubiertos de una pubescencia cenicienta algo espesa $i$ tendida. Aquella es pequeña.

Lateralmente, el lóbulo anterior de los ojos pasa un poco la cavidad cotiloídea, quedand() los carrillos sumamente cortos (O.1). La línea ocular es mui poco mas que tanjente al borde esterno de la cavidad cotiloídea.

Distancia entre los bordes internos de las cavidades cotiloídeas................................. 0.9

Distancia entre los ojos en el vertex................ 0.9

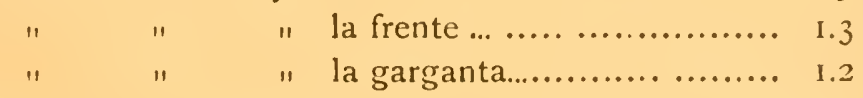

Las antenas son testáceas, con los dos primeros artículos oscuL.onjitud de los artículos I I.3 ros i todos los otros negros

20.3 en su ápice; los 3-5 llevan

3 I.9 una fina espinita en suán-

4 I.6 gulo apical interno; los ar-

5 1.8 tículos I-5 o 6 llevan pun-

6 I.6 tos ásperos, que son gra.

$7 \quad 1.6$ dualmente reemplazados

81.4 por puntos mas finos i

$9 \quad$ I.3 mas ralos, en medio de fi-

10 I.O nísimas arrugas trasversa-

II 1.0 les, probablemente porife-

_ ras i solo visibles con el

I.onjitud de la antena........ I4.8 microscopio, los artículos

"del cuerpo.......... 13.0 llevan tambien una pubcs- 
cenciz erizada, que se convierte gradualmente en una capa de finísimos pelillos, mui cortos i mui tendidos, que ocultan los tegumentos.

Barba tres veces tan ancha como larga; costados levemente diverjentes; ángulos anteriores mui redondeados.

Lengiieta mui corta, con su anchura anterior igual a los $\frac{4}{5}$ de la de la barba; escotadura con forma de ángulo obtuso redondeado en su ápice. El artículo I de sus palpos alcanza al ápice de los lóbulos; el 2 es tan largo como $\mathrm{x} ; 3$ es tan largo como 1.2 juntos (0.3 I), su ápice está truncado oblícuamente, i su mayor an. chura iguala los $\frac{5}{8}$ de su lonjitud.

Quijadas como en el G. signaticolle; sus palpos robustos i i 1 1/2 vez tan largos como los labiales; el artículo 2 es mas largo i mas grueso que 3; la lonjitud del 4 (0.36) no alcanza a igualar la de 2,3 juntos, pero es dobie de su anchura, está truncado oblícuamente en el ápice.

El protórax presenta las medidas siguientes:

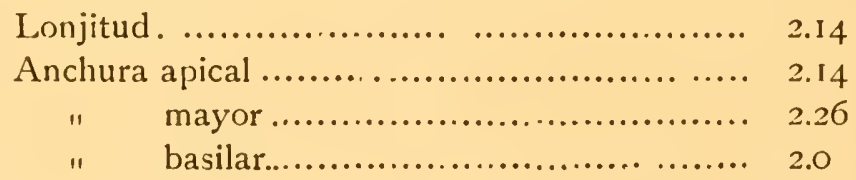

El disco llcva en su mitad basilar una línea lonjitudinal, deprimida $\mathrm{i}$ lisa, que no alcanza a la base, $\mathrm{i}$ de cada lado de la cual se ve a veces otra línea mas pequeña; lleva ademas, despues del medio, dos callos, pequeños pero bien visibles, dispuestos trasversalmente.

Escudo densamente cubierto de una pubescencia pálida corta mui tendida.

Elitros testáceos con una mancha basilar, una faja posterior i una veta marjinal negras: aquella es triangular, con sus ángulos apeyados sobre los callos humerales, sus costados dentellados, i su ápice mas o ménos prolongados sobre la sutura; la 
segunda está situada en la mitad apical, es dentellada cn sus bordes, i, lateralmente, alcanza mas o ménos a la faja marjinal; la cual tcrmina poco mas allá. El disco está cubierto de gruesos puntos medianamente apretados, que van disminuyendo desde el medio, i desaparecen casi por completo en el ápice; cada uno lleva, ademas, dos finas i vagas costillas lonjitudinales, que no alcanzan a la base ni al ápicc. La estremidad anal de cada elitro está truncada, con el ángulo interno bien marcado i recto. La pubesconcia del dorso es blanquizca, mui rala $\mathrm{i}$ tendida, pero mezclada con algunas hebras cnderezadas.

Parte inferior del cuerpo oscura, i con una pubescencia parccida a la de los elitros, pero mucho mas apretada i un poco mas corta. Lleva una puntuacion rugosa sobre el prosternon i el mesosternon, mas fina i mas rala sobre el metasternon i el abdómen. Los segmentos de este último dan las lonjitudes siguientes: I,5-I,4-I,2-0,9-0,8: éste con el ápicc redondeado. Salida prosternal angosta, pero aplanada i con su estremidad dilatada $\mathrm{i}$ arqueada despues de las ancas. Salida mesosternal paralela i truncada. Episternon metatorácico paralelo; su anchura (0.4) da el $17 \%$ de su lonjitud (2.4); i su sutura con el metasternon está marcada por una costilla saliente $i$ lisa, que no alcanza al ápice.

Patas delyadas, variando, scgun los individuos, del oscuro al testáceo rojizo. Su pubescencia es blanquizca, funa i mui tendida, con unas pocas hebras erizadas.

Lonjitud del cuerpo $\ldots \ldots \ldots \ldots \ldots \ldots \ldots \ldots \ldots . . . .13 .0$

" fémur intermediario................. 3.6

Proporcion de esta con aquella............... $28 \%$

Anchura de este en la basc.................... 0.3

$\begin{array}{lll} & \text { de este cn la partc dilatada......... } 0.7\end{array}$

Proporcion de aquella con esta ............. + $+3^{\circ}$ u

" de esta con la lonjitud........... 19\%

El fémur posterior alcanza apénas a la $33^{\text {a }}$ sutura abdominal; i el primer artículo de estos mismos tarsos es un poco mas largo que 2 i 3 juntos. 


\section{G. Signaticolite (Blanch.)}

Leviter convexum, caslaneo-piceum, vix pubescens. Capite pario nugose punctato; antennis subdepressis, pallide castaneis, corpore apud mares vix longioribus, apud foeminas irevioribus; articulo 5 tercio lóngiore. Prothorace dense grosseque punctato, longitudune latutudinem aequante; lateribus in $\frac{2}{3}$ anticis subparallelis, prope basim angustatis; disco sulco loevi, longitudinali tuberculisque duobus pone medium sitis notato et pube favidula congesta lineolas longitudinales formante or nato. Elytris nitidiusculis, punctis magnis ad basim longitrorsum plus minusve confluentibus, apice minoribus dense clathratis; utroque sulcis duobus latis longitudinalibus oblique subimpresso, et ad apicem pilis Julvis subhirsutis lave vestito; angulo anali reoto. Prosterno mesosternoque dense puntatorugosis. Metasterno abdomineque nitidiusculis, punctis haud confluentibus impressis. Femoribus brevissime griseo-pubescentibus, subnitidis, punctis rugisque tranversis minutissimis vix conspicue impressis.

of Long. 15,5; lat. 4.1- \% long. 17.0 ; lat. 4.6.

Este insecto no es escaso en la rejion central de Chile, donde su larva parece vivir en el Espino (Acacia Cavenia).

Es un poco convexo i cilíndrico, escasamente pubescente i de un castaño oscuro uniforme, pero mas claro sobre las antenas i la base de las tibias. En cuanto a lo que Blanchard dice (in Gay), que los artículos de las antenas son mas oscuros en su estremidad, es inexacto para los catorce ejemplares que tengo a la vista.

Cabeza pequeña cubicrta de una gruesa puntuacion mezclada de arrugas, i con una pubescencia algo dorada aglomerada detras del lóbulo posterior de los ojos.

Ojos con su borde posterior contiguo con el protórax; lóbulo anterior ancho, subsinuado adelante, su parte interna pasa le. vemente a la cavidad cotiloídea, $\mathrm{i}$ la distancia que lo separa de esta última es igual a la lonjitud de los carrillos; la línea ocular es un poco mas que tanjente al borde esterno de la cavidad cotiloídea; ésta es oblícua i levemente escotada, con su borde interno un poco hinchado a modo de rodete: lo que hace la frente cóncava. 
En un $\{$ de 15.5 de lonjitud. Distancia entre los bordes internos de la cavidad cotiloídea........ I.I

Distancia entre los ojos, en el vertex............. I.I

$\begin{array}{llll}" & \text { en la frente.............. } & 1.6 \\ " & 1 & \text { en la garganta } \ldots \ldots \ldots \ldots & 1.5\end{array}$

Antenas levemente deprimidas i densamente punteadas, con una pubescencia gruesa, rala i suberizada en la primera mitad poco mas o ménos; corta, fina, apretada i tendida en la otra.

\begin{tabular}{|c|c|c|c|}
\hline \multirow[b]{2}{*}{ Lonjitud de los artículos........ } & \multicolumn{2}{|r|}{ 子 } & 우 \\
\hline & I & I. 6 & I.6 \\
\hline & 2 & 0.15 & 0.15 \\
\hline & 3 & 1.5 & 1.3 \\
\hline & 4 & I.3 & 1.2 \\
\hline & 5 & I. 8 & І.8 \\
\hline & 6 & 2.0 & 1.8 \\
\hline & 7 & 2.0 & I. 8 \\
\hline & 8 & 1.7 & 1.5 \\
\hline & 9 & 1.7 & I. 4 \\
\hline & IO & I. 5 & I.I \\
\hline & I I & 1.7 & 1.0 \\
\hline ........ & $\ldots .$. & 16.95 & 14.65 \\
\hline cuerpo ........... & ....... & 15.5 & 17.0 \\
\hline
\end{tabular}

Los órganos bucales figurados en la obra de Gay (Lam.29 de los coleopt., fig. $7^{b, c, d .}$ ) no son exactos; como se puede constatar, comparándolos con los que doi, los cuales han sido ejecutados con el mayor respeto de la verdad.

Barba un poco mas de tres veces tan ancha como larga; su mayor anchura está en el medio, por hallarse los lados converjentes hácia atras en su mitad basilar.

Lengiüeta con sus lóbulos casi tan anchos como largos, con el borde esterno recto i el interno anchamente arqueado; estan separados por un ángulo casi recto i redondeado en su estremo ápice. Palpos cortos; el artículo 2 es casi de igual lonjitud que I, i su ápice alcanza al del lóbulo: el artículo 3 está trun- 
cado oblícuamente, i su lonjitud es doble de su anchura e igual a la de I i 2 juntos.

Quijadas cortas, $\mathrm{i}$ sus palpes son solamente I/4 mas largos que los labiales; el artículn 2 es levemente mas grueso que 3 ; el 4 está truncado oblícuamente, apénas dos veces tan largo como ancho, $\mathrm{i}$ un poco mas corto que 2, 3 juntos.

El protórax presenta las medidas siguientes en un of de I 5,5 .

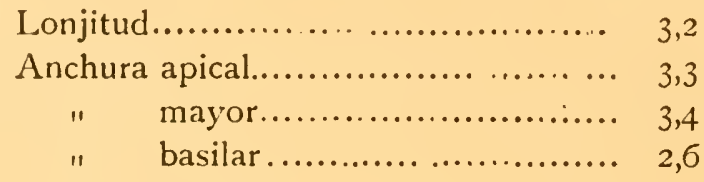

Los costados son casi paralelos en sus $2 / 3$ anteriores; pero, miéntras son mui rectos en los $\delta$, son levementc sinuosos en las $q$, reproduciendo un poco aqui lo que pasa en el flavofasciatum; en el tercio basilar estan contraidos algo brúscamente. E] disco está cubierto de una puntuacion mui gruesa mezclada con fuertes arrugas; en la mitad posterior lleva un surco liso i poco profundo, que está borrado en el I/4 basilar, i se trasforma en una quilla vaga $\mathrm{i}$ angosta en la mitad anterior; en la altura de esta trasformacion hai de cada lado un tubérculo liso i saliente; ademas, una pubescencia rubia i lanuda se aglomera para formar de cada lado unas dos líneas lonjituclinales bastantes irregulares; de las cuales, la interna, que es la mas larga, se estiende hácia adelante hasta envolver al tubérculo.

Escudo como en las especies anteriores.

Los elitros son algo brillantes, i llevan una gruesa puntuacion que se hace gradualmente menor hácia el ápice: es, pues, completamentc inexacto lo que dice Blanchard, (in Gay: $T$. $V$., p. $79 I$ ) que son "uniformemente cubiertos de una puntuacion mui fuerte sumamente apretada॥. En la base, estos puntos estan mui apretados, hasta confundirse en el sentido lonjitudinal i formar cortos surcos irregulares. Cada uno lleva dos impresiones sulciformes lonjitudinales, anchas, poco profundas i levemente oblícuas; resultando entre ellas una ancha costa deprimida, que nace casi en medio de la base, i que, dirijiéndose sobre la sutura, se borra al llegar en el I/5 apical. La pubescen. 
cia de los elitros es rubia, algo erizada i rala, sobre todo en la base. El ángulo anal es recto i puntiagudo.

El prosternon i el mesosternon llevan una puntuacion espesa, confluente i rugosa.

El metasternon i el abdómen son algo brillantes; con una puntuacion gruesa, pero separada, $i$ una pubescencia blanquizca fina, rala $\mathrm{i}$ tendida.

La salida prosternal i la mesosternal son como en la especie anterior.

El episternon metatorácico es casi paralelo, i solamente atenuado cerca del ápice: su anchura basilar $(0,56)$ da el $14 \%$ de la lonjitud $(4,0)$.

Los fémures son ensanchados gradualmente i algo brillantes, con una puntuacion i unas arruguitas mui pequeñas, apénas visibles, $\mathrm{i}$ medio ocultadas por una pubescencia cenicienta fina i tendida.

\begin{tabular}{|c|c|c|}
\hline & $\delta$ & + \\
\hline Lonjitud del cuerpo..... & 15.5 & I 7.0 \\
\hline del fémur intermediario. & 4.6 & 4.2 \\
\hline Proporcion de esta con aquella.......... & $30 \%$ & $25 \%$ \\
\hline Anchura de éste en la base .............. & 0.4 & 0.44 \\
\hline en la parte dilatada.. & I.I & I.O \\
\hline 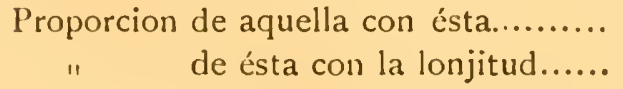 & $\begin{array}{l}36 \% \\
24 \%\end{array}$ & $\begin{array}{l}44 \% \\
24 \%\end{array}$ \\
\hline
\end{tabular}

En el fo, el fémur posterior alcanza a la $4{ }^{\mathrm{a}}$ sutura abdominal i pasa apénas la $3^{a}$ en la $q$.

Las proporciones de los segmentos del abdómen es como en la especie anterior.

La lonjitud del primer artículo de los tarsos posteriores iguala apénas la de los dos siguientes juntos.

Lám. II, fig. 8. a : barba, lengiieta i palpo labial. - Aum. 20 diám. fig. 8. " : quijada i palpo maxilur.- 


\section{G. Minutum. Blanch.}

+: Subdepressum, castaneo piceum, supra setis raris albis subhirsutum. Capite thoraceque tenuissime rugosis et pube appressa brevi tectis. Antennis corpore longioribus, haud ciliatis; articulo 5 longiore, omnibus apice rufulis. Prothorace fere longiore quam lato; disco subinaquali; lateribus in medio tuberculo late conico armatis. Elytris nitidiusculis, dense grosseque punctatis, ad apicem lariorióus; utrinque supra basim inflatis, in medio prope suturam longitrorsum late excavatis et fascia testacea ansulata pictis. Abdominis segmentibus longiludine gradatim decresientilus. Coxis anticis globosis. Femoribus leviter clavatis.

Long. 4.8; lat. 1.26.

No he visto mas que dos ejemplares de esta especie: pertenecen a la coleccion Delfin, provienen de Quilpué i ámbos son ㅇ.

Blanchard (in $G a y, T . V, p .492$ ) dice que, por el mal estado del individuo único sobre el cual describe esta especie, no está mui seguro que pertenezca al jénero Grammicosum. Difiere, es cierto, de las tres anteriores por algunas particularidades en las antenas, en el protórax, en las ancas anteriores e intermediarias i en los fémures; pero, siendo poco partidario de multiplicar tanto los jéneros, creo que conviene dejarla en el presente.

Algo deprimido, sobretodo en los elitros, es de un matiz castaño-oscuro uniforme, i lleva sobre la cabeza, el protórax i los elitros unas pocas cerdas blancas, gruesas i medio erguidas, cuya lonjitud responde en jeneral a las $2 / 5$ partes de la anchura de cada elitro; pero: miéntras estas últimas son brillantes i cargadas de una gruesa puntuacion que se hace gradualmente menor hácia el ápice, los dos primeros presentan una puntuacion rugosa mui fina $\mathrm{i}$ mui apretada algo disimulada por una pubescencia mui corta i tendida.

Cabeza acortada adelante; frente convexa con und fina estría lonjitudinal.

Barba arqueada por los lados, un poco ménos de tres veces tan ancha como larga.

Lengiieta membranosa, con una anchura anterior que da los $3 / 5$ de la de la barba; escotadura en forma de ángulo levemente obtuso, puntiagudo en el ápice; lóbulos poco diverjentes 
redondeados en la estremidad; sus palpos son gruesos, i su lonjitud (0.24) da el $7 \mathrm{I} \%$ de la de los maxilares (0.34); sus dos primeros articulos son casi iguales, i dan, juntos, cl $65 \%$ de la lonjitud del 3; el I alcanza casi al ápice del lóbulo; el 3 es I $1 / 2$ vez tan largo como ancho, i su truncamiento es mui oblícuo.

Palpos maxilares con el artículo 2 mas grueso i mas largo que 3; ámbos juntos son casi tan largos como 4; el cual cs de la misma forma i de las mismas proporciones que el último de los labiales.

Ojos pequeños, distantes del protórax; carrillos mui cortos; cavidad cotiloídea situada al lado interno del lóbulo anterior con la línca ocular tanjente a su borde esterno.

Distancia entre los bordes internos de las cavidades cotiloídeas............................................ 0.37

Distancia entre los ojos en el vertex.................... 0.42

en la frente..................... 0.58

en la garganta................ 0.62

Antenas completamente desprovistas de los pelillos erizados tan constantes en las otras especies de esta seccion; pero, sí, cubiertos con la fina pubescencia que es propia de sus últimos artículos; artículo 2 leonado, así como la estremidad de todos los siguientes; los primeros artículos son cilíndricos, los dos o tres últimos son algo', deprimidos i ensanchados.

Lonjitud de los artículos........ I $\quad$ I 0.60

20.16

30.40

$4 \quad 0.50$

$5 \quad 0.70$

$6 \quad 0.70$

$7 \quad 0.76$

80.64

$\begin{array}{ll}9 & 0.54\end{array}$

ro 0.44

I I 0.44

" de la antena............... 5.88

" del cuerpo ................ 4. So 
El protórax presenta las medidas siguientes:

Lonjitud................................. 1.0

Anchura apical........................ 0.9

" cn el medio, con el callo incluso. $\quad$ I.O

" basilar........................ 0.7

El dorso es algo desigual, sin líneas ni callos; pero, en medio de cada costado, se nota un ancho tubérculo cónico.

El escudo tiene la forma de un medio círculo, $\mathrm{i}$ es fina i densamente pubescente.

Elitros con una hinchazon basilar, situada entre cl ángulo escutelar i el callo humeral; ademas se ve, en la parte intermediaria i a lo largo de la sutura, una ancha depresion cóncava, paralela $\mathrm{i}$ brúscamente terminada al llegar al $1 / 4$ apical; en el medio prescntan, cada uno, una línea testácea en forma de $\mathrm{V}$, cuyo ápice está vuelto hácia la base, i cuyos ramales se juntan sobre la sutura, pero no alcanzan, o alcanzan escasamente, al borde marjinal. El ángulo anal es bien manifiesto, casi recto : apénas romo en un ejcmplar, miéntras que es enteramente borrado en el otro.

Ancas anteriores e intermediarias globulosas i salientes, sobre todo aquellas. Cavidades cotiloídeas de las anteriores levemente angulosas hácia afuera; las de las intermediarias cerradas. Salida prosternal angosta, pero no lameliforme. Anchura de la salida mesosternal igual a la mitad del diámetro trasversal de la anca.

Los segmentos abdominales dan las lonjitudes siguientes: $0.46-0.42-0.35-0.28-0.25$; el último está anchamente arqucado en su ápice. El oviducto i sus palpos son completamente membranosos.

Los femures, en su primera mitad, crecen gradualmente, pero solo de manera a duplicar la anchura basilar; i sc dilatan algo brúscamente en la otra.

Lonjitud del cucrpo ......................... 4.So

" del fémur intermediario. ............ 1.37

Proporcion de esta con aquella............... 29\% 
Anchura basilar de éste....................... 0.10

" de su parte dilatada................. 0.33

Proporcion de aquella con ésta.............. 33 "

" de ésta con la lonjitud............... $24 \%$

El fémur posterior alcanza casi a la $4{ }^{*}$ sutura abdominal; la lonjitud del 1."r artículo de sus tarsos iguala la de los dos siguientes juntos.

I am. II. fig. 7." : barba, lengüeta ipalpo labial.-Aum. 40 diám fig. $7 \cdot^{\text {b }}$ : palpo maxilar.

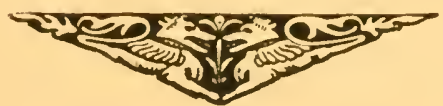





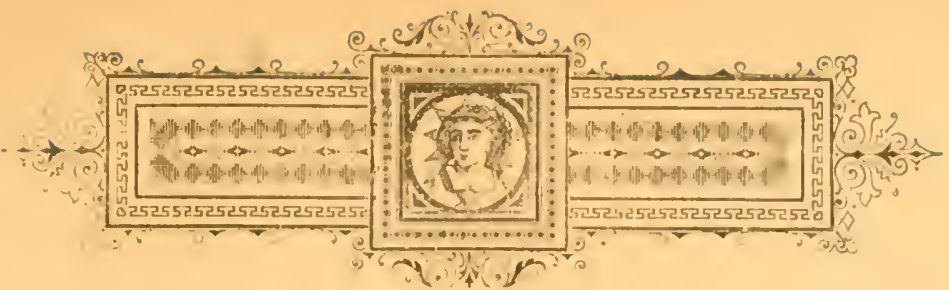

Lonjicornios chilonos

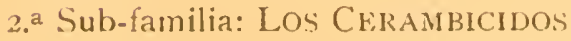

SECTION A

Jénero PIIYMationerus

Lacordaire nos dice (Genera T. VIII, p. 287, nola 2) que, asi como sucedió para el j. Grammicosum, el j. Phymatioderus fué indicado por Blanchard en la obra de L'Orbigny; i cesto sin dar tampoco los caractéres que, segun él, lo distinguian.

lirancamente no comprendo que se conceda el mas minimo valor a nombre; de agrupaciones o de especies, cuando se los echa a correr por el mundo rientífico en semejantes condiciones. Pues, hacerlo es favorecer a cstos trabajos a destajo, en los cuales se podria acusar a sus autores de haber buscado mas bien la satisfaccion de una vanagloria que la utilidad de la ciencia.

Por otra parte, cuando, algunos años despues, se recoje cl nombre de un jénern creadn de esta manera, ¿quién puede jac- 
tarse de darle por base Ins caractéres soñados por su autor? Por esto, cuando Blanchard hace en la obra de Gay (Zool. T. V, p. 495) lo que habia de haber hecho anteriormente en la obra de D’Orbisnyy, no podemos estrañarnos al ver su diagnósis diferir de la que Iacordaire da por su parte en su Genera; i las numerosas inesactitudes que se encuentran en ámbas no tienen tampoco nada que nos deba sorprender.

Voi a empeñarme en indicar las que se notan en estas dos obras, en cuanto a los caractéres clel j. Phymatioderus, $\mathrm{i}$ en restablecer la verdad a este respecto.

"L'espice typique (Ph. bizonatus Rl.) dice Lacordaire, est originaire du Chili, mais parait exister également dans quelques parties du Brésil."

No hai duda que estc insecto tenga Chile por patria, i que aun sea poco escaso en la rejion central; pero las palabras de Lacordaire dejan suponer quc, en su opinion, habria emigrado hasta el Brasil.

Yo desearia saber:

I. Si la especie que "parece existir en el Brasil" es bien la misma que la de Chile.

2. ¿Cómo sucede que no haya sido descubierta todavia tambien en la vasta rejion arjentina que separa Chile del Brasil?

$3 .^{\circ}$ ¿Cuáles son los motivos que han hecho suponer esta migracion singular a Lacordaire, i ver su direccion de sur a norte, en lugar de norte a sur?

l.acordaire da el Ph. bizonatus como tipo del jénero; pero parece que no hai otira especic.

En cuanto a sus proporciones, mientras Lacordaire dice "corps allong $g$, , Blanchard le da un "cuespo mediocremente alongado;" por lo cual cl lector queda algo perplejo, al notar que este insccto figura en el Catálogo de Dejean ( $E d .3, p .352$ ) bajo el nombre de Stenopalpns filiformis, i está con el temor de haberse estraviado en medio de estas contradicciones. I a verdad es que las proporciones del cuerpo son iguales en ámbos sexos; i que una anchura de 4.3 por una lonjitud de 16,5 , que se nota en un $\uparrow$, da una proporcion de $26 \%$, la cual parece poco variable.

Cabeza pequeña i poco saliente. En cuanto a los palpos, que 
I acordaire dice "subégaux," la lonjitud de los labiales solo da los $\$ \frac{2}{3}$ de la de los maxilare;. Blanchard es mas esacto, cuando dice que los palpos son robustos, que su último artículo es securiforme, $\mathrm{i}$ el 2 de los maxilares mayor que I i 3 ; pero exajera un poco las proporciones de aquél cuando lo califica de "mui grande" en los maxilares. El que termina los labiales es dos veces tan largo como ancho, i su lonjitud iguala la de los dos prime ros juntos; $i$, en cuanto al último de los maxilares es mas grueso, i con el truncamiento mas oblícuo; pero su lonjitud, que es tam. bien doble de su anchura, representa apénas los a de la de los tres primeros juntos.

Los lóbulos de las quijadas no ofrecen nada de anormal: el interno es triangular i inenor que el esterno, que es redondcado.

No se comprende claramente a cuál pieza Blanchard se refiere cuando habla del labio inferior. Si por estas palabras entiencle la lengiieta, no veo que sus proporciones scan mui distintas que en las otras especies de esta agrupacion; pero lo que no dice es que, con escepcion de $u 11$ armazon córneo central, es enteramente membranosa, que su parte anterior presenta una gran escotadura en triángulo casi recto cuyo ápice es puntiagudo, i que los lóbulos son dos veces tan largos como anchos, con los costados paralelos, el ápice truncado i la parte esterna pubescente.

En cuanto a las antenas, que Blanchard da como un poco mas cortas que el cuerpo, con los artículos 3-11 subiguales; miéntras que Lacordaire las dice cscediendo la estremidad de los elitros, de la mitad de su lonjitud en los $\hat{\alpha}$ i solamente un poco en las $q$, con el artículo + corto, 3 i 5 - IO iguales i I mas corto que Io, deprimido i obtuso: todo lo que dicc Blanchard es inesacto; miéntras que Lacordaire es esacto, con escepcion de un pequeño error relativamente al último artículo. El cuadro de las medidas de los artículos de las antenas que se da en la descripcion de la especic, aclara esta cuestion.

Blanchard no habla de losi ojos; i, cuando Lacordairc dice "yeur asses fortement séparés en dessus," es o inesacto o incompleto: pues, la distancia que los separa en la frente es casi doble de la que los separa en el vertex. Los tubérculos antenarios están profundamente sinuadó de modo a dejar el cóndilo a la vista. Los carrillos son cortos. 
En cuanto al prot. rax, que 13 inchard dice "ba-tante corto," i Lacordaire "plus long que large;" este último liene razon: su anchura da mas o ménos los $\frac{4}{5}$ de su lonjitud, o le es casi igual; es casi cilíndrico, un poco ensanchado en el medio, angostado gradualmente hácia la base i bruscamente mui cerca del borde anterior; los costados llevan en el medio de su lonjitud una gruesa espina recta o mui levemente encorvada hácia atras; el dorso es desigual con varias callosidades.

El escudo forma un triángulo curvilíneo.

Los elitros son paralelos; pero Lacordaire es inesacto cuando dice su ápice redondeado; está como lo indica Blanchard: levemente truncado con cl ángulo sutural' recto i puntiagudo.

Las cavidudes cotiloiders de las ancas son notablemente angulosas hácia afuera en las anteriores, $i$ abiertas en las intermediarias.

La salida prosternal es mui angosta i arqueada tras de las ancas; la mesosternal es paralcla i aplanada, un poco mas ancha que la base de los fémures intermediarios i con su ápice levemente ahorquillado.

El episternon metatoricico es largo i mui angosto; pues, su anchura (0.4) da el $11 \%$ de su linjitud (3.8).

Lacordaire dice de las patas, que son largas; i que los fémures; atenuados en su ba:se, se ensanchan despues gradualmente. Esto es inesacto: las patas no tienen una lonjitud diferente aquí que en las especies anteriores; i, respecto a los fémures, son notablemente i algo bruscamente hinchados en su mitad apical. En cuanto a la difcrencia de dilatacion, que este entomólogo ve entre los fémures de los $\uparrow$ i los de las $q$, clla existe; pero en un grado muchn menor que el que hace suponer cuando dice "cuisses des $q$ beaucoup plus faibles que celles des $\hat{j} ; " \mathrm{i}$ es de estrañar que lo haya visto aquí, i nó en el Grammicosum flavofasciatum, donde es mas evidente. Los fémures posteriores alcanzan a la estremidad del $5 .^{\circ}$ e egmento abdominal en los $\delta, \mathrm{i}$ del $4 .^{\circ}$ en las $q$; i el artículo.$^{\circ}$ de sus tarsos escede levemente en lonjitud la de los $2.0^{\circ} \mathrm{i} 3 .^{\circ}$ juntor.

Con escepcion de los elitros i del abdómen, que son brillantes i lievan solamente unas pocas cerdas oblícuas, todo lo de- 
mas del insecto es opaco i cubierto de una pubescencia inui corta, mui fina i mui tendida.

Resulta de los caractéres espuestos aqui, que este jénero Phymatioderus difice del jénero Grammicosum solo por te. ner una espina lateral en el protórax, i los fémures mas bruscamente dilatados; pero si, entre los otros que doi como jenćricos, figuran mucho; que, sin duda, son meramente específicos, es preciso ver en ello uno de los primeros inconvenientes que resultan de la creacion exajerada de jén?ros: la obligacion de despojar la especic para caracierizarlos.

Ph. BIZONATUS (Blanch.)

Testaceus; ore, antennarum basi pedibusque fulvis; capite postice, prothorace pectoreque plus minusie bmunen-fumosis. Prothoracis tergo incequali, postice grosse punctato-rugoso. Elytris nitidiusculis, punctis grossis ad basim densioribus, et apicem iersus gradatim lituratis, crabratis; lineis dualus nigris, supra suturam sape dilatatis, transverse pictis: antia angulata, postiia ad marginem arcuata. Prosterno transicrse rugato. Mesosterno lavi, metasterno punctato. Abdomine nitidiusculo fere loirgato.

Long. 16.5; lat. 4.3 .

Blanchard dice de este insecto, que es de un pardo testáceo; i Lacordaire, que es "d'un irun noirître plus ou moins varié de fauve." La verdad es que presenta una mezcolanza de estos matices, algo inconstantes en la cabeza i lo debajo del cuerpo.

Aquella es mas o ménos rojiza delante de las antenas, i a veces en su totalidad.

En un fo de 16.5 de lonjitud:

Distancia entre los bordes internos de las cavi. dades cotiloideas antenarias ........... 1.3

Distancia entre los ojos en el vertex......... I.O

$\begin{array}{lllll}" 1 & \text { " en la frente...... . . } & 1.80 \\ " & \text { " debajo de la cabeza.... } & 1.90\end{array}$


La línea ocular es tanjente al borde esterno de la cavidad cotiloídea. El borde interno de esta última es algo engrosado a modo de rodete.

Las antenas tienen su primer artículo con forma de una maza levemente arqueada; carecen por completo de espinas o dientes; todos sus artículos, con escepcion del primero, son delgadus i filiformes, i son revestidos de una finísima pubescencia mui corta i mui tendida; los 7 " 8 primeros llevan ademas unas pocas cerdas finas $i$ oblícuas.

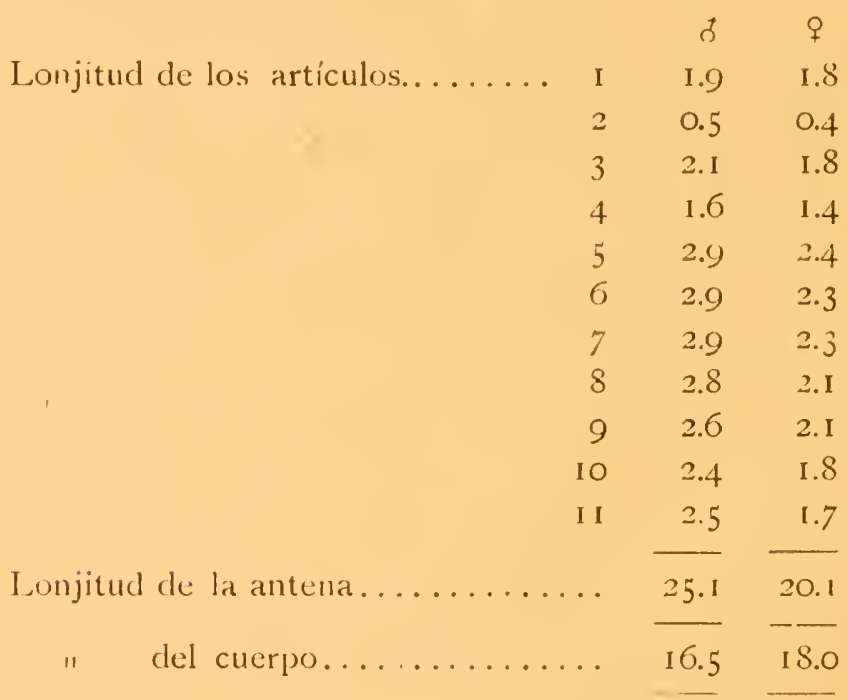

En un macho de 16.5 el protórax mide:

Lonjitud................. 3.1

Anchura apical............. 2.2

" mayor............... 3.I

" basilar.............. 2.5

Es de un bruno ahumado, con el dorso desigual, cubicrto en su parte basilar de gruesos puntos poco abundantes i mezclados con arruga:; lleva de dos a cuatro tuberculillos callosos dipuestos tratver-alment: en el primer tercio anterior; los laterales estan sitnados delante de la espind, pern estan borrados con 
frecuencia; ademas hai en el medio ma linea lonjitudinal callosa, brillante i mas o ménos surcadd, pero que $n$ alcanza ni a la base ni tampoco al ápice.

En un of de 16.5 la anchura basilar de los elitros es $4.3 \mathrm{i}$ su lonjitud 12.5; su base es recta, con el callo humeral redondo i saliente; son brillante; i de un testáceo páli lo, con dos líneas trasversales negras: la primera, situada en el $1 / 3$ basilar, describe sobre la sutura un ángulo aşudo que se dirije hácia el escudo; i, en medio de cada elitro, otro ángulo de la misma forma dirijido hácia atras, pero sin alcanzar al medio. La segunda principia en el ángulo anal, sigue la sutura en su 1/3 apicai, i, despues se arquea de cada lado hácia el borde marjinal. En alşunos cjemplares estas líneas son poco marcadas; pero, en otros, se ensanchan i se dilatan sobre la sutura de modo a formar placas triangulares; el dorso está cubierto de una puntuacion gruesa i densa en la base, pero que va obliterándose gradualmente hácia la estremidad, hasta quedar completancnte borrada.

El prosternon está cubierto de una gruesa puntuacion apretada i mezclada cun arrugas trasversales mas u ménos aparentes.

El mesosternon es liso.

El metasternon presenta una puntuacion irregular i poco apretada.

El abdímen es brillante con unos puntos mui escasos esparcidos irregularmente. El seginento 5) es mas corto en el t que en la $f$, i subtruncado en su ápice: forma que se nota en los Hesperophanes i los Grammicosum descritos aquí.

Los fémures intermediarios presentan las proporciones siguientes en ámbos sexos:

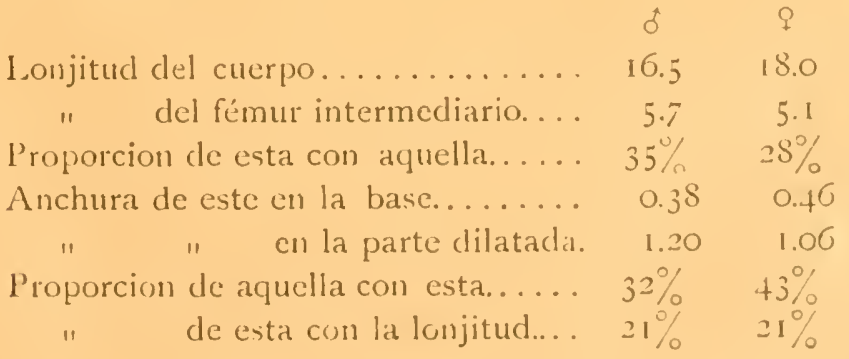


Lám. II; 9. a: barba, lengiueta i palpo labial. Aum. 20 diám.

" 9. ": palpo maxilar.........." " "

\section{Gén. COMPSA. - (Perty)}

Este jénero, establecido por Perty en I830, comprendió luego tantas especies, que en I834. Serville halló conveniente separar bajo el nombre de Ibidion estas cuyas tibias presentan una quilla lonjitudinal; i fué bajo este carácter, de tan poco valor como muchas veces de una apreciacion difícil i de una constatacion dudosa, que vinieron a colocarse la mayor parte de las especies del jénero primitivo. De tal manera que, cuando, en su Genera, Lacordaire reparte entre 25 agrupaciones la seccion $A$ de la subfamilia de los Cerambicidos; es el jénero Ibidion que da su nombre a la que la corresponde: los Ibidionidos.

Como, en el arreglo que Lacordaire hace de estas 25 agrupaciones, la de los Ibidionidos queda separada de la de los Hesperofanidos por otras cuatro, que parecen no tener representantes en Chile, no hablaremos de estas últimas; pero, sí, indicaremos en qué aquéllas se distinguen una de otra. Por ello se verá la frajilidad de los caractéres evocados por este distinguido sabio para la clasificacion actual de esta parte de los Cerambicidos, i la confusion a la cual se llega con el sistema de las escepciones adoptado por él.

Estos puntos diferenciales son dos:

Los Hesperofanidos tienen sus ancas anteriores trasversalmente oraladas o subglobulosas, $i$ mas o ménos angulosas en su parte esterna; sus cavidades cotiloídeas están abiertas atras en las anteriores i fuera en las internediarias.

Los Ibidionidos tienen sus ancas anteriores globulosas $i$ mas o ménos gruesas i salientes; las cavidades cotiloídeas están cerrailas atras en las anteriores, $i$ afuera en las internediarias.

Todas las otras particularidades indicadas por Lacordaire no son de ningun uso práctico; porque, si las formas que señala son ripreciables cuando llegan a su menor o mayor desarrollo, no se dabe qué partido tomar con cllas cuando se quedan en 
los grados intermediario:; pero lo que lo echa a perder todo es el uso arbitrario que hace de las escepciones.

Así vemos que, respecto a la forma de las ancas anteriores, hai a veces grandes diferencias entre las especies de un mismo jénero-por ejemplo Hesperophanus (Genera, T. VIll, páj. 27f, nota (1)-i que en algunas Chlorida de pequeño tamaño, ellas llegan a ser completamente subglobulosas, sin ningun rastro de salida en el lado csterno.

Por otra parte, en unas Compsa lejitimas de Chile-pallidipennis, pallidicornis, etc. - la cavidad cotiloidea anterior presenta en su parte antero-esterna un sinus pequeñ ", pro bien evidente; el cual parece indicar que la abertura angulosa, propia de varias otras agrupaciones, no alcanzó a cerrarse completamente aquí. Ademas, despues de colocar a los Ibidionidos entre las agrupaciones caracterizadas por unas "lunches anterieures non anguleusesn, Lacordaire dice (loc. cit. páj. 20,t, nota t): que lo son levemente en el jénero Heterolepis i en la agrupacion de los Uracantidos; sin dar a conocer cuál es la razon perentoria que le hizo admitir entre los Ibidionidos insectos que no presentan uno de los caractéres fundamentales de esta agrupacion. Tambien es de notar que, cn las especies que describo a continuacion, la parte esterna de la base del prosternon clirije hácia la estremidad de la quilla central un ángulo mui agudo: perơ que no la alcanza nunca: por lo cual no se puede decir que estas cavidades cotiloideas estan cerradas atras; pero vemos que cste tan importante carácter tienc su escepcion en la agrupacion de los Uracantidos: es decir que estos insectos tienenl las cavidades cotiloídeas anteriores abiertas posteriormente $\mathrm{i}$ las intermediarias lateralmente. Es claro que, si las cuatro especies de Compsa descritas aquí no pueden gozar del mismo privilejio, ellas no pueden tampoco, a pesar de sus ancits anteriores globulosas, quedar en el jéncro Compsa, i ni siquiera en la agrupacion de los Ibidionidos.

Dado, pues, el cáos que resulta de leyes establecidas sobre caractéres variables al infinito $\mathrm{i}$ del enredo que las escepciones provocan, cs evidente que, cuando se querrá indagar la colocacion jenérica de una especie, no se habrá de buscar los límites vucstos a estas agrupaciones por la naturaleza, ya quie no lo 
hizo; sino que, siendo éllos el resultado de una concepcion humana i arbitraria, será preciso tratar de penetrar la idea de su creadur, para bien darse cuenta de los puntos sobre los cuales él ha entendido poner en equilibrio su frájil creacion.

Cuento con que la incertidumbre, que resulta para el entomólogo de los límites esactos entre los cuales pasa el camino que se ha de seguir para la colocacion jenérica de muchas especies, scrá suficiente para disculparme, si hago figurar entrc las Compsa de Chile las cuatro especies siguientes-flavo-nitida

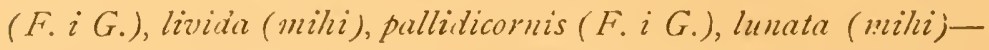
para las cuales cuatro jéneros, tal vez, habrian sido creados por entomólogos riénos enemigos que yo de ver su cantidad crecer sin necesidad absoluta.

Como no hai duda que caractéres notables las separan, los voi a indicar prolijamente; para que otro mas osado pueda hacerlo, si le parece conveniente.

Dejaré estas compsa encabezadas por la especie que mas se acerca al jénero Grammicosum; lo que llega a tal estremo que Farmaire la describió bajo el nombre de Grammicosum flazonitidum (Ann. Ent. Fr. 1859, páj.507); i que el doctor Philippi, aconsejado por el modo de ver de Fairmaire, coloca tambien en el jénero Grammicosum la variedad austral de esta especie, considerada erróneamente como distinta (Grammicosum bifasciatum. Stett. Zeit. I86o, páj. 251).

Quitando de por medio la forma, evidentemente otra de las cavidades cotiloídeas anteriores i de las intermediarias, son tantos los puntos de semejanza que se notan entre estos dos jéneros, que engañaron a Iairmaire; hasta hacerle describir bajo el nombre de Grammicosum semipolitum (Ann. Ent. Fr. I859, páj. 508) la variedad pálida de la especie, que describe mas tarde (Rev. Zool. I864, páj. 387) bajo el nombre de Ibidion pallidicorne.

Ias dos primeras especies llevan una pubescencia finísima, corta i mui tendida; las otras dos son glabras.

Con escepcion de la $1 .^{a}$, el protórax es mas o ménos visiblemente calloso en los lados, sobre todo en la 2.a. En todas, con escepcion de esta última, es oblongo; pero apretado en la base en la $3 .^{\text {a }}$ i enl la $4 .^{\text {a }}$. 
Los carrillos tienen una lonjitud mas o ménos igual a la anchura del artículo 3 de las antenas, en la $I .^{a}$ especie; son mucho mas cortos en la 2.a; i los ojos se hallan casi contiguos con la base de las mandibulas en la 3 a $^{\text {i la }} 4 .^{\text {a }}$.

En la 1.", la frente ei Innjitudinalmente hundida entre los ojos; casi trasversalmente aplanada en las otras tres.

Los ojos son mas globulosos i salientes, sobre todo en la $3^{a}$ i la $4 .^{\text {a }}$ especies, que en la $1 .{ }^{\circ}$.

En la $I^{a}{ }^{a}$ especie, el artículo 3 de las antenas es mas largo que 5, i 5 mas largo que 4. En la 2.a esta difcrencia es apénas notable. En la $3^{a}$, el artículo 3 es apénas mas largo que los siguientes, que son iguales. Pero en la $4 . "$, los artículos 3 i 4 -son iguales entre si, mas gruesns i mas cortos que 5; los demas, de 5 a II, van alargándose levemente. En las descripciones de las especies estas lonjitudes estan todas escrupulosamente indicadas.

En cuanto a la dilatacion de la parte apical de los fémures i a la delgadez de su parte basilar, es en la $2 .^{\text {a }}$ i la $3^{\text {a especies que }}$ es mas notable, i en la $I^{a}{ }^{a}$ que lo es ménos. Fairmaire indica la forma jencral de los fúmures de estas dos especies; i es, sobre lo que dice de eila, que Lacordaire (Loc. cit. páj. 2So, nota 2 ) se basa para creer que no pertenecen al jénero Grammicosum, opinion en la cual to acompaño. Pero, si lo que dice mi sabio colaborador a este respecto (Ann. Ent. Fr., I859, paj. 507, 508) es esacto, está mui léjos de ser suficiente para dar una idea completa de la forma de los fémures en estas dos especies. Pues, dice para la I." "femoribus clavatis, hasi maxime gracilibus""cuisses claviformes, trís grc̀les à la base" ; i para la 3. "femoribus basi glacilibusu-" "cuisses fortement claviformes, tris griles ì la óase" ". Los dibujos que acompañan a las descripciones de estas dos especies, i que han sido ejecutados con toda esactitud, darán una idea de lo deficientes que son estas palabras.

Respecto a esta dilatacion, los fémures de la $4 .^{\text {a }}$ especie son intermediarios entre los de la $1 .^{a}$ i los de las dos siguientes.

El carácter sacado cle la dilatacion de la parte apical de los fémures, en cuanto a su importancia i a la manera gradual o repentina con la cual ella se manifiesta, écon eviulencia un buen carácter; pero lo que sucede aquí indica la moderacion 
con que se ha de usar. Si los estremos, en lo mas i en lo ménos no permiten vacilaciones; los intermediarios, por presentar entre ellos una cantidad infinita de grados, no pueden ser apreciados de una manera útil.

Las ancas anteriores de la $I{ }^{a}$ especie llevan en su parte posterior una quilla lonjitudinal mui saliente, mui angosta i mui visible; miéntras que esta parte es completamente lisa en las otras tres.

Los episternones metatorácicos presentan tambien algunas diferencias: son siempre angostos; en la $I .^{\mathrm{a}}$, la $2 .^{\mathrm{a}}$ i la $4 .^{\mathrm{a}}$ especiestienen la forma de un triángulo alaigado: pero notablemente mas ancho en la $2 .{ }^{a}$; en la $3 .^{a}$ especie sus costados son paralelos.

Las proporciones de estas piezas se dan en la descripcion de cada especie.

La clave analítica siguiente facilitará la clasificacion de estas cuatro especies de Compsa.

A Cuerpo pubescente.

a protórax $\sin$ callos laterales......... flavo-nitidum aa " con " " ......... livida.

B Cuerpo glabro.

$b$ artículos 3,4 de las antenas a lo ménos

tan largos como los siguientes....... pallidicornis

$b 6$ artículos 3,4 de las antenas mas cortos

que los siguientes ............ lunata.

\section{FlaAVO-NITIDA (Faimn. i Germ.)}

Elongata, parallela, fusco-brunnea, opaca, breaiter fulvo-rubescens. Capite tenuiter rugosulo, fronte leviter concava: antenuis, apul mares corpore longioribus, apud faeminas elytrorum apicem wix attingentibus, articulo t $^{\circ}$ brevi, articnlas 6.II fere abrupte gracilioribus. Prothorace oblongo, aliqumito fere cylindrico; dorso dense rugoso, linea longitudinali breii rariabili notato. Elytris nitidis, testacess, basi leviter obscurioriius: pirnun dense punc- 
tulatis, apice suboparis: utrinque costis duabus longitudinalibus, angustissimis et palladioribus, punitisque mujorihus ac distantibus longitrorsum triseriatis, notatis, et fasciis nigris duabus plus minusie dilatatis, aliquando omninó lituratis, suturam hand attingentibus, in medio pictis. Antennis pedibusque obscure fulvis.

Long. I7,O-I 2,O; lat. f,I-2,8.

Esta especie se encuentra en casi todo Chile; pero los ejemplares presentan bastante diferencia respectro a las manchas negras del medio de los elitros, segun procecen del norteo del sur.

Es alargada, paralela i poco cleprimida. Con escepcion de los elitros es opaca. Su ınatiz es un castaño ahumado, algo mas roji\%o sobre las antenas i las patas; i lleva una pubescencia pálida i tendida, notablemente mas larga, espesa i lanuda, sobre todo sobre la cabeza i el protórax en ciertos machos de los ejemplares del norte $\mathrm{i}$ del centro de Chile.

La cabeza lleva rugosidades poco visibles con motivo de la pubescencia. En unos pocns ejemplares se nota una fina costilla lonjitudinal, que a veces se estiende en toda su lonjitud; pero falta jeneralmente, i aun está rcemplazada en la frente por un vestijio de surco. Esta última aparece cóncava, a causa del borde interno de las cavidades cotilóideas antenarias que cstá levantado a modo de rodete.

L.os ojos sun medianamente desarrollados i salientes. I.a línea ocular es tanjente al borde esterno de la cavidad cotiloídea. El lóbulo anterior llega en frente del fondo de la escotadura de la cavidad cotiloidea. En un ई̊ de 14.0: distancia entre los bordes internos de las cavidades cotilrideas.............. I.O

Distancia entre los ojos en el vertex............. 0.9

\begin{tabular}{|c|c|c|c|}
\hline & " & & $\begin{array}{l}\text { en la frente................ } \\
\text { rn la gargantia }\end{array}$ \\
\hline
\end{tabular}

Las antenas, grucsas en sı base, son algo bruscamente adelgazadas despues del artículo 5 ; los primeros llevan por debajo pelillos oblicuos que van gradualmente desapareciendo hácia el 5 o el 6; el artículo I es un poco deprimido en su base, arqueado i ensanchado gradualmente. El último, en los machos, es cilíndrico i levemente arqueado, con una anchura que da mas 
o ménos el $8 \%$ de la lonjitud: en las hembras es oblongo i levemente deprimido, con una anchura que da (iel 20 al $22 \%$ de la lonjitud.

Lonjitud de los artículos de la antena.

$\begin{array}{cccc}\text { Var. } \text { del norte } & \text { Var. del sur } \\ \text { d } & ? & \text { क } & \text { ? }\end{array}$

\begin{tabular}{|c|c|c|c|c|c|}
\hline \multirow{11}{*}{ la antena............. } & 1 & I. & 1.7 & 1.7 & 2.0 \\
\hline & 2 & 0.4 & 0.3 & 0.4 & 0.4 \\
\hline & 3 & 1.9 & 1.7 & 1.6 & 1.8 \\
\hline & 4 & 1.3 & I. 3 & I. 2 & I. 4 \\
\hline & 5 & 1.7 & 1.5 & 1.6 & 1.8 \\
\hline & 6 & 1.7 & 1.4 & 1.7 & 1.9 \\
\hline & 7 & 1.7 & 1.3 & 1.8 & I. 8 \\
\hline & 8 & I. 7 & 1.2 & โ. 8 & 1.6 \\
\hline & 9 & 1.6 & I. I & I. 8 & 1.6 \\
\hline & 10 & 1.5 & 1.0 & I. 6 & 1.7 \\
\hline & $1 \mathrm{I}$ & 1.7 & 1.0 & 2.0 & 1.6 \\
\hline Lonjitud de la antena entera & . & 17.0 & I 3.5 & 17.2 & 17.6 \\
\hline del cuerpo........ & & 14.0 & I 3.5 & 12.0 & 17.0 \\
\hline
\end{tabular}

Es de notar que en la variedad austral ( Gr. bifasciatum Ph.) las antenas del macho son proporcionalmente mas largas que en la variedad boreal.

Los carrillos son desarrollados en proporcion del poco tamaño de los ojos; pucs, su lonjitud iguala mas o ménos a la anchura del artículo I de las antenas en su parte inmediata al cóndilo.

La barba es mui trasversal, levemente encojida en su base, i mui redondeada en su mitad anterior.

La lengiieta es córnea en su parte central; anteriormente está dividida en dos lóbulos membranosos redondeados en el ápice, anchamente arqueados en su borde interno, cerca de tres veces tan largos como anchos, i sostenidos por una nervadura pubes. cente solo visible en la parte interna, $i$ en la cual varios entomólogos distinguidos han visto los rudimentos de las paraglosas: estos lóbulos estan separados por un espacio en ángulo mas o ménos recto. El artículo 2 de los palpos presenta una lonjitud (0.225) que da los 3/4 de la del I (0.300), la cual da un poco 
mas de los $\%$, de la del 3 (0.350); la anchurá de este último hace mas o ménos los $3 / 5$ de su lonjitud. Lit lonjitud total del palpo da el $77 \%$ de la del maxilar.

I as quijadas ticnen sus lóbulos bastante cortos: el de adentro tiene su borde interno con una franja espesa de cerdas arquea. (las hácia atras; el de afuera tiene su estremidad rocleada por pelos finos i ondeados que le dan una forma circular; los tres primeros articulos de sus palpos son de igual lonjitud (0.250), i los 2, 3 de igual anchura; las proporciones del 4 con mas o ménos iguales con las del último de los labiales, i su lonjitud da la mitad de la de los tres primeros juntos.

El protórax no lleva ninguna callosiclad, i se presenta desde oblongo hasta casi cilíndrico, ofreciendo a cste respecto las medidas siguientes, en dos ejemplares de I4.O:

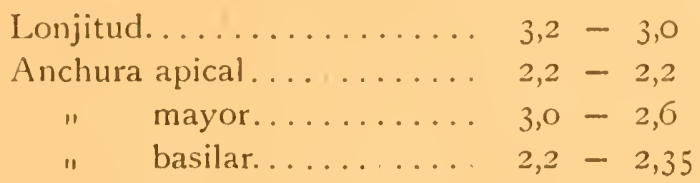

Todas las otras formas pueden ser consicleradas como intermediarias entre estas dos. Es recto en la base i en el ápice. La superficie del dorso es rugosa, i éste lleva en su mitad posterior una línea lonjitudiıal, que no llega nunca completamente hasta ja basc. Esta línea consiste en un surco hundido en la casi totalidad de los machos; miéntras que, en las hembras, se trasfor. ma en una línea aplanada, disimulada debajo de unas pequeñas arrugas trasversales en la mayor parte de los individuos; pero brillante en los demas: siendo meramente lisa en los unos, con forma de una fina costilla en los otros, $i$, en pocos, con esta cos. tilla colocada en un surco.

Esta línea, de la cual tengo hablado co los preliminares de la Seccion A (páj. 15), varia demasiado aquí, para que se pueda sacar ningun carácter fijo de las diversas apariencias que toma. En unos 20 ejemplares que tengo a la vista, solamente un ơ $\mathrm{i}$ una $q$-por ser tal vez los dos tipos que el doctor Philippi turo en manns-presentan las particularidades indicadas por este sabio naturalista: (Stett. Zeit. I860, páj. 251) tergo prothoracis 
in medio in mari carina loeir notats, carina antice obliterata et postice longtrorsum sulcata - carina prothoracis in foemina latiore hand sulcata.

Los elitros presentan una anchura que da mui poco mas de la tercera parte de sulonjitud ( $35 \%$ en un ejemplar oै de 14.0 ); son paralelos, rectos en su base, con el callo humeral redondeado i saliente; en cl ápice estan redondeados en la parte esterna, pero, con mui pocas escepciones, el ángulos sutural está marcado. Son testáceos con la base rojiza. Carecen de la clase de pubescencia que cubre lo demas del cuerpo, la cual está reemplazada por unos pelillos delgados mui escasos con escepcion del ápice. Son brillantes; la base es rugosa, i lo demas está cubierto de una puntuacion fina $\mathrm{i}$ medianamente apretada, pero mas tupida en la estremidad: por lo cual esta parte resulta finamente rugosa $i$ algo opaca. Llevan cada uno dos costillitas lonjitudinales mui angostas $\mathrm{i}$ mas pálidas que no alcanzan al ápice, i tres séries lonjitudinales de puntos apartados i algo mayores, situadas: la $1 .^{a}$ contigua al borde sutural; la $2 .^{a}$ lo es al borde esterno de la primera costilla, i la $3 .^{a}$ al borde interno de la segunda. Ademas, se ve en el medio dos séries trasversales aproximadas de manchitas negras, que desaparecen por completo en la mayor parte de los ejemplares del norte i del centro; i que en los del sur, sobre todo de la provincia de Valdivia,Gr. hifasciatum ( $P h$.) - se dilatan hasta juntarse i formar dos líneas: la anterior angulosa i la posterior oblícua del ápice hácia la base, pero sin alcanzar nunca a la sutura. La dilatacion de estas manchas llega a veces a hacer casi completamente negra la mitad basilar de los elitros.

El prosternon es rugoso, los otros segmentos pectorales i el abdómen son casi lisos i levemente brillantes. La salida del prosternon es aplanada i su anchura da el $75 \%$ de la del mesosternon; la cual es ahorquillada en su estremidad para recibir el ápice del metasternon que está en ángulo agudo.

El episternon metatorácico es triangular, i, en un ejemplar de I6.0, mide una anchura basilar de 0.6 por una lonjitud de 3.2: lo que da una proporcion de $19 \%$.

Los segmentos del abdómen disminuyen gradualmente un poco de lonjitud; i, como en los Hesperofanidos, el 5 está trun. 
cado en el ápice i mas corto que 4 en los machos, miéntras que, en las hembras, es de igual lonjitud i redondeado en su ápice.

Las ancas anteriores llevan en su parte posterior una carena lonjitudinal algo flexuosa, angosta, cortante i mui visible.

El fémur intermediario presenta las proporciones siguientes en un macho de I4.O:

Lonjitud del cuerpo.......... I 4.0

" del fémur intermediario... 4.5

Proporcion de ésta con aquella.... $32 \%$

Anchura basilar de éste........ 0.25

" de su parte dilatada...... 0.9

Proporcion de aquella con esta.... $28 \%$

" de esta con la lonjitud. . $20 \%$

En el macho, el fémur posterior alcanza a la $4 .^{a}$ sutura abdominal, o la pasa levemente; en la hembra, alcanza a la $3{ }^{a}$, o la pasa levemente.

En los tarsos posteriores, el artículo I iguala en lonjitud 2,3 juntos-midiendo éstos desde la base del 2 hasta la estremidad de los lóbulos del 3 - i tambien el $44^{\circ}$, medido desde su nudo basilar hasta la base de los ganchos.

Iámina II, I0.a: barba, lengiieta i palpo labial.-Aum. 20 diám. 10. ${ }^{\mathrm{b}}$ : lengiieta vista por su cara interna............. " " Iо.c: palpo maxilur........... " ", 10.': fémur intermediario de un th de $14.0 \ldots \ldots \ldots \ldots$.

\section{LIVIDA.-(mihi)}

Parum elongata, subdepressa, obscure testacea, brevissime et tenuissime pubescens. Capite opaco, tenuiter rugosulo it stria angusta longitrorsum impresso; fronte transierse clecata, in medio depressit. Antennis corpore apud mares longioribus, apud foeminas subuequalibus: articuln tertiolongiore. Prothorace opace. den. 
se mugnse punctato, lateribus in medio utrinque tuberculo depresso ornatis; dorso antice leviter bicalloso, et in dimidio postico linea breai longitrorsuin notato. Elytris subnitidis, punctatis, ad apicem fere loevigatis, utrinque lineis angustis duabus ad apicem alihreatiatis wix conspicue ornatis; apice separatim perfecte rotundatis, Metastemo abdomineque subnitidis et locvigatis. Femoribus in dimitio basali tenuissimis et in dimidio apicali abrupte cluvatis.

1 , Long. 11.5; lat. 2,7 .

Esta especic, de la cual tenemos solamente un macho i una hembra, fué hallada por mí en las selvas de la Cordillera de Tolhnaca, sacudiendo unas ramas secas de Araucaria imbricata.

Es de un testáceo oscuro, i como ahumado sobre la cabeza i el protórax; es medianamente alargada $\mathrm{i}$ algo deprimida, $\mathrm{i}$ sus tegumentos son notables por su poca consistencia; de lo cual resulta que la parte apical de los clitros, i sobre todo el abdómen, se deforman al desecarse. Todo el insecto cstá cubicrto de una pubescencia mui corta, mui fina i poco abundante; es levemente mas gruesa i oblícua en los elitros sin inezcla de otros pelos, $\mathrm{i}$ algo mas larga, pero tendida en el metasternon $\mathrm{i}$ el abdómen. A pesar de esta pubescencia, presenta un leve brillo, conl escepcion de la cabeza i del protórax.

Lá cabeza es finamente rugosa, i lleva una pequeña estría en toda su lonjitud: la frente está hinchada de cada lado, lo que hace aparecer el medio algo cóncavo, resultando entre las bascs de las antenas una parte elevada pero corta, la cual se halla separada del epistomio, que es deprimido, por un surco trasversal.

Los ojos son salientes, pero poco desarrollados; el lóbulo anterior está truncarlo adelante, i pasa levemente la cavidar cotiInídea, la cual es profundanente escotada. Los carrillos son mui cortos, i la línea ocular pasa por el medio de la cavidad cotilníclea.

Distancia entre las cavidades cotiloídeas... 0.8 " " los ojos en el vertex...... 0.7 
Distancia entre los ojos en la frente....... 1.1

" " 11 la grarganta.... 0.9

\begin{tabular}{|c|c|c|c|c|}
\hline \multirow{2}{*}{\multicolumn{2}{|c|}{ Antenas: lonjitud de los artículos.... }} & & ot & q \\
\hline & & 1 & 1.2 & I. I \\
\hline & & 2 & 0.3 & 0.3 \\
\hline & & 3 & 2.0 & 1.6 \\
\hline & & 4 & I. 5 & 1.2 \\
\hline & & 5 & 1.7 & I. 4 \\
\hline & & 6 & 1.5 & 1.3 \\
\hline & & 7 & I. 6 & 1.3 \\
\hline & & 8 & I. 2 & 1.0 \\
\hline & & 9 & I. 3 & 1.0 \\
\hline & & 10 & I.I & 0.8 \\
\hline & & II & $\mathrm{I} .4$ & 0.8 \\
\hline 11 & lonjitud total . . . . . . . . . & $\ldots$ & 14.8 & I $\mathrm{J} . \mathrm{S}$ \\
\hline$"$ & " del cuerpo ......... & . & II.5 & 12.0 \\
\hline
\end{tabular}

Barba mui redondeada lateralmente.

rengïeta profundamente bilobulada adelante, con su parte central i un ramal triangular que alcanza al medio de cada lí. bulo córnens; estos son membranosos, mui levemente pubescentes, dos veces tan largos como anchos, redondeados en el ápice, anchamentc arqueados en su borde interno, i separados por un seno en ángulo agudn. Los artículos $\mathrm{I}, 2$ de sus palpos son igua. les de tamaño, i la lonjitud de ámbos juntos iguala la del 3 (0.24): la anchura (O. I 3 ) de este último da el $54 \%$ ole su lonjitud: el truncamicnto apical es oblícuo.

Los lóbulos de las quijadas son cortos; el esterno es de ${ }_{3}$ mas angosto que el interno: ámbus son peludos solamente en su ápice. El pulpo maxilar es do: veces tan largo como el labial; el artículo I lleva un profundo seno en su parte basilar-esterna, su inayor anchura es de $1 / 3$ menor que la de los dos iiguientes, i su lonjitud hace un poco mas de la mitad de la del 3: la del 3 es mas o ménos de $1 /$ menor que la del 2 , i la del 2 da pocu mas de los $2 / 3$ de la del 4; la anchura de éste hace la mitad de su Ionjitud, el truncamiento es mui oblícun. 
El protórax no presenta variaciuncs sexuales. En el macho lleva las proporciones siguientes:

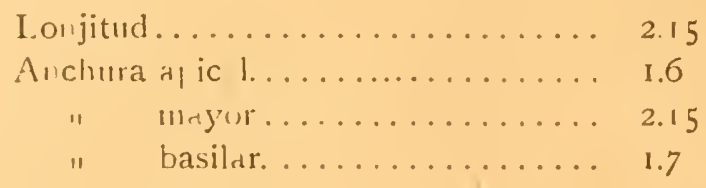

Lleva una puntuacion gruesa i rugusa, $i$, en medio de los costados, un callo redondo proco saliente; en el $1 / 3$ anterior del dorso se notan otros dos callos pequeños i brillantes dispuestos trasver-alm nt, i, cn la mitad posteri r, a! arece $1_{\text {n }}$ pequeña línea Innjitudina! Aplanada $i$ lisa de la expecie antioior.

Los elitros ticnen una anchura que cla el $34 \%$ de la lonjitud; son rectus en su biae, con el callo humeral saliente, i cadi uno está perfectanence rudord, en $\leq$ u ipice. Su superfi ie está cubierta de uni puntuacjon densa, pe ro un poco burrada en el á ice; l mismo que (io). finisimá co-ti las lonj tud na'cs po: o

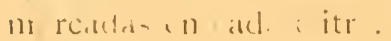

El prosternon i ci mesustemo" son mpacos i finamente rug sos; la sal da cle aqué es mui anno ta, enteradi entr. las anca i no alcanzer a silir er tre llas preteri ru ente; la del último es convexa en el medio, de anchur norma! i ahorquilada en el ápice.

Metastemon $\mathrm{i}$ abdomen liso: $\mathrm{i}$ b illantes. Episternon metatorácico triansular, con una anchura basilar $(0,5)$ que da los $22 \%$ de la lonjitud $(2,3)$.

El abdúmen tiene sus segmentos mas o ménos de igual lonjitud, i es notablemente blando, por lo cual pierde su forma al desecarsc.

Las caridades cotilohileas de las ancas anteriores son abiertas posteriormente, i las de las intermediarias lo son lateralmente.

Los fémures, en su mitad basilar, son mui delgados i casi sin engrosarse hasta la mitad apical; donde estan bru^camente dilatados en furma de ma\%a, con la mayor anchura en medio de su lonjitud.

\begin{tabular}{|c|c|c|}
\hline & $\delta$ & $q$ \\
\hline Ionjitud del cuerpo.............. & I 1.5 & I 2.0 \\
\hline " del fémur intermediario... . & 3.6 & 3.2 \\
\hline
\end{tabular}


Proporcion de ésta con aquella..... $31 \% \quad 27 \%$

Anchura de éste en la base...... . $0.28 \quad 0.22$

$\begin{array}{llll}11 & \text { " prrte dilatada. } & 0.88 & 0.66\end{array}$

Proporcion de aquella con ésta..... $32 \% \quad 33 \%$ de ésta con la lonjitud... $24 \% \quad 21 \%$

En cl ơ el fémur posterior alcanza a la estremidad del abdómen, i en la $q$ solamente a la $3 .^{2}$ sutura.

En el turso postcrior, el artículo 1 es de $\frac{1}{10}$ mas largo que 2,3 juntos.

Lacordaire, cn su Genera, habla con frecuencia de fémures pedunculados, i este modo de cipresarse parece jeneralmente admitidu; sin cmbargo, habria sido preciso esplicar lo que se entiende por esta palabra. P'ues, por mi parte, dándole el verdadero sentido que le corre-ponde, he comprendido que el tal pedínculo era representado por el trocánter; el cual, mas o ménos desarrollado, separa mas o ménos la estremilad del fémur de su anca. i es así que lo indico en los preliminares de la Seccion A de la subfamilia de los Cerambic dos (páj. I6); pero parece que, por otra parte, estoi en cl error mas grande, i que un fémur pedunculado significa un fémur, cuya parte basilar tiene la figura de un pedúnculo sobre una estension mas o ménos grande.

Para no crear confusiones, es preci-o jeneralınente, i sobre todo en entomolojía, no quitar a las palabras su sentido real, para poner otro al antojo del autor. Un pedúnculo sirve para sostener una cosa, sin lo cual ésta seria sésil; pero no hace nunca parte integrante de ella: el pidúnculo de la flor puede separarse de ella, i la flor que la cntera; miéntras que si el pedúnculo de un fémur, con el sentido qu- le dan Lacurdaire i otros entomólogros, fuese scparado del fémur, quedaria solamente la mitad de este último.

Lo repitu: esta palabra está mal empleada, i es preciso buscar otra que no se preste a equivocui; cumo seria, for ejemplo, decir que la base de un fémur tiene firura de pedinculo.

Lám. I I, fig. I Ia: Barba, lengieieta i palpo labial.-Aum. 20 diám. Lám. II, 11. b: quijada i palpo maxalar. - Aum. 20 diaur. 


\section{PALLIDICORNIS (Faim. i Germ.)}

Parum elongata, glabra, nitida, picea vel castanea, aut rufo brunnea; ore, antennis pedibusque fulvis. 'apite pario, opaco, ruguloso; antennis in utroque sexu corpore leviter longioribus, subtus ad basim parce ciliatis, articulo tertio alteris leviter longiore. Prothorace elongato. basi angustiore, opaco, inordinate punctato et inaequali. Scutello rotundato dense pallide pubescente. Elytris fascia lata eburnea ante medium pictis, apice late fulvis et separatim rotundatis; dorso punctis grossis subseriatis, ad basim densioribus, in timidio apicali omnino luturatis, impresso. Prosterno mesostemoque opacis et grisse punctatis. Metasterno abdomineque laerigatis et nitidis. Episterno metathoracico, angusto, lateribus parallelis. Pedibus gracilibus; femoribus in dimidio basali tenuissimis et cylindricis, in dimidio apicali subabmpte clavatis.

Long. 11,0.-8,0; lat. 2,9.-2.0.

Esta especie =e encuentra en toda la zona central de Chile, pero parece poco abundante. Es notablementc ménos alargada que las especies que le doi por compañeras en este trabajo; i mi colaborador Fairmaire, despues de darla como elongata (corps allongé) en su descripcion (Rev. Zool. I86t, páj. 387), hace mui bien en correjir estos calificativos, diciendo que se aparta del jénero Ibidion, en el cual la coloci, por sus elitros mas cortos.

Es glabro i brillante, i su matiz jeneral varia desde un negro de pez hasta un castaño rojizo, con la boca, las antenas i las patas leonadas.

Las mismas diferencias sexuales indicadas para las otras es. pecies de esta seccion se reproducen mas o ménos cn esta; pero de una manera tan poco notable que es dificil constatar algunas de ellas.

La cabeza es pequeña, opaca i cubierta de una puntuacion rugosa mui apretada; la frente es trasversalmente convexa entre las antenas, poco deprimida en el medio, i separada del epistomin, que es corto, por un suren recto.

Los ojos son poco desarrollados; sin embargo, el lóbulo anterior pasá un poco adelante del cóndilo antunario, e invade casi 
completamente los carrillos. La línea ocular atraviesa las cavidades cotiloideas en su parte esterna.

Distancias entre las cavidades cotiloídeas. .... 0.85

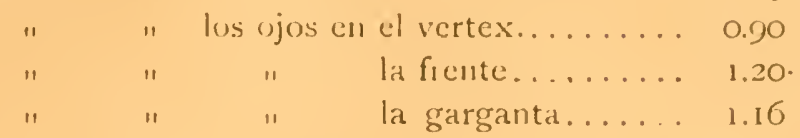

Las antenus llevan algunos pelillos apartados en la parte inferior de sus cinco o seis primeros articulos; $i$, como se ve en el cuadro siguiente, su lonjitud proprorcional que presenta en jeneral tan buenos caractéres para reconocer lns sexos, ofrecc aquí mui pocas diferencias entre ellas; sin embargo, es de notar que los tres o cuatro artículos últimos son un poco ensanchados $\mathrm{i}$ deprimidos en el macho, con el ángulo apical esterno algo dentiforme.

\begin{tabular}{|c|c|c|c|c|}
\hline \multirow{2}{*}{ Lonjitud de los artículos....... } & & $\uparrow$ & $\delta$ & $\uparrow$ \\
\hline & I & 1.2 & 0.9 & I. I \\
\hline & 2 & 0.28 & 0.2 & 0.2 \\
\hline & 3 & 1.66 & 1.3 & 1.5 \\
\hline & 4 & I. 5 & 1.2 & 1.3 \\
\hline & 5 & 1.6 & 1.2 & 1.3 \\
\hline & 6 & 1.56 & I. 16 & 1.3 \\
\hline & 7 & 1.46 & I. 16 & 1.26 \\
\hline & S & 1.36 & 1.0 & I. 16 \\
\hline & 9 & 1.3 & 0.96 & I. 16 \\
\hline & 10 & 1.2 & 0.9 & 1.0 \\
\hline & I I & 1.2 & 0.9 & 1.0 \\
\hline de la antena total.... & . & 14.32 & 10.88 & 12.28 \\
\hline del cuerpo........... & . & I 1.0 & S & 10.0 \\
\hline
\end{tabular}

Barba brevemente redondeada en su mitad basilar, i oblicua en la apical.

Lcngïeta membranosa, con su centro córnco, dividida ante. riormente, por un sem, cn ángulo levemente agudo, en dos lóbulos membranoso-, dus veces tan largos como anchos i redon- 
dos en su ápice. Sus palpos dan el $70 \%$ de la lonjitud de los maxilares. Los artículos 1,2 son iguales entre $s$, , juntos, lo son con el 3 ; la anchura de este último hace la $1 / 2$ de su lonjitud.

El lóbulo esterno de las quijadas es apénas tan ancho como el interno; este está cortado oblícuamente en su ápice, donde solamente es peludo, asi como el esterno. El artículo I de sus palpus es mui corto i sinuado en su parte esterna; el 3 da los ; del 2; i el 2 da apénas los $\frac{3}{4}$ del líltimo: la anchura de éste hace cerca del $60 \%$ de su lonjitud.

En el último artículo de ámbos palpos, la parte interna del truncamiento es notablemente redondeada.

El protórax es opaco, un poco mas largo que ancho; i los costados, que son Easi paralelos en los $\frac{2}{5} 0 \frac{3}{5}$ anteriores, son, despues, levemente couverjentes hacia la base. Sus proporciones son las siguientes en un macho de I I.O:

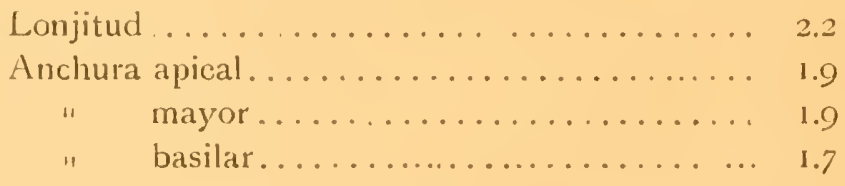

El dorso está cubierto de gruesos puntos un poco irregularmente aglomerados; i es levemente desigual con motivo de unos vagos rudimentos de calloridades, cuyas mas urstables son en jeneral: un pequeñísimo tubcrculillo en el $1 / 3$ anterior de los contados, i una líned lonjitudinal lisa, con frecuencia reducida a una pequeña paste de la mitad basilar.

El escudo es redundo i cubierto de una pubescencia pálicla fina i tendida.

Los éliros son cortos en comparacion de los de las otras especies; pues, su anchura (29), tomada a o.S de la base en un ejemplar de 11.0 de lonjitud total, da el $36 \%$ de su lonj tud (8.o). l'reientan matices que, por su variabilidad, pucden cansar algunos errores; pues, son del crolor del cucrpo, es decir de un neçro de pez pasando a un castaño mas o ménos rojizo, en el sesto basilar, i en uns? faja angosta situada despues de una anche faja de un blanco de inarfil, que termina un poco mas allá 
del medio, formando sobre la sutura un cungulo mui obtuso dirijido hácia el ápice; este último es lennado sobre la tercera parte de la lonjitud del elitm. La segrunda faja morena varia mucho en furma c importancia: pasando primero al cstáco de (los manchas de tamaîo i de forma mui instables, que no alcallan a la sutura, $i$ borrándose poco a poco hasta desaparecer por completo en los individuni mas púlidos; en éstos la faja basilar llega tambien a ser meramente rojiza, o mas pálida aun, i la parte lconadd del ápice palidece hasta confundirse con la faja blanca.

En cstc caso, el insecto cambia tanto de aspecto, que los entomólogos, que se fijan demasiado cn los caractéres engañosos suministrados por la coloracion, se ven espuestos a hacer cspecies con meras variedades. E; lo que sucedió a Fairmairc, cuando, con esta variedad, hi\%o nuestro Grammicosum semipolitum (Soc. ent. Fr. 1850, p. 508).

En cuanto a In demas, que mi colaborador dice del tipo ( Rev. Zool. 1864, páj. 387), haré las rectificacioncs siguientes:

En la diagnósis latina se lee: elytris basi nugosis, medio valde punctatis, postice fere laevibus.n i en la descripcion en frances: "elytres convertes ì la base de gros points en lignes assez régulicires, qui diminuent peu ì peu et se perdent après le milien, le dernier tiers ctant presque complétement lisse.. Todo ento presenta varias inesactitudes:

I. ${ }^{\circ}$ No hai ninguna apariencia de rugosidades en ninguna parte.

2. ${ }^{\circ}$ Los puntos son gruesos, pero de igual tamaño; i si, por una parte, son mas apretados sobre la faja morena basilar, por la otra, se distribuyen en líuess irregulares sobre la faja blanca.

3." Ni uno de esto; puntos p.sa mas allá de está última, es decir, que la segunda faja morena i la parte leonada del ápice son perfectanente lisos.

En cuanto a la frisma jeneral de loi elitros, diré tambicu que lo que sc lee en la descii,ncion franceva: "elyetres it ipanles ben marquées, presque paralides à la base, s'ílargissant un peu après la milieu, plus conive ves de l'extremitén... ncce-ita algunas correcciones.

6. El angulo humeral, aunque recto, es menos saliente que 
en las especies vecinas, i bastante redoncleado, para que, cuan. do tuve que fijar la anchura basilar, me haya sido preciso medirla a 0.8 de lá base en el ejemplar de i I.o.

2." Es cierto que, en la parte blanca, los elitros sufren un mui leve encojimiento, que se hace mas visible, con motivo de una mui leve dilatacion situada frente a la segunda faja morena; pero se tr،ta aquí de diferencias que quedan entre la 14 . $^{\mathrm{a}} \mathrm{i}$ la I 5. ${ }^{\mathrm{a}}$ parte de la anchura, es decir, que pueden espresarse por un decimilímetro en ménos en aquél, i en mas en esta última; i agregaré que, si la última es mas aparente, esto provicne de que, casi siempre desde la basc, Ios elitros se apartan uno de otro en la sutura al secarse. En los ejemplares donde sus bordes suturales quedan en contacto, la tal dilatacion no se puede apreciar sin el socorro de un micrómetro.

3. ${ }^{\circ}$ La convexidad posterior no tiene nada de anormal, por ser meramente el resultado de la forma jeneral.

Cada elitro está redondeado separadamente en su ápice.

El prosternon i el mesosternon son opacos i marcados de gruesos puntos dispersos. La salida del primero se angosta entre las ancas hasta casi perderse de vista en algunos individuos; pero, al nivel de su borde posterior, se dilata hasta formar una pequeña parte triangular. La salida del segundo es mas o ménos de la anchura de la base de los fémures.

Las cavidades cotiloideas de las ancas anteriores están abiertas posteriormente; i las de las intermediarias lo son un poco esteriormente.

El metasternon $\mathrm{i}$ el abdómen son lisos i brillantes. El episternon metatorácico es angosto i paralelo en toda su estension; su anchura (0.25) da el I $\left.5^{\circ}\right|_{0}$ de su lonjitud (

Los segmentos abdominales disminuyen levemente i gradualmente de lonjitud del $1 .{ }^{\circ}$ al $4 .^{\circ}$.

Las patas son delgadas i alargadas. Los fímures tienen su mitad basilar mui angosta i f́liforme, i la apical ensanchada casi bruscamente en forma de maza ovalada.

\begin{tabular}{|c|c|}
\hline & ๘ \\
\hline Lonjitud del cuerpo................ & I I.O \\
\hline " del fémur intermediario..... & 3.6 \\
\hline Proporcious de ésta con aquélla...... & $33^{\circ} \cdot 0$ \\
\hline
\end{tabular}


Anchura basilar dc este........... $0.18 \quad 0.16$

" de la parte dilatadia....... $0.76 \quad 0.64$

Proporcion de aquélla con ésta. ,.... 24" o 25"i"

" de ésta con la lonjitud.... $2 I^{\prime \prime} \%$ 19",

El fémur posterior alcanza casi a la estremidad del abdómen en los machos, $i$ a la $4 .^{a}$ sutura en las hembras.

El artículo I de los tarsos posteriores es apénas mas largo que 2,3 juntos.

Lám. II, fig. 12.a: barba, lengiileta i palpolabial. - Aum. 20 diám.

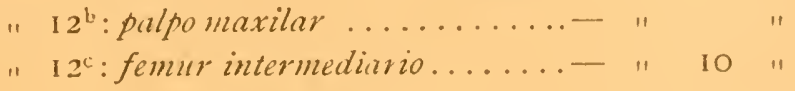

\section{LUNATA (mihi)}

Modice elongata ac depressa, glabra, subnitida, nufa. Capite dense rugoso-punctato, antice abbreviato; fronte transierse convexa, in medio longitrorsum anguste sulcata; oculis prominulis; antennis apud mares corpore longioribus, basi subtus aix ciliatis; articulis $I, 2$ punctatis, nitidiusculis, alteris tenuiter mosulis, tenuissime alutaceis et brevissime velutinis, articulis $3,+$ subaequalibus, sequentibus brevioribus et latioribus. Prothorace fere quadrato postice vix conspicue angustiore, torso inaequali, calloso et punctis grossis inordinate impresso, lateribus tuberculo parvo depresso ornatis. Scutello subrotundato pallicie pubcscente. Elytris subdepressis et fere parallelis; Inmeris rotundatis; apice separatim arcuatis; nitidissimis, nigris, ante medium plaga communi rotundata pallide testacca pictis, in dimidio basali punctis pirrits fere seriatis lave impressis, in dimidio apicali loevissimis. Prosterno mesos. ternoque punctatis. Metasterno inflato, vix punctulato, in medo longitrorsum late sulcato. Abdomine loerigato, segmentis vix aequalibus. Femoribus laxe pilosis, basi angustis, ad apicen gradatum parumque dilatatis.

Long. 10.5; lat. 2.7.

Cunozco de esta especie solu un ejemplar, unue es macho i per- 
tenece a la coleccion Oyarzun; fué capturado volando al anochecer en las Termas de Chillan.

Este insecto es inedianamente alargado, deprimido, glabro, briilante sobre todo en los elitros, i de un rojo castaño mas leonado sobre las antenas $i$ las patas.

La cabeza es levemente opaca, cubierta de una espesa puntuacion rugosa, i mui acortada por delante. La frente es algo le. vantada trasversalmente, pero un poco rcbajada en el medio, el cual lleva un fino surco lonjitudinal; el surco trasversal, que suele separar adelante aquella parte levantada del epistomio, pone aquí meramente término a la frente, por ser éste sumamente corto i trasversal.

Los ojos son bien desarrollados i salientes; el lóbulo anterior es redondeado por delante i pasa al cóndilo antenario, invadiendo casi completamente los carrillos. La línea ocular atraviesa la cavidad cotiloídea, la cual es anchamente pero poco profundamente escotada.

Distancia entre las cavidades cotiloídeas...., . 0.8

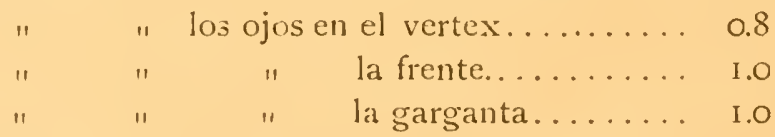

Las antenas, con escepcion de los dos primeros artículos que son brillantes i punteados, son opacas, llevan finas rugosidades i una densa granulacion mas fina aun i solamente visible al $\mathrm{mi}$ croscopio, i estan cubicrtas de una espesa pubescencia aterciopelada; cn la parte apical estan un p:oco deprimidas; i en la basilar, llevan por debajo solamente unos pocos pelilios; los artículos 3, 4 son casi iguales de lonjitud i de anchura: aquella es mui infurior a la de los artículıs siguientes, i la última es casi igual con la del 1 .

$\begin{array}{llll} & & & \begin{array}{c}\text { mayor } \\ \text { anchura }\end{array} \\ \text { Lonjitud de los artículos. } & \text { I } & 1.0 & 038 \\ & 2 & 0.3 & \\ 3 & 1.0 & 037 \\ 4 & 1.1 & 0.36 \\ & 5 & 1.5 & 0.28\end{array}$




\section{mayor}

anchurat

$\begin{array}{rrr}\text { Lonjitud de los artículos. } & 6 & 1.5 \\ 7 & 1.6 \\ 8 & 1.5 \\ 9 & 1.6 \\ 10 & 1.44 \\ & \text { II } & 1.56 \\ & \\ & \\ \text { Lonjitud total de la antena } & \text { 14.10 } \\ \text { "del cuerpo....... } & \text { 10. } 5\end{array}$

Los costados de la harba son oblícuos en la mitad basilar i la mitad apical; pero aquélla es anchamente cscotada i la última es recta: de lo cual resulta en el medio un ángulo obtuso brevementc redondeado.

La lengücta es mas o ménos córnca en su parte posterior; pero su parte antcrior cstá dividida cn dos lóbulos enteramente membranosos por un seno en ángulo agudo. Estos lóbulos son ovalidos, con una anchura que hace mas do la mitad de la lonjitud, su ápice está reclondearo, i su parte interna es pcluda. La lonjitud de sus pulpos (0 62) hace poco mas de los $\frac{3}{5}$ de la de los maxilares (1.O). El artículo I está inserto adelante del fondo del seno anterior, i alcanza casi al ápice del lóbulo; es un poco mas corto i mas angosto que 2 , i ámbos juntos dan los de la lonjitud del 3 . Este ticne una anchura que da los 3 de su Innjitud; su truncamiento es oblícuo i anchamente arqueado.

- El lóbulo esterno de las quijadas es corto, cuadrado i mas ancho que el interno. El artículo I de los palpos da los $\frac{3}{5}$ del 2 , que es poco mas o ménos de la lonjitud i de la anchura del 3 ; el 4 da el 85 de los tres primerns juntos; su anchura da el $46 \%$ de su lonjitud; su truncamiento es anchamente arqueado i mui oblicuo, resultando que el costado interno da solamente los $\frac{2}{5}$ del esterno.

Las mandibulas son cortas, brevemente arqueadas i mui puntiagudas; en el medio del borde interno hai un diente cuadrado que resulta de una escotadura de la parte basilar. 
El protórax presenta las medidas siguientes:

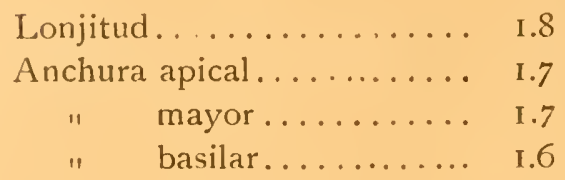

Mui cerca de la base se ve un angostamiento a modo de ancho surco; está enteramente cubierto de una gruesa puntuacion aglomerada irregularmente; los lados llevan en su medio un pequeño tubérculo deprimido; en medio de varias desigualdades, se notan en el dorso dos pequeñas callosidades dispuestas trasversalmente en el tercio anterior, $\mathrm{i}$, tras de ellas, una línea lonjitudina! corta, !isa, pero con una fina estría en el medio.

$\mathrm{El}$ escudo es ovalado i cubierto de una fina pubescencia mui tendida.

Los elitros son levemente deprimidos, mui brillantes i negros, con una mancha redonda mui pálida situada sobre la sutura, pero cuyo borde posterior alcanza apénas al medio de la lonjitud. Su anchura (2.7) da el $34 \%$ de su lonjitud (7.5). Los hombros son cuadrados pero mui redondeados, con el callo humeral no saliente. Los costados son mas o ménos paralelos, con el ápice redondeado separadamente; el borde marjinal i el sutural estan ribeteados por una fina costilla. El dorso lleva unos puntos poco apretados, algo menores que los del protórax, que no son mas numerosos en la base, se disponen un poco en série al llegar al medio, i son completamente borrados despues.

El prosternon i el mesosternon son puntuados, sus salidas estan ribeteadas, pero la de aquél es mui angosta: i se reduce casi a nada en el medio de las ancas; la del último es paralela, i su anchura es menor que la de la base de los fémures.

El metasternon lleva una puntuacion fina i mui escasa, es hinchado i notablemente mas saliente que el abdómen; está anchamente acanalado en el medio. Su episternon tiene la forma de un largo triángulo mui regular, cuya mayor anchura (0.4) hace el $20 \%$ de la lonjitud (2.I).

El abdómen es liso, con sus segmentos casi iguales

Los fémures son mui delgados en la base, pero van ensan- 
chándose algo gradualmente hasta la mitad anterior, que está medianamente dilatada; la mayor anchura de esta dilatacion está en el tercio apical.

\begin{tabular}{|c|c|}
\hline Lonjitud del cuerpo ............ & 10.5 \\
\hline fémur intermecliario.... & 3.2 \\
\hline Proporcion entre ésta i aquélla.... . & $30 \%$ \\
\hline Anchura basilar de éste.......... & \\
\hline de la parte dilatada & 0.7 \\
\hline Proporcion de aquélla con ést & . \\
\hline
\end{tabular}

El fémur posterior alcanza a la $44^{\text {a }}$ sutura abdominal.

El primer artículo del tarso posterior está solamente igual a 2,3 juntos.

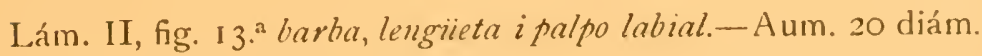

$"$

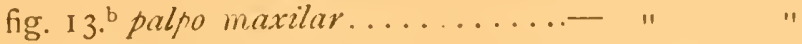

11

fig. 13 . $^{\mathrm{c}}$ mandibula $z$ zquierda.......- " " "

\section{G. DRASCALIA-(Fairm.)}

El insecto para el cual Fairmairc ha creado este jénero (Rev. Zool. $1864, p .387$ ), no deja, como lo dicc mui bien, descubrir fácilmente el lugar de la familia de los I onjicornios, al cual sus afinidades le dan derecho.

Diré, en primer lugar, que Gemminger i Harold, al colocar en su Catálogo el jénero Drascalia en la subfamilia de los Lamiidos, han dado un paso que nada me parece justificar; este insecto pertenece, sin duda alguna, a la subfamilia de los Cerambicidos: tanto por no tener la frente vertical, cuanto por la forma triangular del último artículo de sus palpos, i por carecer de surco en el lado interno de las tibias anteriores.

Esta opinion ha sido tambien la de Fairmaire; pero no creo, como él, que cste insecto pertenezca a la agrupacion de los Cerambicidos, i es de sentir que mi distinguido colaborador no haya dado los motivos de este inodo de ver. La semejanza pal- 


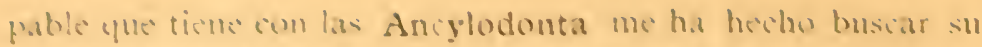

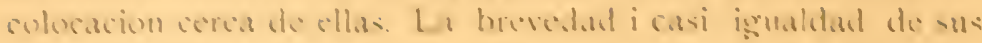

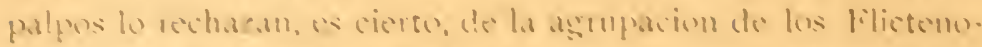

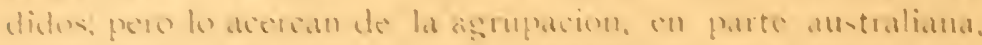

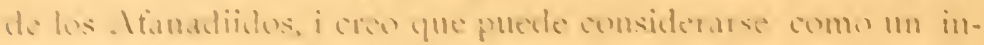
termediario entre estas dws agrupaciones.

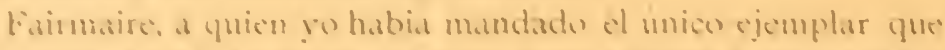
estmiese entonces en mi froder, mo se atrevis a despedarar

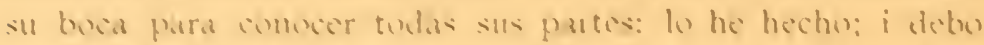

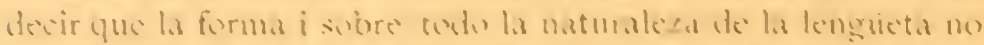

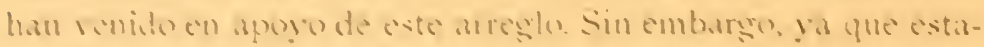

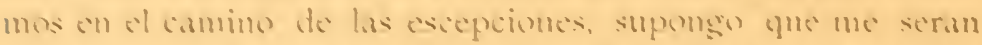

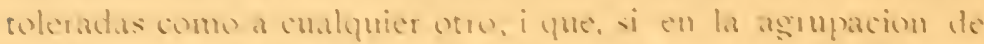

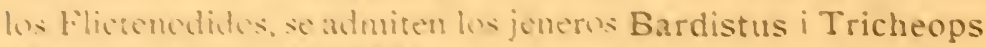

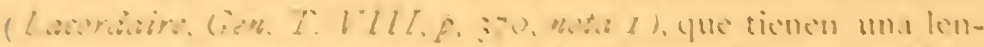

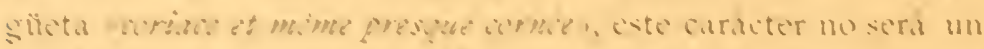

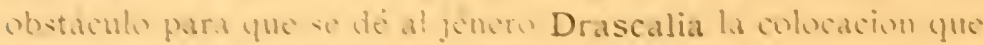

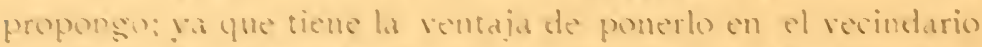

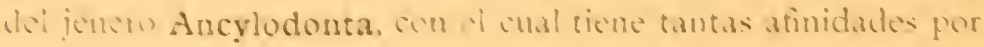
(o) h hemas

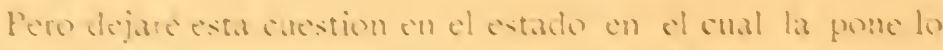

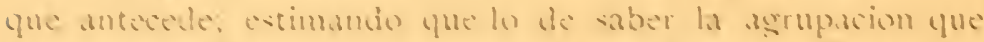

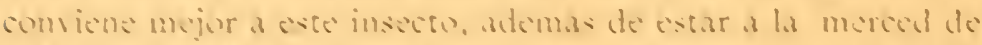

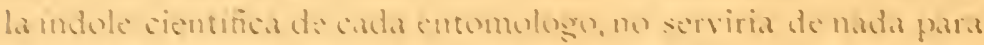

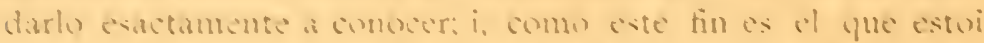
buscamb. me ententare onn completar i rectiticar lo que mi

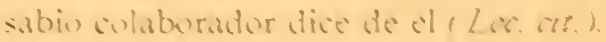

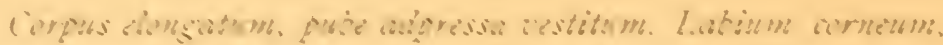

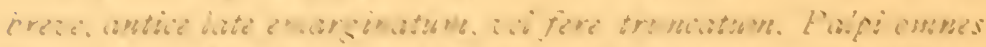

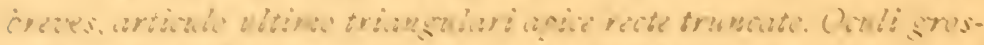

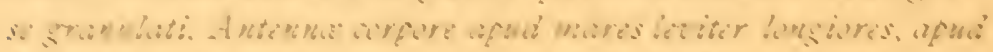

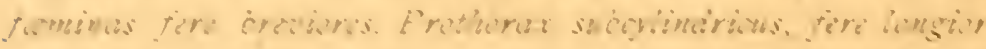

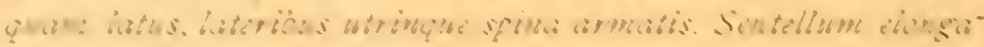

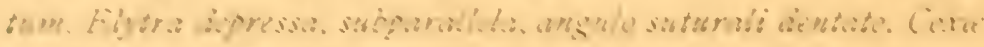

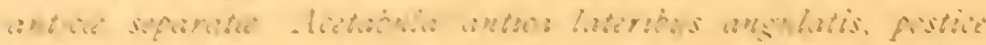

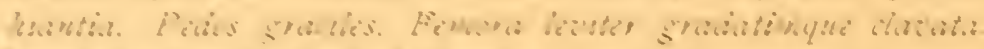

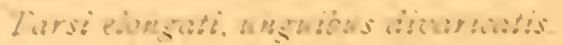




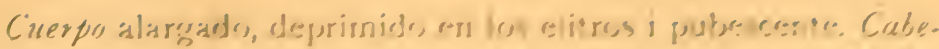

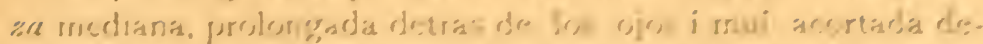

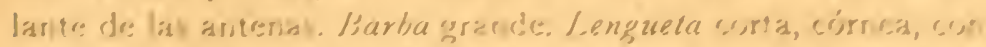

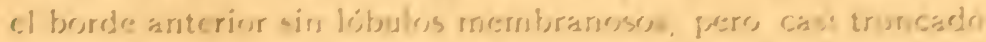

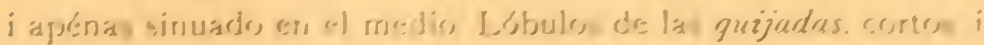
de igual anchura las palpos bon cestes cors el áltimes articuir,

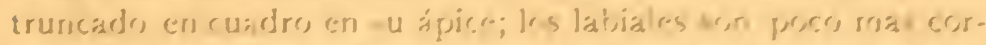
tos que les maxilare. Ojos bien obearebllades, gerue amente

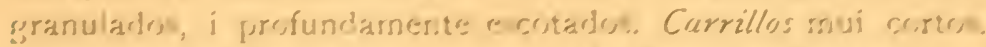
Antenas de la lonjibud de! cuerpors en la herabra, i un jecre rass largas que el en k, maches: le, articules 1,34 ern casi de

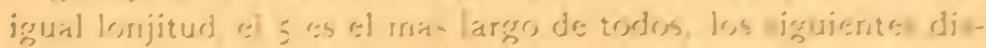
iniriugers : zrardualmeritr.

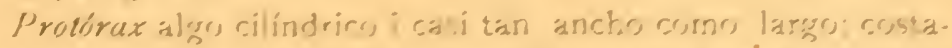
dos con uria fira eppina arqueada hacia atras in vu merliop drerso iarerne.

Escudo alargadr.

Elitros lareges: baes. recta. mas ancha quela del prestiray; son

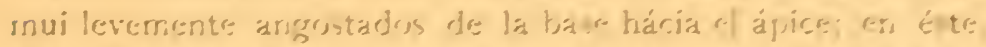
restan separadarnente at"-nuadres $i$ el ángule, surural cs leverrente dentiforme: el pliegue epipleural a mui argostro en la bise i casi enterangente borrade, eri le derna.

I as cavidades cotiloirleas de las ancas anteriores estan abirertas laterainonte, i falta muche, para que sean casi compiete merite cerradas proterirermente. (Jazrm les cit.). Ias delas ancas irlermerdiarias son tambien abjeria lateralanente La

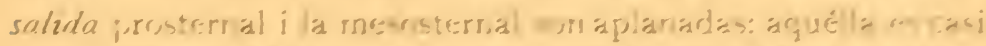

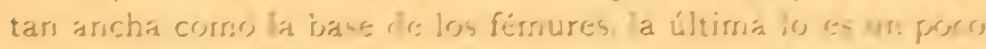

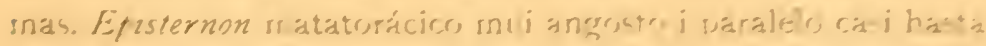
su árjice.

Palns delgardas $i$ alargadas. Ios fimures te envarichan grab dualmente $i$ levernerste de la bace ha:ta rol rnedio de la roitad

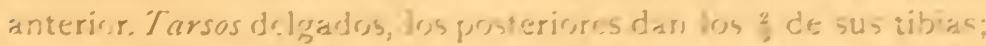
el articules últirnos iguala á les réenre 23 junirs: ganchos tarsalec divericadrs. 


\section{PRALLONGA (Fairm. $i$ G.)}

Obscure brmnea, pube tomentosa adpressa vestita. Capite prothoraceque dense grosseque punctatis, fulvo pubescentibus; hoc linea nigra denudata, pube albidu anguste marginata et in medio interrupta longutrorsum ornato. Scutello elongato, triangulari et linea longitudinali albido-pubesiente notato. Elytris punctis grossis ad apicem minoribus, mpressis; pube albido-grisea fulio variegata et subfasciculata a'estitis, utrmque costis duabus latis longitrorsum ornatis. Pectore abdomineque punctatis.

Long. 14.0; lat. 3.IO.

Este insecto vive en la zona central de Chile, pero parece ser mui escaso. Es enteramente de un castaño oscuru, i cubierto de una pubescencia medio lanosa i tendida, que varía, de un modo irregular, del blanco ceniciento al leonado claro; sobre los elitros i las, patas es mas o ménos vagamente aglomerada en mechones irregulares.

La cabeza i el protórax son densamente puntuados. Aquélla es mui acortada por delante.

Distancia entre los bordes internos de la cavidades cotiloídeas antenarias.................. 0.9

Distancia entre los ojos en el vertex........... 0.7

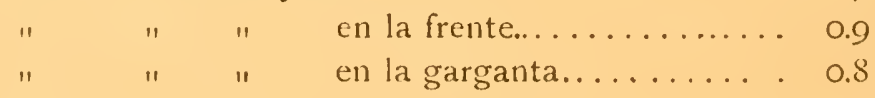

La línea ocular atraviesa las cavidades cotiloídeas. Los tubérculos antenarios son grandes, oblícuos hácia afuera, i separados en su base por un fino surco lonjitudinal.

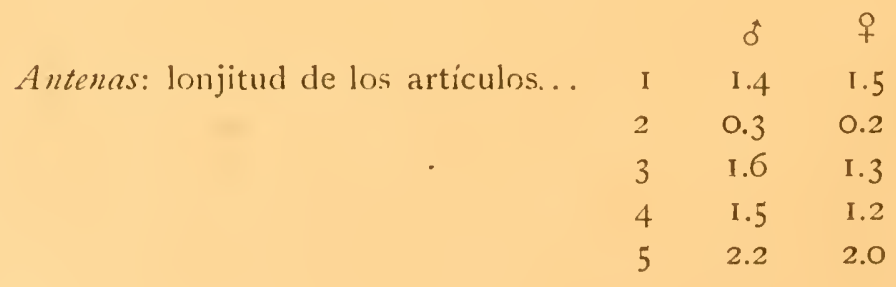




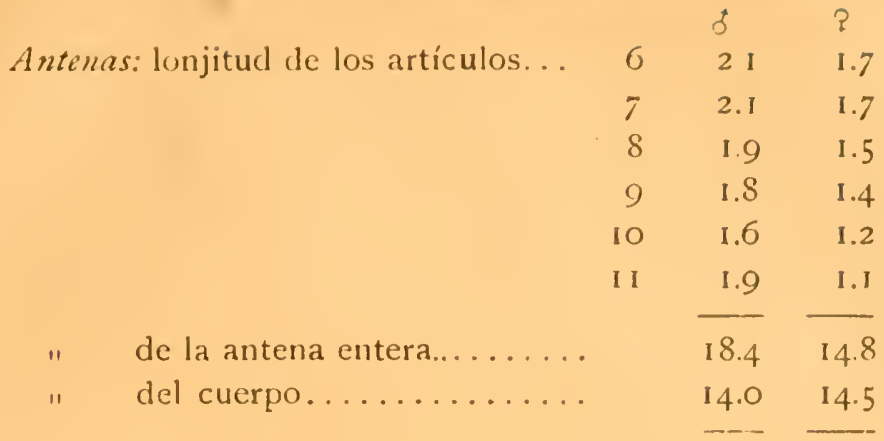

En su base llevan unos pocos pelillos oblícuos en la parte inferior.

La barba tiene sus costados casi circularmente arqueados, i su anchura es mas o ménos doble de su lonjitud. La lonjitud de la lengïeta da la mitad de la de la barba, i su anchura da los $2 / 3$ de la de la misma; su borde anterior es levemente peludo de cada lado. El lóbulo interno de las quijadas está truncado oblícuamente; este truncamiento i la estrcmidad del lóbulo esterno son largamente peludos. La lonjitud de los palpos labiales (0.45) da los $\frac{9}{13}$ de la de los maxilares (0.65). En los labiales el artí-culo a es un poco mas largo i mas ancho que el I, i ámbos juntos son apénas mas largos que el 3 ; la anchura de este último (0.125) da poco mas de la mitad de su lonjitud (0.240). En los maxilares, el artículo I es un poco mas corto i mas angosto que 2 i 3 , los cuales son notablemente iguales, i cuyas lonjitudes juntas esceden apénas la del 4 ; la anchura de este último es algo mayor que la mitad de su lonjitud. Las mandíbulas son cortas, con un diente obtuso en el medio del borde interno.

El protórax tiene las medidas siguientes:

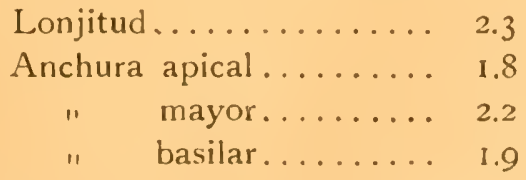

El dorso lleva una línea lonjitudinal negra i lisa, interrumpida en el medio, $i$ orillada por un angosto ribete de pubescencia blanca. 
El escudo tiene la forma de un triángulo alargado, i lleva una línea lonjitudinal de pubescencia blanca.

Los elitros son mas anchos que el protórax; pues la base de este último da solamente los $\frac{3}{5}$ de la de aquéllos, i no la mitad. (Fairmaire, loc. cit.) Están cubiertos de una gruesa puntuacion, un poco menor en cl ápice; i llevan cada uno dos anchas costas lonjitudinales, convexas i poco salientes, que nacen ámbas en el ángulo humeral, pero no alcanzan al ápice; i, miéntras la esterna sigue paralela con el borde marjinal, la interna se dirijc oblícuamente sobre el ángulo apical.

La anchura del episternon metatorácico (0.4) da el I 3 por ciento de su lonjitud (3.0).

Lonjitud del cuerpo............. I 4.0

" del fémur intermediario....... 4.2

Proporcion de ésta con aquella....... 30\%

Anchura basilar de éste. . . . . . . . . 0.3

.$\quad$ de la parte dilatada......... 0.8

Proporcion de aquella con ésta....... 35\%

" de ésta con la lonjitud....... I9\%

Parte inferior del cuerpo puntuada: esta puntuacion mas gruesa en el prosternon i el mesosternon.

Fémures posteriores alcanzando entre la $3 .^{\text {a }} \mathrm{i}$ la $4 .^{\mathrm{a}}$ sutura abdominal.

Lám. II. fig. I4 ; barba, lengüeta ipalpo labial. - Aum. 20 diám. fig. I $4^{\mathrm{b}}$; quijada i palpo maxilar..... " " " "

\section{G. ANCILODONTA (Blanch)}

Los entomólogos están en desacuerdo sobre la cuestion de saber cuál es lo mejor para determinar un insecto ya descrito: o consultar la descripcion que acompaña a su fé dc bautismo, o compararlo con el ejemplar-el tipo-que ha servido para redactar esta descripcion.

Los que no tienen estos tipos a su alcance, dicen que la des- 
cripcion sola ha de valer; pero los que redactan estas descripciones sin hacerlas preceder por un estudio suficiente del insecto, i saben mui bien que la filiacion que dan de él no basta para hacerlo reconocer, pretenden que es preciso acudir a los tipos; los cuales, naturalmente, figuran en su coleccion, i le dan de esta manera un valor comercial que estaria mui léjos de alcanzar sin esto.

Siempre he sido de la opinion de aquéllos.

El tipo, que un descriptor guarda de una especie que describe, lleva, por toda prueba que es bien él i no otro, un rotulito pasado al alfiler que lo tiene clavado. Pero este tipo puede destruirse ... por la polilla, la humedad, un incendio, etc., etc., en los exámenes repetidos a los cuales está condenado, puede suceder que, una vez o la otra. cl rotulito pase de un alfiler a otro; puede acontecer que, a la muerte del autor de una descripcion o aun miéntras vive, el tipo en cuestion sea vendido; i, como hai entomólngos compradores en Yrokohama, Melbourne, San Francisco de California, Valparaiso, el Cabo, etc. ¿qué hace el entomólogo de Lóndres, Paris o Berlin que quiere consultar este tipo para determinar un insecto de su coleccion?. .

Por otra parte, la admision de este sistema tendria por resultado protejer las descripciones hechas sin el estudio suficiente, i con la intencion evidente de llegar primero a dar un nombre a un insecto: trabajos perjudiciales en estremo a la entomolojía, porque es en gran parte a ellos que debe la plaga sinonímica que la invade.

En nuestra coleccion, o en las que tengo a la vista, el j. Ancylodonta está representado por dos especies; i lo que ha succdido con ellas podrá arrojar una luz suficiente sobre esta cuestion, i demostrar cuanto tienen razon los entomólogos, quienes, para determinar un insecto, prefieren la lectura de su descripcion, a la vista del ejemplar que ha servido para redactarla.

Estas dos cspecies son mui homojéneas ell cuanto a sus caractéres jenéricos, con escepcion de las proporciones de los artículos $1,3,4,5$ de las antenas entre si; i felizmente esta diferen. cia es lo que permite distinguirlas fácilmente, i hace descubrir un error notable de que ha sido causa.

En una de ellas, que llegó a mis manos solamente en estos 
últimos años, se podria ver talvez, la $A$.tristis descrita por Blanchard en la obra de Gay (Zool. T. V.p. 494), si no fucra de alguna: diferencias demasiado importantes, para que se puedan considerar como el resultado de unas de estas inexactitudes o deficiencias $\tan$ frecuentes en los trabajos de este sabio entomólogo. Así, dice del protórax que es "brezissimus", miéntras que es a lo ménos tan largo como ancho; da tambien este órgano como encojido adelante i atras, miéntras que su anchura basilar es igual a la del medio; da los elitros como redondeados en su ápice, miéntras que su ángulo sutural es dentiforme o a lo ménos en ángulo recto i puntiagudo; el artículo I de los tarsossin decir cuáles-que da como de una lonjitud igual a la de los dos siguientes juntos, lo pasa en realidad de una sesta parte en los posteriores, que son los que se miden siempre para indicar esta difcrencia; no dice ni una palabra de la granulacion tan particular que cubre los elitros; etc.

En cuanto a la otra, la hallé en Quillota sobre las flores de una Myrtacea hace unos 40 años, i la mandé entónces a mi colaborador L. Fairmaire. Por esto, es, con evidencia, de esta i no de aquella, que este último enticnde hablar, cuando trata de la A. tristis en nuestra Revision des Coleoptères du Chili. (An soc. Ent. Fr. 1859, p. 510); i, por mas prueba de esto, ticne el cuidado de modificar en este sentido cicrtos puntos de la diagnósis de este insecto, que figura en Gay. De lo cual resulta que la especie considerada como !t A.tristis (Blanch.) por Fairmaire, no es la que está descrita bajo este nombre por Blanchard (loc. cit.)

Ahora queda la cuestion de saber si Fairmaire ha descubierto en alguna parte el tipo que se imajina haber servido a Bianchard para su descripcion, i si modifica la diagnósis por no haber encontrado que ésta diese de un modo satisfactorio con aquel.

Yá se ve el enredo al cual se llega, euando un entomólogo tiene la facultad de escojer entre la vista del tipo i la lectura de su descripcion; sobre todo si se trata del trabajo de un naturalista, que a veces describe un insecto bajo un nombre, $i$, bajo el mismo, dibuja otro.

Pero esta confusion tuvo una consecuencia mayor, que es la siguientc: cuando, dic\% años despues (1869), Lacordaire trató la 
parte de su Genera en la cual figura el j. Ancylodonta, es probable que Fairmaire le comunicó los ejemplares de la especie de Quillota, que yo le habia mandado en 1858 ; i esta probabilidad reviste aspecto de certeza. al notar que los caractéres indicados para la única especic que creia existir entónces, son los de la especie de Quillota, i no los de la otra, que solo podria ser la $A$. tristis ( Blanch. in Gay'). Resulta de esto que, cuando I,acordaire quiere caracterizar el j. Ancylodonta, en lugar de dar una copia de lo que dice su creador (in Giry), él le sostituye una diagnósis a su manera, es decir conforme con la especic que tiene en manos i que toma erróncamente por la A. tristis; estableciendo así un jénero Ancylodonta (Lacord.) que no está conforme con el jénero Ancylodonta (Blanch).

La diagnósis siguiente está arreglada de modo a comprender las dos especies.

\section{Corpus elongatum, subdepressum. Caput prothoracis latitudinem} equans, inter antennas concarum. Mentum breve. Labum antice anguste membranaceum et rotundatim sinuatum. Palpi maxillares labialibus duplo longiores; articulo uitimo oblique truncato. Antenna fliformes, corpore apud mares vix longiores, apud fominas breviores. Oculi exserti reniformes, fere transversi, parum profunde smuati. Prothorax longitudine latitudinem cquante; lateribus wirinque in medio uncinatis; tergo antice bituberculato. Scutellum trangulare. Elytra basi tuncata; angulo humerali calloso. Pales gracales, parmm elongati; femoribus gradatim leviter dilatatis; titiils anticis flenuosis; tarsis posticis artuculo I." duobus sequentibus junctis longiore; mngnibus divergentibus. Coxu anticoe extus angulate. Epistermum metathoracioum angustum.

Cuerpo alargado, levemente deprimido, i conuna pubescencia variable segun la especic.

Cabeza de la anchura del protórax, cóncava entre las antenas, por ser los tubérculos anteníferos grandes i oblícuos hricia afueı. Ojos salientes, casi trasversales; reniformes, es decir mui poco profundamente sinuados: el lóbulo anterior no pasa adelante del cóndilo antenario; la línea ocular es apénas tanjente al borde esturno de la cavidad cotiloidea; ésta es profundamen- 
te sinuada; los carrillos tienen su lonjitud igual a la anchura del artículo 1 de las antenas en su base. Antenas filiformes, con su parte basilar erizada de finos pelillos; son de la lonjitud de cuerpo en los machos, i mas cortas que él en las hembras; los artículos I, 3, 4, 5, son variable.s, segun la especie.

Barba pequeña i mui corta. Lengiieta mas larga que ella, inembranosa solamente en su borde anterior i en los lóbulos que resultan de un seno circular mas o ménos profundo segun la especie. Palpos alargados; los maxilares dos veces tan largos como los labiales; el último artículo de aquéllos truncado mas oblicuamente que el de los labiales.

Protórax apénas tan ancho como largu, angostado del medio hácia adelante; costados con un fuerte gancho arqueado hácia atras, dorso con dos gruesos tubérculos cónicos dispuestos tras. versalmente en su tercio anterior.

Escudo triangular.

Elitros truncados en la base; ésta no alcanza completamente a ser doble de la del prótorax; el callo humeral es saliente; el pliegue epipleural es angosto, pero de igual anchura casi hasta el ápice; éste termina de distiuta manera en cada especie.

Las ancas anteriores son mas o ménos trasversales, con sus cavidades cotiloídeas profundamente triangulares lateralmente i abiertas posteriormente; las de las ancas intermediarias lo son tambien esteriormente. La salida prosternal i la mesosternal son angostas; ésta es a lo ménos dos veces tan ancha como aquélla. Episternon metatorácico mas o ménos angosto, triangular o paralelo.

Patas delgadas, con los fémures dilatados poco i gradualmente en su parte anterior. Las tibias anteriores son flexuosas. Tarsos posteriores con el artículo I mas largo que 2 i 3 juntos. Los ganchos tarsales son pequeños i diverjentes.

\section{A. GRANUlatA. (milli)}

A. tristis? (Blanch. in Gay, Zool. T. V, p. f94.)

Fulvo-castanca, opaca, pube pallida brevi adpressa arestita. Capite tenuiter rugosuio, an medio longitrorsum parum ionspicue 
striato; fronte concava. Antennis articulis $3,4,5$ gradatim elongatis, ho6 omnibus longiore. Mento lateribus postice rotundatis, antice recte obliquas. Labio antice late enarginato, lobulis brevihus, parallelis, apice truncatis; palpis labialibus articulo ultimo angulatum subtruncato; palpis maxillaribus articulo $20^{\circ} \mathrm{et} 40^{\circ}$ longitudine aequalibus; hoc afice valde oblique mmanto. Prothorace valde rugoso. Elytris holosericeis, tennissime rugosis, granulis extus sinuatis, aubasim densioribus, apicem vorsus raris, minoribus subscriatisque, ornatis; angulo suturali dentiforme. Corpore subtus tenuiter mgosulo. Abitomine subnitido.

Long. I2. 5; lat. 3.0 .

Este insecto, propio de la parte central de Chile, donde no parece comun, presenta un matiz uniformc de un castaño aleonado, un poco mas pálido sobre las patas, las antenas i la parte apical de los elitros. Es opaco, con escepcion del abdómen, que es un pocobrillante en los machos. Lleva una pubescencia pálida i tendida, mas corta, mas tupida i sedosa sobre los elitros, i mezclada con unos finos pelillos mas largos i medio erizados, visi bles sobre todo en las patas, la base de las antenas, el protórax i los elitros.

Cabeza finamente rugosa.

Distancia entre las cavidades cotiloídeas antenarias. . 1.6

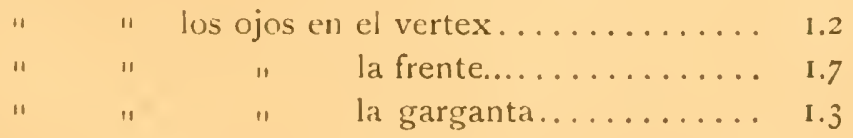

La línea ocular pasa levemente afiera del borde esterno de la cavidad cotiloidea. Esta es profundamente escotada, i su borde interno está engrosado a modo de rodete.

$\begin{array}{cccc}\text { Antenas: Ionjitud de los artículos.... } & & \hat{d} & + \\ & 2 & 1.4 & 1.5 \\ & 3 & 0.2 & 0.2 \\ & 4 & 1.1 & 1.2 \\ & 5 & 1.5 & 1.4\end{array}$




\begin{tabular}{|c|c|c|c|c|}
\hline \multirow{2}{*}{\multicolumn{2}{|c|}{ Antenas: lonjitud de los artículos..... }} & \multicolumn{3}{|c|}{$\hat{\imath}$} \\
\hline & & 6 & I. 4 & I. 2 \\
\hline & & 7 & $\mathrm{I} .4$ & I. I \\
\hline & & 8 & 1.3 & 0.9 \\
\hline & & 9 & 1.2 & 0.9 \\
\hline & & 10 & I.I & 0.8 \\
\hline & & I I & I. 4 & 1.0 \\
\hline$"$ & Lonjitud total.... . . . . . & & I 2.9 & I 1.0 \\
\hline 11 & del cuerpo........ & & 12.5 & 14.0 \\
\hline
\end{tabular}

Barba con sus costados redondeados en la base, rectos i oblícuos en la mitad anterior. La lengiieta lleva adelante un ancho seno semicircular; el borde de este último i los dos lóbulos que resultan de él son solo membranosos; estos lóbulos son cortos, paralelos i truncados en su ápice. El artículo 1 de sus palpos alcanza casi a la estremidad de dichos lóbulos, es un poco mas angosto que 2 , i su lonjitud (O. I 7 ) da solamente el $80 \%$ de la de este último, la de ámbos juntos da el $90 \%$ de la del 3 ; éste ticne el truncamiento apical casi cuadrado en su mitad csterna i mui oblícuo en la interna: to que lo hace ver anguloso en el medio; su anchura (O.I8) da el $44 \%$ de su lonjitue. La anchura del ló. bulo esterno de las quijudas es doble de ia del lóbulo interno; el artículo I de sus palpos es mas angosto que los otros, sinnado en la parte esterna de su base; su lonjitud (0.2 I) da el $55 \%$ de la del 3 ; i ésta da el $68 \%$ de la del 2 (0.54), que es de igual lonjitud que el 4 ; la anchura de éste (0.22) da el $41 \%$ de su lonjitud; el truncamiento apical es mui oblícuo, quedando la lonjitud del costado interno reducida al $54 \%$ de la del cstemo.

El protórax tiene las medidas siguientes:

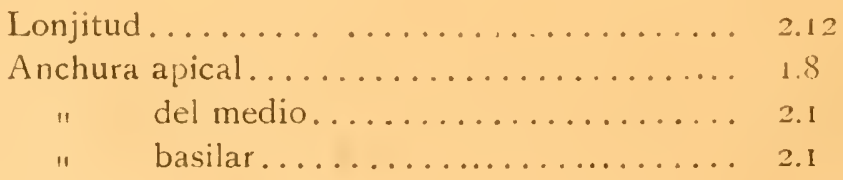

Es mas fuertemente rugoso que la cabeza; loi costados lievan cerca del ángulo anterior un pequeño callo, de lo cual resulta 
una leve sinuosidad entre él i la base del gancho; en el dorso, se nota entre los dos tubérculos un fino pliegue, o mas bien una costillita, que a veces desaparece por completo.

La anchura de los elitros da el $32 \%$ de su lonjitud; están cubiertas de unas finísimas rugosidades, i, ademas, llevan una granulacion gruesa i tupida en la parte basilar, pero que se hace gradualmente pequeña, escasa i levemente en séries lonjitudinales en la parte apical; estos granos llevan en su parte esternoposterior un seno que les da la forma de una creciente; el ángulo sutural es dentiforme, o a lo ménos en ángulo recto i puntiagudo.

La anchura del episternon metatorácico (0.4) da el $15 \%$ de su lonjitud (2.6).

Los fémures son poco adelgazados en su base.

Lonjitud del cuerpo ............... 12.5

" del fémur intermediario......... 3.2

Proporcion de ésta con aquella......... $26 \%$

Anchura basilar de éste.............. 0.4

" de su parte dilatada........... 0.6

Proporcion de aquella con ésta.......... $66 \%$

" de ésta con la lonjitud........ $19 \%$

En los $c$ el féınur posterior alcanza a la $3 .^{\text {a }}$ sutura abdominal; $i$, en las $q$, solamente entre la $2 .^{a} i 3 .^{a}$

Los segmentos abdominales son de igual lonjitud, i el $5 .^{\circ}$ no parece ofrecer diferencias sexuales

Iám. II. figs. I $5^{\text {a: }}$ Barba, lengiueta $i$ palpo labial.-Aum. 20 diám. fig. $15^{\text {b. }}$ : quijudas i palpo maxilar.

\section{A. NITHDPENNIS (mihi)}

A. tristis (Farmaire of G. Au. Soc. ent. Fr. 'I859 p. $510 .-$ Lacurdaire Ganera T. VIII, p. 376).

Livide-castanea, pilis tenuissimis parum atense hirsuta. Capite opaco tenuiter rugosulo. Antennis pube brevi et adpressa dense vestitis, apud mare's corporis longitudinem aquantibus: articulo $30^{\circ}$ brevi; articulo $5 .^{\circ}$ longiorc, prucedentibus duolus junctis aquante. Labio antice profunde rotundatim sunuato; lobulis apice rotundatis, basi lcviter constrictis. Maxilla lobnlo interno cxterno breviore 
ac angustiore, palporum articulo $2 .^{\circ}$ quarto i reviore. Prothorace op.uco fortiter rugoso. Elytris micantibus, punctis piliferis minutis subseriatis, ad apicem sublituratis, impressis; utroque apice valde rotundato, angulo suturali mullo. Corpore subtus nitido.

Long. 10.7 ; lat. 5,5 .

Esta especie, de la cual tengo a la vista solamente un ejemplar, que es macho i pertenece a la coleccion Delfin, se encuentra en las provincias centrales, $i$ parece escaso.

Es un insecto de un castaño poco subido i algo lívido. Todo el cucrpo está cubierto de pelillos crizados i mui finos, alargados $(0.5-0.6)$ sobretodo en las patas, la base de las antenas $i$ los elitros; sin mezcla de otra pubescencia, con escepcion de las antenas que llevan, ademas, una mui corta, mui firia i mui tendida. Es opacn, con escepcion de la parte inferior del cuerpo, i sobretodo de los elitros.

Cabeza finamente i densamente rugosa, con los tubérculos anteniferos separados por una mui fina estría lonjitudinal.

Distancia entre las cavidades cotiloídeas..... 0.95

" " los ojos en el vertex........ 0.80

" " " en la frente......... I.IO

" " $\quad$ " en la garganta....... 0.90

Línca ocular apénas tanjentc al borde esterno de la cavidad cotiloídea. Esta está truncada oblícuamente i poco escotada.

-Antenas: lonjitud de los artículos....... I I.O

$2 \quad 0.2$

$3 \quad 0.8$

$4 \quad 0.5$

$5 \quad$ I.5

6.1 .3

$7 \quad 1.3$

$8 \quad 1.2$

$9 \quad 1.2$

$10 \quad 1.0$

I I $\quad 0.95$

lonjitud total............ 10.95

" $\quad$ del cıtırpo.......... 10.7 
El artículo 1 está con forma de maza levemente arqueada.

Barba con los costados oblícuos en ámbas mitades i brevemente redondeados en el medio. La lengriicta lleva adelante un profundo seno circular, con los lóbulos cortos, angostados en la base, i dilatados adelante a modo de espátula redondeada. El artículo I de sus palpos da los $\% / 3$ de la anchura i de la lonjitud del 2; i la lonjitud de ámbos juntos (0.23) da los $4 / 5$ de la del 3 (0.28); éste está truncado poco oblícuamente adelante, pero con el ángulo interno del truncamiento mui redondeado; su anchura hace la mitad de su lonjitud. El lóbulo interno de las quijadas da la mitad de la anchura i de la lonjitud del esterno; el artículo I de sus palpos da la mitad de la anchura de los dos siguientes, i la mitad de la lonjitud del 3; éste da apénas los $3 / 4$ de la lonjitud del 2 , i el 2 da solo los $4 / 5$ del 4 ; éste está truncado oblícuamente adelante, de modo que el borde interno da la mitad del esterno; su anchura (0.18) hace apénas la mitad de su Ionjitud (0.40)

El protbrax da las medidas siguientes:

Lonjitud...................... I.50

Anchura apical................... 1.25

" del medio................. I.50

" basilar.................. I.50

$i$, como en la otra especie, el dorso lleva unas rugosidades mayores que las de la cabeza.

Los elitros tienen la misma forma i las mismas proporciones que en la especie anterior; pero el ápice está separadamente mui redondeado, es decir sin vestijio alguno del ángulo sutural. El dorso es mui brillante, con un cierto viso aceitunado, i lleva unos puntitos piliferos, dispuestos en cinco o scis hileras irregulares, algo borradas en el ápice.

El prosternon es levemente arrugado adelante; su salida es lancliforme i casi nula entre las ancas. Estas son angulosas lateralmente; i sus cavidades cotiloideas están abiertas, pero no tanto como $\mathrm{cn}$ la otra especic. Mesosternon i metasternon puntuados. El episternon metatorácico está con forma de un triángulo alargado $\mathrm{i}$ angosto.

El cuerpo, por debajo, es apénas pubescente. 
El abdómen es liso, con los segmentos de igual lonjitud.

Lonjitud del cuerpo................ 10.7

" del fémur intermediario......... 2.6

Proporcion de ésta con aquella.......... $24 \%$

Anchura basilar de éste.............. 0.25

". de su parte dilatada .......... 0.50

Proporcion de aquella con ésta.......... $50 \%$

" de ésta con la lonjitud......... 19\%

El fémur posterior pasa apénas delante de la 2. sutura abdominal. Las tibias son levemente arqueadas. Eıl lns tarsos posteriores, los tres últimos artículos juntos dan poco mas de la lonjitud del $\mathbf{r}$.

Lám. II. fig. I $6^{a}$ barha, lengiieta i palpo latial.-Aum. 20 diám. fig. $16^{\mathrm{b}}$ palpo maxilar.

Como se vé, los caractéres que Lacordaire indica para las antenas, la pubescencia, la puntuacion, la forma del ápice de los elitros, la salida prosternal, etc.- pero no las proporciones del artículo I de los tarsos posteriores-son esactamente los que presenta esta especie; pero de ninguna manera los de la especie anterior: la cual, sola, podria tal vez ser la A.tristis (Blanch. in $G(a y)$, mal descrita por este entomólogo. Lo que pone en evidencia la confusion a la cual se llega con descripciones mal hechas, i a las cuales se prefiere la vista de un tipo, que es o no es lo que dice el rotulito clavado en su alfiler.

\section{G. SEMNUS (Lacord.)}

Lacordaire coloca en la agrupacion de los Flictenodidos un jénero Semnus, establecido por él sobre una especie del Brasil (Phlyctenioides) (Genera, T. VIII, p. 376); i, por mi parte, describo (An. Uniw. Chile, i893), como perteneciendo a este mismo jénero, otra especie ( regalls), de la cual he visto hasta ahora solamente cinco cjemplares, hallados todos por mí entre el rio Nuble i la parte setentrional de la Araucanía.

Lacordaire dice lo siguiente de su j. Semnus (loc. cit.): 
"Mêmes caractères que les Ancylodonta, sauf les différences suiremtes:

"d??: Antennes plus robustes, subfiliformes, densiment et "finement pubescentes, ì peine villeuses, un peu plus longues que "le corps. à articles j.. Egaux, plus courts que les suivants, cenx" ci égantrentr'ent.

"-Elytres longuement et assez largement canaliculées dans "leur milzen, le long de la suture; celle-ci velevée dans cet endroit; "leur certremité légèrément íchancrie.

"-Coriss moins alongré.

"L'espèr sur laquelle ce genre noutern est élabli n'est evidem"ment pas congenère des Ancylodonta. Rémnie dì ces devières, " elle forme dans le groupe actuel une section particuliére carac" tériste par la forme de la títe qui déborde fortement le prothora:, "et parait rítricic en arriêre des yeux."

Las inesactitudes que figuran en lo que antecede traen la mayor confusion en la cuestion que se trata aquí.

El carácter sacado de la forma de la cabeza, que, segun él, sobrepasa (déborde) fuertemente el protórax lateralmente, etc., i sirve, en su opinion, para establecer una seccion que comprende el j. Semnus i el j. Ancylodonta, es completamente inesacto respecto a este último. Pues, la anchura de la cabeza en las Ancylodonta-admitiendo que convenga tomarla en los ojos-escede solamente de $1 / 8$ la de la base del protórax; lo que no autoriza a que se diga: "la tête déborde fortement le prothora.z:"

Pero, adema:, no me parece lójico que para conocer esta anchura, se mida el punto en el crial los ojos son mas salientes; porque, tomada así, esta medida indica la impertancia de esta espansion lateral de los ojos, i no la anchura de la cabeza; i que tambien, si se mide la anchura de la cabeza en los ojos, la importancia del encrijimiento posterior, de que habla para aquella, será proporcionada a lo salicnte que serán estos últimos; quedando evidente que el tal encojimiento será una apariencia i no una realidad. Lis to mismo como si, para conocer la anchura del protórax, se la tomara entre los puntos mas salientes de los ganchos laterales.

En cuanto a las antenas, lo que dice de la lonjitud proporcional de los artículos 3, 4, 5 para el j. Semnus, es esactamente in 
que se nota en la ancylodonta tristis (Blanch. in Gay), que él parece no haber conocido; i solamente difiere de las antenas de la Ancyl.nitidipennis (mihi), que toma erróneamente por aquella.

He esplicado, al hablar del Semnus regalis (mihi, An. Univ. Chile, I893), que la mayor parte de los caractéres sobre los cuales Lacurdaire establece este jénero, son meramente especificos. Para mi, pues, las afinidades, que tanto el S. Phlyctonioides como el $S$. regalis tienen con las Ancylodonta, son mucho mas evidentes que lo que él pretend ; dejando aun dudoso que la creacion de este jénero nuevo haya sido necesaria.

No conociendo el S. Phlyctcenioiltes, no hablaré de él; pero el $S$. regalis, que me parece perfectamente conjenérico con él, reproduce completamente los caractéres del j. Ancylodonta, tales como los tengo indicados en las pájinas anteriores, con las escepciones siguientes.

-El ápice de cada elitro está escotado; el ángulo sutural está armada de una espinita afilada, i el ángulo marjinal es dentiforme o a lo ménos recto i puntiagudo.

-Un gran seno en ángulo casi obtuso divide anteriormente la lenguieta en dos lóbulos de costados paralelos, i tres veces tan largos como anchos.

- Los palpos labiales dan mas de la mitad de la lonjitud de los maxilares.

-El último artículo de ámbos es triangular, con el truncamiento apical poco oblícuo.

- Las ancas anteriores son notablemente trasversales, con sus cavidades cotiloídeas largamente angulosas hácia afuera.

- La salida prosternal es aplanada i ribcteada; arqueada i ensanchada despues de las ancas, entre ellas está angostada, pero no lameliforme ni enterrada.

- La salida mesosternal es solamente de 1/8 ménos ancha que las ancas intermediarias en el sentido trasversal.

- En los $\delta^{\circ}$, el $50^{\circ}$ segmento abdominal es mas corto que el $4 .^{\circ} \mathrm{i}$ truncaoo; en las $q$ es tan largo como el $4 .^{\circ} \mathrm{i}$ redondeado.

Para que la descripcion del ' $\%$ regalis qucde en armonía con las otras que figuran en este trabajo, voi a darla de nuevo mas completa $\mathrm{i}$ algo correjida. 


\section{S. REGALIS (milli)}

Elongatus, castaneus, haud conspicue punctatus, pube aurata, lannginoso-sericea, inordinate adpressa, densissime tectus. Corpore, antennis pedibusque griseo-pruinosis. Capite sulco longitudinali impresso, inter antennas subconcavo. Oiulis brevibus, exsertis, late sinuatis. Antennis apnd mares corpore vix longioribus, apua foeminas brevioribus; articulis $1,3,4$ longitudine aequalibus: articulo 5 ommbus longiore. Labio antice membranaceo, profunde angulatim sinuato, utrinque longe lubato. Palpis onnibus articulo ultimo triangulari, apice fere recte truncato; palpis labialibus maxillarum dimidium superantibus. Prothoracc leviter longiore quam lato, antice angustzore, ante marginem apicalem constricto; tuherculis magnis 4 in medio transversim dispositis armato, externis majoribus acute arcuatis. Elytris base recte truncatis; angulo humerali calloso et exserto, utroque apice emarginato, angulo suturali spinoso, marginali dentiformi; tergo utrinque plucis 4 longitrorsum ornato: plica I. ${ }^{\alpha}$ supra basim breviter elevata, 2." validiore, antice posticeque liturata; alteris duabus confusis et parum conspicnis. Prosterno marginato inter coxas angustato. Mesosterno planato lato. Metastcrno in medio longitrorsum sulcato; episterno angusto, in tertio apicali attenuato. Abdomine seg. mentibus ad apicem gradatim brevioribus; $50^{\circ}$ apud mares $4 .^{\circ}$ breviore, apice truncato; apud foeminas $4^{\circ}$ longitudinem aequante, apice rotundato. Coxis anticis transwersis, acetabulis extus longe angulatis. Pelibus robustis; femoribus gradatim parum dilatatis. Tarsis posticis articulo $1 .^{\circ}$ duobus sequentibus junctis longiore. Unguibus divergentibus.

Long. 20.0 ; lat. 4.6 .

Alargado, castaño o de un pardo claro, este insecto es densamente cubierto por encima con una gruesa pubcscencia dorada, medio lanuda, medio sedosa; la cual, por cstar tendida en sentidos mas o ménos contrariados, da un aspecto de muaré a los elitros, i cuya abundancia no permite ver si los tegumentos son lisos, puntuados o rugosos. El cucrpo por debajo, las antenas i las patas están cubiertos de una pubescencia sumamente 
corta i fina, cenicienta o un poco dorada sobre el pecho, la cual simula el vello delicado que se nota sobre ciertas frutas.

La cabeza, si se toma su anchura en los ojos $(3,2)$, la tiene solamente de $1 / 8$ superior a la de la base del protórax $(2,8)$; pero, si se toma ántes $\mathrm{i}$ despues, es decir en los carillos i en el pescuezo, será de $3 / 10$ menor. La anchura de estos dos puntos $(2,2)$ es notablemente la misma; por esto me parece que allí está el punto donde es lójico buscarla. Los tubérculos anteniferos estan mui inclinados hácia afuera, con su vértice medianamente escotado, i con sus bases separadas por una estría lonjitudinal que recorre toda la cabeza; quedando la frente cóncava entre cllos.

Los ojos son pequeños pero mui salientes, i su escotadura es ancha pero poco profunda, con el lóbulo posterior no dilatado en suestremidad; adelante no pasa al cóndilo antenario. Los carillos tienen una lonjitud $(0,6)$ casi igual a la mayor anchura del artículo I de las antenas.

Distancia entre las cavidades cotiloídeas antenarias I.8

" los ojos en el vertex......... I.5

" $"$ la frente......... 2.3

" $"$ la garganta....... I.8

La linea ocular es, como en las Ancylodonta, apénas tanjente al borde esterno de las cavidades cotiloídeas.

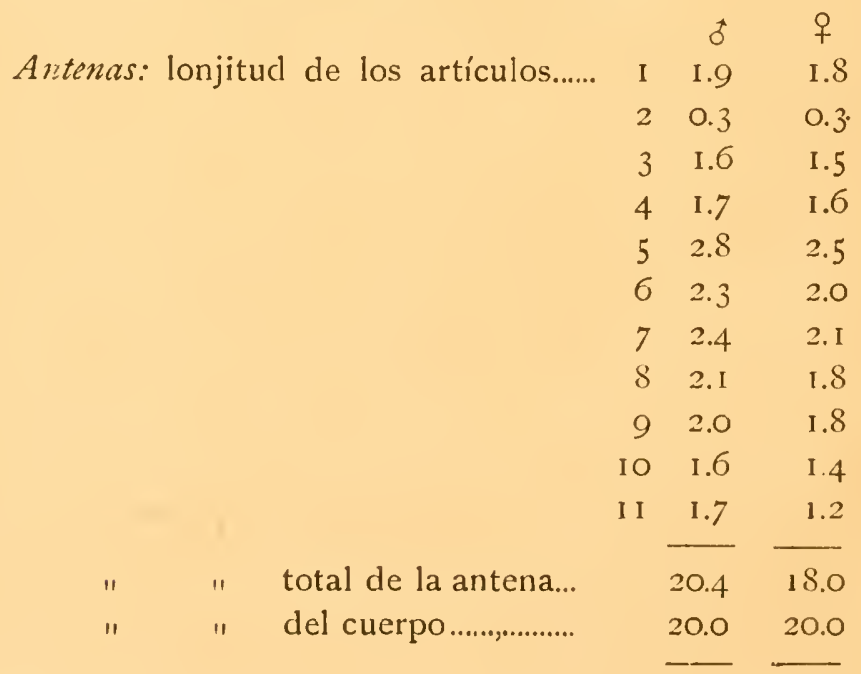


Artículos sin espinas ni carenas, los primeros con unas cortas cerditas en su parte inferior, el $\mathrm{I}^{\circ}$ en forma de maza levemente arqueada.

Barba mui corta, con sus costados redondeados en su tercio postcrior, rectos i mui oblícuos en los otros dos.

Lengiueta grande, casi tan ancha adclante como la barba en su base, i dividida en dos lóbulos por una grande escotadura en ángulo casi obtuso. Estos lóbulos son tnembranosos, tres veces tan largos como anchos; i las nervaduras pubescentes que los atraviesan lonjitudinalmente, $\mathrm{i}$ cn las cuales varios entomólogns creen ver las paraglosas, son mui visibles en la parte interna. Los sostenes de los palpos alcanzan a la mitad de la lonjitud de los lóbulos, de manera que el artículo I alcanza casi en su ápice. La lonjitud del I da los $\frac{4}{5}$ de la del 2 ; i la lonjitud del $3(0.36)$ da el $86 \%$ de la de los dos primeros juntos (0.4I), i su anchura hace el $58 \%$ de su lonjitud. La lonjitud del palpo entero da el $58 \%$ de la del maxilar.

El lóbulo interno de las quijiadus es apénas tan ancho como el esterno, $i$ éste apénas dos veces tan largo como él. El artículo I de sus palpos dá los $\frac{2}{3}$ de la lonjitud del 2, i los $\frac{3}{4}$ de su anchura; éste cs de mui poco mas largo i mas ancho que 3 ; la anchura del 4 da el $54 \%$ de su lonjitud, i ésta hace el $69 \%$ de la lonjitud de 2 i 3 juntos. El último artículo de todos los pripos es levennente securiforme, con el truncaıniento apical en ángulo recto en la parte esterna, i levemente oblícuo en la interna.

El protórax lleva las medidas siguientes:

$$
\begin{array}{ccc}
\text { Lonjitud. ........ } & 3.1 \\
\text { Anchura apical. . . . . } & 2.4 \\
\text { " basilar..... } & 2.8
\end{array}
$$

En sus $\frac{2}{5}$ anteriores está angostado hácia el ápice; $i$, mui poco despues del medio, lleva cuatro grandes tubérculos dispuestos trasversalınente, los laterales son mas grandes, mas agudos $\mathrm{i}$ arqueados hácia atras; ademas lleva un encojimiento circular ántes del borde anterior, de lo cual resulta para los costados, 
una salida tuberculiforme en el ángulo apical i un ancho seno entre este último i el gancho lateral; en el medio del dorso, se divisa una mui fina costillita lonjitudinal acortada atras $i$ adelante.

El escudo es' triangular.

Los elitros son deprimidos i van angostándose levemente de la base al ápice; sı mayor anchura dá el $30 \%$ de su lonjitud. La base está truncada, con el ángulo humeral calloso, deprimido i saliente. El ápice está cscotado, con el ángulo sutural armado de una espina afilada, i el marjinal dentiforme o a lo ménos en ángulo recto i puntiagudo. El dorso lleva cuatro costas lonjitudinales: la r $^{\text {a }}$ es mui saliente solamente mui cerca de la base; la 2..$^{a}$ es la mas marcada, pero está borrada en la base $\mathrm{i}$ en $\mathrm{el}$ ápice; la $3 .^{\mathrm{a}}$ sale del ápice i termina anteriormente despues del primer tercio; la $4 .^{\text {a }}$ sale del callo humeral, i acaba posteriormente casi en el mismo punto que la $3^{a}{ }^{a}$; pero estas dos últimas son confusas, poco marcadas $i$ de una constatacion algo difícil. Plicgue epipleural completo.

La salida prosternal está ribeteada en su base, angostada entre las ancas, pero ni lameliforme, ni enterrada; $i$ es arqueada en su parte apical. La salida mesosternal está aplanada i solamente de $\frac{1}{8}$ mas angosta que la anchura trasversal de sus ancas. El metasternon lleva un profundo surco lonjitudinal en el medio; i su episternon es angosto i solamente atenuado en su tercio apical.

Las ancas anteriores son salientes i casi trasversales, con su cavidad cotiloídea largamente angulosa hácia afuera, i brevemente abierta atras; las de las ancas intermediarias lo son igualmente hácia afuera.

Los segmentos abdominales disminuyen gradualmente de lonjitud hasta el $4 .^{\circ} ; \mathrm{el} 5 .^{\circ}$ es mas corto que el precedente en los of i truncado; pero es tan largo como éste en las $q$ i redondeado.

Las patas son medianas, con sus femures mui poco dilatados.

Lonjitud del cuerpo................ 20.0

del fémur intermediario.......... 6.0

Proporcion de ésta con aquella........... 30\% 
Anchura basilar de éste.............. 0.56

" de su parte dilatada........... 0.90

Proporcion de aquella con ésta . . . . . . . . . . . 62\%

" de ésta con la lonjitud............ 15\%

El fémur pnsterior llega a la $3 .^{\text {a }}$ sutura abdominal en los $c$, i solamente entre la 2.a i la $3 .^{a}$ en las 9 . Las tibias son casi cilíndricas $i$ del largo de sus fémures. Tarsos anchos, con el artículo $1 . "$ de los posteriores mas largo que los dos siguientes juntos. Los ganchos tarsales son pequeños i diverjentes.

Lam. II, páj. 17. : barba, lengüeta i palpo labial.-Aum. 20 diám.

" fig. $17^{\mathrm{b}}:$ palpo maxilar.......... "

G. HOLOPTERUS (Blanch. in Gay, Zool. T. V.p.)

Lacordaire ha tenido evidentemente razon, cuando creó una agrupacion de los Holopteridos para el jénero Holopterus, establecido por Blanchard (in Gay, Zool. T. $V ., p .775$ ) sobre la única especie (chilensis) conocida entónces. Entomólogos, que merecen entera fé, declaran que estos insectos se asemejan mucho a los que Lacordaire comprende en su agrupacion de los Uracantidos, los cuales son todos propios a la Australia : hecho notable, por lo que afirma aun mas el parentezco inesplicado que existe entre los coleópteros de dos rejiones tan distantes una de otra: Chile i la Australia.

A esta especie se han agregado tres otras; pero una de ellas (Sublineatus, Fairm.) no figurara en este trabajo; pucs, la hallé en la posada de Uspallata en I861, i Burmeister, que la describe tambien, la da como hallada igualmente en territorio arjentino, pero nunca en Chile hasta ahora.

Es de sentir que tantos entomólogos de mérito, en lugar de fijar su atencion sobre caractéres suministrados por la anatomía esterna, los cuales son de mucho valor por ser poco sujetos a variaciones, no vean casi otra cosa que la coloracion: fuente de caracté- 
res tan variables en jeneral, que su emplen ticne por resultado la descripcion de una multitud de especies imajinarias i el fomento de la plaga sinonímica que es su consecucncia.

I no es ménos deplorable ver que los insectos de este jénero interesante hayan sido estudiados de un modo tan superficial, que se habló casi únicamente de los de sus caractéres que pertenecen a toda la agrupacion; empleando, ademas, para describir estos, palabras que, por significar todo, no significan nada, $\mathrm{i}$ cuyo sentido vago les quita mucho de su valor: Valde elongatus. . pattes tres longues.. ely'ir's fort longues (Fairm. it G.) -Corpus valde elongatum.. antennue longissina.. eljtra elongatissima. pedes longissimi (Blanch. in Gay").- "Elytres très allongées.. pattes extrếmement longues... corps très allongé... (Lacord. Genera.)"-etc.; quedando imposible hacerse una opinion sobre estos diversos órganos, al ver, por otra parte, atropellado este gasto tan estremo de superlativos: pues, estas "antenne longisime" son al mismo tiempo declaradas poco mas largas o aun mas cortas que el cuerpo - Los fémures posteriores de estas patas "sumamente largas" sobre todo las posteriores resultan ser mucho mas cortos que los elitros-etc.

Para que una descripcion sea buena, es preciso que el insecto dibujado, scgun los datos espucstos por aquella, se parezca al insecto descrito, $\mathrm{i}$ creo que el naturalista, encargado de dibujar un Holopterus con datos como los que acabo de citar, se veria en la impusibilidad de hacerlo. Trataré, por consiguiente, de dar mediclas que indiquen las proporciones de los varios órga. nos de modo a poder apreciar las formas i proporciones escéntricas de estns insectos, mejor que con calificativos de un significado ilimitado.

Ln que mas atrae la atencion en estos insectos, i les da un aspecto verdaderamente estraño, es la lonjitud dermedida de los clitros; la cual trae consigo la de las patas i de las antenas, pero no la del antecuerpo, es decir, de la cabeza i del protórax. Estos quedan relativamente cortos, siendo juntos de una lonjitud en jeneral inferior a la anchura de los clitros. Si se agrega a esto la delgadez de las patas, cuyns fémures no tienen dila. tacion apreciable en su parte apical, el desarrollo estremo de los ojos, que llega a veces a hacerlos casi contiguos en la gar- 
ganta; i la prolongacion, en forma de rostro, de la parte de la cabeza que les está anterior; se tendrán los puntos principales que a primera vista hacen distinguir a estos Lonjicornios de los demas.

El jénero Holopterus puede quedar caracterizado de la manera siguiente:

Corpus elongatum, subdepresum. Caput antice rostratum. Oculi magni, glohosi, erserti, aliquando fere contigui. Antenna, articulis plus minusie numerosis quadrangularibus, apud mares corpus requantes ant leviter superantes, apud faminas breviores. Mentum breaissimum. Lathinm corneum, antice bilobatum, lobis magnis, menbranaceis, untus pubescentibus, sinu acute angulato separatis. Palpiomnes parii, articulo ultimo elongato, subcylindrico, apice truncato; maxillaribus labialibus parum longiuribus. Prothorax conicus, ante apicem constrictus, tuberculis 4 plus minusve acutis in medio transversim ornatus. Scutcllum triangulare. Elytra plus minusve quadruplo longior quam lata, apice unispinosa. Pedes graciles, femoribus cylundricis, unguibus divergentibus. Prosternum inter coxas angustissimum. Mesosternum latum apice furcatum. Metasternum. influtum, sulco profundo postice margina. tum; episterno lanceolato. Abdomen basi plus minusve depressum segmentis subcequalibus.

Creo esta diagnósis suficiente para indicar las bases sobre las cuales ha de establecerse el jénero Holopterus. Lo que sigue trata de pormenores propios a las tres especics chilenas descritas aquí; sin pretender que, en su totalidad, pucdan aplicarse a otras.

Cuerpo largo, levemente deprimido, en jeneral de un matiz aleonado uniforme, i, con excepcion a veces de los elitros, cubierto de una pubescencia mui tendida. Midiendo la lonjitud del cuerpo desde el cóndilo antenario hasta el ápice de los elitros, la de la cabeza i la del protórax juntas dan apénas la anchura de estos últimos, i, mas o ménos, la cuarta parte de su lonjitud.

La caúeza está prolongada detras de los ojos en un cuello corto; i, delante, en un rostro deprimido, casi cuadrado, de $1 / 3$, mas o ménos, mas corto que ancho. 
Ojos mui grandes, globulosos i salientes. Son notab'emente aproximados en el vertex $\mathrm{i}$ sobre todo en la garganta, donde llegan a ser, a veces, casi contiguos; su seno es mediano $i$ algo variable; resultando que la línca ocular es, a veces, apénas tanjente al borde esterno de la cavidad cotiloidea, i que otras la atraviesa por el incelio; el lóbulo anterior termina al nivel del borde anterior de la cavidad cotiloídea, o la execle de una lonjitud igual a su diámetro. I a anchura del cuello i la del rostro son iguales; i la de la cabeza, medida en los ojos, no alcanza a ser doble ce ellas.

Los tubérculos antenarios están inclinados hácia afuera, con su ápice apénas cscotado; sus bases son contiguas i separadas solanente por una estría lonjitudiual, lo que hace la frente cóncava. Las antenas son mas curtas que el cuerpo en las $q, i$ de su lonjitud o levenente mas largas en los d. El artículo I, obcónico i levemente arqueado, varía de importancia en cuanto a su lonjitud, segun las especies; pues, da desde el $63 \%$ hasta el $97 \%$ de la lonjitud total. Los siguientes-es decir 3-I I-O parte de ellos, presentan unos ángulos lonjitudinales mas o ménos salientes $\mathrm{i}$ agudos, separados por depresiones mas o ménos anchas i cóncavas, que recuerdan un poco lo que se ha visto anteriormente en las antenas del Hosperophanus sulcicomis (milii). Tanto la cantidad de cstos ángulos i de estas depresiones, como la cantidad de los artículos que las llevan, varía segun la especie $i$ el sexo. Ellos se forman del modo siguiente: En un articulo, que sigue a otro perfectamente cilíndrico, se dibujan uno o dos surcos angostos mas o ménos borrados en el medio, o aparece en su ápice una depresion corta i ancha. En el siguiente, ya se ven dos depresiones anchas i cóncavas, separadas de un lado por una carena aguda, i del otro por una cara convexa; en cste cstado el artículo es triangular. Pero, en otro artículo mas apical, se forma una carena en medio de la parte convexa, i en el artículo siguiente, se estiende de cada lado de élla otra depresion cóncava; entónces el artículo lleva 4 ángulos rectos separados por 4 caras cóncavas n aplanadas: es cuadrangular. Cuando el artículo es triangular, parece de regla que la carena separativa de las dos depresiones forme un ángulo agudo, que esté situada en el lado esterno de la antena, i que 
su ápice sea prolongarle en 111 diente diverjente: gueda, pues, establecido que los artículos antenarios, por ser sieunpre cilindricos, o triangulares, o cuadrangulares, no pueden nuncá de:cirse deprimidrs ni comprimidos.

Las diversas piezas de la boca quodan, mas " ménos, de acuerdo con el tipo propirs a los Lonjicorniou de resta seccion; solo el último artículo de los palpus ve moclificar esta figura securiforme tall frecuente en ella; pero llega cuanto mas a ser oblongo, o subcilíndrico, i truncadoen ángulo recto en su ápice. Por lo demas, la barba es siempre pegueña i inui corta. Lál lengiieta es grande. siendo membranosa solamente en los dos lóbuIos alargados i pubescentes, (nl 'jue está páticla adclante por uII grande semo en triámgulo agudo. I os scistenes de sus palpos alcanzan al medin de estns lóbulos, i el artículo I de aquellos mas o ménos, al ápice. Fin trodos los palpos el artículo, último es mas corto que lns dos auteriores juntos-los cuales son, mas o ménos, iguales entre sí-en una propurcion que varia del $65 \%$ al $93 \%$.

En cuanto a la diferencia de lonjitud que hai entre los maxilares $\mathrm{i}$ los labiales, ella no justifica las palabras de Lacorraire: palpes maxillames notablement plus longs que les labianx. (Genero, T. P/II, p. 39.3); pues éstos dan del $71 \%$ al $77^{\circ}$ " de aquellos: es decir que son solamente de $1 / 4$ mas cortros.

Pero, respectro a lo que dice Blanchard: falpos largos (in Gay, Zool. T. $V, p$. .75), la inexactitud es escardialosa, i solumente se puede esplicar pror lid coitumbre, 'pue este cntomólogo parece haber tenido, de hablar de Imojitudes i de anchuras, sill medirlas de retra manera que con una miradia ripida i smperficial. Pues, los palpos, en lugar de ser largos, sen, a ln contrario, proporcionalumente los mas pequeños de tendess loi de los I.onjicornios chilenos de esta seccion. Por ejemplo, una ancylodontre granulata (milii), de. I 4.0 de largo, tience palpos maxilares de 1.7.; miéntras que, en un Holopterus levvigratus de 44.0, estos últimos alcanzan sulaments: a 1.9 Si buscárumes las proporcinnes que hal entre la lomjitud del palpu maxilar de varios de estus insectos i la de su cuerpo-midienclo ésta, come lo hago siempre en esta seccion, descle la base de la antena hasta el ápice de los elitrris-ol error de Jlanchard eerá mas palpable: 
así, en las tres especies de Holopterus estudiadas aquí, aquella dá desde el $4 \mathrm{I} \%$ oo hasta el $45 \%$ de la última; miéntras que en la Drascalia proelonga (Fairm. \& $G$ ). - insecto notable por la brevedad de sus palpos-es de $48 \%$, i, en la ancylodonta granulata (milii), de I 2 I \%o.

El protórax es siempre cónico, pero sus proporciones no son constantes: a veces la lonjitud es superior a la anchura basilar, en otras es lo contrario. La anchura apical da de los $\frac{6}{10}$ a los $\frac{7}{10}$ de la basilar. Antes del borde anterior, presenta un ancho encojimiento circular, i lleva cuatro gruesos tubérculos cónicos dispuestos en línea trasversal mui poco despues del medin.

Fil escudo tiene la forma de un triánguln curvilíneo, o rectilíneo i equilateral.

Los elitros son truncados en la base i levemente atenuados hácia el ápice, el cual lleva una espina; pero cada elitro termina de distinta manera segun las especies. Su lonjitud tiene mas o ménos cuatro veces su anchura, el callo humeral está deprimido oblícuamente hácia afuera, saliente lateralmente, pero no levantado. Cada uno lleva encima algrunas finísimas costillas, de las cuales las laterales son mas o ménos obliteradas; sus intervalos son algo variables segun las especies, $i$ la $4 \cdot^{\text {a }}$ parece marcar el epipleuro; el pliegue epipleural es mui angosto, visible casi en todo el márjen lateral de una especie; pero mui corto i reemplazado por una gruesa costilla redonda que alcanza al ápice, en las otras dos.

$\mathrm{Fil}$ prosternon es lameliforme entre las ancas, pero arqueado i dilatado a modo de botoncito tras de ellas.

Fl mesostemon es casi igual con la anchura trasversal de sus ancas, $i$ ahorquillado en su ápice.

El metasternon está hinchado, con un surco lonjitudinal en el medio, i otro mayor en la orilla de su borde posterior; sus episternones son de forma lanceolada, i con una anchura que dá del $14 \%$ al $28 \%$ de la lonjitud.

Abdómen mas o ménos deprimido en su base; i, como consecuencia de esto, con la salida del primer segmento a veces vertical para encontrarse con el metasternon. Lns segmentos son mas o ménos de igual Ionjitud. Lacordaire tiene razon de decir (Genera, $T . V, p .395, n . r$ ) que la válvula, que él cree destinada 
a protejer el pene, lleva una profunda cscotadura $\mathrm{i}$ podria tnmarse por los rudimentos de un $6.0^{\circ}$ segmentr abdominal. Agregaré que los laclos de esta escotadura son a veces espinifurmes; i que estoi mui dispuesto respecto a lo de la válvula, a tener la última de las dos opiniones espresadas aquí.

I as ancas anteriores son cónicas i salientes en su parte esterna. Sus cavidades cotilnideas están abicrtas atras, i largamente angulosas lateralmente

Las patas tienen una delgadez que hace mas aparente su lonjitud: sobretndo a causa de la ausencia casi completa de dilatacion en la parte anterior de los fémures. Pcro, respecto a su Innjitud, I,acordairc cxajera un poco al decir: pattes extrèment longues, surtout les quatre posterieures (loc. cit. p. 394.) En los I onjicornios chilenos de esta seccion, las cuatro patas pos. tcriores son siempre, o casi siempre, mayores que las anteriores, i esto en una proporcion mas o ménos igual con las de los Holopterus: en los machos de las tres especies chilenas, la lonjitud de las tres clases de fémures es ccino sigue: 8, 12, I 4 -7, 12, I3 - I0, I 5, 18. En ámbos sexos, los fémures intermediarios i posteriores llevan dos dientes mui agudos en la parte inferior de su ápice.

Fn cuanto a las tibias, son todas, con mui poca diferencia, de la lonjitud de sus fémures; pero no alcanzan a ser dos veces tan largas como sus tarsos, con escepcioii de los posteriores en los machos de dos especies, i en los dos sexos de la otra. Parece. ademas, de regla que, en los tarsos posteriores, el artículo I sea mas o ménos de igual lonjitud que 2-4 juntos. En cuanto a la diferencia soxual que, mui a menudo, se nota en la lonjiturl de los fémures, aquí es completamente mula en una especie, pero alcanza a una diferencia de $20^{\circ}$ on ménos en las q de las otras dos.

Hemos dicho que, de las tres especies de las cuales se habla en este trabajo, ma fué descrita por Blanchard (in Gay). En cuanto a las otras dos, lo fueron por Fairmaire i Gormain en los Anales de la Sociedad Entomolójica de Francia de I859; al mismo tiempo que lo cran tambien, la una, por el doctor don R. A. Philippi i, la otra, por el profesor don F. Philippi, en lua 
Anales de la Universidad de Chile del mismo año. Gemminger i Harold, en su catálngo, han dado la prioridad a los primeros; i cl profesor don F. Philippi, respetaudo, en su Catálogo de los Coleópteros de Chile, el modo de ver de estos autores, hace lo mismo.

Sin embargo, la prioridad pertenece indudablemente a las deicripciones de los señores Philippi: ellas fueron publicadas en Julio i las nuestras en Noviembre. Esto, a pesar de que las últimas figuren en un trabajo que principió a publicarse en el año anterior.

Esas luchas para el derecho de prioridad, aunque justis en sí misnas, no me han interesado nunca; porgue estimo que sirven mas a satisfacer el amor propio de un autor, que a prestar un servicio de algun provecho para la ciencia. Pero, despues de haber cumplido con el deber de justicia, que consistió en dar a los sciores Philippi lo que les pcrtenece, no creo prudente afirmar, conn lo hacen Gemminger i Harold, que el H. lavigatus (Pli.) i el H. compressicornis (Fairm. \& G.) son sinónimos. Cuando se tratará de aquella especie, indicaré los motios que tengo para pensar de ot a man rit.

\section{H. Annulicoknis (F. Philitpi)}

\section{Syn. Araneipes (Fairm. i G.)}

Valde elongatus; fulito-testaceus, capite, prothoraie, antennarum articulis apice, femoribus tarsisque obscurioribus; pube brevi, fulvescente, aliquando subiirescente, ajpressa, in capite prothoraceque inordinate divaricata, in metathorace sublongiore, plus minusve dense vestitus. Cupite in medio longitrorsum anguste sulcato; rostro infra transversim grosse migato. Oculis subtus fere contiguis Antennis, articulo $1 .{ }^{\circ}$ prothoracis uberculos fere attingente; apud \$, elytrorum apicem attungentibus, articulis 5 primis cylindricis, alteris triangularibus; apud + corpore brevioribus, articutis cylindricis, 3 ael 4 nltimis rix conspicne depressis, sulco lato in medio internuplo longitrorsum impressis. Palporum articuls utimo anguste triangulari. Prothorace leaiter longiore quam lato; tubercu- 
Lis magnis, acutis, lateralibus ai longiorilus; dorso longitrorsum anguste sulcato. Elytris planatis; ad apicem attenuatis; ad busim, prothorace fere duplo latioribus; longitudine latitudunen quinquies cequante; apice breviter declialbus, utrinque in angrulum longre acutum et spinosum terminatis. Metasterni sulco marginali itus albrevinto, intus aruato. Abitomene cylindrico, ad basim, metasterno valde angustiore. Pedibus in utroque sexu conualitus.

is Lon. 33.5; lat. 6.o.

Este insecto tiene una área de dispersion mui estensa; pues, tengo a la visi. cjemplares hallados en Chiloé, Valddivia, el valle del Renaico, Talcahuano, Valparaiso i Quillota. Pero parece escaso en todoc los puntos de esta estensa patria.

Es mui alargado: es decir, que su anchura mayor da, en jeneral, el $17 \%$ de su lonjitud.

Es de un tesiácen aleonado uniforme, quı:e pasa mas o ménos a oscuro sobre la cabeza, el protórax, cl escudu, los fémures, las dos estremidades de las tibias, los tarsos, las ancas i la parte apical de los diez primeros artículos de las antenas o solamente de algunos de ellos.

Notaré aquí que el inatiz oscuro del ápice de los artículos de las antenas, al cual este insecto dcbe su nombre, es mui incons. tante. Si estí siempre mui evidente en los cuatro o cinco primeros artículos, los siguientes, sobre todo en los macho", se oscurecen gradualmente en totalidad i de tal manera que es im posible uistinguirlo. En las hembras sucede casi lo inismo; pues, sobre tres que tengo a la vista, solameinte las antenas de una presentan este carácier en toda su estensión, aunyue debilmonte.

Este insecto citá completamente cubierto de una pubu-cencia leonada, a veces con un viso verdoso, mui tendida, mas fina i mas escasa sobre las patas i las antenas, mas larga i mas gruesa sobre el meta:ternon, dispuesta con regularidad por tudas partes, a escepcion del protórax i aun de la cabe\%a, cn donde está arremolineada.

Por cncima, los tegumentos llevan una puntuacion sumamente fina i densa, apénas visible i completanente ocultach por la pubescencia. 
La cabeza está marcada en el medio, i en toda su estension, por un angosto surco lonjitudinal. La puntuacion es algo mayor sobre el epistomio, i unas gruesa aun en los carrillos. El epistomio tiene atras la forma de un ángulo agudo, cuyo ápice llega casi en frente ciel borde anterior de los ojos, $i$ se une con la frente por medio de una sutura angulosa i profunda.

El rostro es casi glabro en los lados o carrillos i por debajo; en esta última parte lleva unas gruesas arrugas trasversales. Su anchura (2.0) da los $\frac{3}{5}$ de la cabeza medida en los ojos (3.5). L. mayor lonjitud de los carri!los (1.3) da el $65 \%$ de la anchura del rostro.

En tun $\uparrow$ de 33.5: distancias entre las cavidades cotiloideas

antenarias......... I.5

$\begin{array}{cccc}" 1 & \text { los ojos en el vertex.... } & 0.8 \\ " & \text { " } & \text { la frente.... } & \text { I.7 } \\ \text { " } & \text { "l garganta.. } & 0.2\end{array}$

La linea ocular atraviesa la cavidad cotiloídea por el medio.

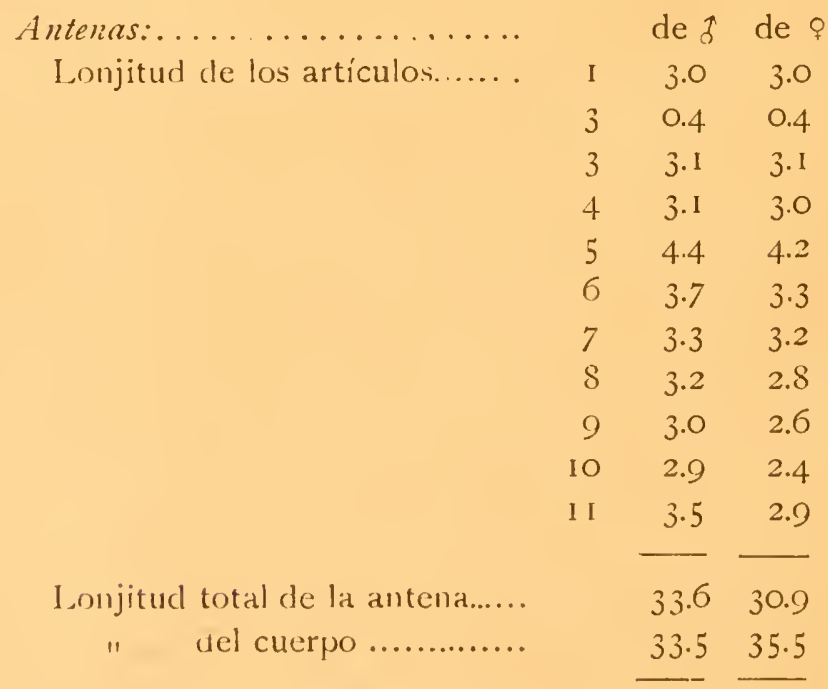

El primer articulcies recto, levemente dilatado hácia el ápice, i profurcionalmente mas largo que en las otras especies; pues 
alcarrar cerca de los tubérculos del protórax, $\mathrm{i}$ da el so\% de la lonjitud total en un macho de $33.5 \mathrm{i}$ el $97^{\circ}$ oo en una hembra de 35.5 . Pero esta diferencia no proviene de una variacion en la lonjitud de este artículn; sino de la lonjitud de la antena, que es menor en las $q$.

En ios machos, los artículos 3, 4, 5 son cilíndricos; pero el tercio apical de la patte esterna de este últimc lleva una ancha depresion lonjitudinal, preludio de lo que ha de pasar en los siguientes, los cuales son triangulares en la forma esplicada al hablar de los caractéres del jénero: la cara cóncava de encima está interrumpida en su medio por un pliegue trasversal, i los ángulos cxterno-apicales son dentiformes, pero poco salientes.

En las hembras ho articulos 3-I I son cilindricos. Sin embargo, los tres o cuatro últimos llevan la apariencia de una leve depresion; con motivo, sin duda, dé un surco interrumpido en el medio que los recorre lonjitudinalmente.

En esta especie, el último artículo de los palpos, aunque mui angosto, ha guarclado una forma triangular inas evidente que en las otras: en ámbos la anchura (0.2) da el 40\% de la lonjitud (0.5). En los palpos labiales, la lonjitud del 3." (0 5) da el $81 \%$ del 1." i el $2 .{ }^{\circ}$ juntos $(0.29+0.33=0.62)$; $\mathrm{i}$ en los maxilares, la lonjitud del 4." (0.5) dá el $76 \%$ de la del $20^{\circ}$ i el $3 .^{\circ}$ juntos $(0.33+0.33=0.66)$. En liss labiales, los dos últimor pasan adelante de los lóbulos de la lengiietas : en los maxilares, solamente el $40^{\circ}$ sobrepasa al lóbulo externo de las quijadas. En cuanto a la Innjitud total, ia del palpo labial (1.12) da el $77 \%$ de la del palpo maxilar $(1,45)$; i esta da el $4^{\prime \prime}, 0_{0}$ de la lonjitud del cuerpo.

El protórax tienc las medidas siguientes en un î de 33.5 .

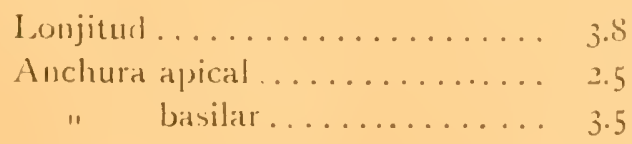

Los tubérculos son grandes i salicutes, sobre todo lus latcrales; los del medio cstán sepurados por ma pecueña línea glabra lonjitudinal, que parece: la continuacion de la entría de la cabc\%a, i tiene casi la figura de un surco en su parte dutcrion i de und costilla en la pusteriur. 


\section{Escudo elı triángulo curvilíneo.}

Elitros inui largos, con su base mas ancha que la del protórax, atenuados hicicia el ápice i aplanados por encima. Para dar un valor a estas palabras, diré: que, en un ${ }_{\text {? }}^{\uparrow}$ de 33.0 que proviene de Talcahuano i pertenece a la coleccion Delfin, la anchura de la base del protórax es de 3.2 ; que la lonjitud de los elitros es de 27.0; que su anchura, en la base es de 5 5; que los costados soll perfectamente rectos; i үu: a 5.0 del ápice, esta anchura es solamente de 3.9. De lo cual resulta que la base del protórax da el $58 \%$ de la de los elitros, que ésta da el $20 \%$ de la lonjitud, i que, a 5.0 del ápice, queda disminuida del $29 \%$.

Encima, los elitros estan aplanados en los $\frac{17}{20}$ basilares de su lonjitud; pero sus costados son verticales, formando así unos epipleuros bien manifiestos. Llevan dos finísimas costillitas lonjitudinales, a veces poco visibles;c on cl intervalo que las separa algo inenor que el que está entre la primera i la sutura; la cual está mui finamente ribeteada. En los $\frac{3}{20}$ del ápice, los elitros sufren una declividad; a consecuencia de lo cual, cada uno presenta en este punto una convexidad ovilada; en cada elitro, estos $\frac{3}{20}$ guardan la forma de un triángulo agudo, cuyo ápice termina con una espina.

El metasternon tienc el surco marjinal acortado en su parte esterna, miéntras que la interna se arquea, $i$ se dirije un poco hácia la base. Su; episternones ticnen una anchura (1.2) que da el $24 \%$ de su lonjitud (5.0).

El aidomen es cilíndrico; i, eli su base, se ve much mas angosto i rebajado que el metasternon; de lo cual resulta que la salida angulurid del primer segmento se encereza oblicuamente, para alcanzar al metastemon por entre las ancas. Aciemas es un poco mas grueso i de $\frac{1}{7}$ mas largo en las hembras.

Las patus no ofrecen diferencias sexuales.

Ën un ô de 33,5 la lonjitud de los fémures es: i en las tibias es: en los anteriores de...... 7.0 de 6.0

" intermediarios. .... I $\mathbf{I} 2.0$ I I.O

$"$ posteriores........ 13.0 12.5

Lonjitud del cuerpo........ 33.5

" del fémur internediario. 12.0 
Proporcion de ésta con aquélla... 36\%

Anchura basilar de éste....... 0.50

" apical........... 0.65

Proporcion de aquélla enn ésta... $76 \%$

" de ésta con la lunjitud. 6\%

En el of, el fémur posterior alcanza cn la mitad del $4^{\circ} \mathrm{seg}$ mento abdominal; pero en la 9 . con motivo ic la mayor lonjitud del abdómen, se queda en la mitad del 3 .

I.as tibius posteriures son del $12 \%$ mas largas que dos veces la lonjitud de sus tarsos.

\section{H. LAVIGATUS-Ph.}

Valde tongatus. Cervino-testaceus; capite, prothorace femoribusque leiriter obscurioribus; antennis, tibiis tursisque rufo fuscis. Opacus, tenuissime densissimequc punctulatus; pube brevi, fuliescente, apprissa, in capite prothoraceque divaricata, in metasterno sublongiore, in pedibus brevissima, in antennis subnulla, dense vestutus. Capite in medio longitrorsum anguste sulcato; rostro infra transiersim grosse rugato, lateribus laxe punctulatis. Oculis in gula atque in aertice alde approximatis. Antennis, articulo I." robusto, brevi, prothoracis marginem anticum air. superante; apud mares, anidioribus, corpore longiorihus, slabriusculis, articulis $3^{-}$ II herfecte tetragonis; apud fominas, gracilimus, corpore brevorions, articulis 3 , cylindricis, sequentilnus sulcis f gradatim latioribus longitrorsuin linpressis, 3 iel + mitimis tetrigimis. Pal. porum artialo ultimo subcylindrico, apice récte truncato. Prothorace aul insim latiore quan longo; tuberulis duobus mtermidus conizis, lateralibus spiniformibus; dorso in medio antace longitrorsum anguste sulcato, foveisque duabus latis, obliquis, parte subelevata triangulari separatus, in dimido postico impresso. Iilytris tenuiter alutace is, aix depressis, at apicem inx attenuntis, quadruplo longiuribus quam latis; ad basim prothorace feri tuplo latio. ribus, latitudine cupitis cum imrothoracis longrtudinem superante; apice, uroque angulo marginali rotundatu et ansulo suturali spina acuta ammato; dorso utrinque costis angustis t. l.utcratitus parce obluteratis, notatis. licmoribus apud o breaioribus.

$\therefore$ Long. 77.0 ; lat. 8.8. 
La descripcion del $H$. compressicornis de Fairmaire $i$ la del 11. leenigratus del Di. R. A. P'hilippi, a mas de unos pocos caracterus-el tubéiculo posierior del medio del protórax, la espina anal de los elitros, la lonjitud de las antenas, etc. - que el uno, u el otro, de estos autores ha desechado u olvidado, difieren cntre sí por un carácter importante i notable, que en cadit una está indicado de un inodo mui diferente: quicro hablar de la forma de los artículos de las antenas.

En aquella, hai: "antemnis corpore longioribus, compressis"... "antennes plus longues qué le corps, comprimées, carrences èn dessusu.

Enl la última: "antennis, articulo prino cylindrico excepto, perfecte tetraquetris".. "las antenas son perfectamente tetragonas con los ángulos mui agudos, a escepcion atel articulo basal, que es cilíndricon.

Luego, esta última descripcion de las antenas corresponde ian exactamente a las de la segunda especie de Holopterns, que estamos cstudiando, que se puede, sin temor de equivocarse, no solamente ver en ella la que el Dr. Philippi describió bajo el nombre de levigatus, sino asegurar, ademas, dos cosas, de las cuales él no habló: I. que el ejemplar descrito por él cra un macho; $20^{\circ}$ que las antenas eran mas largas que el cuerpo.

Miéntras que la forma dada por Fairmaire a las antenas de su compressicornis no permite, de ninguna manera, suponer, como lo hacen Gemminger i Harold en su catálogo, que esta es sonónima de la otra. I el cuidado con el cual anota que las antenas son mas largas que el cuerpo, al demostrar que el ejemplar tenicio en manos por él era tambicı un f̂, le quita la posibilidad de un error debido a la diferencia sexual de las antenas.

Ademas, cuando mi distinguido crlaborador dice que "Les clytres diminuent peu it pou de largen depuis la buse jusqu'a l'extrémití, qui est acuminée et sé termine par une épincu, él habla aquí de un carácter propio a su $H$. arancipes, i no a la especic que estudiamus; en la cual el ápice de cada elitro tiene su ánsulo marjinal redondeado i el sutural con mua espina.

Muibien puede ser, sin duda, que la descripcion de Fairmaire seat incxicta: la cantidad de coleópteros descritos por este fecundu critumóluge es tan inncansa, yue llada estranu seria yue, ell. 
tre tantísimas descripcinnes, algunas hayan salido malas; sin cmbarg(), no admitiré la sinonimia propuesta por Gemminger i Harold, pror miedo de encontrarme, el dia méurss pensado, frente a frente con una eipecie que se diga con la descripcion en litijio, i sea intermediaria entre el $I$. anmulicurnis (F. I'h.) i el levigatus (Ph.)

Agregaré, sin la mas remota intencion de herir el amor propio de radie, que estas descripciones, que, por ser precipitadas, se presentan cuajadas de deficiencias i de inexactitudes, no tienen mis simpatias; lasta que creo malo recompensar trabajos de esta naturaleza, que son perjudiciales a la cicncia, concediéndoles un derecho te prioridad, que es una gloria inmerecida para sus autores.

Esta especie parece cscasi i propia de la parte austral de Chile.

Es mui alargada: cs decir que cs cinco veces tan larga como anchr. Su matiz es de un leonado amarillento uniforme, algo inas oscuro en la cabeza, el protórax i sobre todo los fémures, i algo rojizo en las tibias, los tarsos i las antenas. Está enteramente cubierto de una pubescencia aleonads, corta i tendida; arremolineada en la cabeza i sobie tudo en cl protórax; algo mas gruesa i mas larga en el metasternon; mui corta i mui fina en las patas i en las antcnas, sobre todo en las de los $\hat{\beta}$, de las cuales parece haber desaparecido por completo.

Debajo de esta pubescencir, que lo ocultr todo, los tegumentos son opacos, lebido a una puntuaciun sumamente fina i apretada, que, en los elitru, se cambia en granulaciones como las de la piel de zapa.

La cabeza lleva. en el medio i en toda su estension, un angosto surcu lonjitudina!.

El rostro cs casi glabro en los lados i por debajo, en donde lleva una; grucsas arrugas trasversales. Por encima, el cpisto. inio prescuta la misma disposicion que cu la especie anterior; su puntuacion es igual a la del vertex: es decir que es sumainente fina i apretada; I de los carrillos es tambien find, pero mui ralı. Su anchura $(2.8)$ da el $5 . \$ \%$ rle la de la cabeza en los ujos (4.8). La lonjitud de los carrillos (2.1) da los it de la anchura del rostro.

Los ujus son mediucicmente sirnadus; su lobulu anteriur pasa 
levemente adelante de las cavidades cotiloídeas, i la línea ocular es algo mas que tanjente al borde esterno de estas últimas.

Distancia entre las cavidades cotiloídeas........... 2.2

" los ojos en el vertex ....................... 0.8

" $\quad$ " en la frente.................. 2.0

" en la garganta................ 0.45

Antenas de........................... of de $q$

Lonjitud de los artículos........ 1 l $3.5 \quad 3.0$

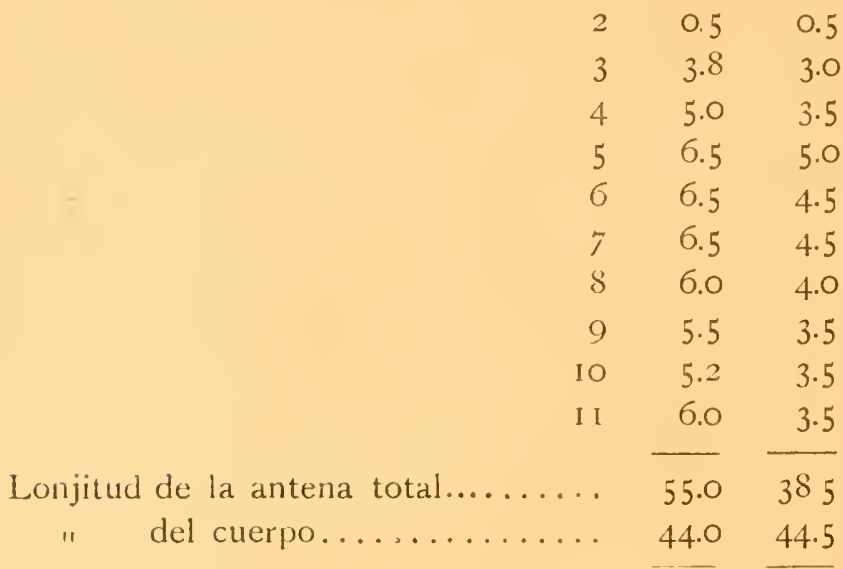

El artículo I es grueso, levemente en mazr o casi cilíndrico, pero es corto; pues, pasa apénas al borde anterior del protórax, su lonjitud da el $63 \%$ ou de la antena total en un $\uparrow$, i el $77 \%$ en una $q$.

En el macho, las antenas son, no solamente mas largas, sino tambien mas gruesas; i, con escepcion de unas pocas cerditas mui cortas que se notan en el ápice de los primeros artículos, parecen glabras. Los artículos 3-1 I son, como lo dice mui bien el Dr. R. A. Philinpi, "perfectamente tetragonas" con los ángulos cortal:es, como lo seria el tallo de una Labiada.

En las hembras, las antenas son mucho mas delgada; sus artículos 3 i 4 son cilíndricos; i los siguientes llevan cuatro surcos lonjitudinales, que se ensanchan gradualmente, hasta dar a los 304 últimos casi la forma cuadrangular de las del macho. En esta especie, el último artículo de los palpos tiene la forma 
de un cilindro levemente atenuado en su bace. En los labiales la lonjitud del 3 (0.7 I) da cl $93 \%$ de 1 i 2 juntos $(0.29+0.37=066)$; en los maxilares, el a es el ma: corto; i la lonjitud del 4 (0.75) da el $85 \%$ de 2 i 3 juntos $1044+0.42=0.88$ ). La lonjitud del palpo labial (1.37) da el $71 \%$ de la dol maxilar (1.92), i ésta da el $43 \%$ oo de la del cuerp s. Los artículo: últimos de aquel pasan a la estremidad clel lóbulo labial; en el último, cl artículo 4 apénas alcanzed a pasar del todo cl lóbulo esterno de las quijadas.

El protórax tiene las medialas siguientes en un $f$ :

Lonjitud................. 4.2

Anchura apical.............. 3.3

" basilar............... 4.8

Lns cios tubérculos del medios son cónicrs, i los laterales tienen su cstremildd en forma de espina. El dorso lleva, en su mitad anterior, m11. angostit estría lonjitudinal; i, en la posterior, dos depresiones foveiformes, oblongas i diverjentes hácia la base, que están separadas por una parte elevada i triangular, cliyo ápice está situado adelante i cs car reniforine.

El escudo forma un triingulo curvilineo.

Los elitros pueden apénas decırse deprimidos. Los ángulos humerales son notablemente redondeados, i es en medio de enta redondez que está la mayor auchura del elitro: la cual va disminuyendo hasta el ápice.

Las proporciones de esta parte del cuerpo presentan pocas variaciones, pero las hai: i, como creo convenie te hacerlas apreciar, doi sus melidas detalladas en un cjemplar de cada sexu.

La disminucion de anchura de los elitros es mucho mas nota. ble en el primer sétimo de liss elitros, que en los cuatro sétimos siguientes; i, en los dos últimos, o apicales, los costados principian a preparar la curva, que en cada elitro marca el ángulo marjinal: miéntras que cl sutural está armado de una espina afilada.

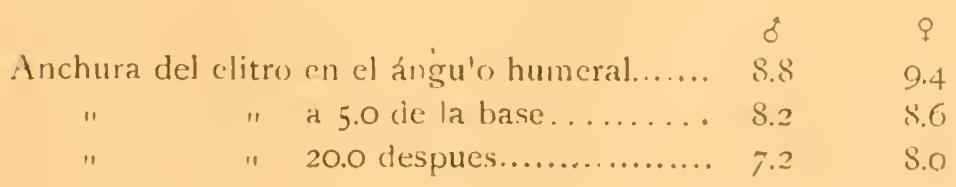


Deciemento de esta anchura a 5.0 de la base. $0.6 \quad 0.8$ " $\quad 20.0$ despues... $\quad$ I.0 $\quad 0.6$

Lonjitud de los elitros... .................. $36.5 \quad 36.5$

Proporcion de la mayor anchura con esta última................................. 24 $1 \%$

Lonjitud de la cabeza $i$ el protórax juntos.... $7.5 \quad 8.6$ Proporcion de ésta con la mayor anchura de

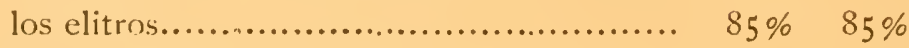

Ancluura basilar del protórax............... $3.8 \quad 5.3$

Su proporcion con la precedente ........... $545^{\circ}$ oo $574^{\circ}$, oo

Cada elitro lleva encima 4 finas costillitas lonjitudinales poco visibles; de las cuales, las dos primeras, que son las mas marcadas, quedan completamente borradas solamente en el ápice; la 3. ${ }^{\text {a }}$ la 4 . $^{\text {a }}$ están obliteradas en ámbas estremidades; pero la última marca el epipleuro de una manera evidente; en el medio del elitro, sus intervalos son bastante iguales, $\mathrm{i}$ inenores que el intervalo entre la $\mathrm{I}^{\mathrm{a}} \mathrm{i}$ la sutura, la cual es tinamente ribeteada.

En cuanto al pliegue epipleural, su borde superior consiste en una gruesa costilla redonda que se continúa hasta el ápice; miéntras que el borde inferior se pierde en ella frente al metasternon.

Metasternon con el surco marjinal recto, ancho i entero. La anchura de su episternon (1.0) da el $14 \%$ de su lonjitud (7.0).

El abdómen, sobre todo en la $q$, es apénas ınas angcsto i mas rebajado que el metasternon; $\mathrm{i}$ la salida de su primer segmento está horizontal.

En la base, los fémures anteriores son rectos; los otros son arqueados, sobre tod" los intermediarios. Su lonjitud, a todos, es como sigue en cada sexo, i en ejemplares de igual tamaño:

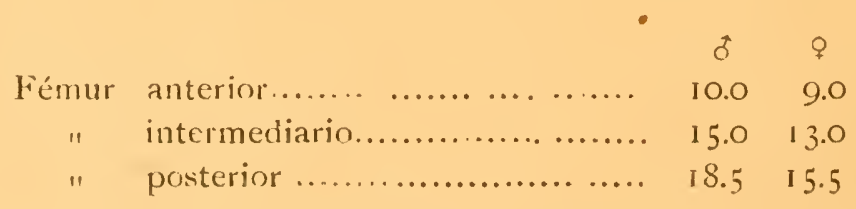

Las proporciones del fémur interınediario son comı sigue en cada sexo: 
1.orjitud del cuerpo............ $44.0 \quad 44.5$

" del fémur intermediario... $15.0 \quad 13.0$

Proporcion de ésta con aquella..... 34\% $\quad 29 \%$

$\begin{array}{llll}\text { Anchura basilar de ésta.......... } 0.7 & 0.8\end{array}$

" anterior................. $1.04 \quad 1.14$

P'roporcion de aquella con ésta..... 67\% $70 \%$

de ésta con la lonjitud... $7 \% \quad 8 \%$

El fémur posterior alcanza al ápice del 3 er segmento abdominal, en el $f ;$ i solamente en el medin, en la i.

Lia lonjitud de las tibias de estas misnas patas hace un poon ménos que dos veces la de su tarso. I cl artículo I de este último da los

Láın. II. Fig. $18 .^{a}:$ hurba, lengièta i palpo latial-Aum. 10 diám.

" " 18." : quijada i palpo maxilar - "

\section{H. Chilensis (Blanch.)}

Elongatus, ferrugineo-rufescens, elytronum parte postica grada. tim pallidiore. Pube testacen, apporessa, in antennis atque in pedihus brevissima, in elytris fere mulla, parman dense tectus. Capite opaco, fere laevigato, in medio longitrorsum anguste sulcato; fronte inter antennas angulatim concai'a; rostro infra transiersim grosse rugato, lateribits aix punctulatis; cpistomii angrulo basali apice. late truncato. Oculis parum profunde sinuatis; apud mares, in gula atque in i'ertice magis approximatis. Antennis, articulo $I_{0}^{\circ}$ leziter obconico, brevi, rolusto, prothoracis marginem anticum zix superante; apud mares, validioritus, corpore longionitus; articulis 3 -II tetragonis et glahriusculis; articulo $3 . "$ apice rotundato; articulis 4 -1O carina externa magis acutu, ad angulum apicalem arcuata, hoc in dentem acutum diaricatumque producto. Apua foeminas, gracilionibus, corpore hrezuritus; articulis i, folindricis, apice rotundatis; articulis 5 o cylindricis, sulcis longitudinalihns duobus latis, in medio soepins intermptis, carina obtusa in dentem acutum apice productu separatıs, extus impressis; articulis 10. If irregulariter tetragonis. Palporum artaculo ultmu cylun- 
drico, in dimidio postico gradatim attenuato, apice rotundatim truncato. Prothorace ad hasim parum latiore quam longo, inordinate rugato; tuberculis duobus intermediis conicis it majoribus; lateralibus leviter postacis ad basim oblaquatis; dorso antice lon. sitrorsum leviter sulcato. Scutello triangulari, in medio depresso, lateribus fere rectis, apice acuto. Elytris longitudine latitudinem fere quater aequante; ad apicem lcviter attenuatis; lumeris vaide rotundatis; apice angulo marginule late rotundato, angulo suturalu acute dentato aut fere spinoso; tergo utrinque costis angustis quinque longitrorsum ormato, interna juxta-scutellari brevissima; punctis irregularibus atque inordinatis juxta costas subsernatis dense impresso, lineis interstitialibus convexis, retiulum efformantibus. Femoribus apud faeminas brevioribus. Abdomine segmento 5. apice late hilobato; apud $\mathrm{n}$, basi metasterno angustiore, holosericeo, impunctato; apud + , punctis ninutis lax issime adspersis impresso, pilis brevibus laxe tecto.

Long. 36.5-48.o; lat. 8.o-II.5.

Este insecto, como asimismo el loevigatus, parece escaso i propio de las provincias australes. Pero no es sin muchas vacilaciones que me determiné a ver en él al H. chilensis (Blanh., in Gay): pues, en la descripcion de este insecto, este entomólogo dice: "Elytris dense punciato-strintis"..... "toda la superficie de los elytros está guarnecita de estrias fuertimente puntuadas $i$ mui apretadas; estas estrins son solve todo was fuertes hácia la base, los intervalos están lijeramentc alzados:" disposicion totalmente diferente de la que la especie descrita aquí presenta en los elitros. Sin embargo, habiendo encontrado en la coleccion Medina un $\delta$ de esta especie, en el cual, a lo largo de las costas, los puntos son mas gruesos, mas profundos i dispuestos en hileras no interrumpidas: el espacio comprenclido entre ellas, en la parte basilar, quedando, por esto mismo, levantado a modo de costa; me convencí de que le habia tocado a Blanchard un ejem. plar, en el cual esta disposicion era mas exajerada aun: i que él lo habia descrito servilmente, sin notar la diferencia que hai aqui entre las costá que son de regla constante i las que se forman accidentalmente en sus intervalos.

Es ménos alargada que las dos precedentes, Su matiz. es un 
ferrujinoso rojizo, que desde el tercio basilar de los elitros, mas - ménos, hasta su ápice se hace gradualmente mas pálido.

La pubescencia es mucho mas corta i ménos abundante que en las otras especies; sobre la cabeza i el protórax, ha perdido en las $q, \mathrm{i}$ aun un poco en los $\delta$, el aspecto arremolineado tan notable en las especies anteriores; es mui corta i mui fina en las patas, en las antenas i en el abdómen de los 5 ; en el pecho es mas larga i mas espesa; en las $\stackrel{q}{+}$ esta última parte i el abdómen llevan ademas unos pelitos dorados, mayores, ralos i ménos tendidos; en cuanto a los elitros, toda pubescencia ha desaparecido de ellas en las $q$, con escepcion de unos vestijios que quedan en el borde basilar i en el marjinal; pero, en el $\delta$, aunque mui corta i escasa, se divisa en toda la superficie.

Cabea sin brillo, i casi sin puntuacion ni arrugas; pero, como asimismo en las especies anteriores, con un angosto surco que la recorre en toda su lonjitud. La concavidad, que los tubérculos anteníferos forman en la fiente, es notablemente angulosa. El rostro es casi glabro i, como tambien en las especies precedentes, lleva por debajo unas gruesas arrugas trasversales; sus costados, o carillos, son casi impuntuados. Su anchura, en un $\delta$ de $36.5,(2.7)$ da el $63 \%$ de la anchura de la cabeza en los ojos (4.3). La lonjitud de los carrillos (1.5) da el $55 \%$ de la anchura del rostro. Estos guarismos sufren, en las hembras, unas pequenas modificaciones. - La anchura del rostro (3.0) da el $64 \%$ de la anchura de la cabeza en los ojos (4.7), en una + de 4 I 0 , i la lonjitud de los carrillos (2.0) da el 66\%, de la anchura del rostrolas cuales traen solamente un cambio en las proporciones de los carrillos con el rostro. En cuantoj al epistomio, el ápice agudo del triángulo, con que se une con la frente cn las especies anteriores, está aquí mas o ménos redondeado, o aun truncado.

En esta especie, la disposicion de los ojos es distinta segun el sexo: carácter que no se presentó en las anteriores.

Eu un of de $36.5-$ En una $q$ de +1.0

Distancia entrc las cávidades cotiloídeas. 2. I $\quad \cdots \quad-2.5$

\begin{tabular}{|c|c|c|}
\hline " & los ojos en el vertex.. 0.9 & - \\
\hline & la frente...2.3 & - \\
\hline , & la garganta. 0.6 & - \\
\hline
\end{tabular}


La distancia que los separa, tanto encima como debajo, está, pues, duplicada en las hembras. Su seno es poco profundo, de lo cual resulta que la línea ocular está apénas tanjente al borde esterno de la cavidad cotiloídea; su lóbulo anterior pasa levemente adelante de esta última. Para poder apreciar debidamente esta disposicion, es preciso dirijir la mirada perpendictarmente al rostro.

Las antenas tienen el artículo I levemente obcónico, macizo i corto; pues, pasa de mui poco adelante del borde anterior del protórax. Su lonjitud da el $66 \%$ de la antena total en el macho, i el $70 \%$ en la hembra.

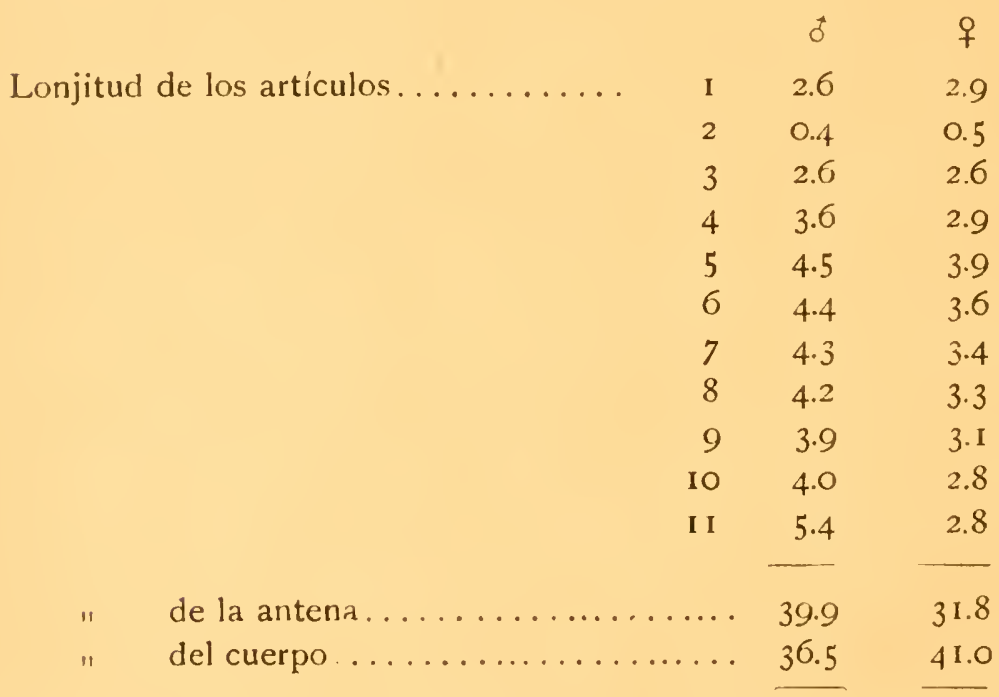

En el macho, las antenas son mas gruesas, i, con escepcion de las cortas cerditas que en ámbos sexos coronan el ápice de los 4 o 5 primeros antículos, parecen completamente glabras. Los artículos 3.1 I son cuadrangulares, pero con ménos regularidad que en el lovigatus; el art. 3 tiene su ápice perfectamente redondeado; en los $4 \cdot 10$, la carena esterna es mas aguda que las otras, i se arquea hácia el ápice donde termina formando un diente agudo i divaricado.

En las hembras, difieren por sus artículos 3, 4, que ámbos son 
cilíndricos con el ápice redondeado; i por los art. 5-9, los cuales, aunque cilfndricos tambien, llevan en su parte esterna dos anchos surcos lonjitudinales mas o ménos interrumpidos en el medio, i separados por una carena obtusa que, en el ápice acaba por un diente agudo; los dos últimos son irregularmente tetrágonos.

El artículo último de todos los palpos es cilíndrico en la parte apical, i termina por un truncamiento redondeado; en la basilar: son atenuados. En los labiales, la lonjitud del art. 3 (0.62) da el $88 \%$ de la de I, 2 juntos (O.7I), que son casi iguales. En los maxilares, la lonjitud de 4 (0.62) da el $65 \%$ de la de 2, 3 juntos (0.96), de los cuales aquel es de mui poco mas grueso. La lonjitud del palpo labial (I.4) da el $74 \%$ de la del palpo maxilar (I.9), i éste da el $46 \%$ de la lonjitud del cuerpo. Los arts. 2, 3 de los labiales $\mathrm{i}$ el 4 de los maxilares pasan solos, aquellos los lóbulos de la lengiieta i este último el lóbulo esterno de las quijadas.

El protórax presenta las medidas siguientes:

en un $\delta$ de 36.5 - en una $o$ de 41.0

\begin{tabular}{|c|c|c|}
\hline Lonjitud... & $4 \cdot 3$ & - \\
\hline nchura apical.............. & 3. I & - \\
\hline basilar .............. & 4.7 & - \\
\hline
\end{tabular}

El dorso lleva fuertes arrugas irregulares. Los dos tubérculos del medio son los mayores i cónicos; los laterales están situados un poco ántes de la mitad de la lonjitud; llevan la misma forma, pero su ápice está notablemente inclinado hácia la base. En la parte anterior se divisa un leve surco lonjitudinal.

El escudo es triangular, deprimido en el medio, con sus costados casi rectos engrosados a modo de rodete, i el ápice agudo.

Loselitros son levemente deprimidos; en un macho de 36,5 la anchura (8.0)es de $4 \mathrm{I} \%$ mayor que la del protórax, i casi lo mismo en una hembra de 41.0 (1.0); es del 6\% mayor que la lonjitud de la cabeza i el protórax juntos en el $f(7.5)$, i del 5 5\% en la $Q$ ( $\$ .5)$; ella da el $28 \%$ de la lonjitud de los elitros (29.0) en el $\stackrel{\uparrow}{-}$, i cl $30 \%$ en la $+(32.5)$. Están levemente atenuados hácia el ápice; 
pero esta atenuacion, evidentemente mas marcada en el $\frac{1}{4}$ basilar, es de una apreciacion difícil de este punto al $\frac{1}{4}$ apical, por estar mas o ménos apartados el uno del otro desde ántes del medio. En el macho, la línea sutural es recta, i, si en él los elitros se apartan desde el escudo hasta el ángulo suturai, csto es el resultado de una desicacion mal operada; miéntras que, en las $q$. los elitros están separados a causa de un encojimiento gradual del borde sutural (dehiscentes), desde cl a basilar, mas o ménos, hasta el ápice: disposicion que no permite dar con seguridad el valor de esta atenuacion. Pero en los machos no es lo mismo i se puede asentar que, mas o ménos, la anchura de los elitros, desde los ángulos humerales (8.0) hasta su primer $\frac{1}{4}(6.5)$, sufre uni merma de 1.5 , i solamente una de 1.0 despues de los $\frac{2}{4}$ siguientes (5.5): lo que da el $31 \%$ para la atenuacion total. La base de los elitros es recta, los ángulọs humerales mui redondeados, i el pliegue epipleural está como en el loevigatus; cada elitro, en el $\frac{1}{8}$ apical, se encoje i deja marcado el ángulo marjinal por una anchá curva, miéntras que el apical lleva una espina, a veces acortada, que nace un poco afuera de la direccion del borde sutural i oblícua levemente hácia adentro. Cada elitro lleva cinco costillas Ionjitudinales mui angostas: la $1 .{ }^{\text {a }}$ i las dos siguientes nacen en la base; aquella sale casi del mismo punto que la 2. a, pero es mui corta, pues alcanza a la sutura despues de dos o tres veces la lonjitud del escudo; las otras se juntan de un modo embrollado e irregular ántes de llegar completamente al ápice; la $4 \cdot^{a}$ i la $5 .^{a}$ nacen adelante del callo humeral, esta última forma el epipleuro. Ademas, todo el elitro está cubierto de una puntuacion de tamaño irregular i dispuesta sin órden, con escepcion de la orilla de las costillas, donde forma séries lonjitudinales, mucho mas regulares, completas i marcadas en el macho que en la hembra. Estos puntos son mas gruesos en la base, i, allí sobre todo, sus intervalos son angostos, convexos $\mathrm{i}$ alzados de modo a formar un enrejado bien visible.

El prosternon, en la mitad apical de la distancia que separa a las ancas del borde anterior es glabro $i$ arrugado trasversalmente; i, en la otra mitad, la salida intcrcoxal forma una corta i gruesa costa lonjitudinal.

El metastemon es puntuado, sus surcos marjinales son rectos, 
i el lonjitudinal es profundo; sus episternones tienen una anchura (2.4) que da el $28 \%$ de la lonjitud (8.5).

En ámbos sexos, el último segmento abdominal está anchamente bilobulado en su ápice. En los machos, el abdómen es mas angosto i mas rebajado que el metasternon; su pubescencia es fina i sedosa, i no presenta punluacion, pero la salida basilar es horizontal. En las hembras, el abdómen es casi de igual anchura i altura que el metasternon, i lleva unos puntos mui pequeños i mui apartados.

La lonjitud de los fimurés varía segun los sexos.

En un of de $36.5^{-\cdots}$ en una $q$ de +1.0

Lonjitud de los fémures anteriores... $8.0 \quad-\quad 7.0$

$\begin{array}{llllll}" 1 & \text { intermediarios } & 12.0 & - & 11.0 \\ " & \text { " } & \text { posteriores... } & 14.0 & - & 12.5\end{array}$

Los de este último sexo resultan, pues, mas cortos de $\frac{1}{5}$, mas o ménos.

En un $f$ de $36.5-$ en una $\rho$ de 410 Lonjitud del cuerpo.................. 36.5 - 41.0

" del fémur intermediario... 12.0 - 11.0 Proporcion de ésta con aquélla........ $33 \%$ - $27 \%$ Anchura basilar de éste............. $0.8 \quad \ldots \quad 1.0$

" apical.................... $0.9 \quad \begin{array}{r}1.26 \\ \hline\end{array}$

Proporcion de aquélla con ésta...... $89 \%$ - $79 \%$ "de ésta con la lonjitud... $7 \%$ - $11 \%$

En las patas posteriores, cl fémur del macho alcanza a la $3 .^{\text {a }}$ sutura abdominal; el de la hembra pasa de poco a la $2 .{ }^{a}$ I as tibias son del $22 \%$ mas cortas que dos veces la lonjitud de sus tarsos; i el art. I de éstos iguala a $2-4$ juntos.

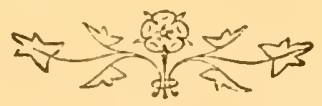




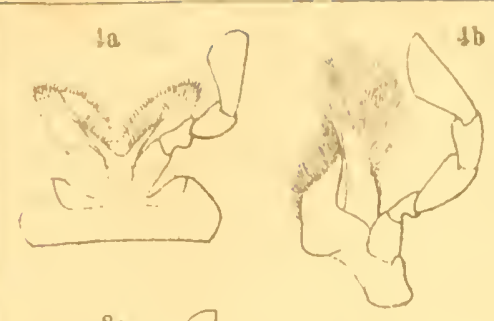

82

$5+2$

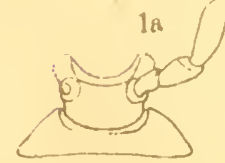

(b)

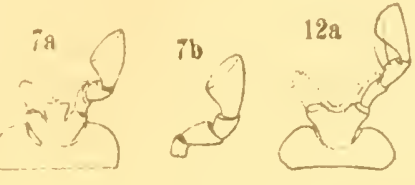

3

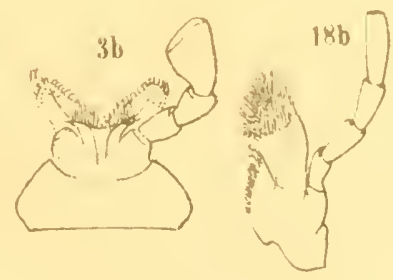

$18 \mathrm{~b}]$
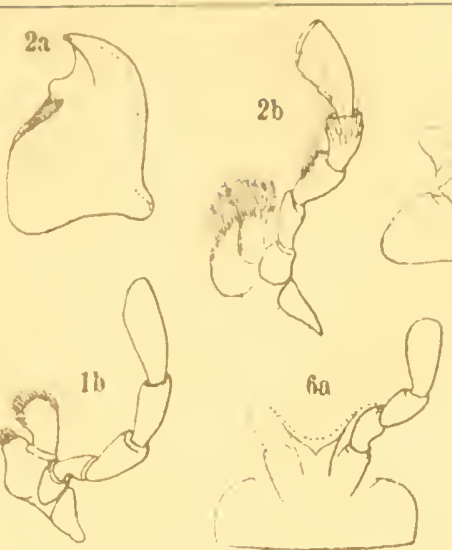

$6 \mathrm{~b}$

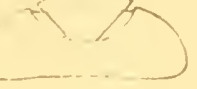

?

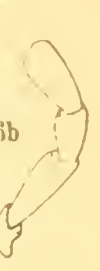




\title{
Ionjlcornlos chilonos
}

\author{
2. ${ }^{a}$ Sub-familia: Cerambicidos
}

SECCION B

Al hablar de los caractéres que separan la $S^{n} A$ de la $S^{n} B$, hemos visto que el mas notable de ellos consiste en la fuerte granulacion de los ojos: disposicion que, por resultar de una vida nocturna o a lo ménos crepuscularia, tiene forzosamente que agrupar alrededor de ella insectos, paia los cuales cierta semejanza de organizacion ha de ser la consecuencia natural de tanta semejanza en el modo de vivir.

Lacordaire, con su notable tino entomolójico, vió el valor de este carácter, desgraciadamente sin comprender su causa; i es de lamentar que, sin cluda por esta razon, haya admitido tan numerosas escepciones a la regla que él mismo acababa de asentar: dejando en la $r^{a}{ }^{a}$ seccion insectos $\mathrm{con}$ ojos finamente granulados, i en la 2. ${ }^{a}$ incectus con ojos fuertemente granulados; cuando habria quizas podido evitarlo valiéndose de caractéres talvez inénos aparentes, pero mas naturales que los de que se 
valió. Esto nos interesa, porque justamente entre los jéneros que favorece esta última escepcion, hai uno entre cuyas cspecies figura una de Chile.

Entre los demas caractéres que este entomólogo indica para esta 2. ${ }^{\text {a }}$ secccion, se notan los siguientes:

I." Lengiieta membranosa (con una escepcion): càrácter que no puede espresarse de esta manera para ninguna especie chilena; pues la lengüeta es córnea, i la parte anterior al punto de insercion de los palpos puede solo decirse membranosa.

2. ${ }^{\circ}$ Lóbulo esterno de las quijadas a momudo delgaito i penicíleo en su estremidad: caso en el cual esta escede la de los palpos i es visible al descunso. Naturalmente este carácter pierde mucho de su valor por ser aplieable sols a uni parte de las especies de esta seccion.

Lo mismo diré de los demas caractéres que indica, i que son los siguientes:

3. ${ }^{\circ}$ Cabeza prolongada adelante a modo de rostro $i$ atras a modo de cuello, en la mayor parte de las especies.

4. Modo de insercion de las antenas z'ariable.

5. Elitros varias veces mas o ménos incompletos, es iccir acortados o angostados de manera a dcjar las alas a la vista: las cuales, en este caso, no están dobladas trasversalmente en su parte apical.

Esta seccion es mui rica; pues hace treinta años comprendia ya 370 jéneros, que Lacordaire reparte en tres Divisiones; de las cuales la primera sola nos interesa, por ser la única donde figuran insectos chilenos.

\section{I. ${ }^{2}$ DIVISION}

Las especies colocadas en esta division son con mucho las mas numerosas $\mathrm{i}$ las mas hermosas tanto por sus matices como por su elegancia; pero el mayor interes que presentan para nosotros consiste en que entre ellas figuran estas formas aisladas, que provienen de Australia, Polinesia i Chile: ofreciendo otra vez a 
nuestras meditaciones un fenómeno inesplicado hasta hoi, i contra la esplicacion del cual vendrá quizas eternamente a estrellarse la sagacidad de lus naturalistas.

Pues si se tiene presente que, por no proceder a saltos, la Naturalcza ha de hiaber formado con los scres numerosas cadenas ( I) no interrumpidas, que se enlazan armoniosamente sin que se produzca nunca ni choques ni claros; parece evidente que los eslabones, a cuya falta estas formas deben su aislamiento, han de haber sido destruidos. Pero ¿cuándo i cómo?

I el entomólogo, entregado a las olas de un mar de hipótesis, queda movido a una parte $\mathrm{i}$ a otra, sin poder descubrir en el polvo de los siglos trascurridos algo que lo conduzca a la esplicacion de este enigma.

Segun Lacordaire, esta primera division presenta los caractéres siguientes:

1. Las antenas están siempre insertas sobre la frente a una distancia mas o ménos notable de las mandibulas.

2. La base de los elitros es mas elevadu que la del protórax.

3. La parte inferior de los segmentos torácicos no presenta una faz continua.

4. ${ }^{\circ}$ El mesosternon no cubre nunca la salida prosternal.

Pero, aquí tambien los caractéres 2 i 3 sufren algunas escepciones.

Despues de estudiar a fondo los insectos de esta division, Lacordaire confiesa haber sido, en alguna masera, impelido a repartirlos en 48 agrupaciones secundarias; las cuales-lo confiesa tambien-no pueden, como asimismo la de la sccion precedente, ser caracterizadas con precision, i, ménos aun, distribuirse de manera a respetar siempre sus analojías; i, para disimular lo mas posible las defectuonidades de estos arreglos, él ha puesto, al principio de esta Seccion B, las especies que se

(1) I no una sola cadena, como se porfian a verlo los naturalistas i los colecionistas: sistema sin duda mui cómodo para el arreglo de los restos de seres que ellos amontonan en sus cajas i para la formacion de las listas que figuran en sus catálngos; pero que, por la necesidad en que se ren de indicar, para calda especie, solamente dos de sus analojías mals inmediatas, los pone en lat obligacion de despreciar, o a lo ménos de dejar en la sombra $\mathrm{i}$ el silencio a una cantıdad de otras de igual valor. 
asemejan con mas evidencia a las formas autralianas i chilenas que terminan la Seccion A.

En cuanto al cuadro sinóptico que da de estas agrupaciones, tiene por bases-i alli está el punto mas flaco de toda esta organizacion-la conformacion de las ancas anteriores i la de las cavidades cotiloídeas intermediarias.

Hemos dicho ya, respecto a la forma globulosa, angulosa o trasiersal de aquélla*, que si los estremos son de constatacion fácil, no se sabe muchas veces qué determinacion tomar con los int rmelio. Se tropi za crın las mismas dificultades relativamente a las últimas: la parte esterno-basilar del metasternon se adelanta tan gradualmente al encuentro de la parte esternoapical del mesosternon, para cortar el paso al epímero mesotorácico e imp dirle que contribuya a cerrar la cavidad cotiloidea; que, muchas veces, la opinion del entomólngo queda en suspenso, sin que le sea posible decir si está cerrada o abierta; cuanto mas que, en las especies en las cuales este carácter queda dudoso, no lo es en igual grado en todos los ejemplares de una misma.

Pero Lacordaire parece no haber visto la cuestion bajo la faz que indico aquí; pues si llega, como yo, a decir que estos dos caractéres son impotentes para clasificar los Cerambicidos, no.entiende que esto provenga de la dificultad que hai en cons. tatarlos; sino que, en todo arreglo que los toma por base, otras analojías, apoyadas sobre caractéres tan respetables como cllos, se hallan tan violentamente atropelladas que la puerta se halla anchamente abierta a las escepcioncs; es decir, a la desorganizacion del plan que propone. Por estc, no hai que estrañar sus palabras cuando dice de él: "Malgré le long travail que ce tableau m'a con̂té, al est trís imparfait, et présente même une lacune que je n'ai pu parvenir á éviter".

Sea lo que fuere de su valor, tomaré, pues, estas agrupaciones tales como él las presenta; cuidando, por cierto, de no au. mentar la confusion en que las dejó, con la introduccion de mejoras o lenitivos mas o ménos acertados. 


\section{AGRUPACION DE LOS PTEROSTENIDOS}

En 1860, hallé, por primera vez, en los valles andinos donde corre el N̂ble i subre el cipres (Libocedrus chilensis), un pequeño Lonjicornio cuyn facies estraño llamó ini atencion. Muchos años despues, en I892, lo encontré en el camino de las Termas de Chillan a las orillas del Reneugado sobre el Mañiu (Podocarpus chlina); i, por fin, en 1893, lo encontré tambien en el norte de Araucania, en cl valle del Renaico; pero entónces fué sobre el Lleuque (Prumnopity's elegans).

Este insecto aparece mas o ménos en Dicieinbre i Enero; $\mathrm{i}$ es de notar que, si habia elejido cada vez por domicilio un árbol de especic distinta, ésta pertenecia siempre a la familia de las Coníferas.

Bajo cl nombre de Pterostenus pseulo-cupes, Fairmaire describió esta especie (Rev. Zool., I867, p. 393) sobre ejemplares de los hallados en el cipres; i, con razon, la colocó en la agru. pacion de los Pterostenidos, que hasta entónces habia comprendido solamente insectos de Australia, i para lo cual Lacordaire (Genera, T. VIII, p. fIO) indica los caractéres siguientes:

1. ${ }^{\circ}$ Palpes très courts, fuiformes, subígant.x.

2. Mandibules courtes, aigies au bout.

3. Téte peu à peu et fortement rétrécie en arrière, prolongée en un museau variable, mais le plus souvent large, court et parallike.

$4 .^{\circ}$ Antennes filiformes on sétacées, an maximum un peu plus longues que les élytres; leur article I plus ou moins allongé.

5." Yeux petits, ovalaires, entiers, longitndinanx, à granulation variable.

6." Prothorax allongri, rétréci en auant, en gínúral uberculeux sur les côtés.

7." Elytres très allongies, munies dé fune's côtes longitudinales trìs regulières; débordant en aìnt la base du prothorax.

8. ${ }^{\circ}$ Pattes de longuenr variable; hanches antéricure's coniqués, suillantes, contigiies; leurs caviti's cotyloüdes oniertes en arriere; celle's des intermedixires onvertes en dehors.

9." Lipisternums metathoraciques, ctroits, aignes in arrière. 
IO. Saillie mesosternale inclinée, etroite.

I I. Corps allongé.

Pero, del jénero Pterostenus, donde mi sabio colaborador lo habia puesto, este insecto pasó luego en el j. Syllitus, creado por Pascoe, para unas especies que, segun Lacordaire, se distinguen de aquél por los caractéres siguientes:

I. O Ojos bastante fuertemente granulados, mas gruesos i mas salientes.

2. ${ }^{\circ}$ Antenas mas delgadas, setáceas.

3. Protórax notablemente mas largo, subcilíndrico, encojido en su mitad anterior, con un surco circular adclante; su parte postcrior es levemente hinchada i tuberculosa lateralmente.

$4 .^{\circ}$ Ultimo segmento abdominal glabro en ámbos sexos.

$5 .^{\circ}$ Cuerpo sumamente angosto i esbelto.

Ademas lia librea i la escultura de los tegumentos son tambien distintas: aquélla es de un leonado livido mas o ménos denegrido, i ésta consiste en unas dos o tres líneas salientes sobre cada elitro.

De paso, me permitiré criticar toda manera comparativa de presentar los caractéres de un jénero. Pues, es evidente que la claridad de las diagnósis no se conseguirá nunc con el abuso, o aun con el uso, de los mas i de los ménos; sino haciéndolas propias i completas para cada jénero. ¿Quién no ve que, por no tener a su alcance un jénero que se toma por tipo, el entomólogo se hará difícilmente una idea exacta de otro jénero que se compara con él?

El hecho de cncontrarse en Chile otra forma esclusivamente australiana, es un ejemplo mas de la semejanza inesplicada que ofrecen las Faunas cntomolójicas de estas dos rejiones; i, delimitar esta forma con exactitud, es lo primero que se debe hacer para llegar al descubrimiento de las causas de esta semejanza.

Bien supongo que nadie se estrañará al ver la especie chilena, que estudiamos, estar en leve desacuerdo con las diagnósis que Lacordaire nos da (Genera, T. VIII, p. $122,4 I 3$ ) de los jéneros Pterostenus i Syllitus; i, comn no se puede asegurar que estas diferencias existen realmente i no resultan de errores cometidos por este sabio entomólogo, el temor de recditar algunos de estos últimos me ha conducido a dar prolijamente los caracté- 
res jenéricos de dicha especie, inclicando las contradicciones que ofrecen con los del uno o del otro de estos dos jéneros.

I uego diré que este insccto se aparta aun de la agrupacion de los Pterostenidos, tal como la caracteriza Lacordaire, por los puntos siguientes:

1. ${ }^{\circ}$ Los palpos no son "subégaux"; pues la lonjitud de los Irbiales (0.26) da el $5 \mathrm{~S}$ por ciento de la de los maxilares $(0 .+5)$.

2.0 La cabeza, en lugar de ser "rétrécie peu ì peu et fortement en arrière", lleva detras de los ojos la misma anchura que delante; i, a una distancia de cllos mas o ménos igual a su diámetro, se contrae brucamente para formar un cuello de una lonjitud semejante, pero del 20 al 25 por ciento mas angosto.

3." No se puede decir que las ancas anteriores son "contigües"; pues la salida prosternal es, sí, lameliforme i enterrada, pero no está suprimida.

$4^{\circ}$ Los ojos tienen de 0.30 a 0.35 "de diámetro, lo que da aproximadamente los $\frac{2}{5}$ de la anchura vertical de la cabeza, $i$ el 3 de la horizontal; ademas son redondos: lo que no permite verlos "longitudinaux".

En cuanto a la disconformidad jenérica que los Syllitus chilenos ofrecen con los Pterostenus i los Syllitus de Australia, ella se manifiesta snbre lis puntos siguientes:

I. Los tubérculos anteníferos no están aproximados hasta formar una parte levantada en medio de la frente (Pterostenus); sino que la distancia que los separa entre sí es doble de la que los separa de los ojos, i, entre ellos, la frente presenta una fuerte concavidad angulosa.

2.0 Los ojos no son "trés élighnés" de las antenas (Pterostenus); la distancia que lus separa de estas últimas siendo mas o ménos igual a los $\frac{2}{3}$ de su diámetro.

3. L Lo fémures no son "graduellement, en massuen (Pterostenus) sino que llevan una forma casi oblonga aunque alargada, sicudo mui angostos casi solamente cerca de los trocanteres, los cuales están en el eje de los fémures i los separan completamente de las aıcas.

4." El 5. segmento abilominal no está "dénsément cilié (Pterostenus). 
$5 .^{\circ}$ Este segmento no es "glabre dans les deux sexes" (Syllitus) sino pubescente como los otros.

6. El cuerpo no es "glabre" (Pterostenus), sino fina i enteramente pubescente con escepcion de los élitros.

7. Estos últimos no llevan cada uno dos o tres costillas (Sy1litus), sino cuatro (Pterostenus).

En cuanto a la granulacion de los ojos que, segun Pascoe i Lacordaire, es gruesa en el j. Syllitus, i forma el principal carácter que lo distingue del $\mathrm{j}$. Pterostenus, ella consiste en séries de doce a catorce ojitos en las hileras centrales, es decir, por una lonjitud de 0.3 a 0.35 .

Pero, ántes de pasar mas adelantc, confesaré que cl estudio prolijo de los ejemplares de la especie recojida sobre el mañíi $\mathrm{i}$ el lleuque, i que son los únicos a mi alcance, pone en evidencia tan numerosas i tan notables diferencias con la descripcion del S. pseudo cupes redactada por Fairmaire sobre ejemplares encontrados en el cipres, que me veo acometido por la sospecha de que estoi en frente de dos especics distintas, aunque mui ve. cinas. A consecuencia de esta conviccion describo aquéllos como una especie nueva, bajo el nombre de S. cylindricus, indicando estas diferencias en el lugar que corresponde a cada una.

\section{S. CILINDRICUS ('mihi)}

Elongatus, cylindricus, haud, depressus, castaneo-fumosus, breriter parceque pubescens. Capite elongato, antice in rostrum latum producto, postice in collum crassum abrupte coarctato, lateritus in medio parallelis; supra dense punctato, postice fortiter rugato; fronte concava; epistomio levi; gula transversim tenuiter mgata; oculis minutis, grosse granulatis, rotundatis et parum ersertis; antennis gracilibus, glabriusculis, apud के elytrorum apicem vix attingentibus, apud o leviter brevioribus, articulo $1 .{ }^{0}$ longiore, gradatim clavato, prothoracis marginem anticum superante; mento brevissimo; labio antice angulatim obtuse sinuato, lobulis membranaceis apice pubescentibus; palpis omnibus articulo ultimo cylindrico procedentibus duobus junctis leviter breviore; palpis maxi- 
llaribus labialibus fere duplo longioribus. Prothorace longiore quam lato, apice capite angustiore; luterihus utrinque hicallosis, callo postico majore, acute obtuso; tergo dense punctuto rugoso tu. berculis pariis tomato, duobus anticis majoribus. Scutello apice rotundato. Elytris conaexis; longitudine latitndinem fere quinquies aquante, capitis prothoracisque longitudinem bis paulo superante; lateribus perfecte parallelis, apice separatzm rotundatis; margine suturali atque laterali anguste costulatis; dorso glabriusculo, obscure testuceo, utrinque maculis irregularibus duabus brunneis unter basim et apicem aquidistantibus, picto, et costis 4 pallidis angustis, usque ad aficem parallelis longitrorsum ornato; interuallis planatis, punctis plus minusve confuse 2 vel 3-seriatis dense impresis. Prosterno mesosternoque inter coxas v'alde angustatis. Abdommis segmentis omnibus pubescentibus. Pedibus parum elongatis; femoribus anguste oblongis; tibiis posticis elytronum apicem aix attingentibus. Tarsonum articulo $3 .^{\circ}$ profunde biiobato.

l.ong. 9, 10-6.50; lat. I, 45-1,10.

La grande analojía que los Holopteridos i los Pterostenidos presentan en las proporciones del cuerpo, como asimismo en la forma de la cabeza i del protórax, es tan notable, que, al hacer terminar la Seccion A por aquéllos, no hai vacilacion posiblc, en hacer principiar la seccion $B$ por los últimos. Cuanto mas que, si en los Syllitus, la gruesa granulacion de los ojosindicativa de costumbres crepusculares-demuestra su parentesco evidente con los Holopteridos, la forma tan característica de esos órganos señala una no menor con los l'terostenidos: este jénero sirve así de eslabon intermediario entre estas dos agrupaciones; las cualea, por su parte, desempeñan un papel idéntico entre las Secciones A i B.

Pero debo advertir que, no conociendo los Silitos australianos sino por unos datos escasos, se entiende que las líneas precedentes sc aplican con exactitud solamente a la especie que describo aquí. I se tendrí tambien presente que, fuera de cscepcimes indicadas en su lugar, las medidas que figuran en esta descripcion han sido tomadas todas sobre un ejemplar? di: 7.90 de lonjitud.

Cuerpo cilindrico, convexo, angosto i alargado, cuya anchura 
da el 7 por ciento de la lonjitud. Es sin brillo, i cubierto de una fina pubescencia sedosa, corta, mui echada i poco abundante. Su matiz jeneral es un castaño mas o ménos ahumado.

La cabeza está densamente puntuada en su parte superior, con escepcion del vertex que es fuertemente arrugado, i lisa en cl epistomio, el labro i la garganta; sin embargo, unas finas arrugas trasversales se dejan ver sobre esta última. Su parte posterior está angostada bruscamente a modo de cuello, miéntras que la anterior se prolonga en forma de ancho rostro. Encima es fuertemente convexa en el sentido lonjitudinal, por lo cual parece mas corta vista de lado que de arriba: los guarismos siguientes facilitarán la rectificacion de toda ilusion de óptica a este respecto.

Vista de lado, la parte situada entre la boca i el cuello es diforme: cónica en sus $\frac{5}{8}$ anteriores, mas angosta i subcilíndrica en los $\frac{3}{5}$ posteriores. Vista de arriba es alargada i con forma de paralelógramo en los $\frac{4}{6}$ intermediarios: Io que no permite de ninguna manera decir que tiene la forma de un "ovoïde court".

La lonjitud del cuello es le $0.30 \mathrm{i}$ su anchura de 0.70 .

La lonjitud del vertex, entre el borde posterior de los ojos i el principio del cucllo, es de $0.40 \mathrm{i}$ su mayor anchura de I.OO.

La mayor anchura del rostro es igualmente de I.00; i su Ionjitud, desde el borde anterior de los ojos, hasta la base de las mandibulas, es de 0.50 ; en la altura del borde interno de los ojos, está separado de los carrillos por un profundo surco fle xuoso.

Los ojos son redondos, con un diámetro medio de 0.33. Son poco salientes; pues la anchura de la cabeza medida en ellos es de I.20; lo que indica que sobresalen solamente de o. Io en cada lado. La granulacion es gruesa; es decir qui, en el medio, las hileras de ojillos constan solamente de doce a catorce. Su distancia entre sí, tanto arriba como abajo, es cle 0.90 .

De las medidas precedentes, resulta que la lonjitud del rostro da los ; de la de la cabeza propiamente dicha; es decir de la parte comprendida entre la boca i el cuello: lo que no permite decir de aquél que es "court".

Las cuvidades cotiloídeas antenarias están situadas sobre la frente a la altura de la parte anterior de los ojos. Su distancia 
de estos últimos es de O.I4, $\mathrm{i}$ la que los separa entre sf es de 0.42. No están escotadas pero mui oblícuas hácia afuera, por hallarse su borde interuo engrosado i saliente a modo de rodete. De lo cual resulta que, entre ellos, la frente está angularmente cóncava. En el fondo de esta concavidad se divisa un fino surco lonjitudinal, a veces prolongado, sobre el rostro, pero en jeneral casi completaınente borrado; el cual se trasforma sobre el vertex en una finísima costillita.

I as antenas son glabras $\mathrm{i}$ filiformes, con una lonjitud que no alcanza completamente a la estremidad de los élitros en los A; i ellas son aun mas cortas en las + . El artículo I es redondeado i con forma de una maza levemente arqueada en su ápice, i bastante largo para sobrepujar al bordc anterior del protórax. I a pequeñez del artículo 2 es tan constante que no veo conveniente hablar de él, sino en los casos mui raros en que hace escepcion a la regla; de los demas, el 5 es el mas largo i el Io el mas corto.

Doi escepcionalmente la lonjitud de los artículos en cuatro machos i en dos hembrą; para poner de manifiesto la constancia de ciertas proporciones, como asimismo la de los límites entre las cuales otras quedan encerradas.

Lonjitud de los ar-

$\hat{\imath} \cdot \hat{\delta} \quad \hat{\delta} \quad \hat{\delta} \quad \hat{q} \quad \hat{q}$

$\begin{array}{lrllllll}\text { tículns............ } & \text { I } & \text { I.IO } & \text { I.30 } & \text { I.IO } & \text { I.20 } & \text { I.00 } & \text { I.00 } \\ & 2 & 0.16 & 0.16 & 0.14 & 0.18 & 0.14 & 0.14 \\ & 3 & 0.76 & 0.86 & 0.72 & 0.76 & 0.72 & 0.72 \\ 4 & 0.80 & 0.90 & 0.76 & 0.80 & 0.76 & 0.74 \\ 5 & 0.84 & 0.96 & 0.80 & 0.90 & 0.80 & 0.80 \\ 6 & 0.74 & 0.82 & 0.76 & 0.74 & 0.60 & 0.66 \\ & 7 & 0.72 & 0.84 & 0.76 & 0.74 & 0.62 & 068 \\ & 8 & 0.66 & 0.82 & 0.70 & 0.62 & 0.60 & 0.60 \\ & 9 & 0.66 & 0.80 & 0.70 & 0.58 & 0.60 & 0.62 \\ & 10 & 0.60 & 0.70 & 066 & 0.48 & 0.54 & 0.56 \\ & \text { I1 } & 0.64 & 0.86 & 0.76 & 0.56 & 0.62 & 0.64\end{array}$

Lonjitud total de la antena..............

$\begin{array}{llllll}7.68 & 9.02 & 7.86 & 7.56 & 7.00 & 7.16\end{array}$

$\begin{array}{llllllll}\text { Lonjitud del cucrpo.... } & 7.90 & 9.10 & 7.92 & 7.80 & 7.70 & 8.20\end{array}$

Diferencia de aquella en ménos. . ...........

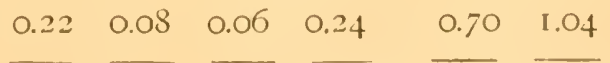


La barba es mui trasversal i mui corta, pues su lonjitud (0.075) da solanente el 23 por ciento de su mayor anchura (3.25); el borde basilar es arqueado con la concavidad hácia atras; los costados son rectos i levemente oblícuos hácia afuera hasta el tercio apical, donde forman un ángulo casi recto $\mathrm{i}$ se dirijen en línea recta i mui oblícuá sobre el borde apical, que es recto tambien.

La lengïeta es dos veces tan larga como la barba i da el 93 por ciento de su anchura; un seno en ángulo obtuso la divide anteriormente en dos lóbulos membranosos pubescentes i redondeados en el ápice, rectos en su borde interno, i de una lonjitud mas o ménos doble de su anchura. Lá lonjitud de sus palpos da el $\sigma_{3}$ por ciento de la de los maxilares; sus artículos I i 2 son mas o ménos de ignal anchura i lonjitud; el ápice del 2 da con el ápice de los lóbulos; el 3 cs cilíndrico, levemente angostado mui cerca de la base i redondeado en el ápice, su anchura $(0.058)$ da el 45 por ciento de su lonjitud (O. I 3 ), i esta da el 88 por ciento de la de los dos primeros juntos.

El lóbulo interno de las quijadas tiene la mitad de la anchura i de la lonjitud del esterno. La anchura de los artículos de los palpos I, 4, 3, 2 va aumentando succsivamente de 0.08 mas o ménos en cada uno; la lonjitud de 1, 2, 3 aumenta gradualmente, pero mui levemente; el ápice del 3 da con el ápice del lóbulo esterno; en cuanto al 4 , su forma es igual a la del último de los labiales, su anchura (0.058) da el 34 por ciento de su lonjitud (0.17), i esta da el 80 por ciento de la de 2 i 3 juntos.

Las mandibulas son cortas, trígonas, sin dicute en el borde interno, i su ápice está arqueado en forma de gancho corto, agudo i entero.

El protórax, está cubicrto de una puntuacion rugosa mui apretada. Sus proporciones son las siguientes:

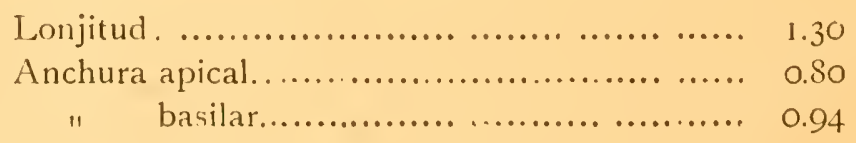

Su anchura apical da, pues, el So por ciento de la anchura de la cábeza delante i detras de los njos, i la basilar da el 67 
por ciento de la de los élitros a 0.5 de la base. Encina, la base es recti, i el borde apical presenta un leve seno anguloso on el medio. El der:o es mui desigual con motivo de ocho callos di-puestos como sigue: cada costado lleva dos, de los cuales el mayor, obtuso pero puntiagudo, está situado apénas en el medio desde la base; delante de él el protórax está contraido $\mathrm{i}$, despues, levemente dilatado para formar ántes del ángulo apical otro callo mucho mas pequeño. Los otros cuatro son pequeños i redondeados, i están dispuestos en cuadro: los dos primeros en el primer tercio desde la base, los otros dos en el segundo. Estos son mas gruesos i mas juntos que aquéllos.

El escudo es casi con forma de medio círculo.

Los élitros son convexos, i de ninguna manera puede decirse de ellos que son "subdepressis (déprimées en dessus"). Su base es recta con los hombros brevemente redondeados; sus costados son perfectamente paralelos desde 0.5 de la base hasta 0.5 del ápice, el cual está redondeado separadamente en cada élitro. Su anchura ( I 40) da el 23 por ciento de su lonjitud (5.90). Pero si, con respecto a esta proporcion, el insecto descrito aquí se asemeja a los Holopterus, no es lo mismo relativamente a la proporcion de la lonjitud de la cabeza i del protórax juntos con la anchura i la lonjitud de los élitros. Pues, cuando en un Hol. chilensis of de 36.5 , aquella lonjitud-medida desde el borde anterior de las cavidades cotiloídeas antenarias hasta la base del protórax-da cl 94 por ciento de la anchura de estos últimos i el 26 por ciento de su lonjitud, vemos que, en un $S y l$. cilindricus, ella da cl 37 por ciento de la lonjitud, i que escede del 36 por ciento a la anchura, en lugar de serle del 6 por ciento inferior.

El borde sutural i el lateral están ribcteados por una fina linea saliente; i, ademas, cadá élitro lleva cuatro costillitas lonjitudinales finas i salientes: la r a i la $2 .^{\mathrm{a}}$ se juntan en la bace; las cuatro siguen paralclas en toda su cstension; pero, miéntras

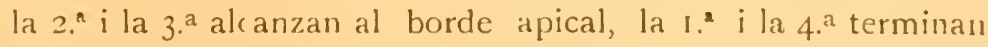
bruscamente un $\mathrm{m} m$ antes de alcanzarlo. Sin embargo, en uno de los dos ejemplares $q$ que tengo a la vista, las costillas $2,3, \mathrm{i}$ 4 se juntan en una sola a $5 \circ 6 \mathrm{~m} / \mathrm{m}$. de la estremidad: lo que indica el poco valor de los caractéres proporcionados por la dis- 
posicion de las estrias, de los surcos, o de las quillas i costillas en el ápice de los élitros.

De los cinco intervalos debidos a estas seis líneas salientes o costillitas, los tres laterales son iguales entre si i mas angosto que el $20^{\circ}$, el cual es livemente mas anchn que el 1.\%. Ellos son toios aplanados $\mathrm{i}$ cubicrtos de una puntuacion mui apretacla $\mathrm{i}$ relativamente gruesa, a reces confusa en IA parte basilar, i dispuesta en séries mas o ménos embrulladar en lo demas. Estas séries están en número de dos en cada uno de los tres intervalos estermos, i de tres en cada uno de los dos intermos: doce por todo.

Aquí diré que la naturaleza de esta puntuacion ha de ser probablemente mui distinta de la que, para el S. psendo-cupes, mi sabio colaborador indica del modo siguiente: "interstitiis tenuissime ciense punctatis (intervalles a ponctuation tris fine', très serví et un pe'll rugikuse) II; o él quizas, no habrá pesado de un modo suficiente el valor de las palabras que cmplea para espresar su tamaño. Voi a esplicarme.

Cuando, para calificar una puntuacion, se dice de ella que es fina o gruesa, no se ha de mirar únicamente el tamaño de los puntos, sino que se ha de considerar tambien el tamaño del insecto que lus lleva; porque aquél es for\%osamente relativo con éste. De otra manera, seria prohibido a $\mathbf{m}$ insecto pequeño tener una puntuacion gruesa, por el motivo-en aparicncia lójico-de yue su tamaño reducido lo condena a puntos de un diámetro reducido tambien: lo que, sea dicho de paso, haria inútil decir que su puntuacion es fina.

En el S.cylindricus, el élitro, que mide solamente 0.7 de anchura, está repartido lonjitudinalmente cn cinco intervalos por seis finas costillitas. Luego, cada una de éstas ocupando una anchura media de 0.04 - sea 0.24 para todas-queda así otra allchura de 0.46 a repartir entre los cinco intervalos. Ahora, como se ha visto que la puntuacion forma en ellus doce séries lonjitudinales mui apretadas, resulta que esta anchura de 0.46 estri recorrida trasiersalmente por lineas de doce puntos contiguns, cuyo diámetro ei $\frac{0.46}{12}=0.038$; los cuales, por esto, serán declaradus finisimos. Pero, si esta disposicion se reproduciese en 
un insecto de diez diámetros mayor, es decir con una anchura de 7.00 para cada élitro, tendriamos puntos de 0.38 de diáme. tro, lo que les mereceria el calificativo de mui grandes.

Estimo que esta manera de apreciar el tamaño de una puntuacion es defectuosid, por no consultar, al mismo ticinpo que su valor incramente jeométrico, la importancia superficial del órgano que la lleva; calificando así de dos modos contrarios dos resultado; iguale; en cuant, a sus proporciones. De lo que se pued: sacar esta conclu-ion: que la puntuacion de los élitros del S. cylindicus no ha de rlecirse finisima, por mas que sea compue:ta de puntos enn solo 0.038 de diámetro; i que, para toda puntuacion, es preferible reemplazar calificativos engañosos por clatrs sue indiquen claramente su importancia relativa.

La superficie de los élitros es casi completamente glabra, con las costillas en jeneral inas pálidas que sus intervalos. Cada uno lleva dos manchitas oscuras levemente alargadas, pero mal limitadas, que cubren casi completamente los intervilos 2 i 3 al concluir el 1. "i el 2." tercio de su lonjitud.

La salida prosternal es lamcliforme i enterrada, pero existe. La salida mesosternal es mui angosta i casi lameliforme.

Los segmentos abdominales son de igual lonjitud, i trodos igualmente pubescentes. Su salida intercoxal es crirta i en ángulo puntiagudo, pero casi recto.

Las ancas anteriores e intermediarias son globulosas, pero aqucllai presentan una salida angulosa en su parte eiterna.

Lis cavidades coliloídeas anteriores están abierta; posteriormentc, i presentan un seno anguloso lateralmente. I,as intermediarias están abiertas en su parte esterna.

Los fémures están completamente separados de las ancas por los trocánteres; pues estos últimos están situados en el eje de aquellos, los cuales pueden así decirse pedunculados. Su forma es oblonga, i su angostamiento basilar va desde la mitad de su lonjitud hasta el trocánter. En un? de 7.80 las proporciones de los fémures es como sigue:

Anteriorcs.. .... Ionj. 1.5... anch. $0.34 \ldots$ prop. 0.226

Intermediarios.. "

Posteriores..... " $1.8 \ldots \quad$ " $0.38 \ldots \quad$ " 0.211 
l'ues de unos munlos, cuya lomjitul queda entre cuatro o cinco veces la an hura, no se pucele decir pue son "ai perille éprissisn,

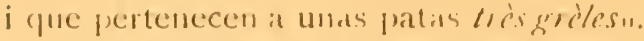

las proporcinnes elel fému interunceliaro son las siguientes:

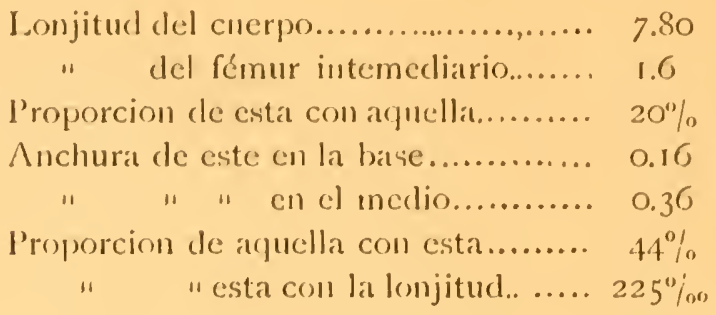

lil fémur postcrior alcan\%a apénas a la tercera sutura abdominal en el $\delta$, i es levemente mas corto en la $q$

lass tilizus son mas o ménos tan largas como su fémur; pero el ápice de las posteriores mo alcanza a la estremidad de los élitros.

I a Innjitud del tarso da la mitad de la de la tibia; i la de su primer artículo iguala la de los 2 i 3 juntos.

fairmaire dice (pue el 3." artículo de los tarsos es "élargi mois non achancré". Esta última palabra ha de ser una equivocion: es, sin ducla "bilobén cjue él habrá querido decir. Sea lo que fuera, el 3." artículo de los tarsos de nuestrat especie es evidentemente bilobulado.

Quedo indeciso sebre la cuestion de saber, si la descripcion de la especie de: liammaire (Psendo-cupes) no se dice con la que tengo en manos (cylindricus), porque restris dos especies son verdaderamente distintas, o porque afuélla está descrita de uin modo defecturoso.

En el priner caso, yo habria hecho hien en describir ésta como nucva; miéntras (jue en el segundo, se daria razon a los que pretenden qur, para reconocer una especic, es preferible ver al tipo que consultar su descripcion. I a inutilidad de estas últimas, quedando ací establecida, seria, me parece, mas senciIlo stuprimilas para sicmpre; i los entomólogos, en lugar de acompañar com una descripcion cnigmática el nombre gue dan a un insecto, podrian contentarse con decir: el tipo está clavado 
en las cajas de tal u cual coleccionista con un rotulito esplicati. vo al alfiler.

Evidente que los entomólogros, víctimas inconscicntes de una pendiente resbaladiza, han llegado y'a at formar dos campos: en el uno están los coleccionistats para cutienes la entomolojia es una reunion de insectos calla uno con su nombre legal, miéntras que el otro comprende los naturalistas, para quicnes esta ciencia descansa sobre una reunion de insectos, citda uno con su descripcion completa i exacla.

Laim. III. fig 1a crbesa vista de lado...... Aum. I 5 diám.

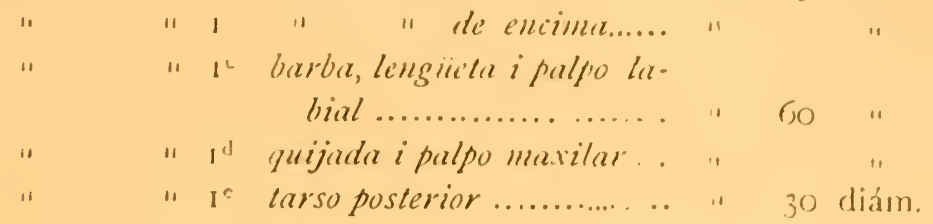

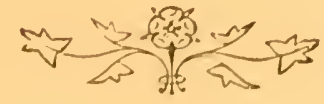





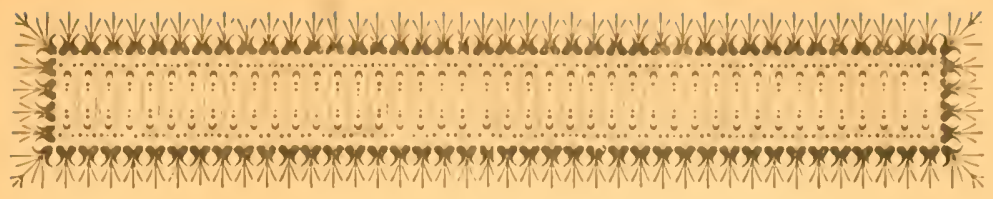

\section{AGRUPACION DE LOS AMETROCEFALÍDOS}

Lacordaire ha establecido esta agrupacion (Genera: VIII, p. 420) sobre el jénero Ametrocephala creado por Blanchard (in Gay Zool. $I$. p, , $S_{S}$ ) para nna especie chilena; a la cual se han agregado tres mas, que tienen la Australia por patria. I, en esta ocasion, Lacordaire hace notar con razon que, con el Syllitus que se acaba de describir, este insecto constituye el ejemplo mas patente de las relaciones que tienen entre sí las Faunas entomolójicas de estas dos rejiones.

Estos insectos son unos Lonjicornios mui orijinales en cuanto a la forma; pues se parecen completamente a hormigas; $i$, por la estructura de la cabeza, así como por la disposicion de los ojos i de las antenas, se apartan mucho de lo que jeneralmente se ve en esta familia.

Al hablar de estos insectos, Lacordaire dice que, por no haber conocido las especies de Australia, no está mui seguro que pertenezcan al j. Ametrocephala tal como fué creado por Blanchard para la especie chilena; i como, por otra parte, los caracteres jenéricos que da no cuadran mui bien con los de esta última, vui a presentar aquí solo los que le corresponden exac. 
tamente, sin ocuparme de las diferencias que pueden presentar con los de las especies australianas.

\section{Gen. AMETROCEPHALA (Blanch.)}

Cabeza con forma de una bolita algo deprimida: depresion a la cual el mayor diámetro vertical debe de estar menor de una quinta parte que el mayor diámetro horizontal. Por delante es levemente atenuada de los ojos a la boca; miéntras que por atras, i a una distancia de los ojos que es casi doble del diámetro lonjitudinal de estos últimos, ella está contraida brúscamente en un corto cuello, cuyo diámetro da los 0.44 de su mayor anchura horizontal.

En el ejemplar $q$ de $\delta . \|$ de lonjitud que nos sirve de tipo, esta anchura es de I.70; miéntras que es solo de 1.05 en ámbas estremidades del protóraxi de I.44 en el medio; pero es de r.80 en la base de los elitros, i de 2.11 en el medio de su mitad apical. Resulta, pues, de estos datos que Blanchard exajera grandemente cuando dice: "caput grossissimum" i "cabeza enormemente gruesa 1 .

Por su posicion en la estremidad de una cabeza globulosa, las piezas de la boca tienen naturalmente que parecer pequeñas; pero, en cuanto a los palpos, cuyos labiales son dichos cortos por Lacordaire i cuyos maxilares son dichos largos por Blanchard, la verdad es que sus proporciones son perfectamente normales: la lonjitud de aquéllos $(0.36)$ da el 55 por ciento de la de los últimos (0.65). Notaré aquí que no es mui exacto decir del último artículo que es triangular (Lacordaire).

La barba es mas o ménos dos veces tan ancha como larga; i es espesa, con la faz esterna saliente a modo de prismo trasversal.

La lengiieta es de igual lonjitud que la barba. Desde el punto de insercion de los palpos es membranosa, i dividida en dos anchos lóbulos oblongos, diverjentes, redondeados i pubescentes en su estremidad, i separados por un ancho seno redondo en su ápice. Los dos primeros artículos de sus palpos son de lonjitud i de anchnra casi iguales; el 2 no alcanza a la estremidad del lóbulo membranoso; i, juntos, dan solo el 75 por ciento de 
la lonjitud del último; en su mitad anterior, éste es poco ménos de dos veces tan ancho como cllos, i tiene su ápice truncado.

Las quijadas tienen sus lóbulos largamente pubescentes en el ápice; el esterno es a lo ménos dos veces tan largo i tan ancho como el interno. En cuanto a sus palpos: cl artículo I ticne la mitad de la lonjitud de cada uno de los dos siguientes; es obcónico, arqueado, i, como en varias especies, tiene un seno en su parte esterna; los 2 i 3, levementc obcónicos, son iguales de lonjitud i de anchura; pero, juntos, alcanzan a dar algo mas que la lonjitud del 4; éste es grueso, oblongo, de una cuarta parte mas ancho que ellos i truncado en su ápice. Como se ve, esta descripcion difiere bastante de la que da Blanchard (Gay, $Z o o l, V, p .780$ ), en la cual dice que los lóbulos de las quijadas son casi iguales, que el artículo i de sus palpos es cilíndrico, i que el 3 es mui corto. Lacordaire no habla de estas piezas.

Las mandíbulas son pequeñas, cortas, triangulares i con su estremidad aguda pero apénas encorvada hácia adentro.

El epistomio i el labro son mui trasversales; éste aun mas corto que aquél; ámbos con el borde anterior recto.

Los ojos son lonjitudinales, pequeños i con forma de un óvalo algo irregular. Estan colocados lateralmente, a 0.7 despues del cuello i a 0.4 ántes del epistomio; la distancia que los separa en la frente es de I,2.

Las cavidades cotiloídeas de las antenas estan situadas entre los ojos, a 0.12 de cllos, i a 0.7 una de otra; son pequeñas, con el borde interno levemente saliente a modo de rodete; entre ellas la frente es aplanada.

Las antenas son filiformes; i su lonjitud, que es mas o ménos la del cuerpo, varía mui poco segun el sexo. Los artículos de la primera mitad presentan unos pelitos rectos i perpendiculares, mui finos, mui ralos i de 0.35 a 0.45 de lonjitud. El artículo I está con forma de una maza arqueada, i la lonjitud de cada uno es como sigue en una + de 8 .": no siendo mui exacto lo que Lacordaire i sobre todo Blanchard dice a este respecto. 


$\begin{array}{rl}\text { Artículo } 1 & 1.40 \\ 2 & 0.20 \\ 3 & 0.70 \\ 4 & 0.64 \\ 5 & 1.11 \\ 6 & 0.80 \\ 7 & 0.80 \\ 8 & 0.70 \\ 9 & 0.60 \\ 10 & 0.50 \\ \text { I I } & 0.56 \\ & \\ \text { Antena....... } & 7.90 \\ \text { Cuerpo....... } & 8.11\end{array}$

El protórax es deforme, contraido ell sus dos estremidades; en el medio está dilatado lateralmente de modo a formar un grueso tubérculo levemente obtuso, pero mui puntiagudo; i encima lleva una jibosidad partida por un profundo surco lonjitudinal, formándose hácia adelante dos tubérculos romos un poco alargados. Sus proporciones son como sigue:

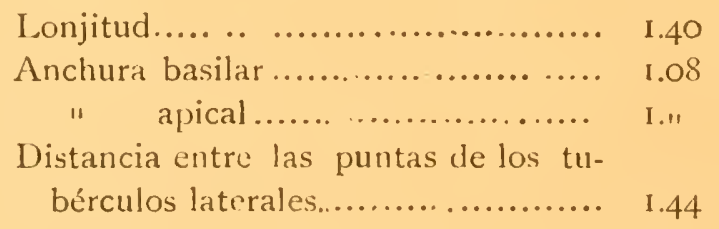

El escudo es mediocre i semi circular.

Los elitros son deprimidos i casi paralelos en su mitad basilar, con la base recta $\mathrm{i}$ el ángulo huıneral redondo; pero son levemente dilatadas i con forma de óvalo convexo en la apical; el ángulo sutural es mui brevemente redondeado. Su anchura basilar (I.8) da el 0.37 de su lonjitud (4.8), i la cabıza con el protórax juntos (2.S) dan apénas los $\$ 3$ de esta última; Lacordaire es, pue;, mui inexacto cuando dice: "Elitres pas plus longues que la tête et le prothorax réunisu. En cuanto a estos últimos, la proporcion de la anchura de la cabeza i la de la base 
del protórax, con la de la base de los elitros, es de o.88 para la primera i de 0.55 para el segundo.

El prosternon tiene su salida lameliforme i enterrada, pero cxiste.

El mesosternon es triangular, con su ápice de igual anchura que la base de los fémures.

El metasternon tiene su salida basilar mui aguda en su ápice. Sus episternenes son angostos i paralelos.

El abdómen tiene sus segmentos gradualmente mas cortos del.$^{\circ}$ al $50^{\circ}$ Su salida intercoxal forma un ángulo mui agudo.

Las cairidudes cotiloideas anteriores estan abiertas posteriormente, i presentan un seno anguloso en su parte esterna; las intermediarias estan abiertas lateralmente.

Las ancas anteriores e intermediarias son cónico-globulosas, aquellas angulosas en su parte esterna.

Los fémures son mui delgados en la base i poco ménos en el ápice, la clilatacion que hai entre cstos puntos tiene su medio en el tercin apical. En nuestro tipo presentan las proporciones siguientcs:

\begin{tabular}{|c|c|c|c|c|}
\hline & Lonjitud & mayor anchura & & proporcion \\
\hline Ant & 2.I & 0.58 & & $27 \%$ \\
\hline Intermediarios... & 2.5 & $\begin{array}{lll}\ldots . . & 0.54\end{array}$ & ....... & $21 \%$ \\
\hline Posteriores....... & $3 \cdot 11$ & $\begin{array}{ll}\ldots \ldots & 0.54\end{array}$ & $\ldots$. & $18 \%$ \\
\hline
\end{tabular}

Las proporciones del fémur intermediario son como sigue:

Lonjitud del cuerpo ...................... $\delta_{\text {, }}$

" del fémur intermediario........... 2.50

Proporcion entre ésta i aquella............. $31 \%$

Anchura de ésta en la base............... 0.20

" " en el tercio a pical......... 0.54

Proporcion de aquella con ésta.............. $0.37 \%$

" de ésta con la lonjitud......... $0.21 \%$

Ell fémur posterior escecle siempre el ápice de los elitros, sobre todo en los,$? ;$ i la proporcion de su lunjitud (3.11) con la de! 
insecto (8.11) es de 0.375, miéntras que en el Syllitus cylindricus es solo de 0.226 .

Las tibias son mui delgadas: la posterior es levemente arqueada, i su lonjitud (3.3) escede de mui poco la de su fémur (3.11).

Los tarsos son angostos; con el $3{ }^{\text {er }}$ artículo i el ápice del $20^{\circ}$, solo i escasamente provistos de pelos esponjosos por debajo. El posterior tiene la mitad de la lonjitud de su tibia, i la del artículo I iguala la de los tres últimos juntos. En las otras patas estas proporciones son gradualmente mas reducidas.

\section{A. MONStruosa (Blanch.)}

Nigra, tenuissime alutacea, pilis elongatis nonnullis rarissime hirsuta. Capite prothoraceque valde opacis. Elytrorum parte basali vix convexa, subopaça, densissime punctulata et setis brevis. simis appressis laxe tecta; parte intermedia nitida et transverse rugosula, in medio planata, lateribus abrupte verticuli. tuberculo magno elevato atque transverso apicem versus ornata; parte apicali dense punctato-rugosa, pube fulva valde appressa dense vestita. Mesothoracis margine laterali, et metathoracis margine apicale epimerisque pube albida appressa dense tectis.

Long. 8.50-5.50; lat. 2.22-1.38.

Todo el insecto es negro, i glabro, fuera de unos que otros pelitos mui finos i enderezados de 3 a $4 \mathrm{dm}$. de lonjitud i de los casos indicados mas adelante. A escepcion de los elitros, está cubierto de finas asperezas a modo de piel de zapa, visibles solamente al micioscopio con un aumento de ro a 12 diámetros. Estas asperezas son granulosas sobre la cabeza i el protórax, haciéndolos mui opacos; i son deprimidas sobre las demas partes, las cuales, por esto, presentan un leve brillo. En sus dos tercios apicales mas o ménos, las antenas estan cubiertas de un vello ceniciento mui fino, corto i tendidn.

Blanchard exajera cuando dice (in Gay): "Cabeza una vez mas ancha que el corselete"; la menor anchura de cste último, que es la apical (1.11), da los $\frac{3}{5}$ de la de la cabera (1.70). Blanchard i Lacordaire son inexactos cuando dicen: aquel "protórax 
una vez mas largo que ancho"; i éste, "Prothorax au moins aussi long que largen. La menor anchura del protórax da los ${ }_{10}^{7}$ de su lonjitud (1.40). Blanchard, cuando dice que el protórax es ahngado anteriormente, se olvida indicar que lo es igualmente posteriormentc.

Lo que éstos dos distinguidos entomólogos dicen de los elitros es jeneralmente defectuoso.

E.l cuarto basilar es levemente convexo, i acribillado de una purituacion mui apretada que lo hace parecer rugoso. De estos puntos salen cerditas mui finas, inui cortas i mui tendidas, solamente visibles con el microscopio.

En el tercio que sigue, los elitros son brillantes, glabros i con unas leves rugosidades trasversales. De cada lado presentan una gruesa costa lonjitudinal, que en este punto marca los epipleuros: los cuales son verticales. Entre éstos, el dorso está aplanado; i lleva de cada lado, cerca de su ápice, un grueso tubérculo saliente i trasversal que va del epipleuro a la sutura.

El tercio apical lleva la forma de un óvalo mui convexo, el cual está cubierto de una puntuacion rugosa i de una gruesa pubescencia lennada mui densa i tendida. En esta parte la anchura del clitro es mui levemente mayor $(5 \%)$ que en la base.

Lacordairc es inexacto al dar, como propio de los tegumentos en esta parte, un color "fauve tanné" que se debe a una pubescencia; pero su equivocacion es mayor aun, cuaudo dice: "Cette couleur est limitíe en ar'ant par une étroite bande d'un noir velontén. Esto no existe! Es evidente que ha sido víctima de una ilusion óptica de las mas raras, pues, es el reflejo del tubérculo trasversal en el brillo de los tegumentos que ha tomado por una faja de un negro aterciopelado.

El borde esterno del episternon mesotorácico, i el borde apical del metasternon con sll epímero estan cubiertos de una pubescencia plateada gruesa i mui tendida.

Lacordaire se equivoca cuando dice que la salida mesosternal es "trés etroite" es triangular i de proponciones normales; i cuando agrega que es "retrêcic postérieurement"; es "antíricurement" que se ha de decir.

He encontrado este singular insecto al fin de Noviembre i 
en las selvas andinas de Chillan, sobre las flores de la Lomatia obliqua.

Lam III fig. $2^{a}$ Cabeza vista de encima. . . A Am. Io diám.

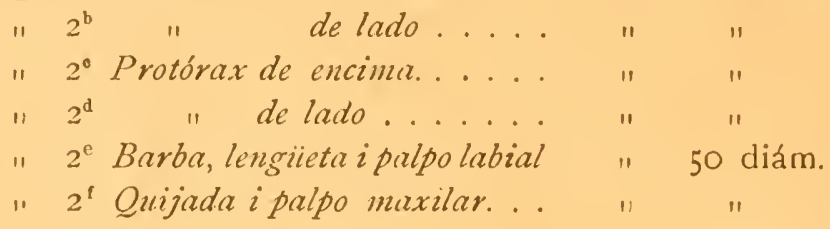

\section{AGRUPACION DE LOS OXYPELTITOS}

Es Lacordaire, que ha crcado a esta agrupacion para los jéneros Cheloderus (Gray') i Oxypeltus (Blanch.), que contie. nen solamente una especic cada uno: insectos hermosos i no. tables que son propios de Chile.

Estos jéneros tienen, sobre todo el primero, un aspecto de Prionidos, que ha conducido a los entomólogos que hablaron de ellos (Gray, Castenau, Blanchard, Fairmaire, etc.), a colocarlos en esta seccion. Sin embargo Thomson i Lacordaire, mirandc la calidad membranosa de la lengiicta como un carácter que resolvia la cuestion, los colocaron entre los Ccrambicidos; en lo cual han sido apoyados por Gemminger i Harold (Catálogo páj. 2878). Encuentro que han tenido razon, aunque su aspecto sea mui diferente del de las especies que les han dado por vecinas; porque, ya que no se pucde contentar todas las analojías, es preciso respetar los linderos que se indican para seccionar a los insectos, so pena de hacer imposible toda clasificacion metódica.

Pero desde luego confesaré, que no he podiclo esplicarme el motivo que tuvo Lacordaire, para imponer a esta agrupacion cl nombre de "Oxipeltidos." El jénero Cheloderus ha sido creado once años ántes que el jénero Oxypeltus; es mas notable por su tamaño $\mathrm{i}$ aun por su hermosura, i, ademas, es él que presenta el facies anormal, que ha inducido a tantos entomólogos a colocar esta agrupacion entre los l'rionidos. A mi humilde juicio, era el nombre de "Cheloderidos" que le correspondia, 
Ahora diré que, tanto en lo que Lacorclaire escribe sobre es. tos insectos en su Genera ( $T . V I I I, p .76 r-76,7)$, cuanto cn las descripciones que Blanchard da de ellos en la obra de Gay (Zool. T. 5, p. $457-46 r$ ), la inexactitudes son tan frecuentes, que creo necesario rectificarlas detenidamente, para que la verdad a su respecto aparezca claramente.

Para caracterizar a la agrupacion de los Oxypeltidos, me veo en la impnsibilidad de admitir in que Lacordaire dice (l. cit.); pues, del estudio prolijo que acabo de hacer de los insectos que se colocan en ella, resulta evidente que éste tan distinguido entomólogo formó su opinion despues de observaciones mui insuficientes.

Si los dos jéneros creados para ellos ofrecen semejanzas mui notables, que justifican su reunion en una misma agrupacion, presentan tambien difercncias bastante importantes para oponerse talvez a esta medida. Lacordaire, que, sin cluda, no ha visto pir no haber inirado, guardó el silencio tanto sobre las una como sobre las otras; $\mathrm{i}, \mathrm{si}$, en la diagnósis que redactó para los Oxypultidos, rectifica varios de los errores que Blanchard hace figurar tanto en el testo como en la lámina de la obra de Gay, él, por su parte, se contenta con cnumerar algunos caracteres jenerales de una exactitud dudosa, u otros que no pertenecen a los jéneros que comprende en esta agrupacion

Aquí hago figurar solamente los que dicen con ámbo:

El cuerpo de estos insectos lleva un brillo metálico, i matices que varian del verde al cribrizo, $n$ al azul en las patas i las an. tenas. Fs oblongo i macizo sobre todo en las hembras, las cuales son tambien algo mayores que los machos; i está acribillado de puntos foveiformes mas grande por encima que por debajo, donde estan acompranados de un vello mas o ménos notable.

Los elitros de aquellas son paralelos en su mayor estension, miéntras que las de los últimos son levemente atenuados de la base al ápice. Llevan con frecuencia dientes cepiniformes en su estremidad.

Fl escudo es grande i triangular, con su ápice prolongalo entre los clitros en punta larga, fina $\mathrm{i}$ agucla.

El protírax es trasversal, i notablemente inclinado hácia ade- 
lante; con una anchura basilar, que da mas o ménos el 55 por ciento de la de los elitros tomada entre los ángulos humerales. E.l dorso no está separado de sus epipleuros. Sin embargo, en el jen. Cheloderus, hai adentro de la línea divisoria de estas partes, i en el medio de su lonjitud, una espansion angulosa, que imita uno de los caracteres mas notables de los Prionidos.

La cabeza es deprimida i pequeña, es decir que su mayor anchura horizontal da mas o ménos el 40 por ciento de la de los elitros. Detras de los ojos, pero a mui corta distancia de ellos, su base lleva un leve encojimiento a modo de pescuezo de apénas un I 5 por ciento en los Oxypeltus, i mucho menor (4 por ciento) en los Cheloderus. El medio de la lonjitud de la cabeza, mirándola de encima, está entre los dos tubérculos antenarios; la mitad basilar, que es vertical tanto por el declive del protórax como por el suyo propio; i la mitad anterior, que se compone de la frente, del epistomio, del labro i de la parte saliente de las mandíbulas, forman en aquel punto un ángulo de mas o ménos $45^{\circ}$. A consecuencia de esto, esta última parte se halla paralela con el corte anterior del protórax, es decir inclinada hácia atras. Por lo que precede, se ve cuán inexacto, es decir dela cabeza que es "saillante"(Lacord. jen Cheloderus); cuando, a lo contrario, es tan inclinada que apénas se alcanza a ver, si se mira de encima perpendicularmente a la sutura de los elitros.

Al examinar las varias piezas de la boca, lo que mas despierta la atencion es la semejanza de las del uno de estos jéneros con las del otro; salvo, talvez, algunas diferencias proporcionales insignificantes que no alcanzan a minorar el parentesco evidente que esta semejanza descubre.

La barba es trasversal i mediocre, no pudiendo de ningun modo decirse "anclua" (Blanchard). Sus costados son rectos $\mathrm{i}$ mui oblícuos hácia adentro; i su lonjitud iguala mas o ménos su anchura anterior, la cual hace casi la mitad de la basilar. Pero el carácter mas notable, que encontramos por primera vez entre los Lonjicornios estudiados en estos apuntes, i del cual ni Blanchard, ni Lacordaire hablaron, es que su mitad anterior es membranosa, comn así mismo la mitad anterior de la lenguieta de los Cerambicidos. 
La lengrieta es algo mas larga que la barba i contraida en su base; la cual es mas angosta que el ápice de la barba. Su parte anterior es un poco ménos anclia que la basc de esta última, membranosa, i terminada por dos lóbulos semi-circulares i pubescentes; pero nunca es "redonda" (Blanchard, testo ifiguras).

Las quijadas tienen sus lóbulns cortos i anchos, casi en totalidad membranosos i densamente pubescentes. El interno es cuadrado; el esterno es mui contraido en su basc, dilatado $i$ redondeado en su parte anterior; no presentan diferencia notable en cuanto a la anchura, pero este último es levemente mas largo.

Los palpos son todos filiformes, pero notablemente cortos; pues, la lonjitud de los maxilares da constantemente soio el 5 por ciento de la lonjitud total del insecto. El artículo r. ${ }^{\circ}$ es pequeño i subcilíndrico; el último es cilíndrico, sobre todo en los labiales, redondeado en su ápice i mas o ménos tan largo como los dos precedentes juntos; los intermediarios son obcónicos, cortados mui oblícuamente en su ápice i del mismo ancho que el último. En cuanto a la lonjitud de los labiales comparada con la de los maxilares, ella queda al rededor del 70 por ciento; no pudiendo esplicarse que, en una proporcion tan perfectamente normal i constante, Lacordaire haya encontrado motivo para decir que los palpos de Cheloderus son "très inégaux", i los de Oxypeltus "subégau.x"

Los ojos son de tamaño regular i profundamente escotados; con el lóbulo anterior dos veces tan ancho como el posterior, i tan irmediato a la base de las mandíbulas, que los carrillos parecen casi suprimidos. Su cblicuidad con la mitad posterior de la cabeza es igual a la de la parte anterior; no siendo mui correcto decir que son "verticuax" (Lacordaire), ya que su pusicion resulta únicamente de la de la parte que los lleva, i con la cual son mas o ménos paralelos. La línea ocular pasa un poco adentro del medio de la cavidad cotiloídea antenaria, quedando en la misma direccion que el epistomio i la parte superior de las mandíbulas.

Los tubírculos antenarios son enteros, pero truncados mui oblícuamente hácia afuera; tienen, pues, su borde interno sa- 
liente, i la distancia entre ámbos queda poco mayor que la en. tre los lóbulos posteriores de los ojos.

El epistomio es grande i levemente trasversal. Su línea sutural, que es mui visible, está arqueada con la convexidad hácia atras: quedando el centro de csta parte en la altura del borde antcrior de los tubérculos antcnarios. Resulta de esto que la frente es sumamentc corta.

El latiro es pubescente, i lleva la forma de un segmento de círculo, cuya Alecha-(0.7) Cheloderus $q$-da mas o ménos la tercera parte de la cuerda-(2.I) d. ${ }^{\circ}$-. Pero no es de ninguna manera "fere triangulare" (Blanchard).

Las mandibulas son mediocres. Su parte interna lleva una escotadura basilar densamente pubescente; su parte anterior está arqueada csteriormente, con su ápice notablemente bífido: no pudiendo pues decirse de ellas "mandibulas apice acute". "MInndibulas terminadus en punta aguda" (Blanchard. Cheloderus i Oxypeltus, testo i figuras).

En cuanto a lo que dice Lacordaire: "mandibules plus ou moins saillantes" (nxypeitides); "mandibules assez saillantes" (jen. Cheloderus); mandibules courtes (jen. Oxypeltus); esto necesita mas claridad.

Siempre las mandibulas estan salientes por delante del labro apénas lo suficiente para dejar descubierta la tercera parte de su lonjitud. Se ve, pues, que este sabio entomólogo tiene razon, cuando llama "un court museau" al rostro compuesto del epistomio, del labro, i de esta tercera parte de las mandibulas que sobresale; $i$, respecto a este rostro, tiene tambien razon de decir con Bates que, en lugar de deberse, como de costumbre, a la cstension de los carrillos, él resulta aquí de la lonjitud del epistomio: hecho raro $\mathrm{i}$ escepcional entre los Lonjicornios.

l'ero. cuando da las mandíbulas por verticales, repetiré lo yue he dicho relativarnente a los ojos: cstos órganos estan en el eje de la mitall anteriur de la cabeza i hacen parte de ella, de tal modo que son: verticales; oblícuas hácia adelante; oblícuas hácia atras; etc., scgun las posiciones en las cuales esta parte se halla colocala con los movimientos de la cabeza.

Las antenas llevan once artículos, completamente glabros, con escepcion de la estremidad del último, donde se divisan 
unas pocas cerditas sumaınente cortas; los tres o cuatro primeros antículos cul las i, i los 203 en los o som lisos con gruesos puntos desparranados; miéntras que los demas estan cubiertos de una finfsima puntuacion inui apretada, que los hace opacos i que creo sean proros. El artículo 1. ${ }^{\circ}$ es obcónicn e hinchado, pero mui delgado i encorvado despues del cóndilo; el 2." es moniliforme i mui trasversal; el $30^{\circ} \mathrm{es}$ mas corto que los siguientes; el $11^{\circ}$ sicmpre levemente mas largo que el procedente, es cilíndrico con su tercio apical cónico. En el $\delta$, no alcanzan a la estromidad de los elitros, pero los artículos 5 o 6 hasta 10 tienen su ángulo apical esterno dilatado a modo de diente romo, prescntando así en esta parte una anchura que iguala a veces la mitad de su lonjitud; en las $\subsetneq$, exceden de mui poco a la mitad del cuerpo.

El prostirnon presenta caractercs mui diferentes segun el jénero; i, por ser lo que dice Lacordaire de esta agrupacion conforme con lo que existe en el jénero Cheloderus, es de toda evidencia que no miró al prosternon de los Oxypeltus; pues, si lo hubiese hecho ¿quién sabe si habria dejado a estos dos jéneros en una misma agrupacion?

Las cavidades cotiloídeas forman lateralmente un largo ángulo agudo que alcanza al borde del epiplcuro; i son, atras, o mui abiertas, o completa $\mathrm{i}$ anchamente cerradas segun el jénero. La forma i la lonjitud de la salida intercoxal varían mucho tambien; pero es siempre mai o ménos aplanada trasversalmente, e igual con la mayor anchura de la parte basilar del fémur anterior.

El mesosternon es vertical al llegar on frente del borde posterior de las cavidades cotiloídeas; la salida que dirije entre éstas es de la misma anchura que la salida prosternal, pero tuberculifurme.

Las cavidades cotiloídeas son, hácia afuera, mas o ménos angulosas $\mathrm{i}$ mui abiertas, por estar el epímero tan grande que no deja ningun epistermon figurar cn la cerradura.

El metasternon está con una salida basilar angulosa que viene a apoyarse sobre la del meiosternon, i lo alcanza a lu ménos frente al merlio de las cruvidades; está acanalado lonjitudinalmente en la línea mediana; de lo cual resultan, en c! ápice, dos 
lóbulos entre los cuales vienc a alojarse la salida del primer segmento abdominal.

Sus episternones son mui grandes, algo angostados en el ápice, pero con una anchura basilar del 50 por ciento al 70 por ciento de la lonjitud.

El abudomen tiene los segmentos 2-4 cortos i casi de igual lonjitud; la salida intercoxal del I. $^{\circ}$ está en triángulo agudo; i el $5^{\circ}$, que viria secrun el sexo, es siempre mas largo i mas angosto en el o qune en la '?. Lacordaire se equivoca pues completancnte cuando dice de ios Oxypeltus: "Les exemplaires que jai vus itaint tous simblables, mais, d'apress la longueur du dimier signe'nt abdominal, itaient probablement de's 9.1 Eran todos o !

Las ancas anteriores son mui trasversales; pero, segun el jénero, cónicas, salientes i de nivel con la salida prosternal, o no. Las intermediarias tambien son angulosas lateralmente, pero mucho ménos.

$\mathrm{Si}$, respecto a las patas de estos insectos, se consulta lo que dicen Lacordaire en su Genera, i Blanchard en la obra de Gay, se lee lo siguiente:

Lacordaire: "Pattes de longuenr variable" (Oxypeltides)."Pattes longues, sub́tgales, tarses courts". (Cheloderus ot) "Pattes moins longu's" (Cheloderus $q$ ) - "Pattes courtes, tarses mediocres" (Oxymeltus).

Blanchard: "Pedes graciles, tarsis sat elongatis"; "Patas bastantes delgadas; Tarsos bastante largos" (Cheloderus)—"Pedes breves"; "Patas bastante cortas" (Oxypeltus).

I, si, para verificar la exactitud de todo esto, se mide los fémures, las tibias, i los tarsos anteriores, internediarios i posteriores de los Cheloderus $i$ de los Oxypeltus $\$ f i$, se llega al resultado siguiente: 


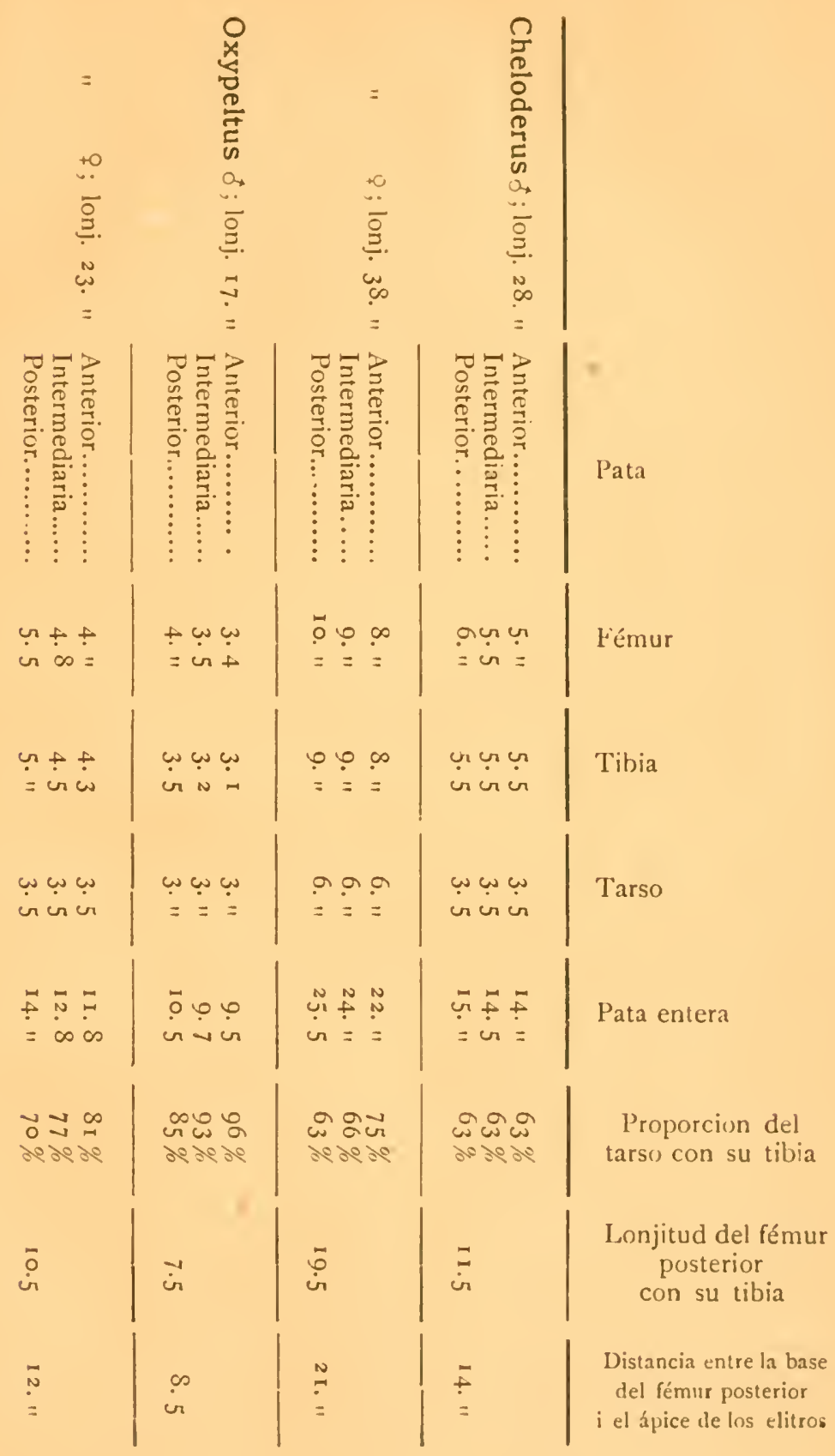


l'or este chadro se nota a primera vista (que, en cada mon:) de estos insectos, cuillpuiera (pue sca su jénero o su sexo, las lonjitudes de los fémures no presentan casj ninguna diferencia entre si i con la de sus tibias; solo, las de aquellos dejan notar un aunconto insignificante del anterior al posterior. En cuanto a otras diferencias mas pecjueñas, bien pueden resultan de variaciones indivicluales o de lijeros errures en la medicion. P'ero la constancia de las lonjitudes de los tarsos atrac la atencion, pucs, como sus tibias respectivas $n 0$ la imitan sicmpre, resulta que su proporcion con ellas, sicmpre mayor cn los Oxypeltus, puede variar de un 30 por ciento.

Ademas de la mui notable semejanza de lonjitud de los fémures i de las tibias, que este cuadro pone en evidencia, él inclica tambien lo cortu que son las patas; ya que nunca el ápice de la tibia posterior puede alcanzar al ápice de los elitros. A lo cual se ha de agreggar, que el ápice del fémur intermediario sicmpre alcan\%a solamente, $\mathrm{j}$ apénas, a la base del posterior.

No sicnto el trabajo que me hat costado dicho cuadro; pues, con él, quedan a la vista las inexactitudes, las insuficiencias, las contrarlicciones $i$, por comiguiente, el poco valor de lo que dijeron sobre este punto los dos entomóloguon citades mas arriba. l'arece que, dominados por la necesidad de hablar sobre el particular, no pudieron, n no quisieron, hacer las averignaciones necesarias para ser exactos; i se contentaron con anotar clatos debiclos a una mirada rápica i superficial.

Los fémures son levemente comprimiclos, lincares o apénas dilatados en su mitad apical, completamente separados de la ancit por el trocunter; cl cual estí en su cje, con lat línca sutural casi trasversal en las patas anteriores i gradualunente mas oblicua en las otras.

Lis tilirs son cilindricas i apénas dilatadas en su cstrcmidad apical. l’úas del ángulo interno, o talon, mui pequeñas.

las tarsos tiencn los artículos 1 - 3 algo anchos i deprimidos, i provistos por debajo de copillos de pelos esponjosos mui cor. tos i mui apretados. ('on proca diferencia, el artículo s.o iguala en lonjitud a 2 i 3 juntos; el artículo $4 .^{\circ}$ es delgado i levenente mas largo que el $1 . "$ 


\section{Gen. CHELODERUS (Gray)}

Cabeza con su mitad basilar acanalada lonjitudinalmente por encima.

Antenas con el artículo 1. ${ }^{\circ}$ levemente mas largo que 2 i 3 juntos; este último es turbinado i truncado mui oblicuamente en su ápice, su lonjitud da la mitad de la del $4 .^{\circ}$; pero esta proporcion es variable en algunos individuos: tenemos, pues, una + en la cual esta variacion es tan exajerada, que el artículo 3 ticne una lonjitud de $\mathbf{\text { .6 }}$ como asimismo el $\mathrm{r}^{\circ}$, i la misma forma que el $4 .^{\circ}$ cuya lonjitud es I.9.

Como lo dije al hablar de los caracteres de la presente agrupacion, el protórax es trasversal; pero aquí lo es con las proporciones siguientes en una $q$ de 38.11

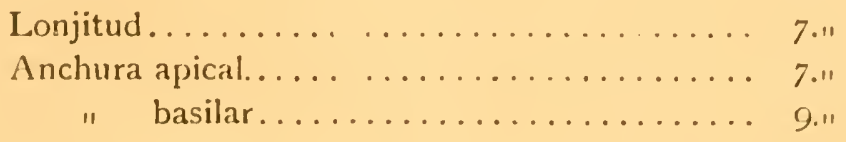

Su borde anterior es recto i el posterior anchamente lobado; el dorso es aplanado, i su union con el epipleuro no está marcada, sino en el borde basilar i en el apical, donde queda indicada por un diente levantado de desarrollo variable, que corresponde a los ángulos apicales i a los basilares del pronoto. Sin embargo, de cada lado, pero adentro de la línea que corresponde a csta union, el dorso lleva en el medio de su lonjitud una cspansion triangular, aplanada, algo levantada, cuyo ápice queda inclinado hácia atras, cuyos lados son cngrosados i lisos, i cuya base se tuerce oblícuamente hácia adentro en su parte anterior.

El escudo es aplanado i densamente rugoso en su mitad basilar; cóncavo i mui liso, o, por escepcion, con grucsos puntos esparcidos, en la apical.

I a base de los elitros está dirijida oblícuamente del callo humeral al ángulo basilar del protórax, $\mathrm{i}$ forma despues, en cada lado de la base del escudo, un rodete mas o ménos saliente. El 
plicgue epipleural es apénas visiblc, o aun completamente indistinto. El ángulo apical cs redondearlo en cada elitro; sin embargo, en los machos está armado de un pequeño diente espiniforme, que otro acompaña a poca distancia hácia afuera; i el borde del clitro, entre estos dientes, es mas o ménos sinuoso. Pero el uno o el otro de estos dientecitos aparece con frecuencia tambien en las hembras, $i$ la sinuosidad de la parte intermediaria es pocas veces enteramente borrada.

El prosternon es mui corto; pues su lonjitud no alcanza a dar la mitad de la del pronoto; lo que favorece con evidencia los movimientos hácia abajo del protórax i de la cabera tan notables en estos insectos. La salida prosternal es cóncava en el sentido trasversal; miéntras que, en el lonjitudinal, describe, del borde anterior al posterior, una curva mui regular i mui alta, pero que, sin embargo, alcanza apénas al nivel de las ancas, por ser éstas mui gruesas i salientes. Las cavidades cotilóddeas estan abiertas sobre una distancia mas o ménos igual con la mayor anchura de la salida prosternal.

El mesosternon tiene su parte horizontal tan larga como ancha, i lleva adelante una pequeña escotadura para recibir la estremidad de la salida del metasternon, union que tiene lugar entre los puntos de insercion de los trocanteres con las ancas.

El metasternon tienc los lobulillos de su ápice, que resultan del surco lonjitudinal, pequeños i redondeados. Sus episternones son mui grandes; pues, su anchura basilar no da nunca ménos de $\operatorname{los} \frac{2}{3}$ de su lonjitud.

El abdómen tiene el segmento $50^{\circ}$ de igual lonjitud que el I. $\circ$

En los machos, el segmento $\mathrm{I}^{\circ}{ }^{\circ} \mathrm{i}$ sobre todo los tres siguientes tienen de cada lado una ancha depresion foveiforme; el $5 .^{\circ}$ tiene una anchura basilar que es del 20 por ciento menor que la apical del $4{ }^{\circ}$; i siguc angostándose gradualmente hasta llegar al ápice, donde se ensancha un poco. Este lleva una ancha escotadura en el medio, con otra pequeña i un poco oblícua de cada lado: las cuales provocan la formacion de cuatro dientecitos triangulares i puntiagudos. El ápice del pijidio es arqueado i ribeteado por una série de pequeñas endentaduras puntiagu- 
das i mui irregulares. I.os huevos cuelgan del placenta por medio de un pedículo que tiene la mitad de su lonjitud.

En las hembras, este segmento $5 .^{\circ}$ tiene su anchura basilar igual con ta apical del $4 .^{\circ}, \mathrm{i}$ se hace gradualmente mas angosto, pero mas convexo i aun medio tubular, en el ápice, el cual está casi truncado, i lleva una franja de pubescencia leonada.

Los fémures son lineares, con una dilatacion apénas aparente de su parte apical.

Las tibias son gradualmente ensanchadas de la base hasta el ápice, el cual no termina nunca por una brusca dilatacion.

\section{Ch. CHILIRENI (Gray)}

Viridi auratus, metallicus, nitidus, subtus parce breviterque pubescens et tenuiter denseque punctulatus. Capite punctis irregulavibus inordinate impresso; antennis obscure violaceis. Prothoracis tergo dense rugoso, sutopaco. Elytris purpureo-cupreis, coe. ruleo-viridi anguste limbatis, omninó punctis grossis viridibus profunde denseque impressis. Abdomine in medio loevigato. Pedibus laxe punctatis; tibiis tarsisque coevuleis.

5. long. 2S.11; lat. 10.11-9, long. 38.1; lat. 14.1"

El color jeneral de este magnífico insecto es un verde brillante i metálico que se tiñe de dorado en varias partes. Con escepcion del abdómen que es liso i glabro en el medio, lo debajo del cuerpo lleva una puntuacion rugosa, fina i mui apretada, cubierta por una pubescencia leonada corta i parada; pero jeneralmente poco abundante.

La cabeza lleva unos puntos de tamaños mui variados, i agrupados con mucha irreģularidad, lo que la hace algo desigual; i ademas una corta pubescencia leonada, parada, rala c irregular, pero tendida $\mathrm{i}$ mas visible en el borde anterior del epistomio i en el labro.

Las antenas son de un morado oscuro. Doi a continuacion las lonjitudes casi constantes de los artículos en las antenas de cada sexo, i tambien en la de una otra hembra, para indicar la 
mayor variacion a la cual parece alcanzar el artículo $3 .^{\circ}$, i aún los demas.

\begin{tabular}{|c|c|c|c|}
\hline \multirow{11}{*}{ Lonjitud de los artículos..... } & I & I. 8 & 2.11 \\
\hline & 2 & 0.5 & 0.5 \\
\hline & 3 & 1.2 & 1.2 \\
\hline & 4 & 2.3 & 2.5 \\
\hline & 5 & 2.4 & 2.5 \\
\hline & 6 & 2.6 & 2.4 \\
\hline & 7 & 2.6 & 2.2 \\
\hline & 8 & 2.4 & 2.2 \\
\hline & 9 & 2.3 & 2.1 \\
\hline & 10 & 2.2 & 2." \\
\hline & I I & 2.6 & 2.4 \\
\hline Lonjitud total de la antena... & & 22.9 & 22.11 \\
\hline " del insecto.... & & 28.11 & 38.11 \\
\hline Proporcion de aquélla con ésta & & $82 \%$ & $58 \%$ \\
\hline
\end{tabular}

El dorso del protórax está cubierto de finas i densas rugosidades que lo hacen opaco. Es jeneralmente glabro; pero, a veces, lleva una pubescencia leonada parada, mas o ménos rala, i sumamente corta.

Los elitros son completamente glabros, i de un espléndido cobrizo purpúreo, con un ribete lateral de un verde azulejo mas o ménos marcado. Estan cubiertas de gruesos puntos redondos verdes en el fondo, apretados i profundos; pero disminuyendo leve i gradualmente de tamaño hácia el ápice.

Las patas llevan unos pocos puntos gruesos i dispersos. Sus tarsos, sus tibias i a veces la parte apical de los fémures son azules.

Las proporciones del fémur intermediario son las siguientes en una ?. 
Lonjitud del cuerpo desde la base de las antenas hasta el ápice de los elitros......... 38."

Lonjitud del fémur intermediario......... 9."

Proporcion de ésta con aquélla........... 23\%

Anchura basilar de éste.............. 1.2

" mayor de su parte apical ......... $\quad$ I.8

Proporcion de aquélla con ésta........... 66\%

1. de ésta con su lonjitud.......... 20\%

Desgraciadamente tengo mui pocos datos respecto a la biolojia del Ch. childreni. Su área de dispersion parece mui estensa; pues, lo he encontrado, él ó sus restos, desde Puerto Montt hasta el valle andino donde corre el Ancoa. Sin embargo, a pesar de la vasta rejion en la cual se estiende sichabitat, es escaso, i sus ejemplares nunca se hallan mas numerosos en puntos preferidos, sino dispersos i uno por uno. Por mi parte, durante mis numerosas esploraciones en distintas partes de su patria, solo dos veces he encontrado a este insecto vivo: la una en la parte andina de la hoya del Renaico, bajo un abrigo donde se aserraba los robles del vecindario; la otra, a las tres de la tarde, pegado i quieto contra el tronco de un roble; esto, tres leguas ántes de llegar a las Termas de Chillan; i eran hembras. En la provincia de Valdivia, parce que, en un principio, se halló en troncos de luma (Myrtus Luma); pero despues, sicndo buscado con mas empcĩo, se encontró mas a menudo, i entónces tam. bien en los troncos de roble; pero siempre las hembras se ha. llaron con mas frecuencia que los machos.

Me han dicho varias personas que este insecto vuela de noche, es decir que seria nocturno o a lo ménos crepusculario. Me es mui difícil creer esto: la granulacion de sus ojos es mui fina, es decir que es la de un insecto diurno, como lo cs tambien la de su compañero el Oxypeltus quadrispinosus, que es diurno por escelencia.

Este último, tanto en el estado de larva como adulto, vive esclusivamente sobre el Nirre (Fargus pumilio), en los puntos frios donde este árbol no pasa de cuatro o cinco metros de al. tura. Sus hembras son macisats i pesadas, como lo son tambien las de los Cheloderus Childreni; $\mathrm{i}$ no recuerdo haberlas visto 
volar, sino haberlas siempre encontrado quietas i de dos a tres paradas sobre las ramas inferiores o mas bien sobre las matas bajas, esperando a sus machos; miéntras que éstos, que parecen constituir el sexo ájil, andaban en su busca, i rejistraban de un vuelo rápido i loco aún las ramas superiores.

Si puedo proporcionar estos datos, es porque, hace 48 años, me tocó por suerte hallar una rinconada de las selvas andinas de Chillan, donde estos insectos no eran escasos; por haber, sin duda, hallado en ella condiciones mui propicias para su desarrollo i favorables a su existencia.

¿Quién sabe si, para hallar los Ch. Childreni con abundancia, no es tambien esto lo que falta descubrir a su respecto? ¿l si sus hembras no se encaminan hácia las altas ramas de los robles, trcpando pesadamente por los troncos, para encontrar a los machos; miéntras que, como para el Ox. quadrispinosus, estos vuelan de dia afanados, buscándolas en los sitios elevados que saben necesarios para la copulacion, i quedando asi fuera del alcance de nuestras miradas i de nucstras manos?

Asi quedaria esplicado porqué estos insectos son tan escasos, aunque desparramados en una tan estensa rejion; i porqué estamos vicndo mas hembras que machos.

Lam. III, fig. $3^{\mathrm{a}}$ : Barba, lengiieta i palpo labial. . aum. Io diám.

" $3^{\mathrm{b}}:$ Quijada i palpo maxilar..... " " "

" $3^{\mathrm{c}}:$ Prosternon............. " 5 diám.

\section{Gen. OXYPELTUS (Blanch.)}

La cabeza lleva entre los tuhérculos antenarios una profunda depresion angular.

Las antenas, cuya lonjitud excede de poco la mitad del cuerpo en las hembras, alcanzan casi a la estremidad de los elitros en los machos. Su artículo 3 es siempre obcónico como el siguiente, i no es nunca tan corto proporcionalmente, como en los Cheloderus.

Las medidas del protórax son las siguientes: 
en un $\delta$ de $17 . .1$ en una $q$ de $23 "$

$\begin{array}{ccc}\text { Lonjitud . . . . . . . . } & 3.3 & 4.2 \\ \text { Anchura basilar...... } & 3.7 & 5.5 \\ \text { " apical ...... } & 2.6 & 3.5\end{array}$

Los costados son paralelos en sus dos tercios posteriores $\mathrm{i}$ converjentes en el anterior; los ángulos basilares son salientes i dentiformes; cl borde apical es recto; el basilar anchamente lobado; el dorso lleva en el medio una depresion recorrida por una costa lonjitudinal irregular i angosta, i separada de los lados por otra costa gruesa chata, desigual i levemente arqueada.

El escudo tiene su parte apical rugosa, desigual i apénas cóncava.

Los elitros ticnen su base apénas oblícua de cada lado del escudo; i su anchura es igual a una vez i $\frac{2}{3}$ la del protórax. El ángulo humeral es casi cuadrado, pero calloso, saliente i mui rcdondeado. Cada uno lleva en su ápice un truncamiento recto i levemente oblicuo, con un dicnte agudo de cada lado: el interno colocado sobre el ángulo sutural mismo. No quedando justificado que Blanchard (in Gay), despues de dar, en el testo, la estremidad de los elitros con cuatro espinas, la represente con seis en la lámina.

El prosternon es aquí completamente diferente del de los Cheloderus. Su lonjitud da casi los $\frac{3}{5}$ de la del pronoto; la salida es algo convexa en el sentido trasversal, pero, desde el borde anterior hasta llcgar al nivel del borde posterior de las ancas, sigue una direccion mui oblícua, sí, pero recta; en cste punto último, termina brúscamente en forma de tubérculo con motivo de un truncamiento cuya cara, perpendicular al eje del cuerpo, es lisa i cóncava. En su parte basilar, las cavidades cotiloídeas estan completamente cerradas por una larga pieza córnea, que me parece ser el epímero prosternal, i cuya anchura no baja de 0.2 a 0.3 .

El mesosternon es mui corto, mas ancho que largo en su parte horizontal, tuberculiforme i pegado a la salida metasternal casi cn frente de la parte basilar de la insercion de los trocanteres con las ancas.

El mefasternon tiene los lobulillos apicales, que resultan del 
surco lonjitudinal, dentiformes i puntiagudos. Sus episternones, aunque mui grandes, lo son mucho ménos que en el jénero anterior, pues su anchura da apénas la ?:2 de su lonjitud.

El abdónen tiene sus segmentos 2-4 lisminuyendo gradualmente, pero mui levemente, de lonjitud; juntos, son sicmpre un poco mas largos que el I." En cuanto al 5.", en los $\delta$, su lonjitud da el 75 por ciento de la de 2-4 juntos; sus costados son rectos, i su ápice es redondeado con una anchura de $\frac{1}{3}$ menor que la basilar. Miéntras que, en las $q$, su lonjitud da el 50 por ciento de 2-4 juntos, i su ápice es ancho, levemente sinuado en el medio, i mui redondeado en cada lado.

Los huevos son grandes, mui poco numerosos en cada hembra i mui brevemente pedicelados.

Las ancas anteriores son apénas salientes, de modo que falta bastante para que lleguen a la altura de la salida prosternal en su base.

Los fémures son levemente dilatados hácia el ápice; los anteriores son levemente sinuosos.

Las tibias llevan una pequeña dilatacion en su estremidad apical.

\section{Ox. QUADRISPINOSUS (Blanch.)}

Metallicus, pube grisea plus minusie dense hirsutus. Capite viridi, in medio cupreo; antice dense rugosulo, postice punctis irregularibus inordinate agglomeratis fortiter impresso. Antennis atrocyaneis. Prothorace cupreo-virescente incqualiter rugoso. Ely. tris glabris, cneis cupreo-purpureo late circuncinctis; areolis irregularibus hand seriatis cupreis, in tergo viridibus aut violaceocoeruleis dense clathratis, lineis interstitialibus angustis reticulum efformantibus; utroque costa loevigata recta, crassa ac elevata, prope hasim abrupte truncata et apicem versus gradatim attenuata longitrosum armato. Corpore viridi.cyanescente; pectore dense punctulato; abdomine laxe punctato, in medio loevi. Pedibus virescentibus; gcnubus, tibiarum apice tarsisque plus minusve cyaneis.

s long. I7.11; lat. 6.11-q long. 23.11 ; lat. $\mathcal{S . 5}$.

Este insecto cstá cubierto de una pubescencia cenicienta fina 
i erizada, mas abundante por debajo; pero completamente suprimida en el inedio del abdómen i en los elitros.

La cabeza es vercle, con su parte central cobriza; su mitad anterior cs fina i densamente rugosa; la posterior lleva puntos profundos de tamaños variados i agrupados mui irregularmente,

Las antenas son de un hermoso azul; su lonjitud varía scxualmente como sigue:

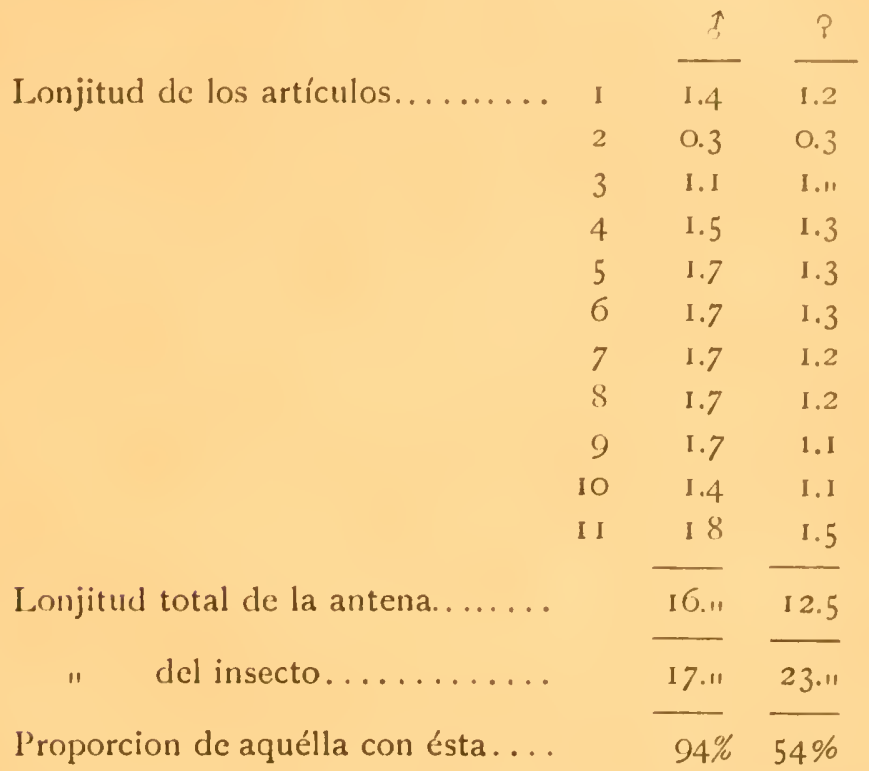

El protórax es de un cobrizo verdoso, i lleva rugosidades mui irregulares, que lo hacen parecer corroido, $i$ a veces cubren en gran parte las costas laterales.

Los elitros son de un bronce morado o verdoso, con una ancha faja de un cobrizo purpúreo que cubre la base, el borde lateral i el ápice; llevan grandes alvéolos irregulares, dispucstos sin órden, i mui apretados, cuyos intervalos son mui angostos i forman una especie de enrejado. El color del fondo de cstos alvéolos es cobrizo en las partes purpúreas; i, en lo demas, pasa del verde al azul oscuro o al morado. Sobre cada elitro hai una costa lonjitudinal lisa i recta, que cstá truncada brúscamente al tocar a la base, cerca del escudo, donde termina a manera 
de tubérculo mui saliente; i, de allí, va disminuyendo gradualmente hasta el ápice, borrándose a igual distancia de los dos dientes apicales, i ántes de llegar al borde.

$\mathrm{El}$ pecho está cubierto de densas rugosidades o de una fina puntuacion mas o ménos confluente, pero mas rala en los costados del abdómen.

Toda la parte inferior es brillante, $\mathrm{i}$ de un verde que pasa con frecuencia al azul, sobre todo en las patas; donde el ápice de los fémures, cl de las tibias i los tarsos son jeneralmente de este último color.

El fémur intermediario tiene las medidas i proporciones siguientes en un $\delta$ :

Lonjitud del cuerpo desde la base de las antenas hasta

el ápice de los elitros................. 17."

Lonjitud del fémur intermediario.............. 3.60

Proporcion de ésta con aquélla............... $21 \%$

Anchura basilar de éste .................. 0.46

" mayor de su parte apical.............. 0.80

Proporcion de aquélla con ésta........................... $57 \%$

" de ésta con su lonjitud.............. $22 \%$

A lo que he dicho, sobre la biolojía de este insecto, al hablar de la del Ch. Childreni, agregaré que su área de dispersion parece bastante estensa, pues lo tenemos de Magallanes, de Valdivia, de Ranco, de Lonquimai i de las cordilleras de Chillan. Respecto a este último punto, esplicaré que está a unas tres leguas ántes de llegar a las Termas; que su aparicion tiene lugar allí solamente del 20 de Noviembre al 10 de Diciembre, i que dura apénas 5 o 6 dias, durante los cuales es preciso campearlo sobre los Nirres bajos, cuando quema cl sol, i desde las ocho o las nueve de la mañana hasta la una o las dos del dia, cuanto mas.

Lám. III; fig. 4. : Prosternon. aum. Io diám.

P. GERMAIN.

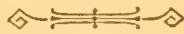




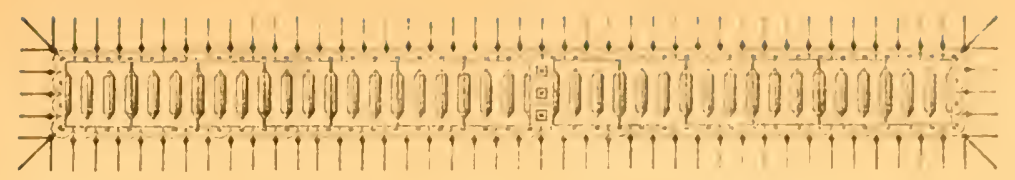

\section{Lonjicornios chilonos}

2.2 Subfamilia: CFR.Mmarmos

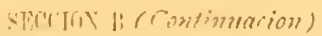

Colocarć aquí una anotacion, gluc sicnto uo haber publicadn ántes.

He reparado que, cuando al hablar de las particularidades que ofrecen las diversas piezas del cuerpo de un insecin, se cmplean las palabras atras i adelante, el espíritu gueda muchas veces indeciso sobre al significatio verdadero que ha entendido darles el descriptor: por esto, i en consideracion de la importan. cia que hai en que un entomóbog quite todo equiroco de sus escritos, dejaré lo siguiente citablecido para los mios:

Un insecto ha de consirlerarse compuesto de dos mitades, las cuales estan en contacto por sus hases respectivas: Ia del protórax i la de los elitrns. liste punto die contiguidad es ci merlio, o mas bien el centro del inserto; i, -icndo el único dondo dos bases estan contiguas, siempre, fuera do él, se ha de considerar como In base de una pieza la parte en contacto con el ípice de la que precede. P'or consiguiente, cu mi concepto, atras 
habria de significar siempre el lado de la base, i adelante el del ápice.

Pero, cuando el insecto en mano del observador está en una posicion normal--es decir con la cabeza dirijida adelante--.., si esta interpretacion no sufre dificuitad respecto a la mitad anterior, puede no suceder lo mismo con la posterior; i no faltar quien, al hablar del ápice de los elitros diga atras, i adelante al hablar de la base; dando así a estas palabras el sentido que tendrian si se hablara del insecto entero, en lugar de hablar especialmente de su mitad posterior. Esto no me parece conveniente. Pero, como puede haber opiniones que difieren de la mia, creo que, para evitar todo equívoco, será mejor desterrar lo mas que se pueda las palabras atras $\mathrm{i}$ adelante, $\mathrm{i}$ emplear las de base o basilar, i ápice o apical.

\section{AGRUPACION DE LOS BIMIIDOS}

Lacordaire ha establecido esta agrupacion (Genera, T. VIII, p. 464) para seis jéneros de Coleópteros: tres chilenos i tres australianos; pero confiesa lealmente que los reune aquí, por no haber encontrado donde colocarlos mejor; i trata de conformarse con esta necesidad-en apariencia poco de su gusto-esplicando que estos jéneros, al mismo tiempo que cada uno tiene una figura propia que los separa entre si, tienen todos otra figura, que llama de familia, que los reune. No he conseguido descubrir los elementos que constituyen a esta última, i me he contentado con admitir lo que habia asentado este sabio entomólogo.

Bases tan poco claras no podian, pues, dar lugar a un arreglo mui satisfactorio; i es evidente tambien que este resultado es uno de los que se deben esperar, cuando el hombre, empeñado $\mathrm{cn}$ establecer secciones que la naturaleza no ha hecho, indica con una mano los linderos que da a una clasificacion metódica; al mismo tiempo que, con la otra, hace intervenir las influencias de un facies que lo desbarata todo.

No me ocuparé de los jéneros australianos; no los conozco, i su estudio no pertenece al cuadro de estos apuntes.

En cuanto a los chilenos, son los j. Sibylla, Adalbus i 
Phantazoderus, a los cuales he agregado uno nuevo (Lautarus) que es mui afin del primero.

Al hablar del j. Sibylla, Lacordaire dicecon razon que liga los Bimiidos con los Oxypeltidos; lo cual puede decirse tambieı del j. Lautarus. Ambos ticnen, como los Oxypeltidos, sus machos mas pequeños que las hembras i notablemente cuneiformes, miéntras que estas últimas tienen los $2 / 3$ o los $3 / 4$ basilares de sus elitros con los costados paralelos; ademas, la forma de sus ancas anteriores, el desarrollo de sus episternones metatorácicos, las formas i proporciones de las patas i tambien de los palpos presentan una semejanza evidente.

Pero, si se ve un parentczco entre los j. Sibylla i Lautarus i la agrupacion de los Oxypeltidos, no es tan fácil descubrir que tengan alguno con el j. Adalbus $\mathrm{i}$ ménos aun con el j. Phantazoderus; con el fin de justificar su presencia a todos ellos en una misma agrupacion.

Respecto a este último, Lacordaire critica con razon que se haya creido ver (Revue Zool. 1864, p. 392) alguna afinidad en. tre él i el j. Pteroplatus (Buquet): cuando lo único que presenta es cierto aspecto de Lampyrido, o mas bien de Iycido; el cual, como todo mimetisino en jencral, sirve aquí para estraviar la opinion respecto a sus analojías verdaderas, en vez de hacerlas resaltar. Pero, si este lugar no es el que corresponde a este insecto, me parece que lo es ménos aun el que se le clió entre los Bimiiclos; de los cuales se aparta por varios caracteres, i sobre todo por unn que nadie indicó todavia: la granulacion de los ojns, que, si no es tan gruesa como en los Ionjicornios de la seccion anterior, lo es mas, sin embargo, que en los de la presente; haciendo necesario crear para él un asiento cscepcional, como ha sido hecho para el j. Sillytus.

Por haber reuniclo en esta agrupacion jéneros tan poco homojéneos, va a resultar que los caractares, que se le asignaran para distinguirla de sus vecinas, serín pocos i de escasa importancia; porque creo que, ántes de torlo, es preciso haccr comparecer solamente los que no provocan escepciones. Con este motivo, algunas palabras relativamente a la lengiieta son necesarias aquí.

Se comprende de sobra que la constatacion de la naturaleza 
córnea o membrinesce de esiérgino pucte dar lugar a aprecia. ciones tan diversas, que, muchas veces, él ha cie verse espucsto a perder su importancia caractcrística. Sin duda, no hai equívoco posible cuando esta naturalcza es, con toda evidencia, el uno o el otro; o aun, si, por ser de una constitucion intermediaria, se salva la dificuitad diciendo que es coricicer; pero sucede a menudo que cl microscopio da a conocer en csta escala otros grados, que 110 se sabe como espresar. A esta dificultad se agrega adcmas, en la agrupacion polimorfa que estudiamos, el caso de que la naturaicza de los tegumentos varie, no solamente scgun los jéneros i las uspecié, sino tambien sn rnu los stexos; viérduse, en. tólices, el abdúm n, lás piezi... bucale-, te, inclinarse a membranosus cin las $q \mathrm{i}$ a cóncos en lus 3 .

Por consiguiente, con el fin de constatar los diversos estados en que la lengii ta se prescuta en esta agrupacion, solamente haré figurar jencralidarles en su diagnósticu; reservándome hablar mas detenidamente cuando trate de cada jénero o de ca. da especie.

Baria pequeña i trasiersal, casi sicmpre cúmca o levemente coriácca hácia el ápice; costados mas o ménos paralclos en la parte basilar i mui converjentes en la apical.

Lengriede variando a parte o en totaifiat de coriáce a membranosa, i lividida pa $r$ un seno anguloso en dos lóbulos diverjent s i de costados paralelos, cuyit lorijiud es nas o ménos deble de la anchura, $i$ que llevan mui a la vista la nervadura lonjitudinal i pubescente en la cual varios entomólogos han visto las paragloses. En su estromidad apical estos lóbulos abarcan juntos una anchura çue en jen ral es casi igual con la de la barba.

La incercin? de sns palpos tiene lugar en el medio de la lonjitud de csto; lóbutos; cuyo ápice excole mui poen la estremidid del pimer artículo.

Las quijudus sin pequeñas, con su parie anterior membranosa i densamente jubiscente; el lóbulo esterno está dilatado i subtruncado en su ápice, el interno es mas rorto, mas angosto i termina en ángulo agurón.

Sus palpos son poco mas largos que los labiales, i salen poco 
adclanic dei lubulo interno. Sus tres primeres articuless son carsi de igual lonjitud.

Las mandibulas son cortas, con el ápice poco arqueado: puntiagruilo i centuso.

Ios ojos son mui escotalos; con escepcion de tos l'hantazoderus, en los cuales lo sin poco.

Los carrillos son bastante desarrillidos.

El protóne cs traspersal - salun en los l'hantazuderus -, casi sicmpre desiglial o tub reuluso.

Los ditros lienen su bas: trmancada i mas ancha que la del protórax. En su parte apical cstan con frecuencia dehiscontus i sin alcanzar a cubrir el pyjidium cn las hembras.

Las ancus anteriores son mas o ménos trasversales i salientes.

Las coridudes cotiloideas anteriores son angulosas lateralınente $\mathrm{i}$ abiertas posteriormentc; las interme iariats bo son en su parte esterna.

Los fímures son, o lineares, o mui levemente dilatados en su parte antorior. I,os posteriores alcanzan cunnto mas enire los segmentos abdominales 2 i 3 ; o, por excepucion, yasan adclante de este último.

La lonjitud del artículo I de los tarsos iguala mas o ménos la de 2 i 3 juntos.

\section{Gen. LAUTARUS ( $P . G$.)}

IIace unos cuarenta años, la colcccion entoriolójica del Mu. seo Nacional recibió de la provincia de Vallivia dos o tres I.onjicornios, que, a pesar de su notáble tamaño -25 a $35^{\mathrm{m} m}-$ habian escapadn hasta entónces a las investigaciones de los naturalistas. Los señores Philippi, en manns de quicic; estos insectos llegaron, vieron en ellos dos especies distintas; de las cuales, una fué descrita por el señor don Feclerico Philippi en los AN.ALES UE LA UNIVERSIDAD ( 859 , !). 670) i cn la StctinZcitt. (I 860, 1). 249), bajo cl nombre de Calíchroma concinina; i la otra por el dructor R. A. Philippi en la Stettin-Zeitt. (1S64, p. 376) bajo el de Callichrona lieviguta.

Cuando, hace unos diez años, vi por primerat vez a estus in- 
scctos, ya no estaban tan solos; pues, del sur de Chile, les habian llegado algunos compañeros. Entónces, si, despues de una prinera inspeccion, me pareció evidente que no pertenecian de ninguna manera al jénero Callichroma, i ni siquiera a la agrupacion de los Callichromitas, no alcanzé, sin embargo, a formarme una opinion sobre sus analojías vcrdaderas; pero, por otra parte, no solamente quedé persuadido, con los señores Philippi, que pertencian a dos especies distintas, sino convencido ademas de que presentaban motivos suficientes para justificar la creacion de dos jéneros nuevos.

En eso estaba, cuando, hacen pocos dias, siéndome necesario dilucidar esta cuestion, i, para esto, teniendo que estıdiar formal i detenidamente a aquellos insertos, fuí a visitar las colecciones Medina, Oyarzun e Izquierdo con el deseo de conseguir la comunicacion de los elementos que me parecian necesarios para este fin.

En esta visita pude constatar que, si el Museo Nacional habia sido bastante feli\% para recibir del Injeniero de la Comision de Limites señor don E. Frick, seis ejemplares de estos insectos, las colecciones arriba espresadas habian aprovechado aun mas la amabilidad de los empleados subalternos. Pues, gracias a esto i a la hidaiguía de sus dueños, tuve a la vista i $S$ a 20 ejemnlares de cada una de estas especies; faltándome solo examinar los ejemplares de la coleccion Paulsen, para estar seguro de poder hablar de ellas sin temer la influencia de las variaciones in dividuales o las aberraciones.

De un prime: exámen resultó para mi la evidencia de que estos insectos se acercaban mucho al jénero Sibylla; pero mi asombro fué grande al descubrir que, de esto: 35040 ejemplares, todas las $C$. laviratı eran unos machos, miéntras que todas la $C$. concinna eran unas hembras. Es dicir, que estas dos especies, para las cuales yo habi. proyectado hacer dos jéneros, eran meramente los dos sexos de una misma: esto, a pesar de una notable desemejanza en el tamaño, la forma, la coloracion, el grabado de los elitros, i sobre todo los caracteres de las antenas.

Esto demuestra que, cuando se estudia un insecto, la constatacion de los sexos es de primera necesidad. 
Llamaré Lautarus, en recuerdo del conocido héroc araucano LAUTaRo, este jéncro, cuya creacion se ha hecho precisa; i cuya colocacion está al laclo ciel j. Sibylla; jurn encabezando la agrupacion de los Bimiiilos, por tener, aun mas que este último, afinidades con el j. Oxypeltus. Creo que será caracterizado de un modo suficiente con los clatos signientes:

Principiaré por indicar tos caracteres del macho, i despucs las diferencias que presenta la hembra.

Macho: Cuerpo levemente aplanado i medianamente alargado: un ejemplar de 25,5 de lonjitud presenta una anchura de 8. ." siendo ésta los $0.3 \mathrm{I}$ de aquella; cstá cubierto, con excepcion de los elitros, las antenas i las patas, ménos cl borde inferior de los fémures, de una larga pubescencia cenicienta mas abundante en el pecho.

Barba con una anchura anterior que da los 0.75 de la de la base, i una lonjitud que da tambien los 0.75 de la de la lengiieta.

Lengücta tan ancha en su ápice como la barba en su base; el seno que aparta a los lóbulos forma un ángulo recto i mas o ménos puntiagudo; estos lóbulos son coriáccos, i un poco mas de dos veces tan largos como anchos, midiendo la lonjitud desde el fonto del seno hasta la estremirlad apical.

Palpos labialis con los artículos I,2 de iggual lonjitud; el I cilíndrico en su base i levemente ensanchado en su ápice, con sus sostenes casi cios reces tan largns como él; cl 2 mas ancho i obcónico, con su medio correspondiendo al ápice de los lóbuloi; el 3 oblongo cilíndrico, redondeado i papiloso en su ápicc, tall ancho como el 2, i tan largos como I, 2 juntos. 1,a lonjitud total de cste palpo da los o.So de la de los palpos maxilares.

Quijautas con su lóbulo estrno angostado cn su mitad basilar, i cuyo ápice está clilatado i cortado oblícuamente hácia adentro.

l'alpos marailures con los articulns I i 3 de ignat honjitud; aquel subcilindrico i sinuado cn el medio de su parte esterna; cl 2 mayor, obcónico, tan ancho como el 4; éste con la misma forma que el 3 de Ins labiales, i tau largo como los dus precedentes juntos. 
Iabro trasver:al, con el borde anterior subemarjinado de una inatera confusa cn su medio.

Epistomio poco inclinalo, recto adelante, su sutura con la frente borrada.

Cabeza con un surco lonjitudinal profundo i recto, que corre descle su base hasta cerca del epistomio.

Frente mui inclinada, casi vertical.

Los ojos sun cortos i en el eje de la frente. Su escotadura es angosta; semi-circular i situada mui atras: la anchura de la parte posteriur (0.56) cia solo los U.4 I de la de la parte anterior (I.35); el borde csterno es r:cto. Su; distancias en un ejemplar de $27^{\mathrm{m} m}$ son de $2.7^{\mathrm{m}}$ en la frente, $1.8 \mathrm{en}$ el vertex, i j.i en la gargantál.

Los tubéroulos autenurios son mui oblícuos hácia afuera, i ocupan cási completamente la escotadura de los ojos. Su truncamiento apical es entero i subvertical; está atravesado en su medio por la línea ocular.

Los carrillos tienen una lonjitud media que iguala apénas la mitad de la anchura del lóbulo anterior de los ojos.

Las antenas tienen doce artículos. Son gruesas; cs decir que un artículo de 4.2 de lonjitud tiene una anchura de 0.7. Son largas; es decir que exceden de los 0.40 a los 0.65 la lonjitud del cuerpo. No llevar pubescencia; pero, fuera de los tres primerosi te una pequeña parte del $44^{\circ}$, que son glabros, estan todos cubiertos de una densa capa de pelillos parados, mui cortos i mui iguales imitando terciopelo. El artículo I, que es el mas grueso, es obcónico; el 2 es trasversal; el 3 es apénas tan largo como el primero, subcilíndrico en su parte basilar i nudoso en su ápice; de los siguientes, los 5-IO son los mas largos, i son cilindricos con una leve dilatacion redondeada en el ángulo inferior de su ápice, el 12 cs de $\frac{?}{4}$ a $\frac{1}{5}$ mas corto que el penúltimo, pero es libre i bien separado de él, i su cóndilo es bien visible.

Protórax trasversal i cilíndrico, con ol borde anterior levement? adelantado i saliente; dorso atravesado en si medio por una hilera de cuatro gruesos tubérculos: Ins laterales puntiagudos, los del medio romos.

El escudo ocupa el i 5 por ciento de la anchura basilar de los 
elitros; su ápice es puntiagudo, i sus bordes luterales levantados a molo le ribete; entre éstor, es puntuad.o i pubescente.

Los élitros glabros, brillantes i lisus, son cuneiformes, es decir que, por una lonjitud de 20 , la anchura tomada $2 \mathrm{~m}$ in ántes del ápice (3.6) da los $0.4 j$ de la basila (\$..1). Esta última es casi doble de la de la batse del protórax. Los custados i la batse son rectos, con el pliegue cpipleural entero, i sin dilatacion notable ni brusca por bajo del calio humeral. Este cs grueso, nudoso, redondeado i saliente, separado de la parte escutedar por una depresion mui nolable. La sutura es finamente ribeteada; el íngulo sutural no es nunca borrado, sino recto i puntiagudo, a veces, aun armado de un dientecito oblícuo hácia adentro.

El prosternon ticne su salida mui angusta, casi lameliforme, i bastante enterrada entre las ancas para no alcanzar a su nirel; su arichura (0.2), aun no da los iv de la de la salida mesosternal. Sus cavidades cotíloídeas son fuertemente angulares en su parte csterna, $i$ abiertas en la basilar.

El mesosternon tiene su salida aplanada, inferior al nivel de sus ancas, i con una pequeña escotadura en su ápice para recibir la salida basilar del inctasternon.

El metasternon tienc sus episternones grandes; en un ejem. plar,+ 1 levan una anchura basilar de 2.3 por una lonjitud de $6^{\prime \prime}$; sus costados, casi paralelos en el tercio basilar, converjen des. pues gradualmente hasta juntarse en el ápice, que es angular.

El abdómen es sólido i cunciforme, con el segmento I mas largo que los siguientes que son iguales de lonjitud; el 5 es anchamente escotado.

Las ancus anteriores son cónicas i salientes en su parte interna, pero mui dilatadas lateralmente en su base.

Los fémures son sub-lincares, levrmente comprimidos i apénas ensanchados en su initad apical; . - anteriores son los mas cortos; el ápice de los intermediarios sulo aicanza a la base de los posteriores, los cuales alcanzan mas o ménos a la $3 .{ }^{n}$ sutura abdominal.

Las tibias son casi rectas, o levemente arqucadas en las patas intermediarias i las posteriores; su lonjitud es casi igual con la de sus fémures. 
En los tarsos anteriores, la anchura de los arí́culos 2.3 (o.8) es igual a los 0.57 de su lonjitud (I.4) juntos. La lonjitud del artículo I da los o 86 de la de los artículos 2, 3 juntos, en los tarsos anteriores; los 0.93 en los intermediarios; i los r.22 en los posteriores.

El pene es corto i triangular. La parte superior de la vaina que lo encierra se termina por dos espigas córneas i cilíndricas, cuyo ápice es adelantado i cerdoso; disposicion que puede engañar a primcra vista, por darle las apariencias de la estremidad de un oviducto.

Hembra: cuerpo aplanado i alargado; un ejemplar de $33^{\prime \prime}$ de lonjitud presenta una anchura de 8.5 siendo ésta los 0.25 de aquella. Pubescencia ménos abundante.

Barba i lengiïeta casi uniformemente coriáceas.

Antenas con once artículos. Son mas delgadas i mas cortas; es decir que la anchura de los artículos centrales es de una tercera parte menor, i que les falta 15 por ciento mas o ménos, para que lleguen a la estremidad de los elitros. Los cuatro primeros artículos i parte dei 5 son briliantes i glabros, con escepcion de unos que otros finos pelillos erizados sobre su ápice, que es nudoso; los demas son casi cilíndricos i opacos, pero sin capa aterciopelada; el i I es algo mas largo que el Io, i siu rastro cle falso-artículo.

El escudo es glabro, liso i mas o ménos cóncavo lonjitudinalmente; el ápice es redındeado, i los costados no estan levantados a modo de ribete.

Los elitros tienen sus costados paralelos casi en sus $\frac{4}{5}$ basilares; su ápice está redondeado en cada uno separadamente, quedando completamente borrado el ángulo sutural. La superficie es opaca por encontrarse cubierta de unas densas rugosidades vermiformes.

El ablómen con frecuencia es blando i se esticude, dejando el pijiclio descubierto; el segmento 5 es mas largo que cada uno de los tres precedentes, i atenuado hácia suápice, que lleva una pequeña sinuosidad borrada con frecuencia.

Los fémures posteriores no alcan\%an, o alcanzan apénas, a la segunda sutura de los segmentos abdominales. 
En los tarsos la anchura de los artículos 2 i 3 de los anteriores (0.7) da los 0.50 de lat lonjitul de estos mismos artículos juntos. El artículo I da los 0.93 de la lonjitud de los artículos 2.3 juntos en loi anteriures, el $1.17 \mathrm{cn}$ los interme.liarios, $\mathrm{i}$ el I.4O $\mathrm{cn}$ los posteriores.

El oviducto lleva en su estremidad, i en la parte esterna de cada lado, un pequeño palpo articulado i cercloso doblado hácia afuera.

L. CONCINNus $(P h . j$.$) I. G.$

Syn. \& Callichroma laevigata (Ph. Stettin-Zeitt. I864)

"t " concinna (Ph. j. Stcttin-Zeitt, I860, An. Univ. I 859).

ô capite prothoraceque nigris, subopacis, punctis irregularitus inordinate impressis. Antennarum articulo ${ }^{\circ}{ }^{\circ}$ laxe punctato, articulis tribus primis nigris, nitidis; reliquis opacis plus minusve obscure mbro-castaneis. Elytris levigatis, nitidis, olivaceis; attroque in medio longitrorsum plus minusue late fuliesconte, lineisque duabus pallidis atque angustissimis picto; callo humcrali nigro. Pedibus nigro-fuliginosis, sparsim punctatis. Pectore obscuro, pube sublanuginosa appressa dense vestito. Abdomine obscure fulvescente, glubriusculo et laxissime punctulato.

Long. 25.11; lat. 8.1.

it Antennarum articulis quatuor primis nitidis. Prothorace nitidiusculo, punctis grossis sparsim impresso. Elytris opacis rugis vermiculatis dense tectis; in dimidio busali dizaceis, margine laterali, th suturali in dimidio apicali gradatim viresientibus; utroque in medio longitrorsum late fulvo-testacen, et lineis longitudinalibus \& angustissimis, elevatis, parum conspicue ornato. Pectore tenuissime rugoso-punctulato, parce pubescente. Abdomine viridi-olivaceo.

Long. 33.11; lat. 8.5.

Al redactar el diagnóstico del jen. Lautarus, he hecho figurar caracteres que son propiamente específicos; por creer con- 
veniente incluir en él la lista completa de las principales diferencias sexuales. Naturalınente no se luablará de ellas al tratar de la especie, quedando para caracterizarla solamente lo que se refiere al grabado de los tegumentos i a su coluracion, i las medidas relativas a las proporciones de los artículos de las antenas, del protórax, de los elitros i del fémur intermediario.

¿. La cabeza i el protórax son negros i levemente opacos: esto, sin duda, con motivo de la finísima puntuacion que llevan; en medio de esta otros puntos inucho mayores se liallan desparramados; unos i otros son algo irregulares $\mathrm{i}$ distribuidos sin órden.

Las antenas son siempre mas laryas yue el cucrpo, pero de una cantidad variable. Aquí está la lonjitud cle los artículos en dos casos cstremos:

\begin{tabular}{|c|c|c|c|c|c|c|c|}
\hline Lunjituc & $\mathrm{d} d \mathrm{de}$ & los & tíc & .... & I & 2.4 & 2.11 \\
\hline$"$ & $"$ & $"$ & $"$ & $\ldots$ & 2 & 0.5 & 0.3 \\
\hline$"$ & $"$ & $"$ & $"$ & ... & 3 & 2.3 & 2.11 \\
\hline 11 & $"$ & 11 & $"$ & $\cdots$ & 4 & 3.4 & 2.8 \\
\hline$"$ & $" 1$ & 11 & 11 & $\ldots$ & 5 & 4.5 & $3 \cdot 5$ \\
\hline$"$ & 11 & 11 & $"$ & $\ldots$ & 6 & $4 \cdot 5$ & 3.8 \\
\hline$"$ & 11 & $"$ & $"$ & ... & 7 & $4 \cdot 5$ & 3.8 \\
\hline " & 11 & $"$ & $"$ & $\cdots$ & S & $4 \cdot 5$ & 3.6 \\
\hline$" 1$ & $"$ & $"$ & $"$ & $\ldots$ & 9 & $4 \cdot 5$ & 3.6 \\
\hline$"$ & $"$ & $" 1$ & 11 & ... & 10 & $4 \cdot 5$ & 3.6 \\
\hline$"$ & $"$ & 11 & $"$ & $\cdots$ & I I & $4 \cdot 11$ & 3.11 \\
\hline$"$ & 11 & $"$ & 11 & $\ldots$ & I2 & 2.7 & 2.5 \\
\hline$"$ & \multicolumn{5}{|c|}{ total de la antena... } & 42.3 & 34.5 \\
\hline$"$ & \multicolumn{5}{|c|}{ del cuerpo............ } & 25.5 & 25.11 \\
\hline $\begin{array}{l}\text { roporc } \\
\text { ésta... }\end{array}$ & & & & on & & 1.66 & 1.3 \\
\hline
\end{tabular}

Los tres primeros artículos i parte del $4 .^{\circ}$ son negros i brillantes; el $\mathrm{I}^{\circ}$ con unos puntos dispersos; parte del $4 .^{\circ} \mathrm{i}$ los de. mas son upacos i de un castaño mas o ménos rojizo. 
Lil protórax lleva làs medidas siguicutes en un ejemplat de 25.5 cle lonjitud:

Lonjitud en el medio

4.11

Anchura basilar..................... 4.8

" apical.................... 4.5

En este mismo ejemplar, los elitros tienen una anchura basi$\operatorname{lar}(8.11)$ que da los 0.40 de su lorjitud (20..1); son lisos, brillantes i de un mati\% aceitunado, mas negro sabre el callo humeral; pero cada uno lleva en su medio una veta Ionjitudinal, mas o ménos ancha, de: un inatiz testáceo-leunado, gradnalmente degradado en su union con el primero; $i$ ademas dos mui finas líneas lonjitudinales mas pálidas.

I as patas son de un riegro de per, algo aceitunadon en los fémures, i llevan unos pocos puntos dispersos. El fémur intermediario prescntat las proporciones siguientes:

Lonjitud del cuerpo............. 25.5

" del fémur intermediario.................. 6.5

Proporcion de ésta con aquella. $25 \%$

Anchura de éste en la base..... 0.90

" en la parte anterior... $\quad \mathbf{1 . 2 0}$

Proporcion de a juella con ésta. $\quad 75 \%$

" de ésta con la lonji-

tud................ Is "

El pecho es oscuro, i su pubescencia, algo lanosa, es mas abundante que en otra parte.

El abdómen es de un leonado irregularmente olivado; es brillante, casi completamente glabro, i soln lleva algunos pequenos puntitos clispersos.

I Los artículos de las antenas son como sigue en un ejemplar de 33.11 
Lonjitud de los artículos... I $\quad 2.7$

\begin{tabular}{|c|c|c|c|c|c|c|}
\hline 1 & 11 & 11 & 11 & ... & 2 & 0.4 \\
\hline " & "1 & " & 11 & $\ldots$ & 3 & 2.4 \\
\hline " & 11 & $"$ & 11 & $\ldots$ & 4 & 2.7 \\
\hline " & $"$ & $" 1$ & 11 & $\ldots$ & 5 & $3 \cdot 3$ \\
\hline "1 & $"$ & 11 & 11 & ... & 6 & 3.2 \\
\hline "1 & " & 11 & 11 & $\ldots$ & 7 & 3. I \\
\hline " & " & 11 & 11 & $\ldots$ & 8 & 2.7 \\
\hline " & $"$ & $"$ & 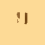 & $\cdots$ & 9 & 2.7 \\
\hline 11 & 11 & 11 & 11 & . & IO & 2.3 \\
\hline " & $"$ & $"$ & $"$ & . & I I & 2.4 \\
\hline " & total & de la & an & aа. & & 27.9 \\
\hline & del & $\operatorname{corp}$ & & $\ldots$ & & 33.11 \\
\hline
\end{tabular}

Proporcion de aquella con ésta ....................

0.84

El artículo I - que siempre se mide despues del cóndilo-tiene una anchura apical ( I. IO) que dá los 0.42 de la lonjitud (2.6). En un ejemplar de 35.1 , que pertenece a la colcccion del Museo, se prescnta una aberracion igual en ámbas antenas: el artículo 3 es mas corto i dilatado desde el primer cuarto basilar, dando su anchura (0.96) los 0.43 de su lonjitud (2.2); miéntras que, en todos los otros ejemplares que tengo a la vista, este mismo artículo está dilatado solamente en su ápice, $\mathrm{j}$ una anchura (0.76) que dá los 0.3 I de la lonjitud (2.4) son sus proporciones constantes.

El protórax presenta las medidas siguientes en un ejemplar de 33.11 :

Lonjitud en el medio.......... 4.3

Anchura basilar............. 4.9

" apical.............. 4.7

En este mismo cjemplar la anchura de los elitros (8.5) dá los 0.32 de su lonjitud $\left(26_{1}\right)$. El matiz de éstos es un aceitunado que pasa a lo verde en el márjen lateral, j, mas o ménos, en la 
mitad apical del márjen sutural; poro cada clitro está invidido por una ancha faja lonjitudinal de un testáceo alconado; illeva, ademas, cuatro finas costillas lonjitudinales, tanto mas acercadas unas a otras cuanto mas latcrales estan; las dos esternas son a veces algo confusas.

El matiz de la parte inferior del cuerpo i de las patas es un aceitunado, mas verdoso sobre el abdómen i a veces los nuslos.

La pubescencia del pecho es poco abundante i no uculta los tegumentos, los cuales son mui finamente rugosos i puntuados.

Las proporciones del fémur intcrmediario son las siguientes:

Lonjitud del cuerpo............. 33 ."

" del fémur intermediario....... $8 . "$

Proporcion de ésta con aquella......... $24 \%$

Anchura de éste en la base.......... 0.90

" $\quad$ en la parte anterior..... I. IO

Proporcion de aquella con ésta......... $64 \%$

" de ésta con la lonjitud........ $17 \%$

Lám. III; fig. 5. a barba, lengöieter i palpo latial.-Aum, I 5 diám. fig. 5. Estremidad del pene........ " 10 " fig. $5 .^{\circ} \quad "$ del oviducto...... " 10 "

\section{Gen. SIBYLLA (Thoms.)}

Respecto al jénero Sibylla, cuyo estudio ahora se presenta, lo primero que tal vez se habria de hacer seria de indicar las inexactitudes en las cuales han incurrido, tanto Lacordaire en su Genera, como Fairmaire \& Germ. al hablar de est $s$ insectos en los "Annales de la Soc. ent. de France, 1859, p. . 8711 ; aunque supongo bien que aquí solamente se habrá reproducido to publicado por Thomson en una obra (Archio. Entom. I, p. fo6) que no está a mi alcance. Pero hablar dos veces de unos mismos órganos traeria quizas alguna confusion; $\mathrm{i}$, para cvitarlo, mcjor será que redacte un diagnóstico, en el cual haré figurar lus caracteres que presentan las especies de este jénero, indicando en su lugar las incxactitudes a las cuales me refiern. 
Las especies que tengo a la vista son tres: (a'meleri (Thoms.), fluarosignata (Fairm. \& Germ.), i livida (P.G.); pero desgraciadamente el único macho que conozco es el de la primera: lo que diré de este sexo será, pues, propio de ella.

En cuanto a las formas i a las proporciones, los órganos bucales son mui parccidos con los del jénero Lautarus; pues, difieren solamente por tener quijadas levemente mas cortas, i cuyo artículo 2 de los palpos es de un tamaño incnor, comparado con el de los artículos I i 3 ; i tambien por los lóbulos de la len. giieta, que son manifiestamente membranosos, cuya lonjitud dá ménos de dos veces la anchura, i porque el seno anguloso que los separa es evidentemente mas cerrado i a veces redondeado en su ápice.

El epistomio con su labro siguen con evidencia el mismo declive que la frente; miéntras que, en el j. Lautarus, esta es mas vertical. Pero es de advertir que la cleclividad de estas partes, ademas de la dificultar que hai en fijar bien sus límites, se vé espucsta a modificaciones, le las cuales la mas leve hace mucho mas dificil describir exactamente esta paste de la cabeza. La sutura del epistomio con la frente, aunque angosta, se vé en algunas especies

En lo: $\hat{~}$, las antenas - por mas que se digan "presqu'aussi longues que le ecrpsu (F. \& $G$.), i ude la longueur du corps on peu s'en faut" (Lacord.) - son siempro mas largas que e! cuerpo: diferencia que varí: pero que veo encerrada entre el r.ro i el r.4O. En cuanto a lo que se dice, que "les antennes sont comprimíes" $i$, luego despues, que "ies articles j-10 sont comprimesu (F.\&. G.), es completamente inexacto: las antenas so!ı filiformes $\mathrm{i}$ sus artículos son cilíndricos. Es tambien inexacto que tengan "ntn donziçme article suphlémentaire" ( $F$. \& $G$.); cu el caso presente, el artículo I i ileva en sus $\frac{2}{5}$ apicales una brusca contraccion lateral, que una mui leve diferencia de nivel permite apreciar en la parte esterna del artículo, estando la antena dirijida hácia atras. Pero una esplicacion es neccsaria aqui.

Para que un artículo sea suplementario o adicional, es, ante todo, preciso que exista; $i$, para que exista, es necesario que sea libre del precedente, es decir, articulado con el por medin de 
una coyuntura compucsta de un cóndilo i de una cavidad cotiloídea. Pero, cuando, en cualquiera parte de su lonjitud, el último artículo de unas antenas sufre ma contraccion lateral brusca, i que este trozo contraido, por estar en perfecta cohesion con el trozo basilar, forma con él parte integrante del artículo, esto se llama un fulso-articulo, por mas que una huclla o un pliegue trasversal mas o ménos visible dije sospechar una sutura. De lo cual resulta que una antena no pucde iliccirse le 12 artículos, cuando el último está en estas condicinues. Esta disposicion es frecuente en ciertas familias (Elatericlat, etc.)

Los artículos $\mathrm{I}-4$ i la mitad basilar del 5 son brillantes, pero con una pequeña puntuacion algo apretada, mezclada con unos que otros puntos mayores sobre cl artículo i; llevan una mui fina, mui corta, mui tendida i mui rala pubescencia blanquizca, que parece ser mui caediza. "Article $x$ aussi long que 3, 3-5 egaux (Lacord.) i "articles 3,4 presque égaux ( F. \& G.)" son aseveraciones poco exactas: el I aumenta gradualmente de anchura de la base (0.5) al ápice (0.74); i su lonjitud - que se mide siempre despues del cóndilo - es levemente superior a la del 3; éste es mas corto que 4 , i ámbos son cilíndricos i delgados; pucs, su anchura (0.4) da solamente los $\frac{3}{5}$ de la del ápice (0.68) que es nudoso; el artículo 5 es el mas largo, es delgado en su mitad basilar i se ensancha gradualmente en la apical; esta parte i los artículos siguientes son cilíndricos, mui levemente arqueados, cerca de un 50 por ciento mas anchos que 3 i 4 i, escepto el úl. timo, con el ángulo apical esterno jevemente dentiforme; ade. mas, estan cubiertos de desigualdades i asperczas irregulares, $\mathrm{i}$ son opacos a causa de una densa capa de cortos pelillos parados que figuran terciopelo. El I I no es nunca "égal ì In et obtus au bout (Lacord.)", sino siempre mas largo, aun en las f; esta diferencia alcanza del $\mathrm{I} S$ al 27 por ciento en los $\hat{\delta}$, $\mathrm{i}$ sir ápice termina en punta.

En las $q$, las antenas son mas cortas, pues su lonjitud da mas n ménos los $\frac{3}{4}$ de la del cuerpo; los artículos 5- I I son ménos grue. sos, con el ángulo apical redondeado $\mathrm{i}$ apénas saliente. P'ero lo que las distingue a primera vista de las rle lo mitchos, es la ca* rencia de devigualdades i asporcas; por otıa parte, la pubes. concia que figura trerciopelo es ma i densa i bicn manificstamen- 
te inclinada hácia adelante. El artículo I I es apénas mas largo que el ro, el falso-artículo es poco marcado, i su ápice ménos atenuado.

Todo lo que se refiere a los ojos, los carrillos i los tubérculos antenarios presenta poca diferencia con lo que se indica para el jénero precedente; pero la escotadura de los ojos envuelve a estos últimos de un modo tan notable a veces, que la línea ocular llega a ser tanjente a su borde interno.

El protórax es siempre mediocremente trasversal; pues su lonjitud da en término medio los 0.83 de la anchura basilar; esta es mayor que la apical; los costados son a veces paralelos, $\mathrm{i}$ otras converjentes en su mitad anterior, pero casi siempre presentan en su medio una dilatacion ancha $i$ poco saliente, que lleva un grueso tubérculo puntiagudo, el cual se llama "une courte épine! ( $F$. \& $G$.) " en el diagnóstico del jen. Sibylla, i "une forte dent! ( $F$. \& $G$.)" en la descripcion de la Sibylla Cometerii. La anchura basilar del protórax da, en término medio, los 0.63 de la anchura basilar de los elitros; siendo inexacto decir "Elytres deux fois aussi larges que la base du corselet ( $F$. \& $G$.) " El dorso es mas o ménos desigual, puntuado, opaco i pubescente.

El escudo varía segun las especies, i aun en una misma; pero su anchura basilar da siempre mas o ménos, los 0.20 de la de los elitros; lo que, segun me parece, no permite decir de él "Ecusson petit ( $F$. \& $G$ )."

Los elitros son lisos i brillantes, notablemente cuneiformes en los $\hat{\delta}, \mathrm{i}$ dehiscentes en su mitad apical; la base es truncada $\mathrm{i}$ recta; el callo humeral es grueso, redondo i saliente, i está separado de la rejion escutelar por una depresion lonjitudinal mas o ménos alargada; el pliegue epipleural es angosto, pero completo; la estría marjinal principia en el ángulo humeral; cada elitro, por estar el borde lateral i el sutural rectos en su parte apical, presenta allí la forma de un angosto triángulo; cuyo ápice tiene una anchura que da solamente los 0.2 I de la de la base, i que varía desde bi-espinoso hasta brevemente redondo, pasando a veces por escotaduras de grados mui inconstantes, no solamente en una misma especie, sino aun en un mismo ejemplar. 
El cuerpo, con escepcion de los elitros i de las antenas, lleva una pubescencia cenicienta, fina, larga i erizada, mucho mas escasa en las hembras.

El caráctcr, al cual Lacordaire hace dcscmpeñar un papel de primera importancia en la diagóstica del jén. Sibylla, i que consistc en que la salida prosternal está cn el mismo nivel que las ancas, presenta-aclemas de una constatacion algo incierta-el gran defecto de estar espuesto a lo mas i a lo ménos: a lo mas, si las patas estan dirijidas adelante, porque entónccs las ancas se hallan perpendiculares al eje del cuerpo, i, por esto, mui erguidas; a lo ménos, si las patas estan dirijidas hácia atras, porque entónces las ancas estan en una posicion oblícua, i son, por consiguiente, ménos salientes. Sin cmbargo, descartando este leve motivo de error, este carácter tiene un valor notable.

Pero, en cuanto a "plaque prosternale moins grande chez le f." i tambien "plaque mesosternale moins apparente chez le $\delta$ (F.\&G.) "; estos son datos que nacieron de una ilusion, i que fueron admitidos sin consultar el compas o el micrómetro; haciéndonos ver una vez mas, que es un error figurarse que el ojo puede medir con precision las anchuras $i$ las lonjitudes sin la ayuda de un instrumento.

El cuadro siguicnte, que ha sido formado con mucho cuidado, será suficiente para dcmostrar, que, no solamente la tal diferencia sexual no existe, sino, tambien, que la Naturaleza parece no saber con fijeza cuáles son las proporciones, que, en ca. da sexo, la anchura de la salida prosternal i la de la mesosternal deben guardar con la lonjitud del cuerpo. I, ademas, estas vacilaciones nos dicen con mucha elocuencia, que no hemos de mirar estas infinitas modificacioncs esternas de los insectos, como una mina donde podemos sacar ciegamente i a manos llcnas elementos para su clasificacion; sino que, para esto, es preciso, ante todas cosas, sometcrlas a una seleccion escrupulosa i razmnada. 


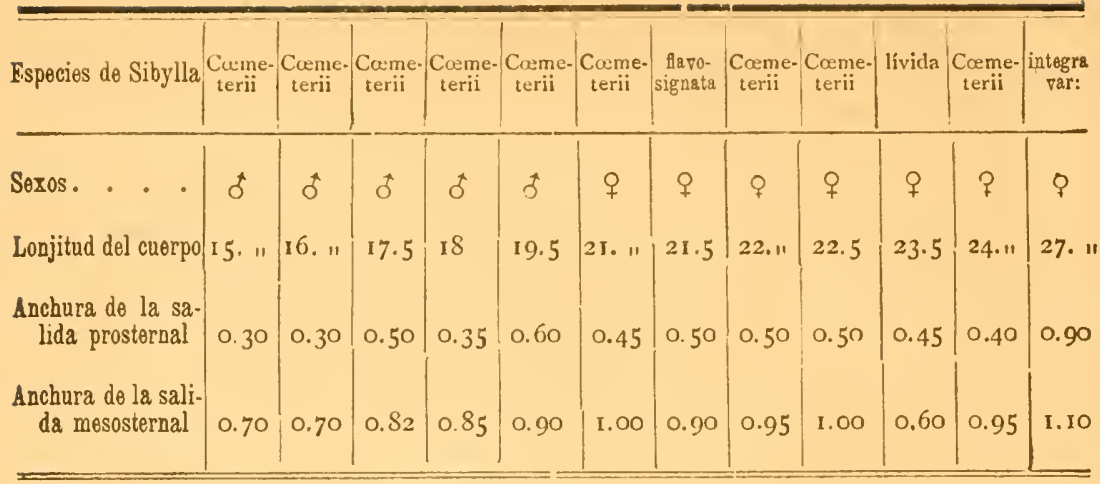

Mirando la cuestion bajo un punto de vista mas jeneral, no hai duda que la naturaleza tiene por mision producir hijos parecidos a sus padres; pero, al mismo tiempo, goza de cierta libertad de movimientos en la angosta senda por donde tiene que caminar. Por esto, al lado del facies específico que llevan todos los seres salidos de sus manos, hai siempre otro-el facies individnal-que, con motivo de las atrevidas correrías que esta buena madre suele permitirse en las herencias colaterales, puede muchas veces hacer pasar a una especie por distinta. En es. tos casns, le toca al naturalista ser bastante perspicaz para no dejar dominar su criterio por leves modificaciones.... de una estria, de un punto, de un pelo, de un matiz, etc., o de las proporciones tan variables de las anchuras i de las lonjitudes de tal o cual órgano. Pocos serán los entomólogos, que habrán visto sin asombro estos jéneros tan henchidos de especies imajinarias, superabundancia que hace imposible distinguirlas unas de otras.

En jeneral, estas leves modificaciones han de inspirar mucha desconfianza cuando estan aisladas; i solo llamar sériamente la atencion cuando varias de ellas se presentan siempre juntas en repetidos ejemplares. En este caso, aun es preciso no olvidar que, en manos de la naturaleza, los seres se modifican segun el medio, que el medio varía segun el clima, i el clima segun la rejion; i que puede presentarse entónces el peligro de considerar, como especies ya establecidas, unas meras variedades jeográficas; es decir, colonias, que sin duda anhelan separarse del 
tronco del cual derivaron, pero que andan todavía en busca de su unificacion i autonomía.

Volvicndo a la salida prosternal, que esta pequeña digrcsion me habia hecho dejar momentáneamente a un lado, agregaré: que es fuerte i densamente puntuada; convexa trasversalmente en los ó; a menudo aplanada i ribeteada por una fina estria en las 9 ; casi paralela entre las ancas, arqueada algo bruscamente despues de ellas, i vertical en su estremidad. Su anchura, cuando se da, cs la que tiene entre los cóndilos femorales.

Las cavidades cotiloídeas anteriores son largamente angulosas lateralmentc, i mui abiertas en la base.

La salida mesosternal lleva una escotadura angulosa en su ápice; i tiene mas o ménos dos veces la anchura de la prosternal. Pero, si las proporciones de esta anchura con la lonjitud del cuerpo parecen rehuir toda regla constante, su forma es mas irregular aun; pues, sus costados laterales son a veces rectos i a veces arqueados en su parte apical. En el primer caso son paralelos, o converjentes adelante; $i$, en el último, la curva se dirije hácia adentro o hácia fuera, sin que se pueda sacar cl menor partido de estas modificaciones.

Las cavidades cotiloideas inteimediarias son mui abiertas lateralmente, por ser el epímero mesotorácico grande hasta no dejar ningun episternon entrar en contacto con las ancas.

El metasternon lleva dos clases de puntuacion de una densidad variable, pero mayor en los of: la una consiste en puntitos mui finos, la otra en puntos pilíferos mayores i mui ralos. Lleva cn su medio una depresion acanalada lonjitudinal. Los episternones son grandes, i mui parecidos a los del jénero precedente: en uno encuentro que la anchura da los 0.27 de la lonjitud.

El abdomen es muchas veces ablandado i dilatado en las + hasta dejar el pygidium descubierto; es brillante por estar su puntuacion mucho mas escasa que en los esternones, aunque de misma clasc. La lonjitud de sus segmentos disminuy"e gradualmente del I al 4 ; la del 5 es mas o ménos igual con la del 2; pero, tanto respecto a esto como respecto a la forma de su borde apical, es mui variable segun las especies, los sexos, i aun los individuos; poniendo en evidencia la inexactitud de lo que dice 
Lacordaire: "dernier segment abdominal des mâles assez long, legèrement arrondi au bout" i "dernier segment abdominal des femelles plus long, subtronqué au bout.. En todas las hembras que tengo a la vista, este $5 .^{\circ} \mathrm{segmento}$ varía a veces de lonjitud segun las especies, pero su borde apical es siempre evidentemente curvo; miéntras que, en los machos, es jenerdlmente mas corto, con el borde apical a veces curvo tambien, otras subtruncado, $i$ aun con un seno bien manifiesto aunque poco profundo: todo esto a veces en ejemplares de una misma especie.

Las ancas anteriores son gruesas, salientes i angulosas lateralmente. Las intermediarias son ovaladas i convexas, i tambien algo angulosas lateralmente.

Pero "Pattes assez longues surtout les postérieures (Lacord)." i tambien "Pattes assez grandes et assez fortes, les posterieures plus longues". "Cuisses posterieures fortement arquées". I "Cuisses fortement arquées, sauf les antérieures". (F. \& G.) son palabras cuya presencia aqui no deja de estrañar, tanto por su inutilidad cuanto porque son de una exactitud mui discutible.

En cuanto a la lonjitud i a la anchura de los fémures, ellas son como sigue en una 9 de $24.1 \mathrm{i}$ en un de 18 :

Sexos.

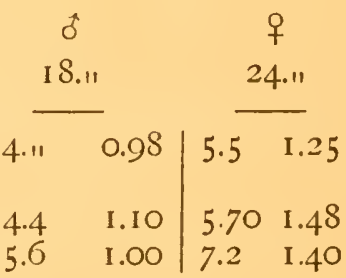

Comose ve, la mayor lonjitud de las patas posteriores no es otra cosa que la aplicacion de una lei jeneral; i forma un carácter que, por no presentar nad a de anormal, no podia ser utilizado para la diagnóstica de este jénero; pues, e; solamente en caso de que hubiese constituido un a escepcion que habria habido oportunidad eis exhibirlo. Pero, a este dato inútil, es preciso agregar que el ápice del fémur intermediario alcanza escasamente a la base del posterior, sin pasar nunca mas adelante; i que el ápice de este último alcanza cuanto mas en la base del 3. er $^{r}$ egimento abduminal en las ', , i d 21 4." en los machos. 
En cuanto al arqueo de los fémures intermediarios i posteriores, sorprendc que el creador del j. Sibylla haya creido convenieñte hacer figurar tambien a este carácter en su diagnóstica; i la razon es esta:

La articulacion de la anca con e! fémur está sicmpre colocada en un plan inferior a la del fémur con la tibia-o rodilla-, i es evidente que, despues de aquella primera articulacion, los fémures intermediarios i posteriores, por estar dirijidos no solamente hácia arriba sino tambien hácia atras, tienen que arqucarse, como si quisieran abrazar al abdómen i aplicarse contra su parte cilindrica para llegar al nivel que les corresponde. Los fémures anteriores que, por estar dirijidos hácia adelante, no tienen nada que abrazar, no estan arqueados; i muchas veces los fémurcs intermediarios i posteriores no lo estan tampoco, cuando su articulacion con las ancas está rechazada lateralmente, por encontrarse éstas últimas mui salientes o separadas por una salida intercoxal de anchura anormal. Todas estas disposiciones son tan jenerales, tan lójicas i tan propias de todos los Lonjicornios, que no me esplico la necesidad que ha habido de hablar de ellas, i mucho ménos la idea de utilizarlas como carácter jenérico.

En una $q$ de 24." de lonjitud, la de los tres primeros artículos de los tarsos es como sigue:

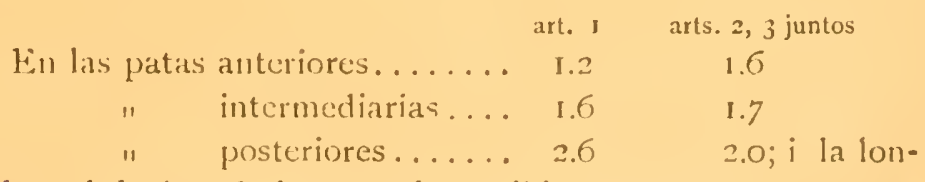

jitud total de éste da los 0.90 de sı tibia.

Los brganos sexuales no presentan diferencias con los del jén. precedente.

\section{S. COMETERII (Thoms.)}

Nigra, nitida. Capite prothoraceque, apud mares opacis et pube grisea hirsutis, apud feminas glabriusculis et subnitidis. Capite in medio longitrorsum profunde sulcato, dimidio antico obsolete 
punctulato, dimidio postico grosse punctato-varioloso; apud faminas minore. Prothorace inaquali dense virioloso. Scutello triangulari, supra lavigato, aut laxe punctato; longitrorsum cañaliculato, aut concavo; apice acuto, scepins obtuse bifido. Elytris aliquando basi apiceque late coccineis; utroque apice emarginato, aliquando subtruncato, scepius bispinoso.
? long. 19.5; lat. 6.7-long, 15.11; lat. 5.I.
i long. 24.11; lat. 8.3-long. 21.11 ; lat. 7.5 ,

Brillante i mui negra; pero un matiz púrpureo hace a veces su aparicion bajo el calio humeral, con forma de una pequeña mancha, la cual se estiende a veces sobre la base de los elitros, aparece tambien en su ápice, i por fin llega a estenderse, hasta dejar solamente una gran mancha negra ovalada i comun que cubre la sutura. Lacordaire dice que estas manchas rojas "sont sujettes à disparaître complètement, surtout chez les +11 . Tengo a la vista cuatro ejemplares que las llevan; un solo es f!

Para dar una idea exacta de la lonjitud i de la anchura de esta especie en jeneral, he medido, para cada sexo, el ejemplar mayor i el menor de los que tenia a la vista; i se puede ver, por los guarismos espresados mas arriba, que la anchura representa constantemente la tercera parte de la lonjitud.

La cabeza es mayor en los machos: así, en uno de I8.1. de lonjitud, i cuya anchura es de 6.3 en la base de los elitros, la anchura de la cabeza tomada en los ojos es 3.6; lo que da los 0.57 de aquella. Miéntras que, en una hembra de 24.11 de lonjitud i de 8.3 de anchura, la de la cabeza es de 3.5 ; lo que da solamente los 0.42. En los machos, es opaca i lleva una pubescencia cenicienta larga i crizada sobre to lo en la frente; en las hembras, la pubescencia es mui poco aparente i el brillo es no. table. Encima, presenta un surco Ionjitudinal angosto pero profundo, que va desde el protórax hasta el epistomio. Este último tiene su línea sutural con la frente completamente borrada; pero lleva una puntuacion rala un poco mas marcada que la de la frente, que es fina; miéntras que, entre las antenas i sobre el el protórax, es mucho mayor, desigual i sin órden.

Los costados de la barba llevan ántes del medio una pequeña cscrutadura, despues de la cual son rectos i mui converjentes 
hasta encontrarse con la lengüieta. El seno que scpara los dos lóbulos membranosos de csta última, forma un ángulo agudo, con el ápice anchamente redondeado.

Los ojos son mui parecidos a los del jén. precedente; en una hembra de $24 . "$, su distancia es de 2.3 en la frente, de I.8 en el vertex, i de 2.5 en la garganta. La línea ocular es tanjente al borde interno de las cavidades cotiloídeas, con escepcion de unas pocas hembras, en las cuales las atraviesa levemente.

En cuanto a las antenas, aquí está su medida en dos machos i en una hembra.

\begin{tabular}{|c|c|c|c|c|}
\hline \multirow{12}{*}{ Lonjitud de los artículos.. } & & 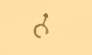 & $\delta$ & '? \\
\hline & I & 2.3 & 1.8 & 2.2 \\
\hline & 2 & 0.5 & 0.3 & 0.3 \\
\hline & 3 & 2.2 & 1.5 & I. 8 \\
\hline & 4 & 2.4 & I. 7 & I.7 \\
\hline & 5 & 3.11 & 2.11 & 2.11 \\
\hline & 6 & 2.6 & I. 8 & I. 6 \\
\hline & 7 & 2.6 & I. 8 & I.6 \\
\hline & 8 & 2.6 & I.6 & I. 4 \\
\hline & 9 & 2.6 & 1.6 & 1.4 \\
\hline & 10 & 2.5 & I. 4 & 1.2 \\
\hline & I I & 3.4 & 1.7 & I. 4 \\
\hline \multirow{3}{*}{$\begin{array}{l}\text { Lonjitud de la antena.... } \\
\qquad " \text { del cuerpo...... } \\
\text { Proporcion de aquella con } \\
\text { esta............... }\end{array}$} & & 26.7 & 17.2 & I6.6 \\
\hline & & 19.5 & I 5.11 & 22.11 \\
\hline & & $1.37 \%$ & I. $14 \%$ & $.75 \%$ \\
\hline
\end{tabular}

En los machos, el protórax es opaco i pubescente, i la puntuacion gruesa, rugosa i confluente; en las hembras, es casi glabro i llcva brillo; el dorso es desigual, dejando sospechar a veces unos dos o tres gruesos tubérculos redondos $i$ achatados mui poco aparentes; la puntuacion es mui gruesa i mui apretada; pero, en cuanto a ver "au milicu un sillon bien marqué. ( $F$. \& $G$.)" Confieso haber solamentc podido descubrir, en la parte anterior del pronoto de dos o tres de los ejemplares que tengo 
entre manos, la huella mui indecisa de una corta impresion lonjitudiual.

Sus proporciones en una hembra de 24.1 son como sigue:

Lonjitud..................... 4."

Anchura apical................... 4.

Anchura basilar................. 4.7

El escudo es quizas, con cl ápice de los elitros, la parte mas variable de estos insectos; $i$ estas variaciones son tales que disminuyen mucho su valor característico, o podrian hacer creer que los individuos que las llevan pertenecen a varias especies; pero, si es cierto que este órgano es utriangulaire ( $F$. \& $G$.) i que algunas hembras presentan "une impression longitudinale $\left(d^{\circ}\right)$ "I, que existe tambien en algunos machos; no he podido descubrir en ninguno "nne impression transversale ( $\left.d^{\circ}\right)$." Las principales variaciones quc presenta el escudo son las siguien-. tes:

I. ${ }^{\circ}$ Puntuacion fina i rala, una impresion triangular en la mitad basilar, la apical con un surco lonjitudinal poco profundo, ángulo apical entero i agudo, una hembra.

2. Liso, acanalado lonjitudinalmente desde los bordes laterales; este canal se hace angosto en el ángulo apical, i lo divide en dos pequeñas puntas romas i tuberculiformes, varias hembras.

3." Liso, cóncavo, con los costados levantados i salientes a mocio de ribetes, ápice como en el anterior, varios macíos.

$4 .^{\circ}$ Como el $20^{\circ}$, pero liso solamente en la parte central, lo demas cargado de gruesos puntos pilíferos, un macho.

5. Casi aplanado; cargado con gruesos puntos pilíferos, escepto en el centro; ápice ancha i profundamente escotado, varios machos i una hembra.

Los elitros presentan una anchura que da mas o ménos los 0.45 de su lonjitud. La depresion lonjitudinal acanalada, que separa la rejion humeral de la escutelar, se angosta gradualmente hácia el ápice, i desaparece en jeneral en la mitad de la lonjitud del clitro, pocas veces sigue hasta su estremidad. La sutura es deprimida i finamente ribeteada. Hemos dicho ya que, en 
cada elitro, el ápice tienc una forma mui inconstante, que recore la escala siguiente:

1. En pocos ejemplares, es truncado, i este truncamiento es a veces mui levemente escotado, pero sin que los ángulos que produce lleguen a ser dentiformes.

2. En la jencralidad, el ápice termina con una escotadura, desde poco manifiesta hasta semicircular, produciendo ángulos dentiformes i puntiagudos, con frecucucia mui desiguales, hasta desaparecer por completo uno de ellos, tanto el interno como el esterno.

3. ${ }^{\circ}$ Algunas veces, estos ángulos son contraidos hastit tomar la forma de verdaderas espinas cilindricas i puntiagudas.

Las proporciones del fémur intermediario son las siguicntes:

Lonjitud del cuerpo de una hembra........ 24."

" del fémur intermediario......... 5.70

Proporciones de ésta con aquélla......... $24 \%$

Anchura de éste en la basc............. c.84

" de éste en la mital apical........ I.48

Proporcion de aquélla con ésta.......... $57 \%$

" de ésta con la lonjitud........ $26 \%$

Este insecto es escaso, aunque se halle esparcido por toda la parte austral de Chile desde el rio Ňuble. Por mi parte lo he encontrado en las selvas andinas de Chillan, en las mismas condiciones, en los mismos lugares, $i$ en la misma época que los Oxypeltus; pero me estrañó mucho leer "zole peu". ( $F$. \& $G$.) No me esplico quién ha porido propurcionar tal dato; cuando cl vuelo de este insecto cs, por lo contrario, mui rápido; i se parece al del Oxypeltus, con el cual podria competir.

Respecto a la S. intesra ( $F$. \& $G$.) no pucdo ver en ella sino apénas una variedad de la S. Ciemeterii. Pues, las dos diferencias claramente lefinidas que sirven de pretesto il su separacion, son 1.0 "la coloration entièrement noiren. $20^{\circ} \mathrm{el}$ ápice de los elitros "non pas bidents, mais tronqué et très faiblement sinué". I, con esto, varias diferencias que, por Io visto, no pueden espre. salse de utra mancer que por "un poco mas" o "un poco inénos". 
I. El matiz enteramente negro no puede presentarse como un carácter que la distinga de la Cemeteriz; ya que, en esta, los ejemplares enteramente negros son tambien numerosos.

2.0 En cuanto a la forma del ápice de los elitros, las diferencias que hai, en esta parte cuando es truncada, i cuando es mui levemente sinuada; cuando la sinuosidad es mui leve, i cuando es un poco mas marcada; cuando es así, i cuando los ángulos producidos alcanzan a verse, presentan tanta dificultad para ser espresadas de una manerit que no dé lugar a equívocos, i los límites de las formas que indican me parecen tan inciertas, que no creo cuerdo fundar una especie sobre bases tan frájiles.

$3 .^{\circ}$ Lo mismo diré del valor que se quiere dar a los poco más i a los poco ménos, con los cuales suele espresarse la diferencia dudosa de dos formas vecinas.

En la coleccion Izquierdo, hai un cjemplar hembra i negro de 27." de lonjitud; cuyos ápices de los elitros estan: el uno claramente truncado, i el otro con una mui leve sinnosidad; i, no obstante, no me atrevo a ver en él otra cosa que una variedad de la $S$. Cameterii, por mas que presente unos caracteres distintivos de mucho mas valor segun mi opinion:

I. La salida prosternal que, en lugar de ser aplanada i ribetcada como en todas las hembras, cs mui convexa trasversalmente i sin ribetc.

2. ${ }^{\circ} \mathrm{Su}$ anchura que, proporcionalmente a la lonjitud del cuerpo, es doble de las otras.

Sin embargo, un solo ejemplar es mui poco; i creo que, solamente encontrándose otros iguales, habrian motivos suficientes para ver en ellos una especie distinta de la Cemeterii. Pero, lo esplico bien, esto se deberá entónces a los caracteres proporcionados por la salida prosternal, i de ninguna mancra a diferencias problemáticas como las que sirvieron para establecer la S. integra (F.\& $G$ ).

Lám. III fiğ. 6.a Barba, lengieta i palpo latial. Aum. 20 diám. "6." Escudo........................ " 10 " 


\section{S. Filavosignata (Firim. \& $G$.)}

Nigra, oblongo-elongata, pube grisea subappressa parce a'estita. Capite subopaco dense punctuato, punctis majoribus postice irregulariter impresso, a'ertice longitrorsum anguste sulcato. Prothorace lateribus in dimidio antico convergentibus; tergo incequal nitidiusculo, a'arioloso. Scutello, parte antica lata, apice semicirculari. Elytris tennissime punctulatis et ange rugosulis; utroque vitta longitudinali fulica, aliquando pone medium interrupta picto, et punctis rarissimis longitrorsum biseriatis, parum conspicue impresso; apice rotundato, in medio arcuatim emarginato. Long. 2r.5; Lat 6.8.

Fuera del ejemplar hembra, que hace 45 años mandé al sabio entomólogo L. Fairmaire i que le sirvió para la descripcion de esta especie (An. Soc. Ent. Fr. I 859, p. 489), no conozco mas que el otro ejemplar, hembra tambien, que pertenece al Museo Nacional i me sirve hoi dia para su estudio. Pero desgraciadamente, por un lado, este ejemplar está mutilado, faltándole los palpos labiales, el último artículo de las antenas i la casi totalidad de los tarsos; i por el otro, con escepcion de "vitta basala abbreviata flava", la descripcion del año i 859 se contenta casi únicamente con dar una repeticion de los caracteres, que poco ántes se hacen figurar en la diagnóstica del jen. Sibylla. Por consiguiente, convendrá examinar de nucvo a esta especie, cuando se tenga individuos completos i sobre todo el sexo que falta.

El cuerpo, en esta especie, es proporcionalmente mas alargado que en la anterior; pues, en el cjemplar que tengo entre manosel cual es hembra, es decir del sexo que presenta mas anchurala de los elitros (6.8) da solamente los 0.4 I de su lonjitud (I6.5); miéntras que en dos S. Cameterii hembra de igual tamaño, esta proporcion es 43 i $44 \%$. El mati\% jeneral es un negro de pez; i sus tegumentos lleran una pubescencia cenicienta, fina larguita i tendida, mas abundante en la parte inferior del cuerpo, con escepcion del medio del abdómen; es mas escasa, mas larga i mas erizada en la cabeza i en el protórax; se ve tambien en 
la parte inferior de los fémures, i aun los elitros del ejemplar que tengo entre manos presentan algunas hebras vagabundas. Si se tiene presente que el mal cstado de este ejemplar indica que ha de haber sufrido mucha frotacion, es permitido suponer que la pubercencia de cstas últimas es mas abundante en los ejemplares frescos.

La cabea tiene poco brilln, por llevar una puntuacion fina $\mathrm{i}$ apretada, pero invadida sobre todo en el vertex por unos gruesos puntos irregularmente repartidos. Lleva entre los ojos un surco lonjitudinal profundo, que se borra en la frente.

El efistonio es trasiersalmente hundido en el medio; $i$ su linea sutural con la frente, fina pero bien visible, es arqueada: la comexidad hícia atras.

La barha tiene mas o ménos las mismas proporciones que en la especie anterior, pero lns costados son anchamente redondeados en la mitad basilar i comerjentes en la apical.

Los lóbulos de lat léngrietur son anchos, con sus costados casi paralclos en la parte libre, i su ápice mui levemente arqueado; el seno que los separa figura un ángulo levemente agudo con el ápice apénas romo.

El artículo + de los palfos maxilares es oblongo, de la misma anchura que el 3 i truncado en su ápice.

Las antinas son clelgadas i filiformes comoen la $S$. Ca'meterii, pero un poco mas largas proporcionalmente a la lonjitud del cuerpo, pucs, los diez primeros artículos, que son los únicos que tengo a la vista, dan los $0 . \$_{3}$ de ésta; miéntras que, en la S. Cometini que me ha servido de tipo, estos mismos articulos dan solamente los 0.69. Las lonjitudes de cada uno de estos diez articulos en la especie presente son como sigue:

Lonjitud de los articulos.................. I 1.9 
Lonjitud de los artículos.................. , , 1.9

" tistal de los in articulos..........

Los ojos distan uno de otro de $2 . "$ en el vertex, 2.2 en la frente i 2.5 en la garganta. La línea ocular es tanjente al borrle interno de la cavidad cotilódea.

El protórax presenta las medidas siguientes:

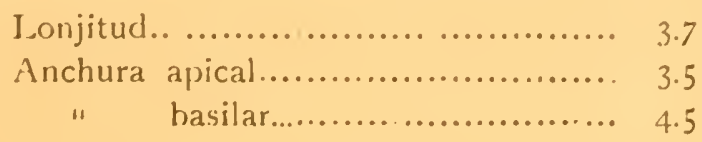

En su mitad anterior, los costados se arquean del tubérculo al borde apical, quedando su anchura en esta parte casi igual con la de la cabeza (3.3); la de su base da los 0.66 de la de los elitros. El dorso lleva unas desigualdades algo tuberculiformes, i es brillante a pesar de una gruesa puntuacion confluente, que lo hace parecer coroido, i lo cubre, con escepcion de unos pequeños espacios mui irregulares i poco notables, que corresponden a la parte mas saliente de las desigualdades.

El escudo es liso; su anchura basilar (1.45) da los 0.2 I de la de los clitros (6.8); su mitad apical es ancha i de forma semicircular.

Los elitros llevan una mui fina puntuación poco apretada, i confusamente mezclada con unas pequeñas arrugas mui vagas e irregulares. La depresion acanalada, que separa la rejion humeral de la escutelar, presenta de cada lado una série poco aparente de pequeños puntos mui distantes entre sí, i desaparece poco despues del medio. Cada clitro tiene su ápice redondeado, pero con una corta escotadura arqueada en su estremidad, i lleva en el dorso una veta ancha i mal definida de un testáceo aleonado, que principia en el lado interno del callo humeral i se dirije oblícuamente hácia la parte sutural del ápice. Esta 
veta es entera en el ejemplar que tengo en manos, pero con una leve angostura despues del medio; la cual puede llegar a interrumpirla completamente en esta parte, como parece haber sucedido en el ejemplar que sirvió de tipo a L. Fairmaire; por lo cual este entomólogo dice: "Elytres d"un noir brillant, avec une bande juune partant i'auprès l'épaule et n'atteignant pas le milieu, et une petite tache de même couleur aĩunt l'exirếmitén.

La salida prosternal lieva una puntuacion fina i densa, mezclada con otra mucho mayor; es convexa trasversalmente, i la fina estria, que la ribetea en la especie precedente, es apénas visible.

Las patas son mas delgadas que en ella; el cuadro siguiente, que da las proporciones del fémur intermediario, indica de un modo suficiente el valor de esta diferencia.

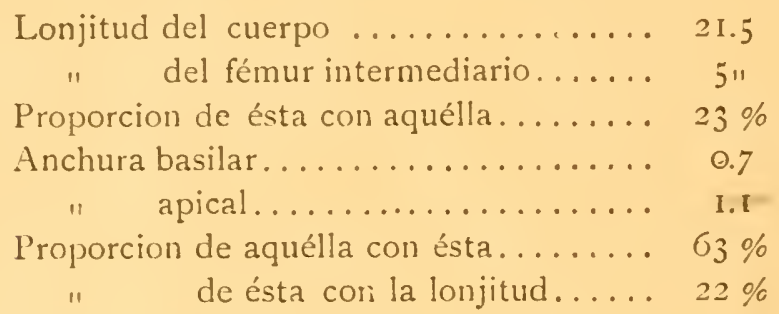

Con mui poca diferencia la lonjitud de las tibias es igual con la de sus fémures respectivos.

Los segmentos abdominales disminnyen gradualmente de lonjitud, del I al 4; la del j es igual con la del 3; aquél tiene su borde apical anchamente arqueado, i su anchura en este punto da los 0.57 de la de su base.

Esta especie se encuentra con la anterior, pero parece ser mucho mas escasa.

Lám. III, Fig. $7^{\mathrm{a}}$ Barba i lengïetr.. Aum. It diám.

$$
\text { " } 7^{\mathrm{b}} \text { Escudo........ " I0 " }
$$

S. LIVIDA. (P.G.)

Nigro-picea, oblongo-elongata, nitidiuscula et parce grisco-pubescens. Capite suhopaco; supra stria longitudinali angusia tenu:- 
ter impresso; fronte punctulata; vertice punctis majoritus haud confuentious laxe impresso. Prothorace nitido, lateribus in dimidio antico convergentibus; callo laterali parmin exserto: dorso valte inciguali, punctis grossis, haud confuent,bus el inordinate agglomeratis impresso; dimidio basali tuherculis tribus transver. sim dispositis, intermedio parum conspicuo, ornato. Scutellu triangulari, breai, lavigato, apice integro atque acuto. Elytris larigatis, fulio-testaceis, utroque apice anguste rotundato.

long. 23.5 ; lat. 7.11

Tenemos esta especie representada por un solo ejemplar que es hembra i proviene de las selvas de Vialdivia.

No ocultaré mi opinion de que la fastidiosa variabilidad de las partes del cucrpo de estos insectos, a las cuales se piden sus diferencias específicas, i la escasez de estas últimas, hacen poco prudente establecer sus especies sribre ejemplares únicos. Si, a pesar de esto, lo he hecho aquí, ha sido impelido por un cierto aspecto, difícil de analizar, que me ha parecido superior a los que jeneralmente caracterizan a unas meras variedades. En todo caso, he tratado de dar una descripcion completa i exacta, para que mi error --si error ha habido-se descubra luego que se hallen otros ejemplares, o sea posible el estudio de cuantos insectos duermen todavía inutilizados en las cajas de varios coleccionistas.

Esta especie aparenta con la favosignata una semejanza mui notable; pero un estudio atento descubre diferencias numerosas, que, aunque leves, son suficientes a mi parccer para hacerla considerar como distinta.

La forma del cuerpo es un poco mas alargada; pues, la anchura de los elitros que da los 0.44 de su lonjitud en la Cemeterii hembra, i los $0.4 \mathrm{I}$ en la favosignata, aquí da solamente los 0.37 (0.7, I 8.5). El matiz jeneral, el brillo i la pubescencia siguen casi iguales.

La cabeza es levemente mas angosta, aunque la lonjitud i la anchura del cuerpo sean mayores; cs tambien levemente opaca, pero el surco lonjitudinal del incdio queda reducido a una estría fina i superficial; la puntuacion de la paite pesterior es roda bastante gruesil. pcro apartada i nunca confluente la de la fren- 
te es toda sumamente fina. El epistomio es aplanado, su línea sutural con la frente es tambien fina, arqueada $i$ bien visible, $\mathrm{i}$ su puntuacion es toda un poco mayor que la de la frente.

Los órganos bucales no presentan diferencia; escepto la lengiieta, cuyos lóbulos estan visiblemente apretados en su parte libre. El último artículo de sus palpos es anchamente truncado en su ápice.

Los ojos son tambien cortos i profundamente escotados; las distancias que los separan es de $\mathrm{I} .7 \mathrm{en}$ el vertex, $2 . \mathrm{I}$ en la frente i 2.5 en la garganta; la línea ocular es tanjente al borde interno de las cavidades cotiloídeas.

Las antenas son tambien filiformes, pero son proporcionalmente mas largas que en la Cameterii i mas cortas que en la flavosignata; pues la lonjitud de los diez primeros artículos da los 0.74 de la del cuerpo, miéntras que da los 0.69 en aquella i los 0.83 en la última.

Lonjitud de los artículos.... . . . . . . I I I.8

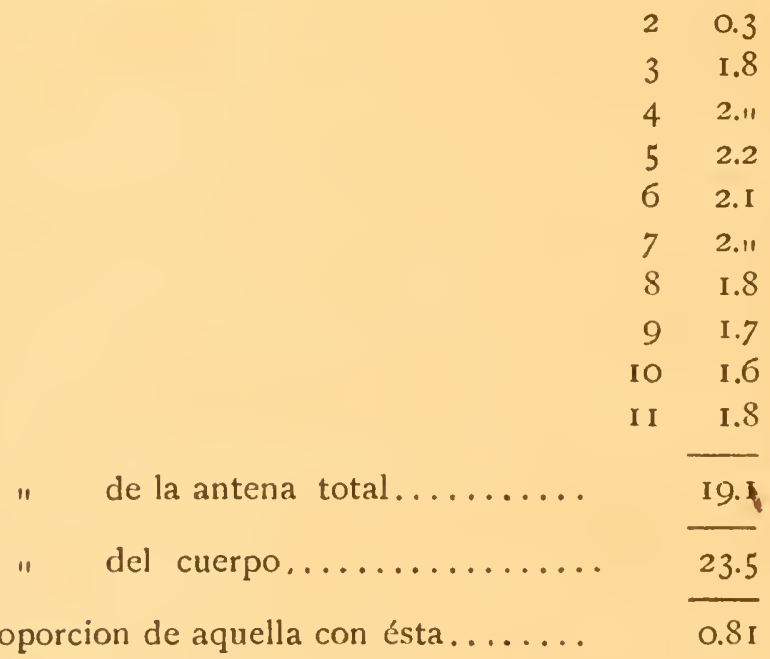

El protorax tiene las medidas siguientes:

Lonjitud............. 3.1

Anchura apical.......... 3."

" hasilar......... 4.2 
las cuales indican, como para la cabeza, que es menor a pesar de ser el cuerpo mas largo i mas ancho; pues, su anchura basilar da los 0.60 de la de los elitros; miéntras que, en la favosignata, aquella da los 0.66 de la última. El tubérculo lateral es menor, pero los costados son tambien converjentes en la parte anterior. El dorso es brillante, con una puntuacion gruesa, igual, irregularmente amontonada i nunca confluente; es mui desigual con motivo de unos tres tubérculos achatados colocados trasversalmente en la parte basilar: el del mcdio es pequeño, ovalado, i aproximado a la base; los otros son alargados, mas salientes, i situados un poco mas adelante entre los laterales.

El escudo es triangular, pero de los 0.43 mas corto que ancho; su ápice es entero i puntiagudo, i su superficie es completamente lisa.

Los elitros son mui brillantes i mui lisos, sin apariencia de puntuacion ni arrugas; la depresion canaliculada de la base está aun obliterada. Su matiz es un leonado, testáceo algo lívido, i un poco oscurecido en la base $i$ tambien en la parte sutural i la lateral de la mitad basilar. Su ápice, en cada uno, forma una punta angosta i mui redonda situada casi en el eje de la sutura, $i$ ribeteada por una costillita encorvada que queda separada del borde.

La salida prosternal i la mcsosternal, a fuera de ser un poco mas angostas, sobre todo la última, presentan poca diferencia con las de la flavosignata.

El $5 .^{\circ}$ segmento abdominal es ménos encojido en su ápice, i de la lonjitud del 4.

Las proporciones del fémur intermediario son las siguientes:

Lonjitud del cuerpo............. 23.5

" del fémur intermediario..... 5.3

Proporcion de ésta con aquella....... $22 \%$

Anchura basilar de éste........... 0.7

" anterior............... 1.2

Proporcion de aquella con ésta....... $58 \%$

" de ésta con la lonjitud...... $22 \%$

Lám. III, fig. 8a Barba, lengiieta i palpo labial. Aum. 20 diám. " $8^{\mathrm{b}}$ Escudo............... " so " 


\section{Gen. ADALBUS Fairm. \& $G$.}

En I 859, mandé de Chile al mui conocido entomólogo L. Fairmaire tres Lonjicornios, que luego describió como tres especies distintas: crassicornis, favipennis i dimidiatipennis; $\mathrm{i}$ para los cuales creó cntónces el jénero Adalbus.

I, en I 869, al hablar de este jénero (Genera $T$. VIII, p. 466) Lacordaire, que según toda probabilidad tenia entre manos los mismos ejemplares, que, diez años ántes, habian servido para su creacion, dió de él una diagnóstica mas completa i algo diferente.

Estos dos trabajos son, creo, los únicos en que los entomólogos se ocuparon de estos insectos.

Por mi parte, lo que diré de ellos hoi dia va desgraciadamente a ser poco; $\mathrm{i}$ el silencio que tendré que guardar sobre varios puntos importantes de su diagnóstica, tendrá por causa, tanto la rareza de las tres especies descritas (Fairm. \& G. An. Soc. Ent. Fr. 1859), como la insuficiencia de sus descripciones i la imposibilidad en que estoi de ver, con el fin de sacar alguna luz de su estudio, los tipos que sirvieron para la creacion de este jénero Adalbus.

A hora tengo a la vista siete ejemplares que le pertenecen: uno de la coleccion del Museo Nacional, tres de la coleccion Izquierdo i tres de la coleccion Paulsen; sin que me haya sido posible descubrir otro en parte alguna; $i$ me induce a suponer que son, talvez, los únicos que se han hallado desde 4 I años!

Pero luego diré que, si estos siete ejemplares me permiten hacer una crítica comparada de los caracteres jenéricos indicados por estos dos entomólngos, no me encuentro en el mismo caso en cuanto a los caracteres específicos de las tres especies descritas por Fairmaire. Pues tanto las modificaciones que Lacordaire introdujo a título correctivo en la diagnósis del jénero, sin duda por haber encontrado inexactitudes o insuficiencias en las descripciones de las especies, como la abundancia de datos vagus o inútiles que caracterizan a aquellas, rodean a este trabajo de una atmósfera de desconfianza, la cual, si bien no me es suficiente para invalidar las tres especies que figuran en 
él, lo es para hacerme dudar de su valor efectivo e impedir que tambien las haga figurar aquí.

Para redactar la diagnósis de este jénero, Lacordaire parece haber tomado por base la que publica liairmaire, suprimiendo lo inexacto i agregando lo omitido; i debo confesar que, con estas enmiendas, cuadra mucho mejor, pero no lo suficiente, con los ejemplares que tengo a la vista. Por esto haré lo mismo; es decir, tomando la diagnósis de Lacordaire por base, la arreglaré de manera que corresponda completamente a mis ejemplares; sin tomar en cuenta las especies de Fairmaire, por los motivos indicados mas arriba.

Lo primero que diré, es que la diseccion de estos siete ejemplares me ha demostrado que todos eran hembras; miéntras que Lacordaire principia la diagnósis que da de este jénero por la palabra "Mâles" i la concluye por éstas "Femelles inconnues." En cuanto a Fairmairc, parece que no se preocupó de la cuestion sexual. Por mi parte, declaro que, salvo en el caso de una contraccion anal que en articulo mortis proyecte los órganos sexuales, no es posible conocer el sexo de un Adalbus, sin averiguar, por medio de una operacion bastante delicada, si lo que se oculta entre el pygidium i el último segmento abclomí. nal es un pene o un oviducto. Por mi parte, hablo despues de haber procedido de esta manerd; por esto, si tuviera que dar mi opinion sobre lo que dice Lacordaire, diria que, por no haber hecho lo mismo, este sabio no estuvo mui seguro del sexo de sus "Mâles."

El cuerpo es levemente alargado, paralelo i aplanado. El insecto es, en jeneral, opaco, con una pubescencia cenicienta, parada $\mathrm{i}$ poco abundante, en su parte anterior. El matiz es un negro profundo, variallo con un testácco amarillento o rojizo, que, ademas del protórax, figura a veces i con inucha inconstancia en los elitros, $\mathrm{i}$ aun en el prosternon i en el ápice del abdómen. Notaré de paso que, miéntras tres ejemplares han ser. vido a Fairmairc para hacer tres especies, distinta; unas de otras casi únicamente por el matiz, Lacordaire, que no habia visto a ninguna otra, dice sin emburgo de ellas: "leur livrée n'a rien de constant." Su instintı entomolójico le habia sin duda hecho sospechar un error. 
La cabeza es poco saliente, i se angosta leve i gradualmente de los ojos hácia la base. La frente, el epistomio, el labio i las mandíbulas estan sobre un mismo plano, cuyo declive forma con el vertex un ángulo de $45^{\circ}$ mas o ménos, i que en el estado normal es vertical.

La barba es mui trasversal: su lonjitud da los 029 de su anchura.

La lengiieta tiene en su ápice una anchura que da los ${ }_{7}^{5}$ de la de la barba. Sus lóbulos estan angostados brúscamente en la parte interna de su mitad apical; el seno que los separa tiene su ápice levemente obtuso pero puntiagudo.

Sus palpos dan en lonjitud los 0.73 de los maxilares. Sus dos primeros artículos son de anchura $\mathrm{i}$ lonjitud iguales; el $\mathrm{I} .^{\circ}$ alcanza á la estremidad de los lóbulos; el 3 , mas corto que los anteriores juntos, es levemente triangular i truncado en su ápice; los sostenes son largos, es decir que alcanzan casi a la mitad de los lóbulos.

El lóbulo esterno de las quijadas está angostado en su base, $i$ es cerca de tres veces tan ancho como el interno, el cual tiene su ápice puntiagudo.

En cuanto a lonjitud i a anchura, el artículo I de los palpos iguala al 3 , i el 2 iguala casi al 4 ; este es oblongo i truncado en su ápice; el ápice del 3 alcanza apénas al ápice del lóbulo esterno.

Labro trasversal, truncado adelante en línea recta o apénas arqueada.

Los dos entomólogos que cito aquí no hablaron de los órganos bucales.

La sutura del epistomio con la frente está borrada.

Los carrillos son de lonjitud normal.

Los tubérculos antenarios estan dirijidos casi horizontalmente hácia afuera; su estremidad llena la escotadura de los ojos; i su truncamiento apical es casi perpendicular a una línea recta trasversal, que pasaria por el borde interno de ámbas cavidades cotiloídeas. La línea ocular es tanjente a este último.

La frente queda casi completamente aplanada entre los ojos.

En cuanto a las antentas, las diferencias que presentan con las 
diagnósis de Fairmaire son notables; sin que nada se pueda decir respecto a su cxactitud, miéntras no se conozca las de machos auténticos. Pues, a pesar de lo que dice Lacordaire, todo me induce a creer que los tres (?) ejemplares que tuvo en sus manos eran hembras, lo mismo que los siete que tengo en las mias.

Lo primero que noto es relativo a los 12 artículos que ámbos entomólogos les atribuyen. Pues, lo que pasa en mis siete ejemplares, respccto a esto, es lo siguiente: en cuatro de ellos, el artículo II tiene su tercio apical con una leve contraccion, que está separada de la parte basilar por una brusca angostura, poco visible, o aun enteramente borrada cn la faz superior de la antena: lo cual indica un falso artículo manifiesto; en dos otros, esta separacion es mui marcada, pern la parte contraida sigue unida con la que precerle por medio de una sutura, es decir de manera a constituir siempre un falso articulo; por fin, en un solo ejemplar, este tercio apical queda separado completamente del artículo $\mathrm{I} \mathrm{I}$, $\mathrm{i}$ forma un artículo $\mathrm{I} 2$ evidente, unido con él por medio de un cóndilo i de una cavidad cotiloídea. Luego creí estar aquí en presencia de un carácter sexual, pero este ejemplar salió hembra como los demas; i, como el cambio gradual de esta disposicion no pernite ver caracteres específicos en sus diversos estados sucesivos, resulta que el punto, donde yo espcraba encontrar motivos terminantes para ver di. versas especies en estos insectos, presenta, a lo contrario variaciones que van a aumentar las dificultades de su clasificacion.

Pasemos ahora a lo que dicen de los demas caracteres de las antenas:

Fairmaire dice en la diagnósis del jénero:

"Antennes de forme assez variable - s'epaississant vers l" ex. tremite - ordinairement moins longues que le corps-de 12 articles-3 et + presque égaux et minces - les autres spais - 12 plus court que II".

I en las de las especies:- "CrAsSICORNIS, antennes un plus longues que la moitié du corps-à articles presque igaux-s'élargissant et s'aplatissant vers l'extremite-II suivi d'un $I 2^{\mathrm{e}}$ article asse's petit this distinct. = FLAVIV'ENNIS, antchites un pele moins 
longues que le corps-un peu aplaties à partir du $5^{\mathrm{e}}$ article $-I I$ suivi d'un $12^{\mathrm{e}}$ article seulement un peu plus court=DIMIDIATIPENNIS, antennes à peine plus longues que le corps-article 3 un peu plus long que $+-7-10$ prolongés en dent à l'extremité in. terne."1

I Lacordaire, que parece haberse empeñado en dar de estos insectos una diagnósis jenérica exacta, mas completa i libre de inutilidades, dice lo siguiente:

"Antennes de 12 articles-assez robustes - un peu plus courtes que les elytres - peu à peu épaissies et déprimées, (CRASSICORNIS) fortement et seulement à leur extremité, (FLAVIPENNIS) faiblement et à partir du 5 e article-article I mediocre-en cône renversé-brillant ainsi que 2-7-7plus conrt que 3 et que 5-les trois on quatre derniers dícroissant peu à peul."

Dando casi a comprender que, al redactar esta diagnósis, tenia en manos los tipos de las dos especies que cita, i que no entendió dar una copia ciega de los caracteres indicados por Fairmaire.

Por mi parte, declaro que esta diagnósis se dice casi enteramente con los caracteres de los siete ejemplares que tengo entre manos. Por lo cual, a lo que he dicho respecto a los doce (?) artículos de estas antenas, agregaré solamente, en vista de completarla, los datos siguientes que les son propios a todos.

Las antenas son enteramente glabras.-Su lonjitud da de los 0.70 a los 0.75 de la del cuerpo, tomada desde el borde anterior de la cavidad cotiloídea antenaria hasta la estremidad de los elitros.-Con un aumento de IO a 12 diámetros, los artículos de las antenas se ven cubiertos de finísimas granulosidades mui densas; las cuales son deprimidas en los artículos $\mathrm{I}-4 \mathrm{i}$ parte del 5 , que por esto son brillantes; miéntras que son globulosas en los demas, que por esto son opacos. - Aquellos llevan ademas una gruesa puntuacion dispersa; miéntras que en los últimos es menor, $i$ apretada a modo de poros.-El artículo I es oblongo, pero atenuado en su base, i con una anchura que iguala la mitad de su lonjitud-3 i 4 son cilindricos en sus $\frac{2}{3}$ basilares, donde la anchura da la cuarta parte de la lonjitud; son un poco dilatados en el tercin apical-el 4 es siempre de un $20 \%$ mas corto que 3 i 5 ; los cuales son casi iguales.-Los otros, desde la 
mitad del 5, se haeen gradualmente deprimidos, mas espesos i con el ángulo apical interno mas dilatado, hasta tener esta parte una anchura de $14015 \%$ mayor que en el 5.-Los artículos 8 - 10 son acortados.

El protórax tiene el borde basilar $i$ el apical ribeteados por un angosto cordoncillo, i levemente saliente en el medio; de modo que la línea lonjitudinal es un poco mayor tomada en el medio que en los lados. Los costados presentan en el medio una dilatacion, a veces regularmente arqueada, $i$ otras con una salida angulosa bien visible; cerca de la base, se enderezan $\mathrm{i}$ forman unos ángulos cortos pero rectos; adelante, se dirijen oblicuamente sobre la cavidad cefálica, de modo que la anchu. ra del borde anterior del protórax no es otra que la de la base de la cabeza. La proporcion de la mayor lonjitud con la mayor anchura varia del 6 I al 69\%. El pronnto es densa i gruesamen. te puntuado, con una ancha depresion mediana mui inconstante, a veces enteramente borrada, $\mathrm{i}$ jeneralmente acompanada de un pequeño surco lonjitudinal basilar.

En su base, el escudo lleva una anchura que dá los 0.17 de la de los elitros; es triangular, pero con un truncamiento apical mas o ménos importante que a veces lo hace trapeziforme: disposicion concorde con lo que indica Fairmaire (écusson tronqué), pero no con lo que indica Lacordaire (écusson en triangle rectiligne). Su superficie pasa de convexa ifuertemente puntuada en la base, a lisa $i$ cóncava en su mitad apical; quedando, sin embargo, csto espuesto a leves variaciones.

Los elitros son aplanados, diverjente; (dehiscentes) desde la base, o a lo ménos desde el cuartn o el tercin basilar, con la mitad apical gradualmente levantada i sin epipleuros. Se angostan separadainente i poco a poco de la base aí ápice, hasta tener éste una anchura que es solo la mitad de la de aquella. No son "minces" ni tampoco" tronquées" (Lacordarire); sino que son mas bien espesas i firmes relativamente a su poca anchura, i que, desde el ángulo sutural que es recto i puntiagudo, el borde del elitro se arquea con mucha regularidad hasta encontrarse con el márjen lateral, esto sin formar ningun ángulo. Los ángulos humerales son rectos, con lns callos redondeados $\mathrm{i}$ algo salientes hácia alelante. La anchura basilar de los elitros, 
frente al ápice del escudo, da los 0.42 de su lonjitud, i es de los 0.33 supcrior a la anchura basilar del protórax. El dorso está cubierto de rugosidades mui clensas i salientes, pero un poco aplanadas en la base: a lo cual ésta debe de presentar algun brillo. Cada elitro lleva, ademas del cordoncillo que ribetea su contorno, cuatro finas costillitas lonjitudinales poco salientes; de las cuales las dos intermediarias se juntan, $i$ forman una sola en la mitad de su lonjitud o poco despues.

Los segmentos pectorales i las patas presentan los caracteres indicados mas arriba para la agrupacion, pero con las siguientes modificaciones.

La salida prostermal cstá algo cnterrada entre las ancas; su ápice, que es peludo, no alcanza al nivel posterior de estas últimas, i su anchura (0.16) solo da un poco mas de la cuarta parte de la de la salida mesosternal (0.6). Esta es aplanada, i su ápice, que es redondeado, descansa sobre la base del metasternon. Este último es notable por tener su parte apical hinchada i notablemente mas abultada que la base del abdómen-carácter, que por ier propio de la siguiente agrupacion (los Necidalidos) parece estraviado aquí.-Sus episternones son oblongos, con el ápice terminado en punta, i una anchura basilar (I.") que dá los 0.28 de su lonjitud (3.5).

$\mathrm{El}$ abdómen es levemente convexo i casi paralelo, es decis apénas atenılado en ámbas estremidades; su salida intercoxal es mui corta; el segmento I no alcanza a ser dos veces tan largo como cada uno de los tres siguientes, cuyas lonjitudes son cási iguaies, i mas o ménos doble de la del 5 ; éste tiene la estremidad de su ápice truncada, o aun con un ancho seno apénas marcado.

El pygidium está a descubierto i semicircular.

Las ancas anteriores son salientes. Los fémures anteriores e intermediarios son iguales cntrc sí, en cuanto a lonjitud i a anchura, pero de un $15 \%$ mas cortos i levemente mas anchos que los posteriores. Las tibias son de ignal lonjitnd que sus fémures, con una diferencia insignificantc, en ménos para aquellos dos, i en mas para el último. La mayor anchura del fémur anterior corresponde al moủio de su lonjitud; la de los otros dos es uII poco mas apical. 
Este jénero une evidentemente la agrupacion de los Bimiidos con la de los Necidalidos; i aun no sé si el lugar que le corres. ponde no está en esta última, con motivo de la forma tan ca. racterística del metasternon i del abdómen, la de los elitros, la disposicion de las antenas i de los seginentos esternales, etc. Si, respecto a las analojías de este jénero, dejo las cosas como las dispuso Lacordaire, es únicamente por miedo al desórden que resulta de cambios innecesarios.

\section{A. Proteus $P . G$.}

Apud fominas: niger. Capite dense rugosulo, stria longitudi. nali angusta, aliquando litturata, inter oculos impresso; antennis plus minusve distincte i2-articulatis. Prothorace testaceo. Elytris sape testaceo plus minusve pictis. Prosterno mesosternoque opacis tenuiter nugulosis. Metasterno nitidiusculo, dense punctulato. Abdomine opaco, punctis, irregularibus parum dense impresso. Pedibus nitidis punctulatis.

Long. 15.11-11.5; lat. 4.5-3.5.

Apesar de las variacione; que sufre el artículo suplementario de las antenas, como asímismo ia coloracion de los elitros i de algunas otras partes del cuerpo, es bien evidente que los siete ejemplares que tengo entre manos forman una sola especie. Aun mas; creo no equivocarme al suponer que las tres especies de Fairmaire pertenecen a una sola, de la cual la dimidiatipennis seria tal vez el $\delta, i$ que, ademas, es idéntica con la que describo aquí; no creyendo, sin embargo, prudente juntar ésta con ninguna de ellas a causa de varias diferencias que presentan sus descripciones.

La cabeza está cubierta de rugosidades finas i apretadas, $\mathrm{i}$ lleva entre los ojos una fina estríd lonjitudinal, que se debilita gradualmente hasta quedar completamente borrada en los mas pequeños individuos. En un ejemplar de 14.5 de lonjitud, las distancias que separan a los ojos estan como sigue:

En el vertex.......................... I.56

En la frente.......................... I.80

En la garganta..................... 1.90 
Las medidas de los artículos de las antenas son como sigue, en los dos ejemplares de lonjitud mas diferente:

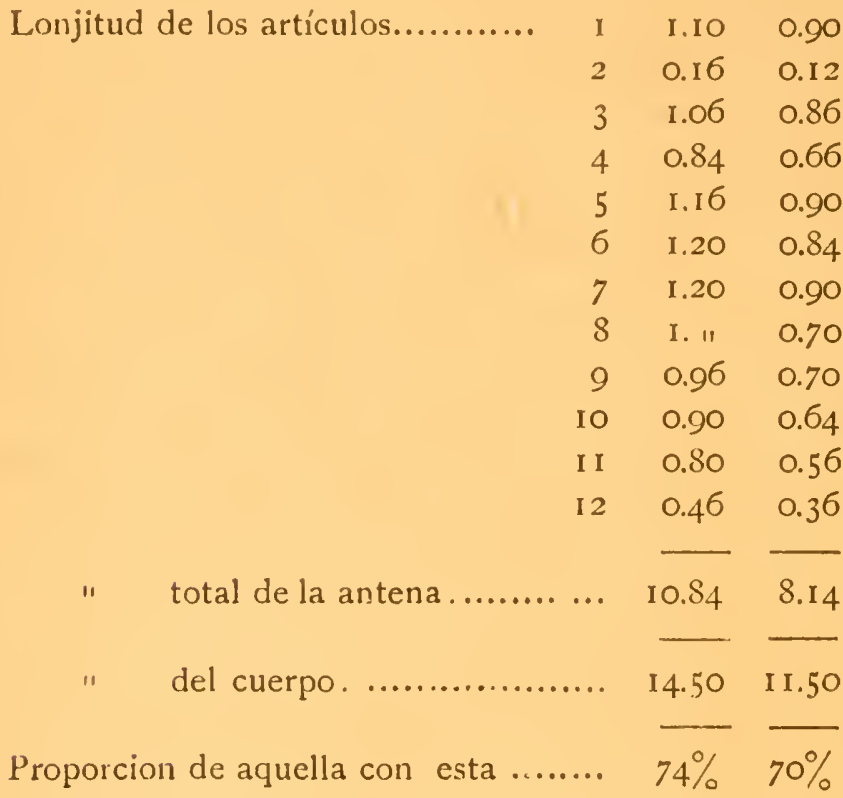

El protórax presenta las medidas i las proporciones siguientes:

En un ejemplar cuya lonjitud es de....... 14.50 o de II.50 Lonjitud del protórax.................... 2.20 " " 1. .So

Mayor anchura.......................... $3.20 \quad$ " $\quad 2.95$

Anchura basilar.......................... 2.8 " " 2.30

Proporcion entre la lonjitud i la mayor anchura................................. $69 \%$ " " $62 \%$

Hemos visto en el exámen preliminar de los datos que caracterizan a este jénero, que el color negro del cuerpo era invadido con mucha frecuencia e irregularidad por un matiz testáceo o testáceo rojizo; pero alı̀ra ha llegado el momento de agregar que la manera de presentarse de este matiz es tan variable, que no encuentro dos de mis siete ejemplares en que sea 
igual. Resultando de esta inconstancia siete variedades, i la necesidad de esponer claramente sui diferencias a cada una.

El matiz testáceo cubre:

VAR. A. El pronoto, con escepcion del ribete apical i del basilar..................... (Col. Izquierdo).

VAR. B. El pronoto, con escepcion del ribete apical i del basilar; i forma una mancha triangular $i$ trasversal en la parte anterior del prosternon................. (Col. Paulsen).

VAR. C. El pronoto, con escepcion del ribete apical i del basilar; i forma una manchita alargada $i$ mui irregular en el medio de cada elitro.................... (Col.Izquierdo).

VAR. D. El pronoto, con escepcion del ribete apical i del basilar; i forma, en cada elitro, $10^{\circ}$ una mancha grande, en óvalo lonjitudinal i aislada, en medio del tercio basilar; $2 .^{\circ}$ otra mancha trasversal, dilatada sobre la sutura, i cubriendo el borde sutural i el marjinal al principiar el tercio apical... (Col. Paulsen).

VAR. E. El pronoto, con escepcion del ribete apical i del basilar; i forma una manchita redonda $i$ aislada en la parte anterior del prosternon; $i$, en cada clitro, una ancha faja lonjitudinal que nace despues del callo humeral, i, ensanchándose, cubre el borde marjinal del elitro en su tercio basilar, i, que, desde alli, se angosta levemente $\mathrm{i}$ se prolonga hasta el $50^{\circ}$ apical, sin cubrir el borde sutural ni tampoco el marjinal ............................ (Col. Paulsen).

VAR. F. El pronoto en totalidad, el $50^{\circ} \mathrm{seg}-$ mento abdominal, el pijidio, $i$ los eli. tros con cscepcion de una diminuta manchita apical i de una faja tras- 
versal que cubre la base hasta el ápice del escudo............................... (Col. del Museo)

VAR. G. El pronoto en totalidad, el $50^{\circ} \mathrm{seg}$ mento abdominal, el pijidio, i los elitros con escepcion de la pequeña parte basilar que es vertical................... (Col. Izquierdo).

El prosternon i el mesosternon son finamente rugosos $\mathrm{i}$ opacos. El metasternon es brillante i finamente puntuado. El $a b$ dómen es opaco, i lleva una mui fina puntuacion, a la cual se junta otra un poco mayor i mui rala.

Patas brillantes i puntuadas.

Las proporciones del fémur intermediario son las siguientes:

Lonjitud del cuerpo................. I4.50

" del fémur intermediario.... 2.90

Proporcion de ésta con aquélla....... 20\%

Anchura basilar de éste................ 0.46

" mayor " ............... 0.92

Proporcion de aquélla con ésta....... 50\%

" de ésta con la lonjitud...... $31 \%$

Estos insectos, que descubrí hace mas de 40 años en las cordilleras de Chillan, se encuentran tambien en la provincia de Valdivia.

Lam. III, fig. 9a: Barba, lengueta $i$ palpo labial. Aum. 25 diám. " 9 : Quijada i palpo maxilar. " "

PHANTAZODERUS Fairm. \& $G$.

Ya, en las jeneralidades relativas a los Bimiidos, dije algunas palabras sobre el jénero Phantazoderus, para señalar cuán poco habia sido acertado hacerlo figurar en esta agrupacion, donde está mas estraviado aun que el jénero Adalbus

La especie, para la cual Fairmaire creó este jénero en 1864, fué descubierta por mí en las cordilleras de Chillan durante el año anterior; i la suma escasez de sus ejemplares me permite 
snponer que el tipo, que sirvió para esta creacion, fué el mismo que Lacordaire tuvo a la vista, cuando cinco años despues habló de él en su Genera (T. $V I I I$, páj. f66). Pero es de notar que ámbos sabios no estan completamente concordes respecto a los caracteres de la diagnóstica que redactaron, cada uno por su parte, para este jénero; i ménos aun relativamente a sus analojías. Me veo, por consiguiente, en la necesidad de dar, como para el jénero Adalbus, una tercera diagnóstica, que tendrá por base las dos primeras; valiéndome del estudio prolijo de cinco ejemplares que tengo a la vista para hacer las correcciones necesarias, agregando lo omitido i reproduciendo en cursiva lo que ha de ser suprimido por inexacto.

Cuerpo alargado i deprimido, mui finamente rugoso, opacc por encima i levemente brillante por debajo, glabro excepto una fina pubescencia mui corta i mui espesa, de aspecto aterciopelado en algunas partes, i apénas visible en otras.

Cabeza pequeña metida hasta los ojos en el protórax. Frente cuadrada, trasversal i con un surco lonjitudinal, angosto i profundo, pero que no se prolonga sobre el vertex; su declive propio forma un ángulo de $45^{\circ}$ mas o ménos con la direccion lonji. tudinal del vertex; pero, en cuanto a su verticalidad o su oblicuidad, ellas resultan naturalmente de las posiciones que toma la cabeza.

-Fairmaire; téte fortement sillonnée. Es solamente la frente.

- Lacordaire: front vertical, muni de denx bourrelets lonjitudinaux parallèles partant des tubercules antennifères. Estos dos rodetes son el resultado de una ilusion óptica: cada mitad de la frente, comprendida entre el surco lonjitudinal por un lado, i el ojo seguido del carrillo por el otro, es de un matiz negruzen orillado en cada lado por un angosto ribete blanquizco. La parte oscura, figura una ancha faja lonjitudinal, que principia, no en el borde anterior de los tubérculos anteníferos, sino al nivel del borde postcrior de las cavidades cotiloideas, orilla el borde interno de estas últimas i sigue adelante hasta la base del epistomio; resultando del contraste de estos matices que parece saliente, cuando en realidad es aplanada.

Los ojos estan en el eje de la frente $\mathrm{i}$ alargados, es decir que su mayor anchura (0.54) dá la mitad de su lonjitud (I.00); su 
borde esterno es levemente cóncavo; miéntras que su cscotadura, que es poeo profunda, ocupa la mitad posterior de su borde interno, quedando esta parte de anchua igual hasta la cstremidad del lóbulo posterior yue no lleva dilatacion propia. La granulacion es notablemente mas fuerte que en el jénero Adalbus; he tratado de dar un valor definido a esta diferencia, i le llegado al resultado signiente: 211 un Adalbus \{ de 14.5 de lnnjitud, los ncelos tienen 0.025 de dismetw, es decir que hai 40 pror $111 \mathrm{~m}$; si esta propurcion fuera la misma en un Phantazoderus $\{$ de 13.5 , el ocelo le éste tendria 0.02327 de dianetro, es decir que habria $4 j$ por m m; miéntras que es de 0.03125 , lo que dá solamente 32 por $m \mathrm{~m}$, es decir que es de la cuarta parte mayor. Las distancias que separan los ojos son las siguientes en un ejemplar $f$ de 13.5 :

En el vertex...................... 0.9

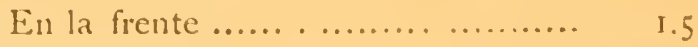

En la garganta...................... I.4 .

Los tubrerilos anteniferos son mui oblicuos, pero dejan sin embargo, entre ellos una depresion angulosa mui notable. Las caridudis cotilódeas son casi verticales i completamente afuera de la escotadura de los ojos, de lo cual resulta que la linea ocular queda casi afuera de su borde esterno, o le es cuando mas tanjente.

Fairmaire: yeur fortiment ichuncrés et resserrís en dessus, assea rupprochess en de'sous.

-Lacordaire:... no habla de los ojos.

Las antinas tienen una lonjitud que da los $0 . \$ 5$ de la del cuerpo en un ơ de $\{1$, ", i los 0., 2 en ma ? de 16. ". El artículo I es oblongo; Ins $3-7$ son levementi deprimidos; son dilatados en los of ap modo a igualar casi la anchura del 1 ; los 3,4 son siempre mas cortos que $\vec{j} \cdot 7$, pero casi iguales, aunque la pequeñez del 2 haga parecer al 3 mas largo que el 4 ; el I I, siempre mas largo que IO, presenta en su $50^{\circ}$ apical una contraccion que figura un falso-artículo, pero que es tan sumamente leve que, con frecuencia, cuesta descubrirla. 
-Fairmaire: article 4 visiblement plus court que 3 et 5, les suiwauts égaux, 11 termine par un petit article suplementaire.

- Lecordaire: article + notablement plus count que 3 el que 5.

Burba con los costados redondeados en el $3 .^{\circ}$ basilar, rectos i converjentes en los dos apicales; su lonjitud da los "̈ de su mayor anchura.

La lengiieta es de la misma anchura que la barba, pero de la $4 .^{2}$ parte mas larga. Los lóbulos estan separados por un seno mui obtuso $i$ anchanente redondeado; su ápice es redondo, i su anchura en el medio da la mitad de su lonjitud.

Los lóbulos de las quijadias son densamente peludos en su parte interna i en la apical; el interno ticne por anchura la cuarta parte de la del esterno, i alcanza apénas al ápice del artículo I de los palpos; el esterno alcanza al ápice del artículo 3.; i la pieza córnea que le sirve de base figura una placa ancha, recta por delante i semi-circular por atras, en lugar de ser, como en las especies anteriores, angrosta i con figura de anillo.

La lonjitud de los palpos labiales hace los $\frac{2}{3}$ de la de los maxilares; en ámbos, el artículo último es mas corto que los dos precedentes juntos, pero mas ancho, oblongo i truncado en el ápicc. En aquellos, el artículo I es el menor i alcanza al ápice de los lóbulos; los sostenes alcanzan al medio de éstos, i en su parte apical interna llevan unos pocos pelitos mui largos i dirijidos hácia adelante. En los últimos, el artículos 2 es un poco mayor que I i 3 .

- Lacordaire nada dice de las piezas bucales, i Fairmaire solo habla de los palpos.

l.abro i epistomio pequeños i truncados adelante; la sutura de la frente con éste borrada.

Los carrillos son grandes, pues tienen 0.37 de lonjitud en un I de 11.".

- Lacordaire: joues mediocres.

Protórax con mui poca diferencia tan largo como ancho en la base $\mathrm{i}$ en el ápice. Los costados llevan en el medio una hinchazon angulosa $\mathrm{i}$ redondeada, separada del borde apical por una ancha depresion circular a modo de canal; el dorso es levemente convexo en el medio, i lleva una feble depresion trasversal cerca de la base, cuyo borde es alyado. 
- Lacordaire: Prothorax transversal, muni de deux renflements peu saillants sur le disque.

Escudo en triángulo curvilíneo.

- Fairmaire: Ecusson presque cordiforme.

Elitros alargados, aplanados, sin epipleuros desde el metatórax, levemente dehiscentes en el ápice; base truncada, con los ángulos humerales rectos, pero redondeados. Su anchura basilar da casi el tercio de su lonjitud, i es de una tercera parte mayor que la anchura basilar del protórax. El borde marjinal es paralelo con el borde sutural hasta cerca del ápicc; el cual está redondeado en cada elitro separadamente i ribeteado por un grueso cordoncillo.

La salida clel prosternon es lameliforme i enterrada entre las ancas, pero es corta i no alcanza al nivel de su parte posterior. Las cavidades cotiloídeas anteriores son anchamente abiertas posteriormente, i prolongadas angularmente de cada lado hasta alcanzar al borde del epipleuro.

El mesosternon es horizontal en toda su estension; su salida es aplanada, casi paralela i finamente ribeteada; su anchura, que es mas o ménos igual con la de la base de sus fémures, alcanza a 0.3 en una $q$ de 12,5 , su ápice es levemente escotado, $\mathrm{i}$ se encuentra con la estremidad de una salida triangular de la base del metasternon entre los cóndilos femorales. Sus cavidades cotiloídeas estan abiertas.

Lacordaire: saillie mesosternale triangulaire.

El metasternon es abultado i mucho mas saliente que las ancas posteriores, i sobre todo el abdómen. Sus episternones estan oblongos con su ápice en ángulo agudo; su anchura da el 20 por ciento de su Innjitud.

El abdómen es subcilíndrico i mui levemente ensanchado en el ápice; su anchura da el 66 por ciento de la del metasternon en un 2 de 12.5 , i el 82 por ciento en una $q$ de 16 ". La salida intercoxal es mui corta, casi nula; los segmentos son mas o mé. nos de igual lonjitud, el $50^{\circ}$ tiene su ápice brevemente, pero bien visiblemente, bilobulado en los machos, i truncados en las hembras.

-Lacordaire: $5{ }^{\text {e }}$ segment abdominal égal au précédent, ojizal.

Las ancas anteriores son dilatadas lateralmente i notable- 
mente salientes. Las intermediarias son ovaladas, tendidas i poco salientes.

-Fairmaire: Hanches antérieures contigiies. Pattes gréles.

Los fémures disminuyen gradual i levemente de lonjitud de los anteriores a los posteriores, las lonjitudes siguientes: 2.6 $3.2-3.5$ indican esta proporcion; su anchura respectiva la sigue, i se produce gradualmente de la base al tercio apical, dando en este punto mas o ménos el $5 .^{\circ}$ de su lonjitud. Los intermediarios $\mathrm{i}$ los posteriores de los $\delta$ llevan por debajo una franja lonjitudinal de pubescencia espesa, corta $i$ parada. En ámbos sexos el posterior alcanza más o ménos al ápice del $20^{\circ} \mathrm{segmento}$ abdominal. Las proporciones del fémur intermediario son las siguientes:

o lonjitud del cuerpo............ 11.1

" del fémur............... 2.5

Proporcion de esta con aquélla........ $22 \%$

Anchura basilar.................. 030

" anterior................... 0.56

Proporcion de aquélla con ésta....... $53 \%$

" de ésta con la lonjitud.......... $22 \%$

Las tibias son un poco mas cortas que sus fémures, i los tarsos que sus tibias. El artículo I de éstos es tan largo como los dos siguientes juntos en los anteriores, levemente mas largo $\frac{1}{10}$ ) en los intermediarios, i mas aun $\left(\frac{1}{8}\right)$ en los posteriores.

Como es el caso en los jéneros Lautarus i Sybilla, pero no en los Cheloderus $\mathrm{i}$ los Oxypeltus, la vaina donde corre el pene termina por dos espigas cilíndricas $\mathrm{i}$ cerdosas en su ápice; pero aquí son algo mas largas, diverjentes i submembranosas; el pene es corto i truncado en su estremidad.

Ph. rrenatus. Fairm. \& $G$.

Subparallelus, nigro-fuliginosus. Capite subtus, frontis vittis tribus longitudinalibus, prosterni medio antico, femorum apice tarsorum articulis duobus primis hasi, elytrorumque upice aliquando anguste pallide testaceis. Capite tenuiter rugoso. Protho. race tenuiter denseque punctulato, palide testacen aliquando subro. 
seolo; basi vittisque duabus longitudinalibus nigris ornato; omnino pube relutino concolore dense vestito. Flytris ad aficem leriter dehiscentilus dense tenniter punctulato-rugosis, costis duabus, vel tribus angustissimis parmm conspicne longitrorsum ornatis.

\& long. 17. "1-11. "; lat. 3.2-2.5. 9 long. 16. "; lat. 4. 1.

Alargado; pues las cantidades cspresadas aquí arriba indican ujue su lonjitud da de 4 a 5 veces su anchura. Es de un negro ahumado, con lo debajo de la cabeza, tres vetas lonjitudinales en la frente, la parte anterior del prosternon, la parte apical de Ins rémures, la base de los dlos primeros artículo; de los tarsos, i a veces el estremo ápice de los elitros de un testáceo pálido a veces un poco sucio.

Lia cabear es levemente rugosa. Aquí doi las medidas de los artículos de las antenas en el mas pequeño : i en la mayor $q$; coıno asimismo la anchura de los artículos basilares, intermediarios i apicales, advirtiendo que en aquel la dilatacion intermediaria es variable, i que es el máximım que doi aquí:

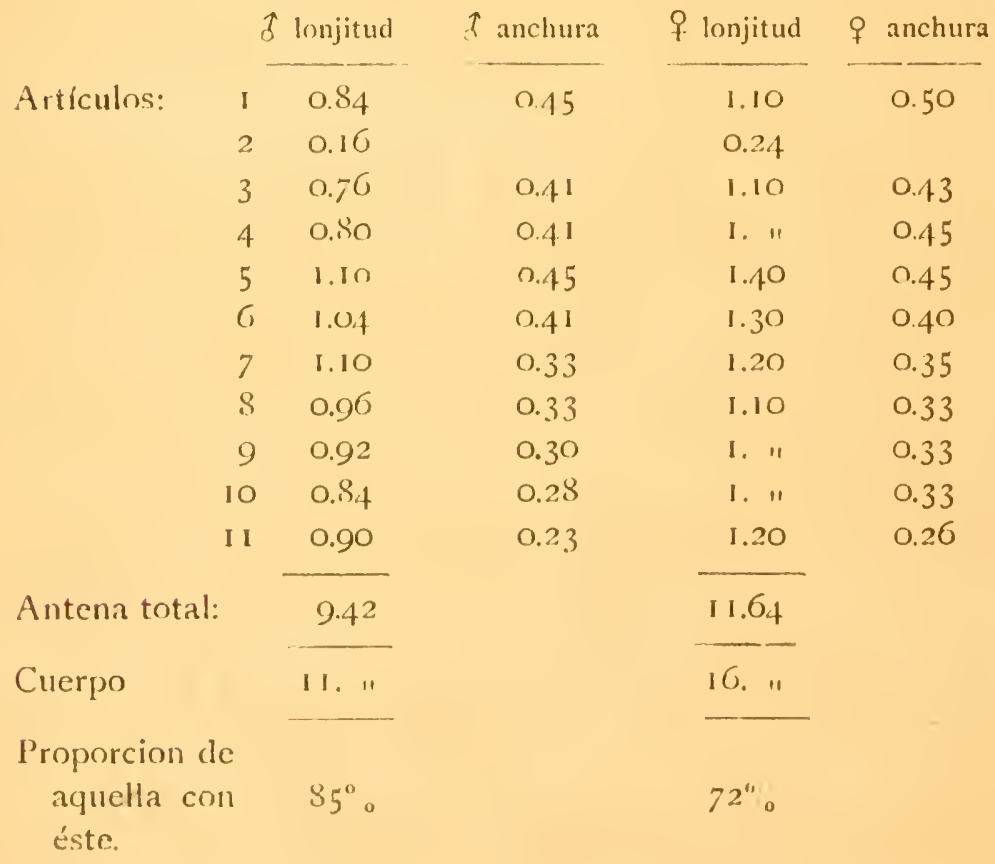


El protórax es tambien de un testáceo pálido, pero a veces con un matiz rosado; cstá adornado con dos vetas angostas negras lonjitudinales, que van del borde apical al basilar, son un poco converjentes adelante, $i$, entre cllas, la base es tambien negra sobre una anchura igual a la suya; está enteramente cubicrto de una fina puntuacion i de una espesa pubescencia aterciopelada que lleva el color de la parte dunde se encuentra. L leva las medidas siguientes en un of de 13. "

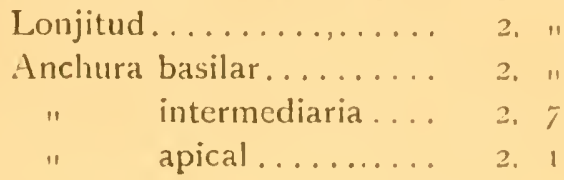

Los elitros llevan una puntuacion vaga, enterradd sin órden i como perdida en medio de una infinidad de pequeñas arrugas cmbrolladas; i estan cubiertas de una pubescencia caediza negra, algo tendida, pero ticsa, mui corlat i mui densat. P'ur ser los clitros un puco dehiscentes en el ápice, parcecen ensanchados cil esta porte; cuando, en realidal, cadla une ticne: su borde inarjinal paralelo con el sutural. Cadda uno lleva dos o tres castillas lonjitudinales mui firas.

La parte inferior del cuerpo, subre tudo el abdómen, llevia una pequeña puntuacion apretada que resalta sobre un campo de finisimas lineitas algo trasversales, i reticuladas, visibles solamente con un aumento de 10 a 12 diámetros.

- Fairmaire: Elitres légriment sinuces al bovel exlerne, pres de la basc chez la + , après le milieu chez le d, ee qui les fuit paraitre un peu divuriquées.

Estos clatos son completanente imajinarios. O yuilas los elitros sicndo dehiscentes - es decir diverjentes, pero no diânviquées - hácia el ápice sobre una estension vartiable, es evidente que, cuando esta separacion se produce, ella tiene gue manifestarse, por un codus sebre la lincea sutural, i por un seno en la lined marjind; estu sead talvez la sinuosidad de la clat se habld.

tantennes plus ipuisses. His lu contrario que sucede.

Este insecto, que sur segmentus esternales I su abdomen co- 
locan de un modo tan evidente cerca de los Necidalidos, es escaso i se encuentra en las provincias australes.

Lám. III. fig. 10a: Barba, lengüeta, i palpo labial. Aum. 40 diám. fig. $10^{\mathrm{b}}$ : quijada i palpo maxilar..... . " " " flg. $10^{\circ}:$ Pene................ " I7 "

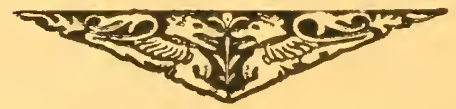






